\title{
Collected Papers on
}

Methods of Analysis for Uranium and Thorium

GEOLOG I CAL S U R VEY BULLETIN 1006

This report concerns work done on behalf of the U.S. Atomic Energy Commission and is published with the permission of the Commission

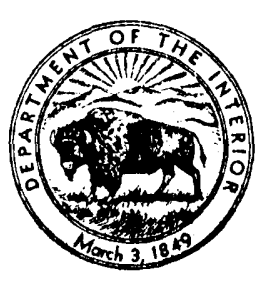





\section{Collected Papers on}

Methods of Analysis for Uranium and Thorium

Compiled by F. S. GRIMALDI, IRVING MAY, MARY H. FLETCHER, and JANE TITCOMB G E O L O G I C A L S U R V E Y B UL L E T.I N 1006

This report concerns work done on behalf of the U. S. Atomic Energy Commission and is published with the permission of the Commission

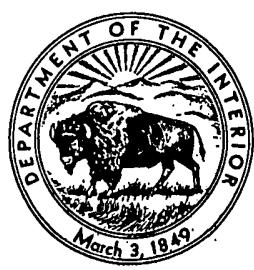




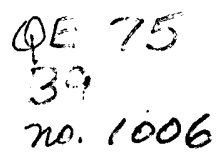

UNITED STATES DEPARTMENT OF THE INTERIOR

Douglas McKay, Secretary

GEOLOGICAL SURVEY

W. E. Wrather, Director

For sale by the Superintendent of Documents, U. S. Government Printing Office Washington 25, D. C. - Price $\$ 1.00$ (paper cover) 


\section{FOREWORD}

The U. S. Geological Survey has made an extensive investigation of radioactive raw materials in the United States since 1945. This investigation was first undertaken on behalf of the Manhattan District Project and later on behalf of the U. S. Atomic Energy Commission. As a vital part of this program more than 200,000 samples have been chemically analyzed for uranium. These samples included nearly all types of minerals, rocks, and ores; mill, smelter, refinery, and other plant products; and natural waters.

From the start of the program it was evident in the Geological Survey and elsewhere that the existing methods of uranium analysis were inadequate, and therefore much work has been done in modifying known techniques and developing new ones. The first stage of this work was based on classical techniques; the second stage led to the development of more rapid methods to meet the constantly expanding analytical load. Work is continuing along both lines.

What has been said about uranium analysis applies equally to thorium analysis. No satisfactorily rapid analytical methods for the chemical determination of thorium, especially for very small amounts (less than 1 percent), have been developed. The demand for thorium analyses is always pressing in the Survey program, and research in this field has been and is intense.

The analytical methods developed from these investigations have been reported from time to time in U. S. Geological Survey Trace Elements Investigations and Memorandum reports, and many of these have been reproduced by the Technical Information Service of the Atomic Energy Commission at Oak Ridge, Tenn. These reports have had limited distribution in the Geological Survey and to the Atomic Energy Commission and its contractors, but it is desirable to make them available for wider distribution through formal publication. This bulletin will serve that purpose.

The methods herein described include standard ones as well as those requiring the use of rather elaborate and highly specialized instruments. The primary goal has been to develop methods that are of the widest applicability, and some procedures may be unnecessarily long when applied to simple materials.

The papers are presented in nearly chronologic order and thus reflect the changing demands on the laboratory. The reports have been kept essentially in their original form except where it has been necessary to bring the material up to date. Some of the earlier methods havg been superseded by those described in later reports; 
nevertheless, they are presented here because the information they contain is valuable and useful.

The authors who compiled this bulletin have prepared a general discussion (part 1) of uranium and thorium analysis that will be most useful to those working in this field.

$$
\text { JoнN C. R ABBITT, }
$$

Chief, Trace Elements Section. 


\section{CONTENTS}

PART 1. Summary of methods of analysis for the determination of uranium and thorium, by F. S. Grimaldi, Irving May, M. H.

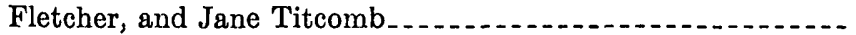

2. Methods for the complete decomposition of rock and ore samples to be analyzed for very small amounts of uranium and thorium, by M. D. Foster, R. E. Stevens, F. S. Grimaldi, W. G. Schlecht, and Michael Fleischer.

3. The Geological Survey cupferron precipitation-extraction method for the determination of very small amounts of uranium in naturally occurring materials, by F. S. Grimaldi

4. The Geological Survey carbonate-phosphate-peroxide method for the determination of very small amounts of uranium in naturally occurring materials, by M. D. Foster and R. E. Stevens..

5. Elimination of interference by nickel in the determination of uranium by means of zinc amalgam reductors, by F. S. Grimaldi.

6. The visual fluorimetric determination of uranium in low-grade ores, by F. S. Grimaldi and Harry Levine.

7. A volumetric filtering pipette, by F. S. Grimaldi

8. A study of critical factors in the "direct" fluorimetric determination of uranium by Mary $\mathrm{H}$. Fletcher.

9. A direct fluorimetric method for the determination of small amounts of uranium in the field and laboratory, by F. S. Grimaldi, F. N. Ward, and Ruth Kreher Fuyat.

10. An improved fluorimeter for the determination of uranium in fluoride melts, by Mary H. Fletcher and Irving May.......-

11. A transmission fluorimeter for use in the fluorimetric method of analysis for uranium, by Mary H. Fletcher, Irving May, and

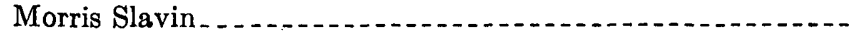

12. The design of the Model $\mathrm{V}$ transmission fluorimeter by Mary $\mathrm{H}$. Fletcher, Irving May, and J. W. Anderson..................

13. A battery-powered fluorimeter for the determination of uranium, by Irving May and Mary H. Fletcher...................

14. Short routine direct method for the fluorimetric determination of uranium in phosphate rocks, by F. S. Grimaldi and Norma S. Guttag - . . . . .

15. Fluorimetric determination of uranium in shales, lignites, and monazites after alkali carbonate separation, by Norma S. Guttag and F. S. Grimaldi......................................

16. Noninterference of arsenate ion in the volumetric determination of uranium using the Jones reductor, by Jack J. Rowe...-..-

17. The fluorimetric determination of uranium in nonsaline and saline waters, by Audrey Pietsch Smith and F. S. Grimaldi.-

18. The Geological Survey phosphate-fluoride-iodate method for the determination of very small amounts of thorium in naturally occurring materials, by F. S. Grimaldi and J. G. Fairchild.-- 
Part 19. The Geological Survey carbonate-iodate-iodine method for the determination of small amounts of thorium in naturally occurring materials, by J. J. Fahey and M. D. Foster.

20. The determination of thorium in high-grade and low-grade ores, by F. S. Grimaldi and Charlotte Marsh Warshaw ........

21. Mesityl oxide extraction method for thorium analysis, by Harry

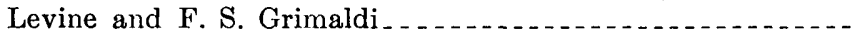

\section{ILLUSTRATIONS}

[Plates 3-8 in pocket]

Plate 1. Assembly of Model II transmission fluorimeter.......

2. Model II transmission fluorimeter.........................

3. Rear-view assembly and expanded details of the modified fluorimeter.

4. Fluorimeter assembly.

5. Cutaway view, cross section, and details of parts of "fluorimeter".

6. Details of parts of fluorimeter assembly shown in plate 4 .

7. Details for construction of shield.

8. Details for construction of type- $B$ phototube housing.

Figure 1. Volumetric filtering pipette

2. Details of volumetric filtering pipette. . .

3. Effect of fusion conditions on fluorescence of blank samples . - -

4. Effect of fusion conditions on fluorescence of standard samples.

5. Effect of fusion conditions on sensitivity ...

6. Equipment .

7. Effect of fusion conditions on fluorescence of standard samples

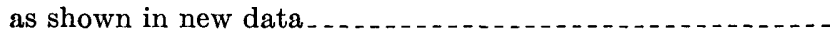

8. Effect of fusion time and type of platinumware on fluorescence

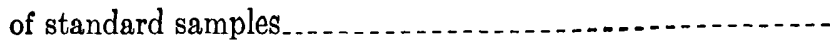

9. Complete assembly of the modified fluorimeter

10. Standardization curves for $3.0-\mathrm{g}$ discs prepared by fusion in

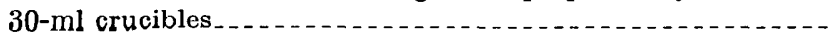

11. Standardization curves for $1.5-\mathrm{g}$ discs prepared by fusion in crucible lids

12. Calibration curves for routine work

13. Schematic diagram of a "reflection"-type fluorimeter......

14. Schematic diagram of a transmission-type fluorimeter

15. Lamp eircuit used in the instrument

16. Reflecting support for the lamp.

17. Power circuit for the photomultiplier tube.

18. Standard curve

19. Platinum dish used for fusions.....

20. Working curve

21. Spectral transmittancy curve for the determination of thorium

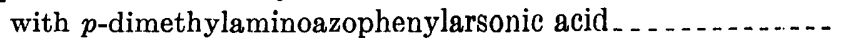


Figure 22. Fisher electrophotometer readings for the photometric determination of thorium with $p$-dimethylaminoazophenylarsonic acid.

23. Spectral transmittancy curve of iodine in carbon tetrachloride.

24. Transmittance-concentration curves of iodine in carbon tetrachloride

25. Spectral transmittancy curves of iodine in carbon tetrachloride, methyl red in acid solution, thymol blue in acid solution 



\section{Part 1. SUMMARY OF METHODS OF ANALYSIS FOR THE DETERMINATION OF URANIUM AND THORIUM}

By F. S. Grimaldi, Irving May, M. H. Fletcher, and Jane Titcomb

\section{CONTENTS}

Uranium analysis.

Fluorimetric methods . . . .

Direct or "dilution" method

Extraction method.......... 4

Carbonate method............... 5

Accuracy of fluorimetric methods

Colorimetric methods .

Thorium analysis...

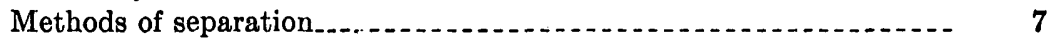

Separation based on precipitation of thorium orthophosphate...- $\quad 7$

Separation of thorium from the rare earths............... 8

Separation based on the extraction of thorium nitrate with

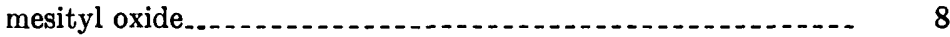

Separation of thorium from the titanium-zirconium and $\mathrm{R}_{2} \mathrm{O}_{3}$ group......... 8

Methods of determination

Gravimetric ......... 9

Colorimetric .

Nephelometric ...

CHART

Quenching data on elements for 2 grams of flux.

\section{URANIUM ANALYSIS}

Fluorimetric, colorimetric, and polarographic methods are commonly used for the determination of small amounts of uranium. The fluorimetric method based on the fluorescence of uranium in fluoride phosphors is one of the most sensitive for the determination of uranium; $10^{-10} \mathrm{~g}$ of uranium is detectable. The lower limit of detection for most of the colorimetric and polarographic techniques is about $10^{-5} \mathrm{~g}$ of uranium. Although all methods can be used for larger amounts, a convenient upper limit for the fluorimetric determination may be set at $10^{-5} \mathrm{~g}$, and for colorimetric and polarographic determinations at $10^{-2} \mathrm{~g}$ of uranium. 


\section{FLUORIMETRIC METHODS}

Melts obtained by fusing uranium salts with sodium fluoride fluoresce a brilliant yellow green when exposed to ultraviolet light. ${ }^{1}$ The intensity of the fluorescence is proportional, within wide limits, to the amount of uranium present, and this relationship is the basis for the quantitative fluorimetric determination of uranium.

The fluorescence test for uranium is specific when the excitation is with long wavelength (3650A) ultraviolet light. Niobium fluoresces only weakly when exposed to short wavelength light (2536A). In spite of this specificity, many elements may interfere by quenching the uranium fluorescence. For example, a few micrograms of cobalt, chromium, nickel, or manganese will reduce the fluorescence of uranium by more than 10 percent.

The uranium fluorescence may be enhanced by minute amounts of other elements that by themselves do not fluoresce in fluoride phosphors. This effect is seldom encountered in practice. Jacobs ${ }^{2}$ has shown that this enhancement is frequently instrumental and is due to a shift in the spectrum of the emitted light to a region generating a greater response from the phototube. Depending upon the particular combination of filters and phototube used, this shift in the spectrum may appear as enhancement or quenching. In some cases the opposing effect of increased phototube sensitivity and decreased transmission by the filter will be balanced, and no change will be apparent.

Two techniques are used commonly to reduce or to eliminate interference due to quenching. One technique, called the "dilution" method (or direct method) involves no chemical separations. It originated with Price ${ }^{3}$ who found that it is possible to reduce quenching to a negligible factor by using sufficiently small samples for analysis. The degree of quenching depends only on the concentration of quencher in the flux, and not on the ratio of concentration of quencher to concentration of uranium.

In the second technique the uranium is separated from quenching elements before the fluoride phosphor is prepared. In one type of procedure uranium may be freed from quenching elements by precipitating them with alkali carbonate solution; the uranium remains in solution as a complex carbonate. Alternately, the separation may be accomplished by extraction of uranyl nitrate by organic solvents. The latter procedure is also very useful for the concentration of uranium.

1 Nichols, E. L., and Slattery, M. K., 1926, Uranium as an activator: Optical Soc. America Jour., v, 14, p. 449 .

2 Jacobs, S., 1950, A study of the determination of uranium by measurement of fluorescence: CRL/AE 52, Department of Scientific and Industrial Research, Teddington, Middlesex.

3 Price, G. R., Ferretti, F. J., and Schwartz, S., 1945. The microfluorimetric determination of uranium: AECD 2282. 


\section{DIRECT OR “DILUTION”' METHOD}

The direct fluorimetric method consists of taking a small aliquot of an acid solution of the sample, evaporating it in a standard platinum or gold container, adding the fluoride flux, and preparing the phosphor by fusing at a low temperature. The fluorescence of the melt is then measured in a fluorimeter.

The size of the aliquot in the direct method depends on the composition of the material to be analyzed. This size may range from a few micrograms of sample (for materials containing strong quenchers such as chromium or manganese) to a few milligrams (for materials with low concentration of quenchers and/or containing relatively mild quenchers). The accompanying chart summarizes the magnitude of quenching produced by various elements. In general a $0.1-\mathrm{mg}$ sample results in negligible quenching for most rocks; for some materials (phosphate rocks) several milligrams usually yields little or no quenching. It is preferable to use the maximum weight that results in no serious quenching in order that the level of fluorescence to be measured is considerably above that introduced by background contamination. If many samples of about the same composition are to be analyzed, it is advantageous to determine the maximum weight that can be used in the direct method. The measurement of very low fluorescence intensity levels requires the use of sensitive fluorimeters.

Quenching data on elements for 2 grams of flux

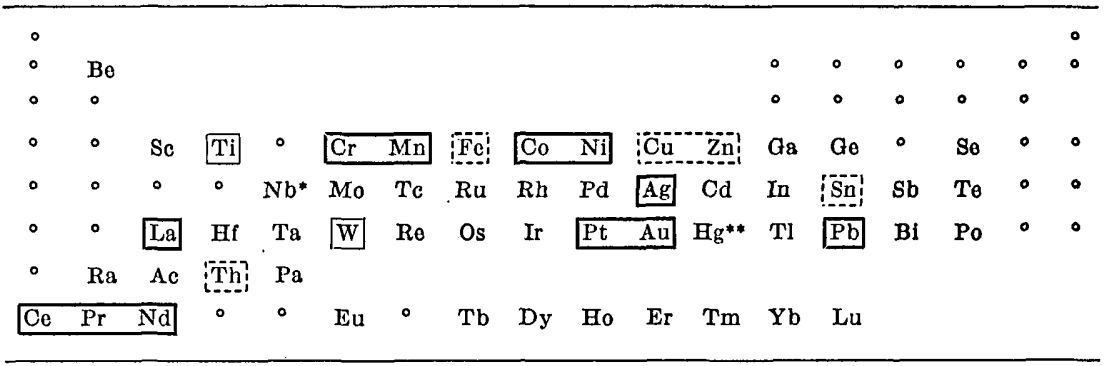

Heavy solid lines enclose elements that are strong quenchers $(1-10 \gamma$ quench uranium fluorescence by 10 percent or more).

Heavy dotted lines enclose elements that are moderate quenchers (10-50r quench fluorescence about 10 percent).

Light solid lines enclose elements that are weak quenchers $(50-1,000 \gamma$ quench fluorescence by about 10 percent).

For elements shown but not enclosed there are no data. The transition elements are probably moderate to strong quenchers. Elements not shown do not quench the uranium fluorescence.

*Niobium fluoresces only with short-wave excitation (2536A).

**Mercury has been reported as a strong quencher of uranium fluorescence, but it is volatilized in the preparation of the melt.

\section{EXTRACTION METHOD}

In this method the uranium is separated from quenchers before preparation of the fluoride phosphor. This separation usually in- 
volves the extraction by means of organic solvents of uranyl nitrate from nitric acid solution after the addition of a salting agent. A portion of the solvent is then transferred to the standard container and after evaporation of the solvent, the phosphor is prepared.

The Geological Survey procedure (part 6) uses batch extraction with aluminum nitrate as the salting agent and ethyl acetate as the solvent. Aluminum nitrate serves also to complex $\mathrm{F}^{-}, \mathrm{PO}_{4}^{-}$, and $\mathrm{SO}_{4}^{-}$ ions that otherwise seriously. hinder the extraction of uranium. Aluminum nitrate is also advantageous because any aluminum extracted does not quench the uranium fluorescence. Vanadium and quadrivalent cerium, thorium, and zirconium are partly extracted. Neither vanadium nor zirconium quenches the uranium fluorescence significantly, but cerium or thorium quenching may be serious. Interference due to cerium is eliminated when necessary by reducing the cerium to the trivalent state before extraction. With large concentrations of cerium, it is usually necessary to repeat the extraction. Because larger samples may be used with the extraction-fluorimetric procedure, less sensitive fluorimeters may be used; errors due to contamination are less serious.

The extraction of uranium by ethyl acetate may be made from solutions at acidities ranging from slightly acid to 20 percent by volume nitric acid. Depending on the acidity of the solution before extraction, the volume of the ethyl acetate layer may decrease or increase after extraction. Thus with slightly acid solutions the volume of the ethyl acetate layer decreases by 3 percent; with 15 percent by volume nitric acid, there is a 3 percent increase. In the range $6 \frac{12}{2}$ to $7 \frac{112}{2}$ percent nitric acid there is no significant volume change. Corrections for volume changes may be made by basing the working curve on extracted standards. Although the extraction procedures given in this bulletin are based on extraction from $(15+85)$ nitric acid solutions, our present practice is to use $(7+93)$ nitric acid solutions.

\section{CARBONATE METHOD}

In this procedure (part 15) an aliquot of a sulfuric acid solution of the sample representing $15 \mathrm{mg}$ or less is treated with alkali carbonate solution in excess to precipitate quenching elements; the uranium remains in solution. After filtration, an aliquot of the filtered solution is transferred to a standard container, the solution is evaporated, and tho standard melt is prepared as before. Cerium, cobalt, and copper may interfere in this procedure. A very small amount of cerium and cobalt follow uranium because the precipitates formed from sulfate solutions tend to pass through the filter. Most materials do not contain sufficient cerium to interfere. With suitable modification tho procedure may be used even for the determination of uranium in monazite. Cobalt is quantitatively removed when an element other 
than cobalt is precipitated with alkali carbonate. Copper may remain completely in solution yielding an intense blue solution. If the amount of copper not precipitated is insufficient to yield a blue solution, no quenching of the uranium fluorescence results. When a blue solution is obtained, a small amount of hydroxylamine is added after the alkali carbonate to precipitate cuprous oxide and thus remove the interference of this element.

The carbonate procedure does not accommodate more than $15 \mathrm{mg}$ of various metal oxides and should not be extended without testing to determine that no occlusion of uranium occurs in the carbonate precipitate for greater quantities of metal oxides.

\section{ACCURACY OF FLUORIMETRIC METHODS}

With careful work uranium may be determined by the fluorescence method with no greater error than \pm 4 percent of the uranium content. Under routine conditions, where speed may be important, the error generally is greater and may range from \pm 8 to 15 percent of the uranium content. When errors occur the results are generally low.

\section{COLORMMETRIC METHODS}

Reagents.-Various reagents have been used for the colorimetric determination of uranium. The most important of these are hydrogen peroxide (both in alkaline and slightly acid solution), ammonium thiocyanate, and ascorbic acid. The Geological Survey has adopted the alkaline peroxide colorimetric method. This procedure (part 3) is applicable generally and useful for the range $5 \times 10^{-5} \mathrm{~g}$ to $2 \times 10^{-2} \mathrm{~g}$ uranium.

In the alkaline-peroxide procedure provision must be made not only to remove elements that precipitate in sodium hydroxide solution, but also to remove vanadium, chromium, and molybdenum that give yellow solutions similar to that given by uranium. Two separation procedures are in current use. The first depends on the extraction of uranyl nitrate as previously described, and the second uses cupferron for the separations. As a little vanadium accompanies uranium in the extraction procedure, it may be removed by cupferron before the colorimetric estimation of uranium, or the vanadium color may be destroyed by heating the alkaline peroxide solution." The cupferron separations consist of first reducing the uranium in a Jones reductor and precipitating the reduced uranium with cupferron. Usually the sample solution contains sufficient titanium to act as a carrier for the uranium. If no elements that precipitate with cupferron in acid solution are present in the solution, a few milligrams of titanium

\footnotetext{
- Goldbeck, O. G., and others, 1945, Colorimetric determinations of uranium by means of peroxide: Nat. Bur. Standards Rept. A-1074.
} 
are added as a carrier. The cupferron separates uranium from the major constituents and from chromium. The cupferron precipitate is ignited and dissolved; uranium is oxidized to the sexivalent state and then separated from elements that are precipitated with cupferron in acid solution by extracting the cupferrates of these elements with ethyl acetate. Uranium remains in the water layer. The uranium then is determined colorimetrically with hydrogen peroxide in sodium hydroxide solution, the hydroxide serving the additional function of precipitating the very small amounts of rare earths that may accompany uranium in these separations. A little chromium tends to follow uranium in the cupferron separations when the chromium content of the solution is high. Chromium is eliminated when necessary by repeating the reduction step.

Instruments.-The colorimetric estimation may be made visually by comparing samples with a series of standards in Nessler tubes. These standards are made to contain amounts of uranium differing by $0.1 \mathrm{mg}$ in a total volume of $50 \mathrm{ml}$.

Measurements may be made with filter photometers using Corning filter no. 5543 but the sensitivity is appreciably lower than with a spectrophotometer. The Geological Survey uses the Beckman spectrophotometer; transmittancy measurements are made at $400 \mathrm{~m} \mu$. With a $0.1-\mathrm{mm}$ slit, 1-cm light path, and water as the reference solution, an optical density of about 0.9 is obtained for solutions of concentration $0.2 \mathrm{mg}$ of uranium per milliliter. With the Beckman spectrophotometer a precision of \pm 1 percent of the uranium content may be obtained.

\section{THORIUM ANALYSIS}

Chemical methods for the determination of thorium are complex, involve difficult and tedious manipulation, and require the services of thoroughly experienced analysts. The analytical chemistry of thorium is complicated by the colorless nature of the ion, by its single valence state, by the lack of selective and sensitive reagents, by the refractory nature of its ores, and by its association with elements that present difficult analytical problems.

In most thorium analyses, provisions must be made for the separation of thorium not only from elements commonly determined in rock and mineral analyses, but also from the rare earths, from the aundrivalent elements, and from the quinquivalent elements such as niobium and tantalum. There are many proceaures for voo soparaviou of thorium from the rare earths, but only two procedures are commonly used for the separation of thorium from the titanium-zirconium group. 


\section{METHODS OF SEPARATION}

SEPARATION BASED ON PRECIPITATION OF THORIUM ORTHOPHOSPHATE

With zirconium as a carrier, thorium is precipitated quantitatively as the phosphate from solutions $2 \frac{1}{2}$ percent by volume in hydrochloric acid $(0.3 \mathrm{~N})$ and containing $2 \mathrm{~g}$ diammonium phosphate per $100 \mathrm{ml}$ of solution (part 18). This precipitation reaction separates thorium from most of the major constituents of rock samples and is a useful concentration procedure for trace analysis. In addition to titanium and zirconium, some rare-earth phosphates are also precipitated.

\section{SEPARATION OF THORIUM FROM THE RARE EARTHS}

With ammonium hydroxide.-Thorium is separated from calcium, magnesium, manganese, and most of the rare earths by ammonium hydroxide precipitations at controlled acidity (part 20). At a $p H$ corresponding to the neutral color of methyl red, thorium is precipitated quantitatively, whereas most of the trivalent cerium and the other rare earths remain in solution. Either nitrate or chloride solutions of thorium may be used, but the sulfate ion must be absent. If much sulfate is present, considerable losses of thorium result at the methyl red end point, although precipitation of thorium is complete when excess ammonia is used. Sulfate may be removed by preliminary precipitations of thorium with sodium hydroxide.

Complete separation of thorium from the rare earths is not obtained in this separation, as the last few milligrams of rare earths are retained persistently by the thorium precipitate. The separation, however, is simple and exceedingly useful for removing most of the rare earths. Zirconium and titanium are not separated.

With potassium iodate.-The separation of thorium from the rare earths by precipitation as the iodate is one of the best procedures. For macro amounts the reaction is carried out in $6 \mathrm{~N}$ nitric acid solution. For quantities less than a few milligrams the final acidity of the solution (after all reagents are added) should not exceed $1 \mathrm{~N}$ nitric acid because loss of thorium results at higher acid concentrations (part 18). Two precipitations of thorium iodate from $6 \mathrm{~N}$ nitric acid solutions are usually sufficient for separating the rare earths; four or five precipitations may be necessary at the low acidities. Cerium ${ }^{+4}$, zirconium, and titanium also are precipitated by iodate. Cerium ${ }^{+4}$ may be reduced by hydrogen peroxide to cerium ${ }^{+3}$. More elements tend to coprecipitate with thorium iodate at low acidity than at high acidity. As the range of thorium content of most of the samples to be analyzed is unknown, we have standardized on low acidity for 
iodate precipitation because it is sounder. At high acidities the precipitation of thorium iodate is made by adding $50 \mathrm{ml}$ of nitric acid and $100 \mathrm{ml}$ of 15 percent solution of potassium iodate in $(1+1)$ nitric acid to $100 \mathrm{ml}$ of slightly acid solution of the sample. For low acidities $3 \mathrm{ml}$ of nitric acid and $8 \mathrm{ml}$ of $7 \frac{1}{2}$ percent water solution of potassium iodate are added to the slightly acid solution of the sample, and the total volume of the solution is made to $50 \mathrm{ml}$ by the addition of water. Thorium iodate may be dissolved by reducing acids, such as hydrochloric acid, and also by concentrated nitric acid.

With hydrogen peroxide.-Thorium is precipitated by hydrogen peroxide as the peroxynitrate from solutions $0.03 \mathrm{~N}$ in nitric acid or less. The concentration of hydrogen peroxide used is $5 \mathrm{ml}$ of 30 percent hydrogen peroxide per $100 \mathrm{ml}$ of solution. The method adopted by the Geological Survey (part 20) uses $0.03 \mathrm{~N}$ nitric acid because fewer elements are precipitated at this higher acidity. The precipitation of thorium with hydrogen peroxide is somewhat sensitive to changes in conditions of precipitation. Zirconium causes low recovery of thorium and must be removed completely before applying the peroxynitrate precipitation. Very slight losses of thorium (about $1 \mathrm{mg}$ or less of thorium oxide) occur in the presence of the sulfate ion.

\section{GEPARATIONS BASED ON THE EXTRACTION OF THORIUM NITRATE WITH MESTTYL OXIDE}

Thorium nitrate is quantitatively extracted by mesityl oxide from solutions $2.5 \mathrm{M}$ in aluminum nitrate and $1.2 \mathrm{M}$ in nitric acid (part 21). The concentration of nitric acid is not critical and may range from 5 to 30 percent by volume. The extraction is a batch extraction. All of the uranium is extracted quantitatively, most of the zirconium and some of the rare earths and vanadium. The rare earths are stripped from the mesityl oxide by several washings with a solution $2.5 \mathrm{M}$ in aluminum nitrate and $1.2 \mathrm{M}$ in nitric acid. Thorium is stripped from the mesityl oxide by water after removal of the rare earths. The mesityl oxide separation is also a useful means of concentrating trace quantities of thorium and may be applied in the presence of phosphate and arsenate. The mesityl oxide separation is especially important for the separation of large amounts of thorium and from small amounts of rare earths because precipitation reactions do not yield as clean a separation for such a combination.

SEPARATION OF THORTUM FROM THE TITANIUM-ZIRCONIUM AND $\mathrm{R}_{3} \mathrm{O}_{3}$

With oxalic acid.-The separation of thorium by precipitation as the oxalate is a standard method and is widely used. The advantage 
of oxalic acid over hydrofluoric acid for the same separation is that the thorium oxalate may be ignited and then weighed as the oxide. As the precipitant, $4 \mathrm{~g}$ of oxalic acid per $100 \mathrm{ml}$ of solution are used, and the acidity of the solution may be as high as 4 percent by volume of mineral acid. The rare earths accompany thorium. The solubility of thorium oxalate is such that for traces of thorium (less than a few milligrams) precipitation as the oxalate is not always applicable.

With hydrofluoric acid.-Hydrofluoric acid provides approximately the same separations as oxalic acid. We prefer hydrofluoric to oxalic acid for these separations because the former is more consistent and reliable and also because it must be used when small amounts of thorium are to be precipitated. In the presence of alkalies and alkaline earths the precipitates from hydrofluoric and oxalic acid tend to occlude zirconium and titanium.

\section{METHODS OF DETERMINATION}

These methods presuppose that all interferences have been eliminated in the initial stages of the analysis.

\section{GRAVIMETRIC}

Thorium hydroxide, thorium peroxynitrate, and thorium oxalate are ignited to thorium dioxide which is weighed.

\section{COLORIMETRIC}

Few useful colorimetric methods exist for the determination of thorium because of lack of selectivity. $p$-Dimethylaminoazophenylarsonic acid (pararsonic acid) is used at the Geological Survey (part 18) for microgram amounts. Thorium is precipitated with the dye from buffered acetate solution, and the thorium precipitate is filtered and washed with the acetate buffer. The precipitate is decomposed with sodium hydroxide solution, and the density of the released dye solution is measured with a spectrophotometer.

An iodine liberation method (part 19) is also used in the Geological Survey laboratory and depends on the reduction of thorium iodate by hypophosphorus acid in the presence of sulfuric acid. The iodine liberated is dissolved in carbon tetrachloride and imparts a bluish-red color to the carbon tetrachloride.

\section{NEPHELOMETRIC}

Thorium, in less than 1-mg amounts, may be estimated nephelometrically as thorium iodate (part 18). The thorium is precipitated from normal nitric acid solutions with potassium iodate. The resulting turbidity is compared with a series of standards. 



\title{
Part 2. METHODS FOR THE COMPLETE DECOMPOSITION OF ROCK AND ORE SAMPLES TO BE ANALYZED FOR VERY SMALL AMOUNTS OF URANIUM AND THORIUM
}

\author{
By M. D. Foster, R. E. Stevens, F. S. Grimaldi, W. G. Schlect, \\ and Michael Fleischer
}

\section{CONTENTS}

Page

Introduction . . . . .

General procedure . . . 13

Nonocclusion of uranium by hydrolytic precipitates................ 14

\section{TABLE}

TABLE 1. Experiments showing nonocclusion of uranium by hydrolytic precipitates.

\section{INTRODUCTION}

This paper presents the methods used for the decomposition of samples to be analyzed for very small amounts of uranium and thorium. It is desirable to have a general method applicable without modification to most types of rocks and ores, although some samples will require special treatment. Unless it is known otherwise, complete decomposition of the sample is essential, as uranium and thorium may be present in some of the most refractory minerals such as zircon, microlite, and monazite. The procedures presented in this report are based on experience gained from the analyses of hundreds of samples over a period of more than 2 years.

The general procedure given below is satisfactory for most types of rocks and ores, whether siliceous or phosphatic. It is not satisfactory for samples, such as placer concentrates, that contain large amounts of very refractory minerals; a special procedure is given for these samples.

To determine traces of uranium and thorium, large samples may have to be decomposed; the procedure is designed to avoid introduction of large quantities of alkali salts. The samples are decomposed by means of volatile acids wherever possible; nitric and hydrofluoric

Note.-This report was issued as Trace Elements Inv. Rept. 31A and AECD 1782, 1946. 
acids are used for the initial treatment. The hydrofluoric acid is removed by repeated evaporations with nitric acid, which is then removed by evaporations with hydrochloric acid. This is a slow procedure, but requires little attention by the analyst, and many samples can be handled simultaneously. If desired, the hydrofluoric acid may be removed more rapidly by fuming in sulfuric or perchloric acid. However, the use of sulfuric acid is undesirable for several reasons. Many samples, such as phosphate rock and limestone, have high calcium contents and most of the calcium precipitates as sulfate. In one of the procedures for the determination of thorium (part 18), the insoluble calcium sulfate will accompany thorium, and the separations of thorium from zirconium and titanium using hydrofluoric acid or oxalic acid may fail because of the formation of insoluble salts such as calcium zirconium fluoride and calcium zirconium oxalate. Furthermore, the presence of the sulfate ion ties up thorium as a complex anion and interferes with many precipitation reactions of thorium. For instance sulfate may interfere in the precipitation of thorium with iodate, with ammonia; and with peroxide.

Perchloric acid is avoided because the presence of perchlorates may lead to the formation of rather stable emulsions during the extractions with organic solvents (such as ethyl acetate) in the analytical procedures.

The attack with volatile acids generally decomposes most rock samples. If a little unattacked residue remains, it is generally brought into solution by sintering or fusing with a minimum of sodium carbonate.

Elements such as niobium, tantalum, titanium, zirconium, thorium, tin, tungsten, and antimony may form hydrolytic precipitates, especially in the presence of phosphate. Such precipitates do not occlude uranium (table 1) and may be filtered off and rejected if only uranium is to be determined, but must be reserved if thorium is to be determined.

Modifications of the general procedure are desirable for certain unusual samples, and judgment must be exercised by the analyst. Two examples will illustrate. Samples very high in iron oxide are best digested first in porcelain with $(1+1)$ hydrochloric acid, filtered, and washed with hot water. The filtrate is reserved. The insoluble residue is ignited in platinum then treated as in the general procedure starting with step 3. The reserved filtrate is added after the fluoride has been removed. Samples containing much fluorite $\left(\mathrm{CaF}_{2}\right)$ are not decomposed readily either by concentrated nitric acid or concentrated hydrochloric acid. They may be fumed with perchloric acid, or better, evaporated twice with (1 - 2) hydroshloric acid. 
Special procedures are used for decomposing refractory minerals. These usually involve fusion with fluxes, such as sodium peroxide, sodium fluoride, mixtures of sodium fluoride and potassium pyrosulfate, and mixtures of sodium carbonate and sodium borate. One fusion gives nearly complete decomposition of minerals such as zircon, monazite, cassiterite, ilmenite, and betafite. Platinum crucibles are used for all these fusions except for sodium peroxide. Here either porcelain or iron crucibles may be used. Because these are specialized procedures, they are discussed in detail under the individual methods in other parts of this report.

\section{GENERAL PROCEDURE}

1. Weigh into a platinum dish $5 \mathrm{~g}$ of sample (ground to pass $60-80$ mesh) for samples with total radioactivity equivalent to 0.015 percent uranium or less; for samples of higher radioactivity, take a proportionately smaller sample.

2. If the sample contains organic matter, heat the sample over a burner, gently at first, gradually increasing the heat until the organic matter is burned off. Caution: sulfide ores, which may contain arsenic, lead, or antimony, should be ignited in porcelain.

3. Add $45 \mathrm{ml}$ of $(1+2) \mathrm{HNO}_{3}$, cover the dish, and digest the sample on the steam bath for 30 minutes.

If most of the sample goes into solution by this treatment, decant most of the liquid through a small filter paper and wash the paper with a little hot water. Reserve the filtrate. Burn the paper in a small platinum crucible and transfer the ash to the original dish containing the reserved insoluble portion. Proceed to step 4.

If relatively little of the sample was dissolved by the treatment with $(1+2) \mathrm{HNO}_{3}$, proceed to step 4 directly.

4. Add 10 to $15 \mathrm{ml}$ of $\mathrm{HF}$ and $10 \mathrm{ml}$ of $\mathrm{HNO}_{3}$ to the dish and slowly evaporate the mixture to dryness on a steam bath. Repeat if there is much unattacked material. Combine with any filtrate reserved in step 3 and evaporate the solution to dryness twice with $\mathrm{HNO}_{3}$ to remove fluoride.

5. Moisten the residue with a little hot dilute $\mathrm{HNO}_{3}$, transfer the contents of the dish to a beaker, and wash the dish with water. Add $10 \mathrm{ml}$ of hot $(1+1) \mathrm{HCl}$ to the dish to dissolve any residual stains and then transfer this solution to the beaker containing the sample.

6. Evaporate the solution to dryness. Follow by two more evaporations to dryness with $\mathrm{HCl}$.

7. Digest the residue with 20 to $40 \mathrm{ml}$ of $(1+1) \mathrm{HCl}$ and filter. Wash with hot $(1+1) \mathrm{HCl}$. Reserve filtrate, 
8. Ignite the residue in platinum, add a little $\mathrm{HF}$ and a drop of $\mathrm{H}_{2} \mathrm{SO}_{4}$. Evaporate the solution on the steam bath and then fume off the excess $\mathrm{H}_{2} \mathrm{SO}_{4}$. Sinter the residue with a minimum of $\mathrm{Na}_{2} \mathrm{CO}_{3}$ and dissolve the cooled melt in $(1+1) \mathrm{HCl}$.

If much $\mathrm{SiO}_{2}$ separates when the fusion is treated with $(1+1) \mathrm{HCl}$, evaporate the solution to dryness in platinum, treat with $\mathrm{HF}$ and a few drops of $\mathrm{H}_{2} \mathrm{SO}_{4}$, and fume off the sulfuric acid until dry. Dissolve the residue in $(1+1) \mathrm{HCl}$ and add the solution to the main sample. If little or no $\mathrm{SiO}_{2}$ separates when the fusion is treated with $(1+1)$ $\mathrm{HCl}$, add the solution to the previous filtrates.

9. Any hydrolytic precipitate may be filtered off and rejected if only uranium is to be determined (table 1). It must, however, be reserved if thorium is to be determined, as such precipitates may carry down thorium, especially if phosphate is present.

\section{NONOCCLUSION OF URANIUM BY HYDROLYTIC PRECIPITATES}

In the preparation of the solution of the sample, an insoluble hydrolytic residue that may contain niobium, tantalum, titanium, thorium, zirconium, tin, antimony, tungsten, with or without phosphorus, may be obtained. The experiments in table 1 show that these residues occlude no uranium.

To a mixture of the elements under investigation, as soluble ions, were added $10 \mathrm{ml}$ of $\mathrm{HCl}$ and $5 \mathrm{ml}$ of $\mathrm{HNO}_{3}$. The solution was evaporated to dryness three times with intermediate addition of 10-ml portions of $\mathrm{HCl}$. The dry salts were then digested with $10 \mathrm{ml}$ of $(1+1)$ hydrochloric acid, diluted to $35 \mathrm{ml}$ with water, and again digested. The insoluble material was filtered, ignited, and weighed. Uranium was then determined in the filtrate. No uranium was occluded in the precipitates, as shown in table 1.

At the time these data were obtained we were interested in amounts of uranium convenient for colorimetric determination. We have no formal data on occlusion for the smaller amounts of uranium handled in the fluorimetric methods. However, our experience with the small samples used in the fluorimetric determinations has been that here also no uranium is occluded by hydrolytic precipitates. 
TABLE 1.-Experiments showing nonocclusion of uranium by hydrolytic precipitates

\begin{tabular}{|c|c|c|c|c|c|c|c|c|c|c|c|c|}
\hline \multicolumn{10}{|c|}{ Amounts (mg) } & \multirow{2}{*}{$\begin{array}{c}\mathrm{H}_{3} \mathrm{PO}_{4} \\
\text { (85 } \\
\text { per- } \\
\text { cent) } \\
\text { (drops) }\end{array}$} & \multirow[b]{2}{*}{$\begin{array}{l}\text { Insolu- } \\
\text { ble } \\
\text { residue } \\
\text { (mg) }\end{array}$} & \multirow[b]{2}{*}{$\begin{array}{l}\text { U found } \\
\text { in fll- } \\
\text { trate } \\
\text { (mg) }\end{array}$} \\
\hline $\mathrm{U}$ & $\mathrm{Nb}_{2} \mathrm{O}_{3} 1$ & $\mathrm{Ta}_{2} \mathrm{O}_{5}{ }^{1}$ & $\mathrm{TiO}_{2}$ & $\mathrm{ZrO}_{2}$ & $\mathrm{SnO}_{2}$ & $\mathrm{WO}_{2}$ & $\mathrm{Sb}_{2} \mathrm{O}_{3}$ & $\mathbf{B i}$ & $\mathrm{Ce}_{2} \mathrm{O}_{3}$ & & & \\
\hline 0.6 & & & 300 & & & & & & & & 230 & 0.6 \\
\hline $\begin{array}{l}.6 \\
3\end{array}$ & 100 & $\ldots$ & 300 & & & $\cdots$ & & & & 2 & 315 & .6 \\
\hline .3 & 100 & & & & & & & & & 2 & 112 & .3 \\
\hline .3 & $\mid-\ldots . . . . .$. & 100 & (n) & & ... & $\ldots$ & $\ldots$ & $\ldots$ & & & 98 & .3 \\
\hline .3 & - & 100 & $\cdots$ & & & & - & $-\cdot$ & & 2 & 103 & .3 \\
\hline .3 & $-\cdots$, & $-\ldots$. & $-\cdots$ & 70 & & & & & & 3 & $<1$ & .3 \\
\hline .3 & nen & & & 0 & 100 & & & & & & $\begin{array}{r}144 \\
0\end{array}$ & 3 \\
\hline .3 & ............ & ........... & $\ldots .$. & $\ldots$ & 100 & &.- &.- & & 2 & 2 & .3 \\
\hline .3 & .. & …n-ne- & $\ldots$ & -.... & -- & 105 & & - & & 0 & 105 & .3 \\
\hline $\begin{array}{r}.5 \\
3 \\
3\end{array}$ & . & ............ & ....... & - & $\cdots$ & 100 & & & 100 & 2 & 0 & .3 \\
\hline .3 & . & & & & & . & & 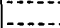 & 100 & 2 & 0 & 3 \\
\hline .3 & & 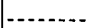 & & & & 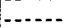 & 100 & & & & 5 & .3 \\
\hline$: 3$ & $\mid--$ & - & $\ldots .$. & $\ldots$ & -- & $\ldots$ & 100 & & $\ldots . .$. & 2 & 0 & .3 \\
\hline .3 & & & & & & & & 60 & & 2 & 0 & .3 \\
\hline .8 & 100 & 100 & 300 & 70 & 100 & 105 & $\ldots$ & $-\ldots$. & 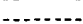 & & 370 & .3 \\
\hline .3 & 100 & 100 & 300 & 70 & 100 & 105 & & $-\ldots$ & .......... & 4 & 670 & 2 \\
\hline 2.5 & 100 & 100 & 300 & 70 & 100 & 105 & & & $\ldots$ & 4 & 670 & 2.7 \\
\hline
\end{tabular}

1 Added after $\mathrm{Na}_{2} \mathrm{CO}_{3}$ fusion. 



\title{
Part 3. THE GEOLOGIGAL SURVEY CUPFERRON PRECIPI- TATION-EXTRAGTION METHOD FOR THE DETERMINA- TION OF VERY SMALL AMOUNTS OF URANIUM IN NATURALLY OCGURRING MATERIALS
}

\author{
By F. S. Grimaldi
}

\section{CONTENTS}

Abstract............... 17

Introduction . .

General method.

Outline and discussion . . .

Procedure . . .

Special methods for monazite, concentrates rich in titanium or zirconium,

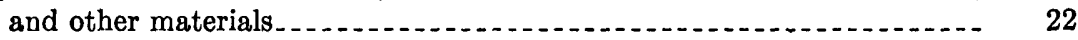

Experiments . . . . .

Verification of general method.......... 24

Comparison of analytical results with those obtained by other methods. $\quad 24$

Removal of chromium by double precipitation by cupferron from reduced solution

Removal of chromium by volatilization as chromyl chloride.........

Effectiveness of ether and ethyl acetate in extracting cupferron

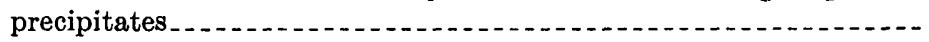

Removal of cerium by precipitation with sodium hydroxide-hydrogen peroxide...

\section{TABLES}

TABLE 1. Recovery of uranium from samples and synthetic mixtures....-

2. Chromium occlusion with uranium in samples high in chromium after one reduction and precipitation with cupferron ........

3. Removal of chromium by two reductions and precipitations with cupferron.

4. Removal of chromium by volatilization as chromyl chloride

5. Effectiveness of ether and of ethyl acetate in extracting cupferron precipitates.

6. Separation of cerium from uranium by sodium hydroxide-hydrogen peroxide

\section{ABSTRACT}

Detailed procedures are given for the determination of very small amounts of uranium (as little as 0.002 percent) in naturally occurring materials of widely

Nore.-This report was issued as Trace Elements Inv. Rept. $31 \mathrm{C}$ and AECD 2631, 1946. 
varying compositions. Uranium is concentrated by cupferron precipitation from reduced solution, then purified by cupferron precipitation and extraction of impurities after oxidation of uranium to the sexivalent state. Final determination is made colorimetrically in alkaline peroxide solution. Detailed procedures are presented, together with experimental data in support of the principal steps of the procedure.

\section{INTRODUCTION}

The object of the investigation was to develop a general method for the determination of very small percentages of uranium (as little as 0.002 percent) in naturally occurring materials. The samples to be analyzed included igneous and sedimentary rocks of various types, as well as placers, sands, and ores. Because of the complexity and diversity of these samples, special attention was given to the preparation of the solution and to several separation procedures to make certain that no uranium was lost and that all interferences were eliminated.

The literature available when this work was done contained no thoroughly tested methods for the determination of traces of uranium. Certain principles and separations in the unclassified literature for the determination of large amounts of uranium were tested to determine their suitability, with or without modification, for the problem at hand. After considerable investigation of the different procedures, it was found that separations by means of cupferron and the estimation of uranium colorimetrically by means of alkaline peroxide were the most satisfactory.

\section{GENERAL METHOD \\ OUTIINE AND DISCUSSION}

1. Complete decomposition of sample (part 2).

2. Removal of nearly all the iron by extraction with ethyl acetate from $(1+1)$ hydrochloric acid solution.

3. Reduction followed by precipitation of uranium with cupferron; titanium, vanadium, or zirconium already present in the solution act as carriers. (Separation from aluminum, calcium, and phosphorus.)

4. Ignition, fusion with oxidizing flux, and solution of the melt.

5. Separation of the uranyl ion by extraction of the cupferrates of other elements with ethyl acetate.

6. Colorimetric estimation of uranium by alkaline peroxide.

For materials high in niobium, tantalum, titanium, zirconium, tin, or vanadium, a preliminary extraction with ethyl acetate of the cupferrates of these elements is made from a large volume or solution to remove most of these constituents.

In the preparation of the solution, hydrolytic precipitates containing niobium, tantalum, titanium, zirconium, tin, tungsten, thorium, and phosphorus may be formed even though the sample is completely 
decomposed. These hydrolytic precipitates are filtered and discarded because they do not occlude uranium, whether the elements mentioned are present individually or together (part 2). However, monazite and samples rich in titanium, zirconium, and other elements that give large hydrolytic precipitates are more conveniently handled by a special method given on page 22 .

Iron is removed by extraction with ethyl acetate or ether from a $(1+1)$ hydrochloric acid solution of the sample. The excess acid is evaporated and the solution is made to $(1+9)$ hydrochloric acid, the volume is kept as small as is consistent with solution of the salts. It is then passed through a small Jones reductor directly into an iced cupferron solution.

For solutions containing nickel, which interferes in the reduction of uranium, zinc amalgam containing 10 percent mercury is substituted for the usual 2 to 3 percent amalgam (part 5).

With ores containing metals of the acid hydrogen sulfide group, it may be necessary to pretreat the solution with zinc or with hydrogen sulfide to avoid the precipitation of these elements in the reductor. Passage through the reductor reduces uranium to the trivalent and quadrivalent states, both of which are quantitatively precipitated by the cupferron in the receiving flask.

The cupferron precipitation is made at acidities of $(4+96)$ to $(8+92)$ hydrochloric acid. Perchlorate and sulfate ions do not interfere. The cupferron will precipitate uranium together with iron, titanium, zirconium, hafnium, vanadium, niobium, tantalum, molybdenum, tin, and part of the tungsten that escaped previous separation. The process separates these from other elements such as aluminum, phosphorus, manganese, cobalt, nickel, calcium, and chromium in the solution.

Experience with actual rock samples showed that with relatively high chromium content and with large cupferron precipitates a little chromium is occluded (p. 24). The chromium gives a color similar to, but more intense than that of uranium in the photometric determination, so its complete removal is imperative. When necessary, this is done by repeating the reduction and precipitation with cupferron. It is also feasible (p. 25) to remove chromium before the reduction and precipitation, by volatilization as chromyl chloride from a boiling perchloric acid solution. ${ }^{1}$ If the samples contain much potassium, the perchloric acid must be removed to prevent formation of a precipitate of potassium perchlorate; this is done by

' Smith, F. W., 1938, Volatilizing chromium as chromyl chloride: Ind. and Eng. Chem., Anal. Ed. 10, p. 360 . 
adding ammonium chloride and heating to decompose the unstable ammonium perchlorate. ${ }^{2}$

The cupferron precipitate is carefully ignited, and dissolved by fusion with potassium bisulfate, with the addition of sodium nitrate to insure that uranium is in the sexivalent state. The melt-is taken up in hydrochloric acid to make a $(1+9)$ hydrochloric acid solution.

In the next step the solution, chilled with ice, is treated with cupferron and extracted with ethyl acetate. This separates the uranium from iron, titanium, zirconium, vanadium, molybdenum, and other elements that form insoluble precipitates with cupferron; sexivalent uranium is not precipitated. These cupferron precipitates are completely extracted by ether or ethyl acetate; and the uranium. is left in the aqueous layer (p. 26). The solution at the start of the extraction of the cupferrates is $(8+92)$ hydrochloric acid. In the extraction, most of the excess cupferron dissolves in the ethyl acetate. The extraction method avoids the uncertainty inherent in separation of a trace element in the filtrate from a precipitate.

Organic matter in the aqueous layer is decomposed with nitric and sulfuric acids, and the nitrates are then removed. The uranium is then determined photometrically by the intensity of the yellow formed by adding hydrogen peroxide and making the solution alkaline; the solution must first be filtered to remove hydrated oxides of rare earths that may have escaped previous separation. The amount of cerium and other rare earths accompanying uranium should be small. For example with cerium solutions, about $0.6 \mathrm{mg}$ of cerium is found in the first cupferron precipitate if the original solution contained $25 \mathrm{mg}$ of cerium. If $2 \mathrm{mg}$ of cerium were originally present, enough escapes separation to give a very faint, but definite yellow in the final sodium hydroxide-peroxide test. It is likely, that even more cerium is carried down in the cupferron precipitate when other elements are present that are also precipitated. The precipitate of cerium in sodium hydroxide-peroxide solution has a color intensity about twice that produced by an equal weight of uranium. Filtration of the final sodium hydroxide-peroxide solution separates uranium quantitatively from cerium (p. 27).

\section{PROCEDURE}

1. Prepare a 100 $150 \mathrm{ml}$ hydrochloric acid solution $(1+1)$ of the sample (part 2).

2. Remove iron by two extractions with $50-100 \mathrm{ml}$ ethyl acetate. Reject the ethyl acetate layers.

3. Evaporate the solution to dryness to eliminate the excess acid.

\footnotetext{
${ }^{2}$ Noyes, A. A., and Bray, W. C., 1927, A system of qualitative analysis for the rare elements, New York, p. 237, 463, The Macmillan Co.
} 
4. Add $10 \mathrm{ml}$ of hydrochloric acid $(1+1)$ and digest on the steam bath. Add $20 \mathrm{ml}$ of water and digest until soluble salts dissolve. Filter if necessary and wash with water. Reject the hydrolytic residue.

5. Pass the solution, $50 \mathrm{ml}$ in volume, through a Jones reductor 10 to 12 inches long and of about $1 / 2$-inch bore. Collect the solution directly into $15 \mathrm{ml}$ of 6 percent cupferron solution contained in a 125-ml Erlenmeyer flask immersed in an ice bath, shaking the flask during the passage. Wash the reductor column with $10 \mathrm{ml}$ of 5 percent hydrochloric acid and then with enough water to make the contents of the flask $100 \mathrm{ml}$. If no precipitate forms add $10 \mathrm{ml}$ of titanium sulfate solution $\left(1 \mathrm{ml}=1 \mathrm{mg} \mathrm{TiO}_{2}\right)$ to act as carrier. If a large precipitate forms add more cupferron to insure an excess of the reagent. Let stand in the ice bath for about 5 minutes, stirring occasionally. Mix in a little paper pulp and filter. Wash with cold 6 percent hydrochloric acid containing $1.5 \mathrm{~g}$ of cupferron per liter.

6. Burn the cupferron precipitate in porcelain; start the ignition at low heat until the paper carbonizes, and increase the heat until the carbon is burned off. The final temperature should be about $750^{\circ} \mathrm{C}$.

7. If the solution (step 4) before passage through the reductor showed no visible green chromium, omit steps 7 and 8 and proceed directly to step 9. See "Experiments."

Fuse with a little potassium pyrosulfate. Keep the melt in quiet fusion until the residue is dissolved and any carbon that might be present due to faulty ignition of the cupferron precipitate is also gone. Allow the melt to cool. Dissolve the melt in $50 \mathrm{ml}$ of water containing $4.5 \mathrm{ml}$ of hydrochloric acid.

8. Pass the solution through the reductor as in step 5. This second reduction is not necessary if the color of the solution before the first passage through the reductor (step 4) showed no visible green chromium.

9. Fuse the second ignited cupferron precipitate with potassium pyrosulfate. Keep the melt in quiet fusion until the residue is dissolved and any carbon that might be present is also gone. Cool. Add a little sodium nitrate (about $10-25 \mathrm{mg}$ ) and fuse again until the nitrate is gone. Cool and dissolve the melt in $30 \mathrm{ml}$ of water containing $3.5 \mathrm{ml}$ of hydrochloric acid. The nitrate insures complete oxidation of the uranium to the sexivalent state. Cool the solution in an ice bath.

10. Transfer the solution to a separatory funnel. Add $15 \mathrm{ml}$ of cold 6 percent cupferron solution. Shake several times. Add $20 \mathrm{ml}$ 
of cold ethyl acetate, shake, allow to settle, and separate the layers. Make two more extractions of the water layer with ethyl acetate. Reject the ethyl acetate layers.

11. Evaporate the water layer to a small volume. Add $15 \mathrm{ml}$ of nitric acid and evaporate to dryness. Add $1 \mathrm{ml}$ of sulfuric acid, cover with watch glass, and fume gently on the hotplate. Destroy the last trace of organic matter by cautious dropwise addition of $1 \mathrm{ml}$ of nitric or fuming nitric acid. Allow to fume for 5 minutes after the nitric acid is gone. Repeat with a $1-\mathrm{ml}$ portion of fuming nitric acid. Allow to fume 5 minutes after the nitric acid is gone. While the solution is still fuming, add cautiously $2 \mathrm{ml}$ of water dropwise from a. pipette to remove any traces of nitrogen compounds, and again bring to fumes of sulfuric acid. Cool.

12. Add $35 \mathrm{ml}$ of water and boil gently until a solution is obtained. The double sulfates of rare earths and potassium may precipitate. These are not filtered. Cool to about $50 \mathrm{C}$. Add six drops of 30 percent hydrogen peroxide, then 50 percent sodium hydroxide solution drop by drop until neutral, then $1 \mathrm{ml}$ in excess. Cool. Transfer to a graduated cylinder and dilute to $50 \mathrm{ml}$. Filter through a 7-cm Whatman no. 40 paper, but do not wash.

13. Compare the solution visually with solutions containing known quantities of uranium made up to $50-\mathrm{ml}$ volume and containing $1 \mathrm{ml}$ of 50 percent sodium hydroxide solution and five drops of 30 percent hydrogen peroxide. Narrow-bore Nessler tubes may be used for the visual comparison. Density measurements may also be made spectrophotometrically at about $400 \mathrm{~m} \mu$ (part 3).

\section{SPECIAL METHODS FOR MONAZITE, CONCENTRATES RICH IN TITANIUM OR ZIRCONIUM, AND OTHER MATERIALS}

The general method is modified for certain refractory materials for two reasons: (1) the cupferron precipitates obtained in step 5 are extremely bulky and are not easily handled, and (2) very large hydrolytic precipitates are obtained. Although experiments show no occlusion of uranium by moderately large hydrolytic precipitates, it is preferable to avoid their formation by eliminating the bulk of the constituents by a preliminary ethyl acetate extraction of the cupferrates from large volumes of solution. The procedure follows:

1. Fuse $0.5 \mathrm{~g}$ of finely ground sample in a porcelain crucible with $3 \mathrm{~g}$ of sodium peroxide.

2. Transfer the crucible containing the cooled melt to an $800-\mathrm{ml}$ beaker and add $225 \mathrm{ml}$ of Waterg! Bring to a gentle boil and allow to 
simmer for a few minutes to destroy most of the peroxide. Cool. Add slowly $225 \mathrm{ml}$ of cold $(1+4)$ hydrochloric acid solution. The purpose is to prevent the precipitation of silica at this point. Warm the sample gently if complete solution is not obtained. Cool in an ice bath. Samples containing both phosphate and elements like titanium and zirconium will give phosphate precipitates that are filtered and rejected before proceeding to the next step.

3. Transfer the cold solution to a 2-liter separatory funnel and add enough cupferron (generally $100 \mathrm{ml}$ of 6 percent cupferron solution is enough) to precipitate elements giving insoluble cupferrates. Add 300 to $400 \mathrm{ml}$ of cold ethyl acetate and extract. Extract again with 300 to $400 \mathrm{ml}$ of ethyl acetate. Reject the ethyl acetate layers.

4. Evaporate the water layer to about $50 \mathrm{ml}$ and add $50 \mathrm{ml}$ of nitric acid. Evaporate to dryness.

5. Digest residue with dilute nitric acid and filter off silica. Reserve the solution. Ignite the silica and treat with hydrofluoric acid and a few drops of sulfuric acid. Evaporate and bring to fumes of sulfuric acid, then evaporate to dryness on the hotplate. Fuse the residue with a minimum of sodium carbonate. Leach the cooled melt with dilute hydrochloric acid and combine with reserved solution.

6. Evaporate the solution to dryness. Add hydrochloric acid and evaporate the solution to dryness to eliminate nitrate. Repeat with another portion of hydrochloric acid.

7. Dissolve the residue with $10 \mathrm{ml}$ of $(1+1)$ hydrochloric acid. Follow the general procedure from steps 4 to 13 .

Silica occasionally will precipitate in step 2 of the special procedure. When this happens, the solution is taken to dryness to dehydrate the silica, and the silica is then filtered off. The silica may be contaminated with large amounts of hydrolytic oxides such as those of titanium and zirconium. The silica is volatilized with hydrofluoric acid and sulfuric acid, and the sulfuric acid is removed as before. The residue is fused with potassium pyrosulfate and then leached with a large volume of $(1+9)$ hydrochloric acid. This solution and the filtrate from the silica are carried separately through the cupferronethyl acetate extraction, and are afterward combined. The cupferron is destroyed with nitric acid which is removed by repeated evaporations with hydrochloric acid. The solution, $50 \mathrm{ml}$ in volume and containing $10 \mathrm{ml}$ of hydrochloric acid $(1+1)$ and a few milligrams of titanium is then carried through steps 5 to 13 of "General method." 


\section{EXPERIMENTS}

\section{VERIFICATION OF GENERAI METHOD}

Table 1 shows data on procedure discussed under "General method."

TABLE 1.-Recovery of uranium from samples and synthetic mixtures

\begin{tabular}{|c|c|c|c|c|c|c|c|}
\hline Sample & $\underset{\substack{\mathrm{U} \text { in } \\
\text { (mg) }}}{\mid}$ & $\underset{\text { (mg) }}{U \text { added }}$ & $\begin{array}{l}\text { Total U } \\
\text { found } \\
\text { i (mg) }\end{array}$ & Sample & $\begin{array}{c}\text { U in } \\
\text { sample } \\
(\mathrm{mg})\end{array}$ & $\underset{(\mathrm{mg})}{\mathrm{U} \text { added }}$ & $\begin{array}{l}\text { Total U } \\
\text { found } \\
\text { (mg) }\end{array}$ \\
\hline $\begin{array}{l}\text { Synthetic mixture } 1 \\
\text { Do } \\
\text { Do } \\
\text { Do }\end{array}$ & $\begin{array}{l}0 \\
0 \\
0 \\
0\end{array}$ & $\begin{array}{r}0.30 \\
.60 \\
1.30 \\
2.50\end{array}$ & $\begin{array}{l}0.3 \\
.6 \\
1.3 \\
2.5\end{array}$ & $\begin{array}{l}\text { Sample } 65-67 \\
\text { Do } \\
\text { Sample } 108-154 \\
\text { Do }\end{array}$ & $\begin{array}{r}0.15 \\
.15 \\
.50 \\
.50\end{array}$ & $\begin{array}{l}0 \\
.60 \\
.30\end{array}$ & $\begin{array}{l}0.15 \\
.75 \\
.5 \\
.8\end{array}$ \\
\hline
\end{tabular}

1 Synthetic mixture: $50 \mathrm{~g}$ quartz, $50 \mathrm{~g}$ albite, $50 \mathrm{~g} \mathrm{Na}_{3} \mathrm{PO}_{4} \cdot 12 \mathrm{H}_{2} \mathrm{O}, 50 \mathrm{~g} \mathrm{CaCO}_{3}, 50 \mathrm{~g} \mathrm{Fe}_{2} \mathrm{O}_{3}, 10 \mathrm{~g} \mathrm{MgCO}$, $10 \mathrm{~g} \mathrm{MnO}_{2}, 1 \mathrm{~g}$ chrome alum, $1 \mathrm{~g} \mathrm{~V}, \mathrm{O}_{3}, 0.2 \mathrm{~g} \mathrm{TiO}$. The analyses were made on 5-g portions of the synthetic mixture after known quantities of uranium had been added.

\section{COMPARISON OF ANALTTICAL RESULTS WITH THOSE OBTAINED BY OTHER METHODS}

Typical results obtained in the laboratory of the Geological Survey by the cupferron method described in this paper and by the carbonate method are given in table 2 (part 4) describing the latter method. Table 3 (part 4) shows results of both methods compared with the results obtained in two other laboratories where different procedures were used.

\section{REMOVAL OF CHROMIUM BY DOUBLE PRECIPITATION BY CUPFERRON FROM REDUCED SOLUTION ${ }^{3}$}

Uranium was determined ${ }^{3}$ on 21 samples containing from 8 to 40 mg of chromic oxide by double precipitation with cupferron after reduction. After the uranium was determined by sodium hydroxidehydrogen peroxide, the solutions were tested for chromium by ether extraction of the chromium compound with peroxide, from ice-cold, barely acid solutions in this manner: The alkaline peroxide solutions $(50 \mathrm{ml}$ in volume) were made just acid with hydrochloric acid and then barely alkaline again with a few drops of sodium hydroxide. The solutions were cooled in an ice bath and transferred to a separatory funnel. Twenty-five milliliters of ice-cold ether were added and hydrochloric acid drop by drop until the solutions were slightly acid. The mixtures were shaken immediately and then allowed to settle. The water layers were drawn off and treated again with alkali, ether, and acid in the same manner three more times. This method of removal of chromium was sugseated to us by Margaret D. Foster of this laboratory, and additional tests confirmed that small umounes of chromium may be removed completely without loss of uranium.

\footnotetext{
I Experimental work by W. G. Schlecht and F. 8. Grimalda.
} 
After four extractions, the solutions were made alkaline, a few drops of 30 percent peroxide added, and the uranium determined again. Table 2 gives typical results obtained with only one reduction. Table 3 gives typical results obtained after two reductions. The decreases in intensity after ether extraction (table 3) are too small to be considered significant as evidence for the presence of chromium; even the highest discrepancy, 0.004 percent, occurred in a solution found to be free from chromium. Such decreases may be due to other causes such as the presence of organic matter, or the presence of nitrogen compounds in the final sodium hydroxide-peroxide test.

TABLE 2.-Chromium occlusion with uranium in samples high in chromium, after one reduction and precipitation with cupferron

[Original chromium content from 8-42 $\mathrm{mg} \mathrm{Cr}_{2} \mathrm{O}_{3}$ ]

\begin{tabular}{|c|c|c|c|c|c|c|c|c|c|}
\hline $\begin{array}{c}\text { Sample } \\
\text { no. }\end{array}$ & $\begin{array}{c}\text { Apparent } \\
\text { percent } \\
\text { U before } \\
\text { extraction } \\
\text { of } \mathrm{Cr}\end{array}$ & $\begin{array}{c}\text { Percent } \\
\text { U after } \\
\text { extraction } \\
\text { of } \mathrm{Cr}\end{array}$ & Difference & $\begin{array}{c}\mathrm{Cr}_{2} \mathrm{O}_{3} \\
\text { ocluded } \\
\text { (mg) }\end{array}$ & $\begin{array}{c}\text { Sample } \\
\text { no. }\end{array}$ & $\begin{array}{c}\text { Apparent } \\
\text { percent } \\
\text { U before } \\
\text { extraction } \\
\text { of } \mathrm{Cr}\end{array}$ & $\begin{array}{c}\text { Percent } \\
\text { U after } \\
\text { extraction } \\
\text { of } \mathrm{Cr}\end{array}$ & Difference & $\begin{array}{c}\mathrm{Cr}_{2} \mathrm{O}_{2} \\
\text { occluded } \\
\text { (mg) }\end{array}$ \\
\hline $\begin{array}{l}\mathrm{CC}-4 \ldots \\
\mathrm{CC}-19 \ldots \\
\mathrm{JJ}-20 \ldots \\
\mathrm{JJ}-24 \\
\mathrm{JJ}-29 \\
278\end{array}$ & $\begin{array}{r}0.008 \\
.011 \\
.007 \\
.011 \\
.009 \\
.019\end{array}$ & $\begin{array}{r}0.008 \\
.007 \\
.004 \\
.004 \\
.006 \\
.008\end{array}$ & $\begin{array}{l}0 \\
.004 \\
.003 \\
.007 \\
.003 \\
.011\end{array}$ & $\begin{array}{l}0 \\
.10 \\
.06 \\
.12 \\
.05 \\
.20\end{array}$ & $\begin{array}{l}658 \ldots \\
659 \\
1537 \ldots \ldots \\
1540 \ldots \ldots \\
1541 \ldots \ldots \\
1544 \ldots\end{array}$ & $\begin{array}{r}0.026 \\
.026 \\
.008 \\
.010 \\
.014 \\
.023\end{array}$ & $\begin{array}{r}0.014 \\
.013 \\
.006 \\
.008 \\
.005 \\
.007\end{array}$ & $\begin{array}{r}0.012 \\
.013 \\
.002 \\
.002 \\
.009 \\
.016\end{array}$ & $\begin{array}{l}0.24 \\
.25 \\
.03 \\
.03 \\
.20 \\
.30\end{array}$ \\
\hline
\end{tabular}

TABLE 3.-Removal of chromium by two reductions and precipitations with cupferron

[Original chromium content of samples $8-42 \mathrm{mg} \mathrm{Cr}, \mathrm{O}_{3}$ ]

\begin{tabular}{|c|c|c|c|c|c|c|c|}
\hline Sample no. & $\begin{array}{l}\text { Apparent } \\
\text { percent U } \\
\text { before ex- } \\
\text { traction } \\
\text { of } \mathrm{Cr}\end{array}$ & $\begin{array}{l}\text { Percent U } \\
\text { after ex- } \\
\text { traction } \\
\text { of Cr }\end{array}$ & Difference & Sample no. & $\begin{array}{l}\text { A pparent } \\
\text { percent U } \\
\text { before ex- } \\
\text { traction } \\
\text { of } \mathbf{C r}\end{array}$ & $\begin{array}{l}\text { Percent U } \\
\text { after ex- } \\
\text { traction } \\
\text { of } \mathrm{Cr}\end{array}$ & Difference \\
\hline $\begin{array}{l}174 \\
1756 \\
234 \\
278 \\
651 \\
655 \\
656 \\
657 \\
658 \\
059\end{array}$ & $\begin{array}{l}0.006 \\
.011 \\
.015 \\
.009 \\
.008 \\
.006 \\
.004 \\
.007 \\
.007 \\
.014 \\
.013\end{array}$ & $\begin{array}{l}0.007 \\
.011 \\
.011 \\
.009 \\
.008 \\
.006 \\
.004 \\
.007 \\
.007 \\
.014 \\
.013\end{array}$ & 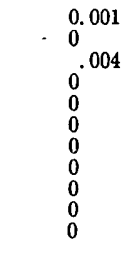 & $\begin{array}{l}660 \\
661 \\
662 \\
721 \\
722 \\
724 \\
743 \\
744 \\
1285 \\
1544\end{array}$ & $\begin{array}{l}0.004 \\
.007 \\
.005 \\
.010 \\
.009 \\
.008 \\
.008 \\
.009 \\
.013 \\
.007 \\
.\end{array}$ & $\begin{array}{l}0.004 \\
.007 \\
.005 \\
.008 \\
.008 \\
.006 \\
.008 \\
.007 \\
.012 \\
.007\end{array}$ & $\begin{array}{l}0 \\
0 \\
0 \\
.002 \\
.001 \\
.002 \\
0.002 \\
.001 \\
.001\end{array}$ \\
\hline
\end{tabular}

\section{REMOVAL OF CHROMIUM BY VOLATILIZATION AS CHROMYL CHLORIDE}

Chromium ${ }^{4}$ is oxidized to the sexivalent state by fuming with perchloric acid and is then volatilized as chromyl chloride with sodium chloride. This procedure has been described by Smith. ${ }^{5}$ The perchloric acid remaining in the solution causes, in the later stages of the

Experimental work by W. G. Schlecht and F. S. Grimaldi.

s Smith, F. W., op. cit.

$268681-54-3$ 
analysis, the precipitation of potassium perchlorate in samples containing sufficient potassium. To avoid this, the perchlorate is removed following essentially the same method described by Noyes and Bray. $^{6}$

The complete procedure follows:

After the extraction of iron from $(1+1)$ hydrochloric acid solution by ethyl acetate, evaporate the solution to near dryness in a casserole. Add $5 \mathrm{ml}$ of nitric acid and $15 \mathrm{ml}$ of perchloric acid and bring to fumes of perchloric acid. Cover the casserole with a watch glass and strongly fume for a few minutes until the chromium is oxidized to chromate. Add $1 \mathrm{~g}$ of sodium chloride with a spatula and fuse until the chloride is eliminated. Bring to fumes of perchloric acid again and repeat twice with $0.5-\mathrm{g}$ portions of sodium chloride. If the perchloric acid is greatly depleted it should be replenished before each addition of sodium chloride. Cool. Add $5 \mathrm{~g}$ of solid ammonium chloride, cover, and digest on the steam bath for about 30 minutes. Remove the cover and heat on the hotplate until excess perchloric acid is driven off. Now cover and heat strongly on the hotplate until a gentle deflagration takes place. Cool. Add $10 \mathrm{ml}$ of $(1+1)$ hydrochloric acid and digest on the bath. Follow the general method from step 4.

Five samples were tested in the above manner and the final sodium hydroxide-hydrogen peroxide solutions were tested for chromium by ether extraction of the perchromic acid. Table 4 shows the results obtained.

TABLE 4.-Removal of chromium by volatilization as chromyl chloride

\begin{tabular}{|c|c|c|c|c|c|c|c|}
\hline Sample no. & $\begin{array}{c}\text { Apparent } \\
\text { percent U } \\
\text { before ex- } \\
\text { traction } \\
\text { of } \mathbf{C r}\end{array}$ & $\begin{array}{l}\text { Percent } U \\
\text { after ex- } \\
\text { traction } \\
\text { of } \mathrm{Cr}\end{array}$ & Difference & Sample no. & $\begin{array}{l}\text { Apparent } \\
\text { percent U } \\
\text { before ex- } \\
\text { traction } \\
\text { of } \mathrm{Cr}\end{array}$ & $\begin{array}{l}\text { Percent U } \\
\text { after ex- } \\
\text { traction } \\
\text { of } \mathrm{Cr}\end{array}$ & Difference \\
\hline $\begin{array}{l}278 \\
658 \\
1543\end{array}$ & $\begin{array}{l}0.008 \\
.015 \\
.009\end{array}$ & $\begin{array}{r}0.008 \\
.014 \\
.008\end{array}$ & $\begin{array}{l}0 \\
.001 \\
.001\end{array}$ & 1544 & $\begin{array}{r}0.006 \\
.004\end{array}$ & $\begin{array}{r}0.006 \\
.003\end{array}$ & $\begin{array}{l}0 \\
.001\end{array}$ \\
\hline
\end{tabular}

\section{EFFECTIVENESS OF ETHER AND ETHYL ACETATE IN EXTRACTING CUPEERRON PRECIPITATES}

The following tests were made to determine the effectiveness of ether and ethyl acetate in extracting the precipitate formed with cupferron. The test solutions had a volume of $30 \mathrm{ml}$ and contained $4 \mathrm{ml}$ of hydrochloric acid. Each solution was cooled in an ice bath and $10 \mathrm{ml}$ of cool 6 percent cupferron solution were added. The mixture was extracted three times with $15-\mathrm{ml}$ portions of ether or ethyl acetate. Either the aqueous layer or organic solvent layer was

'Noyes, A. A., op. cit. 
then tested for the elements in question after destruction of the organic matter (table 5).

\section{REMOVAL OF CERIOM BY PRECIPITATION WITH SODIUM HYDROXIDE-HYDROGEN PEROXIDE}

The use of solutions of cerium and uranium indicate that removal of cerium by the sodium hydroxide-hydrogen peroxide precipitation is nearly complete, and uranium is not occluded by the precipitate as shown in the experiments in table 6 .

TABLE 5.-Effectiveness of ether and of ethyl acetate in extracting cupferron precipitates

\begin{tabular}{|c|c|c|c|}
\hline \multirow{2}{*}{ Elcments taken (g) } & \multicolumn{2}{|c|}{$\begin{array}{l}\text { Amount, in grams, left in aqueous } \\
\text { layer after extraction with- }\end{array}$} & \multirow{2}{*}{ Method of detection } \\
\hline & Ethyl acetate & Ether & \\
\hline 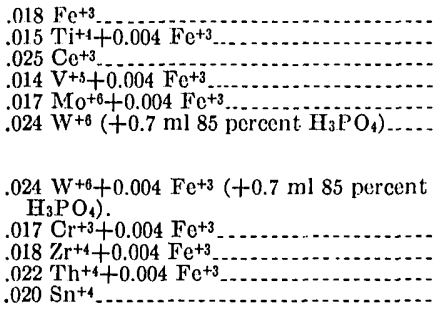 & 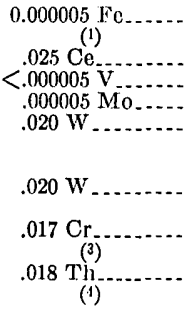 & \begin{tabular}{c}
0.000003 Fe. \\
$(1)$ \\
\hdashline$<000005 \mathrm{~V}_{1}$
\end{tabular} & 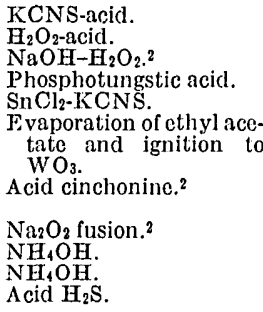 \\
\hline
\end{tabular}

1 No titanium.

2 Ethyl acetate layer tested.

3 No zirconium.

4 No tin.

TABLE 6.-Separation (in $\mathrm{mg}$ ) of cerium from uranium by sodium hydroxidehydrogen peroxide

\begin{tabular}{|c|c|c|c|c|c|}
\hline $\begin{array}{l}\mathrm{Ce} \text { in } \\
\text { solution }\end{array}$ & $\underset{\text { tion }}{U}$ in solu- & $\begin{array}{l}\text { U found in } \\
\text { filtrate }\end{array}$ & $\begin{array}{l}\text { Ce in solu- } \\
\text { tion }\end{array}$ & $\underset{\text { tion }}{U}$ in solu- & $\begin{array}{l}\mathrm{U} \text { found in } \\
\text { filtrate }\end{array}$ \\
\hline $\begin{array}{l}5.0 \\
5.0 \\
5.0 \\
2.0 \\
2.0 \\
1.0 \\
1.0\end{array}$ & $\begin{array}{l}0 \\
0 \\
0.3 \\
0 \\
.3 \\
0.3 \\
.\end{array}$ & $\begin{array}{l}0 \\
0 \\
.3 \\
0 \\
.3 \\
{ }^{3} .3 \\
.3\end{array}$ & $\begin{array}{l}0.2 \\
.2 \\
.1 \\
.1 \\
.03 \\
.03\end{array}$ & $\begin{array}{l}0 \\
0.3 \\
0.3 \\
0.3 \\
.3\end{array}$ & $\begin{array}{l}0 \\
0.3 \\
0^{.3} \\
.3\end{array}$ \\
\hline
\end{tabular}





\title{
Part 4. THE GEOLOGICAL SURVEY GARBONATE-PHOS- PHATE-PEROXIDE METHOD FOR THE DETERMINATION OF VERY SMALL AMOUNTS OF URANIUM IN NATU- RALLY OCGURRING MATERIALS
}

\author{
By M. D. Foster and R. E. Stevens
}

\section{CONTEN'TS}

Outline and discussion of procedure 30

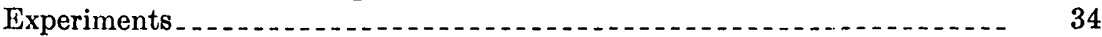

Occlusion of uranium by the carbonate precipitate using synthetic mixtures

Comparison of results obtained by this and other methods tation.

Effectiveness of the phosphate precipitation for the separation of vanadium and uranium

\section{TABLES}

TABLE 1. Determination of uranium in synthetic mixtures of known

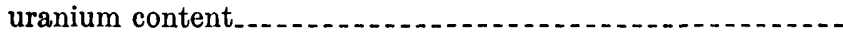

2. Comparison of results of uranium analyses by the carbonatephosphate-peroxide and the cupferron methods.

3. Comparison of results of uranium analyses by different methods in several laboratories

4. Amount of titanium and vanadium removed from solution by one carbonate precipitation . . .

\section{INTRODUCTION}

A procedure is described for the determination of very small amounts of uranium (as little as $0.10 \mathrm{mg}$ ) in a wide variety of naturally occurring materials. Most of the constituents are separated from uranium by hydrochloric acid extraction (of iron) and by repeated precipitation with sodium carbonate, and the uranium is then coprecipitated with aluminum as the phosphate in acetic acid solution. The phosphate precipitate is dissolved in sodium hydroxide

NorE.-This report was issued as Trace Elements Inv. Rept. 31B, 1946. 
peroxide solution, and uranium is determined colorimetrically. A discussion of the important features of the method, experimental work done in connection with the development of the method, and comparative results by this and other methods are given.

The published methods for the determination of uranium were either inadequate for the determination of the small amounts of uranium (as little as 0.002 percent) sought in this study, or not applicable in the presence of phosphate, a major constituent of some of the samples to be analyzed. Methods developed at other laboratories were not available to us when this work was done. It was necessary, therefore, to develop methods especially designed for the determination of small amounts of uranium in the presence of large amounts of phosphate.

\section{OUTLINE AND DISCUSSION OF PROCEDURE}

The main features of the method are as follows:

1. Complete decomposition of the sample (part 2).

2. Removal of most of the iron (and molybdenum) by extraction with ethyl acetate from a $(1+1)$ hydrochloric acid solution.

3. Removal of calcium, magnesium, titanium, zirconium, chromium, manganese, most of the rare earths, and some of the aluminum and phosphate by precipitation with sodium carbonate.

4. Coprecipitation from acetic acid solution of uranium and aluminum as phosphates. This step also separates vanadium from uranium.

5. Colorimetric determination of uranium in sodium hydroxide solution containing hydrogen peroxide.

The sample is decomposed and a solution in $(1+1)$ hydrochloric acid is obtained by methods given in part 2. Complete decomposition is essential as it is not safe to assume that no uranium is present in undecomposed material. Any hydrolytic precipitates of tantalum, niobium, tin, titanium, zirconium, or tungsten may be ignored, however, as they do not occlude uranium. If, however, the sample is used also for the determination of thorium, the hydrolytic precipitates should be reserved, as they may occlude thorium.

Although iron is removed from the solution by precipitation with sodium carbonate, the amount in a 5 -g sample forms such a bulky precipitate that it is desirable to remove iron before the carbonate precipitation. Removal of iron is also desirable if the sample is used for the determination of thorium as well as of uranium. Extraction with ethyl acetate from hydrochloric acid solution affords a quick and nonily complete romoval of iron (and molybdenum) from tho solution.

The carbonate precipitation, with cooling before filtration, removes calcium, magnesium, titanium, zirconium, chromium, manganese, thorium, most of the rare earths, and part of the aluminum and phosphate from uranium that is left in solution. However, the precipitate may occlude some uranium, and it is, therefore advisable 
to make a second or even third precipitation. The amount of uranium retained in the first carbonate precipitation depends on the amount of uranium present and on the bulk of the carbonate precipitate. With the amount of precipitate expected from a 5-g sample of most rocks, less than 4 percent of the uranium is retained after two precipitations if the uranium content is less than $2 \mathrm{mg}$ (p. 34). With the amount of precipitate expected from a 2 -g sample, less than 2 percent of the uranium is retained after two precipitations if the uranium content is less than $20 \mathrm{mg}$.

Thorium is precipitated quantitatively by sodium carbonate under the conditions used, and may therefore be determined in the same sample. The method is given in part 19 .

Precipitation of uranium as the phosphate in acetic acid solution, with ultimate solution in sodium hydroxide, makes it possible to obtain the uranium in a smaller volume for colorimetric comparison. It is necessary, however, to use some other element as a collector for the very small amounts of uranium for which this method was designed. Aluminum was chosen because (1) it forms a phosphate insoluble in acetic acid, (2) its phosphate and hydroxide are soluble in excess sodium hydroxide, and (3) it gives no colored compounds to interfere in the colorimetric determination of the uranium.

The phosphate precipitation also separates most of the vanadium from the uranium (p. 36). Double precipitation as phosphate may be necessary if the vanadium content is relatively high. The complete removal of vanadium is unnecessary, as it produces a color in the sodium hydroxide-peroxide solution that is much lower in intensity than that of uranium (p. 36) and this slight interference may 'be overcome by boiling the solution before making the color comparison ${ }^{1}$ (p. 33, step 9).

Small amounts of rare earths may be carried through the phosphate precipitation. These are precipitated by the sodium hydroxideperoxide treatment. Filtration of the sodium hydroxide-peroxide precipitate separates uranium quantitatively from cerium (part 3). If the sodium peroxide precipitate is large, it should be dissolved in acid and reprecipitated to recover any uranium that might be occluded.

The final sodium hydroxide-peroxide solution used for the colorimetric comparison may occasionally have a brownish hue due to colloidal hydrated iron oxide. This may be removed by filtering after warming the solution on the steam bath to precipitate the iron.

The use of 30 percent hydrogen peroxide is specified because 3 percent hydrogen peroxide contains organic preservatives, such as acetanilide, which give in alkaline solution a yellow color similar to

\footnotetext{
1 Goldbeck, C. G., Petretic, G. J., Minthorn, M. L., and Rodden, C. J., 1945, Colorimetric determination of uranium by means of peroxide: Nat. Bur. Standards Report A-1074.
} 
that of uranium. This interference may be serious for very small amounts of uranium.

1. Decomposition of sample: Weigh out $5 \mathrm{~g}$ of the sample if it has a total radioactivity, by counting, equivalent to 0.015 percent uranium or less. Use proportionately smaller weights of samples having higher radioactivity. Prepare a hydrochloric acid solution of the sample (part 2). If thorium is to be determined on the same sample, do not filter any hydrolytic precipitate that may have formed during the decomposition of the sample. If thorium is not to be determined on the same sample, the hydrolytic precipitate may be filtered off.

2. Extraction of iron: After obtaining a $(1+1) \mathrm{HCl}$ solution of the sample, evaporate down to a volume about $25 \mathrm{ml}$. Transfer the solution to a 250-ml separatory funnel and shake with $40 \mathrm{ml}$ of ethyl acetate. After the two layers have separated, draw off the acid layer into another separatory funnel of the same size. Add $20 \mathrm{ml}$ of ethyl acetate, shake well, and, after the layers have separated, draw off the acid layer into a 400-ml beaker. Combine the ethyl acetate layers and wash once by shaking with $5 \mathrm{ml}$ of $(1+1) \mathrm{HCl}$. Add the washings to the acid layer in the $400-\mathrm{ml}$ beaker.

3. Dilute the acid solution from the extraction of iron to a volume of about 250 or $300 \mathrm{ml}$ and heat to boiling. Remove the beaker from the heat and slowly add 50 percent $\mathrm{NaOH}$ solution until a slight permanent precipitate forms, then add solid $\mathrm{Na}_{2} \mathrm{CO}_{3}$ very carefully until effervescence ceases. Add 2 or $3 \mathrm{~g}$ of $\mathrm{Na}_{2} \mathrm{CO}_{3}$ in excess and stir until all the $\mathrm{Na}_{2} \mathrm{CO}_{3}$ is dissolved. Place the beaker in a cold water bath for about 45 minutes and filter on a Whatman no. 40 12.5-cm paper. Wash once with a 1 percent $\mathrm{Na}_{2} \mathrm{CO}_{3}$ solution.

4. Allow the precipitate to drain well, transfer to the precipitation beaker with a fine stream of distilled water, and add $7 \mathrm{ml}$ of $\mathrm{HCl}$. Dilute the solution to 250 or $300 \mathrm{ml}$, heat to boiling, and reprecipitate as before with 50 percent $\mathrm{NaOH}$ and solid $\mathrm{Na}_{2} \mathrm{CO}_{3}$. Cool and filter on a Whatman no. 40 12.5-cm paper. Scrub out the beaker and wash the precipitate on the paper five times with a 1 percent solution of $\mathrm{Na}_{2} \mathrm{CO}_{3}$. Add the filtrate and washings to the filtrate from the first precipitation. Make the combined filtrates acid with concentrated $\mathrm{HCl}$, then add $2 \mathrm{ml}$ in excess, and note the approximate amount of aluminum precipitated as the neutral point is passed.

5. Reduce the volume of the combined filtrates to about $150 \mathrm{ml}$ (time can be saved if the filtrate from the first carbonate precipitation is made acid and evaporated during the second precipitation and filtration). If, in the process of neutralizing and acidifying the fil- 
trates, they were found to contain little or no aluminum, add 7 to 10 $\mathrm{ml}$ of an $\mathrm{AlCl}_{3}$ solution containing $6.7 \mathrm{mg}$ of $\mathrm{AlCl}_{3}$ in $1 \mathrm{ml}$. If the filtrates contain some aluminum, add $4 \mathrm{ml}$ or less of the $\mathrm{AlCl}_{3}$ solution, depending on the amount of aluminum present. If on addition of the aluminum a precipitate forms, add sufficient $\mathrm{HCl}$ to dissolve it. Then add $1 \mathrm{~g}$ of solid $\left(\mathrm{NH}_{4}\right)_{2} \mathrm{HPO}_{4}$ and heat to boiling. Remove the beaker from the heat and add $\mathrm{NH}_{4} \mathrm{OH}$ until the solution is just alkaline to methyl red; then add, dropwise, sufficient ammonium acetateacetic acid solution (containing $308 \mathrm{~g}$ of ammonium acetate and 460 $\mathrm{ml}$ of acetic acid per liter) to make the solution distinctly acid to methyl red. Boil the solution (with precipitate) for about 1 minute and digest it on the steam bath for 30 minutes.

6. Filter on a Whatman no. 429 -cm paper and wash the precipitate five times with a solution containing $20 \mathrm{ml}$ of the ammonium acetateacetic acid solution in $100 \mathrm{ml}$ of water.

7. After the precipitate has drained, transfer it from the paper to a 100-ml beaker with a fine stream of distilled water, keeping the volume below $50 \mathrm{ml}$. Add $\mathrm{HCl}$ dropwise until the precipitate just dissolves, then $2 \mathrm{ml}$ of $\mathrm{HCl}$ in excess. Add three drops of 30 percent $\mathrm{H}_{2} \mathrm{O}_{2}$. Estimate the vanadium content from the color developed. If the solution contains (a) more than $3 \mathrm{mg}$ of vanadium, proceed with step 8; (b) if 1 to $3 \mathrm{mg}$ of vanadium, proceed with step 9; (c) less than $1 \mathrm{mg}$ of vanadium, proceed with step 10 of the procedure.

8. If more than $3 \mathrm{mg}$ of vanadium are present, transfer the solution to a $250-\mathrm{ml}$ beaker, dilute to about $150 \mathrm{ml}$, add $2 \mathrm{~g}$ of $\mathrm{NaCl}$, and proceed with the precipitation, digestion, filtration, washing, and solution of the phosphate as in steps 5,6 , and 7 above. Uranium is then determined by the procedure in step 10 below.

9 . If 1 to $3 \mathrm{mg}$ of vanadium is present, add 6 drops of 30 percent $\mathrm{H}_{2} \mathrm{O}_{2}$, make the solution just alkaline with 50 percent $\mathrm{NaOH}$ solution, then add $5 \mathrm{ml}$ in excess. Heat the solution to boiling; boil 1 or 2 minutes. Cool, adjust the volume to $50 \mathrm{ml}$, and proceed with the filtration and comparison as in step 10 below.

10. If less than $1 \mathrm{mg}$ of vanadium is present, add 6 drops of 30 percent $\mathrm{H}_{2} \mathrm{O}_{2}$, make the solution just alkaline with 50 percent $\mathrm{NaOH}$ solution and then add $5 \mathrm{ml}$ in excess. Adjust the volume to $50 \mathrm{ml}$ and filter through a paper previously treated with a sodium hydroxideperoxide solution of the same concentration as the sample solution. Compare the filtered solution visually in Nessler tubes with uranium standards containing the same amounts of $\mathrm{NaOH}$ and $\mathrm{H}_{2} \mathrm{O}_{2}$ in the same volume. The optical density of the solution may be measured with a spectrophotometer at $400 \mathrm{~m} \mu$ wavelength, and the amount of uranium determined by reference to a standard curve. 


\section{EXPERIMENTS}

\section{OCCLUSION OF URANIUM BY THE CARBONATE PRECIPITATE USING SYNTHETIC MIXTURES}

The procedure described above was tested by determining uranium in solutions of known uranium content. These solutions were prepared by adding different amounts of a standard uranium nitrate solution ( $1 \mathrm{ml}=0.5 \mathrm{mg} \mathrm{U}$ ) to $15 \mathrm{ml}$ or $35 \mathrm{ml}$ of a synthetic mixture. This was a solution containing 10 percent $\mathrm{HCl}$ and, per liter, $10 \mathrm{~g}$ $\mathrm{CaCl}_{2}, 20 \mathrm{~g} \mathrm{Na} \mathrm{PO}_{4} \cdot 12 \mathrm{H}_{2} \mathrm{O}, 30 \mathrm{~g} \mathrm{AlCl}_{3} \cdot 6 \mathrm{H}_{2} \mathrm{O}, 5 \mathrm{~g} \mathrm{MgCl}_{2} \cdot 6 \mathrm{H}_{2} \mathrm{O}, 1 \mathrm{~g}$ $\mathrm{MnCl}_{2} \cdot 4 \mathrm{H}_{2} \mathrm{O}$. The results obtained are given in table 1 .

TABLE 1.-Determination of uranium in synthetic mixtures of known uranium content

\begin{tabular}{|c|c|c|c|c|c|c|c|}
\hline \multirow[b]{2}{*}{ Sample no. } & \multirow[b]{2}{*}{$\begin{array}{l}\text { Amount } \\
\text { of } \\
\text { sample } \\
\text { (ml) }\end{array}$} & \multirow[b]{2}{*}{$\begin{array}{l}\text { Uranium } \\
\text { added } \\
\text { (mg) }\end{array}$} & \multicolumn{5}{|c|}{ Uranium recovery } \\
\hline & & & $\begin{array}{l}\text { From 1st } \\
\text { carbonate } \\
\text { precipita- } \\
\text { tion (mg) }\end{array}$ & Percent & $\begin{array}{l}\text { From 2d } \\
\text { carbonate } \\
\text { precipita- } \\
\text { tion (mg) }\end{array}$ & $\begin{array}{c}\text { Total } \\
\text { mg }\end{array}$ & $\begin{array}{c}\text { Total } \\
\text { percent }\end{array}$ \\
\hline 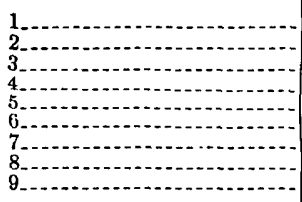 & $\begin{array}{l}35 \\
35 \\
35 \\
35 \\
35 \\
15 \\
15 \\
15 \\
15\end{array}$ & $\begin{array}{r}0.25 \\
.50 \\
1.00 \\
1.50 \\
2.00 \\
2.00 \\
5.00 \\
10.00 \\
20.00\end{array}$ & $\begin{array}{r}0.23 \\
.45 \\
.80 \\
1.15 \\
1.42 \\
2.01 \\
4.65 \\
8.30 \\
18.00\end{array}$ & $\begin{array}{c}92 \\
90 \\
80 \\
76.7 \\
71 \\
100.5 \\
93 \\
83 \\
90\end{array}$ & $\begin{array}{l}\text { (1) } \\
(1) \\
0.20 \\
.32 \\
.50 \\
(1) .34 \\
.34 \\
1.62 \\
1.76\end{array}$ & $\begin{array}{r}0.23 \\
.45 \\
1.00 \\
1.47 \\
1.92 \\
2.01 \\
4.99 \\
9.92 \\
19.76\end{array}$ & $\begin{array}{r}92 \\
90 \\
100 \\
98 \\
96 \\
100 \\
100 \\
99 \\
99\end{array}$ \\
\hline
\end{tabular}

1 Uranium not determined.

In these tests, the filtrates from the first and second carbonate precipitations were not combined as directed in the procedure, but were carried through independently to determine the degree of recovery of uranium after one and after two carbonate precipitations.

To simulate the amounts of accompanying constituents when $5 \mathrm{~g}$ of sample are taken for analysis, $35 \mathrm{ml}$ of the synthetic mixture were used for the tests with the smaller amounts of uranium (tests nos. 1-5). For those tests to which $2 \mathrm{mg}$ or more of uranium were added, $15 \mathrm{ml}$ of the synthetic mixture, representing the amount of accompanying constituents to be found in 2 to $2.5 \mathrm{~g}$ of sample, were used.

The results on the tests indicate that (1) as the amount of uranium present was increased, the percentage recovery after one carbonate precipitation decreased but that (2) after two carbonate precipitations, the recovery of uranium (on the amounts used in the tests) amounted to at least 96 percent. If the amount of uranium present is greater than $20 \mathrm{mg}$, the percentage of recovery may decrease, although this may be offset to some extent by the smaller sample taken for analysis and the consequent smaller bulk of carbonate precipitate obtained that results in less occlusion of uranium. If it is suspected, however, 
that a sample has a high uranium content, three or even four carbonate precipitations should be made, unless analysis of the filtrate from the second carbonate precipitation alone indicates that the separation of the uranium is nearly complete.

\section{COMPARISON OF RESULTS OBTAINED BY THIS AND OTHER METHODS}

Results for uranium obtained by the carbonate-phosphate-peroxide method are compared in table 2 with results obtained by the cupferron method (part 3) developed in the laboratory of the Geological Survey. The samples include a wide variety of rock types.

TABLE 2.-Comparison of results of uranium analyses by the carbonate-phosphateperoxide and the cupferron methods

\begin{tabular}{|c|c|c|c|c|c|}
\hline \multirow{2}{*}{ Sample no. } & \multicolumn{2}{|c|}{ Percent uranium } & \multirow{2}{*}{ Sample no. } & \multicolumn{2}{|c|}{ Percent uranium } \\
\hline & $\begin{array}{c}\text { Carbonate } \\
\text { method }\end{array}$ & $\begin{array}{c}\text { Cupferron } \\
\text { method }\end{array}$ & & $\begin{array}{l}\text { Carbonate } \\
\text { method }\end{array}$ & $\begin{array}{c}\text { Cupferron } \\
\text { method }\end{array}$ \\
\hline $\begin{array}{l}\text { MB } 6-79 \\
\text { 65-7 } \\
\text { MB } 6-86 \\
\text { BC } 59-4800 \\
\text { BC } 100-815 \\
\text { BC } 101-825 \\
\text { BC } 90-738\end{array}$ & $\begin{array}{l}0.002 \\
.003 \\
.003 \\
.005 \\
.006 \\
.006 \\
.006\end{array}$ & $\begin{array}{l}0.004 \\
.003 \\
.005 \\
.006 \\
.005 \\
.006 \\
.007\end{array}$ & $\begin{array}{l}\text { BC 67-542 } \\
\text { MGR 5-295. } \\
21-3 \text { - } \\
150-9-64 \\
\text { BCX }-22\end{array}$ & $\begin{array}{r}0.007 \\
.007 \\
.013 \\
.016 \\
.026 \\
.036\end{array}$ & $\begin{array}{r}0.007 \\
.009 \\
.012 \\
.014 \\
.028 \\
.038\end{array}$ \\
\hline
\end{tabular}

Table 3 shows the results of analysis for uranium obtained by the carbonate-phosphate-peroxide and cupferron methods in the Geological Survey laboratory as compared with results obtained on the same samples by other laboratories using different procedures. Although the carbonate-phosphate-peroxide procedure is designed particularly for the determination of very small amounts of uranium, the results obtained on samples 12 and 13 indicate that the method can also be used for the determination of larger amounts. Larger amounts are not determined colorimetrically, but volumetrically (on the filtrate from the phosphate precipitation) after reduction.

TABLE 3.-Comparison of results of uranium analyses by different methods in several laboratories

\begin{tabular}{|c|c|c|c|c|c|c|c|c|c|}
\hline \multirow{2}{*}{ Sample no. } & \multicolumn{4}{|c|}{ Percent $\mathrm{U}_{3} \mathrm{O}_{8}$} & \multirow{2}{*}{ Sample no. } & \multicolumn{4}{|c|}{ Percent $\mathrm{U}_{3} \mathrm{O}_{8}$} \\
\hline & A & B & $\mathrm{C}$ & $\mathrm{D}$ & & A & B & $\mathrm{C}$ & $\mathrm{D}$ \\
\hline $\begin{array}{l}1 \\
2 \\
3 \\
4 \\
5 \\
7\end{array}$ & $\begin{array}{l}0.035 \\
.07 \\
.09 \\
.15 \\
.19 \\
.19 \\
.20\end{array}$ & $\begin{array}{l}0.038 \\
.11 \\
.14 \\
.15 \\
.19 \\
.18\end{array}$ & $\begin{array}{l}0.034 \\
.07 \\
.11 \\
.10 \\
.16 \\
.23 \\
.17\end{array}$ & $\begin{array}{r}0.029 \\
.15 \\
.18\end{array}$ & $\begin{array}{l}8 \\
9 \\
10 \\
11 \\
12 \\
13\end{array}$ & $\begin{array}{r}0.26 \\
.35 \\
.38 \\
.56 \\
1.98 \\
23.62\end{array}$ & $\begin{array}{r}0.28 \\
.32 \\
.35 \\
.57 \\
2.15 \\
23.41\end{array}$ & $\begin{array}{r}0.33 \\
.36 \\
.41 \\
.57 \\
2.28 \\
23.35\end{array}$ & $\begin{array}{r}0.38 \\
.40 \\
.55 \\
2.07 \\
23.30\end{array}$ \\
\hline
\end{tabular}

\footnotetext{
A. Geological Survey, carbonate-phosphate-peroxide method. M. D. Foster, analyst.

B. Geological Survey, cupferron method. F. S. Grimaldi and W. G. Schlechht, analysts.

C. National Bureau of Standards,

D. Princeton University.
} 


\section{THE REMOVAL OF TITANIUM AND VANADIUM BY ONE CARBONATE PRECIPITATION}

To determine the effectiveness of the carbonate precipitation for the separation of titanium and vanadium from uranium, known amounts of these elements were added to $35 \mathrm{ml}$ of a synthetic mixture (p. 34), a carbonate precipitation was made as directed in the procedure, and the filtrate was tested for titanium and vanadium.

The results obtained, which are given in table 4, indicate that the removal of titanium by one carbonate precipitation is nearly complete. The amount retained in the filtrate is so small that it would cause no interference in the colorimetric determination of uranium with hydrogen peroxide in alkaline solution. As expected, little vanadium is removed from solution by the carbonate precipitation. Presumably the amount that was removed in this test was occluded by the carbonate precipitate and would be recovered on a second precipitation.

TABLE 4.-Amount of titanium and vanadium removed from solution by one carbonate precipitation

\begin{tabular}{r|r|r|r|r}
\hline \multicolumn{1}{c|}{ Sample no. } & $\begin{array}{r}\text { Ti added } \\
(\mathrm{mg})\end{array}$ & $\begin{array}{c}\text { Ti in fl- } \\
\text { trate } \\
(\mathrm{mg})\end{array}$ & $\begin{array}{c}\mathrm{V} \text { added } \\
(\mathrm{mg})\end{array}$ & $\begin{array}{c}\mathrm{V} \text { in fll- } \\
\text { trate } \\
(\mathrm{mg})\end{array}$ \\
\hline 1 & 10 & 0.2 & $\cdots$ & \\
\hline
\end{tabular}

\section{EFFECTIVENESS OF THE PHOSPHATE PRECIPITATION FOR THE SEPARATION OF VANADIUM AND URANIUM}

The principal purpose of the phosphate precipitation in this procedure is to separate vanadium from uranium. Tests indicate that the filtrate, from a phosphate precipitation on a sample containing $10 \mathrm{mg}$ of vanadium, contained $8.6 \mathrm{mg}$ of vanadium, but $1.4 \mathrm{mg}$ remained in the precipitate. However, this amount of vanadium, carried in the phosphate precipitate with uranium and subsequently into the sodium hydroxide-peroxide solution on which the colorimetric comparison is made, does not interfere seriously in the determination of uranium, as it causes a color equivalent to only about $0.1 \mathrm{mg}$ of uranium. 


\section{Part 5. ELIMINATION OF INTERFERENCE BY NICKEL IN THE DETERMINATION OF URANIUM BY MEANS OF ZINC AMALGAM REDUCTORS}

By F. S. Grimaldi

\section{CONTENTS}

Abstract._...

Introduction

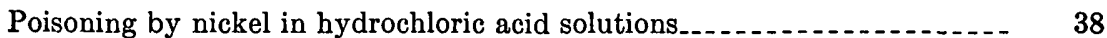

Nonpoisoning of the " 10 percent" Jones reductor in sulfuric acid solutions_ $\quad 39$

Nonpoisoning of the "10 percent" Jones reductor in hydrochloric acid solutions

Behavior of vanadium, titanium, and molybdenum on reduction in the "10 percent" Jones reductor. 40

Preparation of the "10 percent" Jones reductor...... 40

\section{TABLES}

TABLE 1. Poisoning of reductor by nickel in hydrochloric acid solutions.-

2. Elimination of nickel interference with the "10 percent" reductor

3. Test of the "10 percent" reductor with hydrochloric acid solutions

\section{ABSTRACT}

Previously reported observations that zinc amalgam reductors are poisoned by sulfuric acid solutions containing nickel are confirmed; experiments show that poisoning also occurs with nickel in hydrochloric acid solutions. The effect is caused by deposition of nickel on the amalgam surface that promotes the vigorous evolution of hydrogen. This interference is easily overcome by using a solid amalgam richer in mercury than usual; this lowers the activity of the zinc enough to prevent deposition of nickel.

A Jones reductor containing a zinc amalgam consisting of 10 percent mercury by weight does not become poisoned by passage of nickel-bearing solutions through the reductor. Either hydrochloric acid or sulfuric acid solutions may be used. The valence changes during reduction of the elements commonly determined by means of the Jones reductor are the same for the " 10 percent" reductor as with the standard reductor.

\section{INTRODUCTION}

One of the most useful tools for the chemical determination of uranium has been the Jones reductor. Its performance has been the

Note.-This report was issued as Trace Elements Inv. Rept. 23 and AECD 1815, 1946. 
subject of many studies. Recent work by J. B. Heberling ${ }^{1}$ has shown that the Jones reductor quickly becomes poisoned by passage of solutions containing nickel through the reductor. He used a zinc reductor amalgamated with about 2 percent by weight of mercury. Working with sulfuric acid solutions containing about $0.2 \mathrm{~g}$ of uranium and $0.04 \mathrm{~g}$ of nickel, Heberling concluded that only 6 to 10 samples of comparable nickel content could undergo 100 percent reduction in a standard reductor. Because of this interference, it has been necessary to remove nickel by electrolysis with a mercury cathode or to reduce the uranium by shaking with a liquid zinc amalgam.

This work was undertaken to overcome the poisoning difficulties, so that the convenient standard procedure using the Jones Reductor could be retained.

\section{POISONING BY NICKEL IN HYDROCHLORIC ACID SOLUTIONS}

The first experiments show that poisoning by nickel also occurs from hydrochloric acid solutions. Seven solutions were made, each solution had a volume of $45 \mathrm{ml}$. Six solutions contained $0.15 \mathrm{~g}$ of nickel, $0.1117 \mathrm{~g}$ of iron, and $4.5 \mathrm{ml}$ of hydrochloric acid as the only acid. One solution contained $0.0279 \mathrm{~g}$ of iron. These were passed consecutively through the Jones reductor filled with a zinc amalgam containing 3 percent by weight of mercury. The solutions were titrated with $0.1 \mathrm{~N}$ potassium dichromate using diphenylamine as internal indicator after the addition of phosphoric acid. Iron instead of uranium was chosen as the element to be reduced because of the certainty of valence change after reduction. Table 1 shows the results obtained.

TABLE 1.-Poisoning of reductor by nickel in hydrochloric acid solutions

\begin{tabular}{|c|c|c|c|c|c|c|c|}
\hline \multirow{2}{*}{ Solution no. } & \multicolumn{2}{|c|}{ Amounts taken (g) } & \multirow{2}{*}{$\begin{array}{l}\text { Fe found } \\
\text { after reduc- } \\
\text { tion }(\mathrm{g})\end{array}$} & \multirow{2}{*}{ Solution no. } & \multicolumn{2}{|c|}{ Amounts taken (g) } & \multirow{2}{*}{$\begin{array}{l}\text { Fe found } \\
\text { after reduc- } \\
\text { tion }(\mathrm{g})\end{array}$} \\
\hline & $\mathrm{Fe}$ & $\mathrm{Ni}$ & & & $\mathrm{Fe}$ & $\mathrm{Ni}$ & \\
\hline 1... & $\begin{array}{r}0.1117 \\
.1117 \\
.1117 \\
.1117\end{array}$ & $\begin{array}{r}0.15 \\
.15 \\
.15 \\
.15\end{array}$ & $\begin{array}{r}0.1115 \\
.1112 \\
.1079 \\
.1072\end{array}$ & $\begin{array}{l}5 \\
6 \\
7\end{array}$ & $\begin{array}{r}0.1117 \\
.1117 \\
.0279\end{array}$ & $\begin{array}{r}0.15 \\
.15 \\
.15\end{array}$ & $\begin{array}{r}0.1055 \\
.1047 \\
.0275\end{array}$ \\
\hline
\end{tabular}

The results show that the reductor became poisoned after about $0.3 \mathrm{~g}$ of nickel passed through, and that this poisoning occurred in hydrochloric acid solutions, as well as in the sulfuric acid solutions studied by Heberling. Solution 7 indicated that more nearly 100 percent reduction is obtained for smaller quantities of iron. This is to be expected because there is a larger area of zinc per weight of iron. As

1 Heberling, J. B., 1944, Rept. 1040, Sec. 2F. 
observed by Heberling in using sulfuric acid solutions, metallic nickel was deposited, darkened the reductor, and promoted the evolution of hydrogen. The evolution of hydrogen was so vigorous that after solution 7 had been passed through the reductor, it was almost impossible to get another sample through the reductor. This vigorous evolution of hydrogen probably interferes with the proper contact of the solution with the zinc amalgam.

\section{NONPOISONING OF THE “10 PERCENT' JONES REDUCTOR IN SULFURIC ACID SOLUTIONS}

Amalgamating the zinc so that the mercury content was 10 percent by weight reduced its activity sufficiently so that no nickel plated out in the reductor and the poisoning difficulties were eliminated.

Solutions were prepared to have a total volume of $45 \mathrm{ml}$; they contained $0.15 \mathrm{~g}$ nickel and $0.1561 \mathrm{~g}$ uranium (average of three standardizations) and 10 percent by volume of sulfuric acid. The solutions were passed through the " 10 percent" reductor, the preparation of which is described in a later section, at the rate of about 40 $\mathrm{ml}$ per minute and were washed with 3 percent sulfuric acid and enough water so that the final sulfuric acid concentration after reduction was about 4 percent by volume. The solutions were aerated for 5 minutes, because the color of the solution indicated the presence of trivalent uranium. They were then titrated with standard potassium permanganate solution $(0.02980 \mathrm{~N})$. The results are given in table 2.

$\mathrm{T}_{\mathrm{ABLE}}$ 2.-Elimination of nickel interference with the "10 percent" reductor

\begin{tabular}{|c|c|c|c|c|c|c|c|}
\hline \multirow{2}{*}{ Solution no. } & \multicolumn{2}{|c|}{ Amount taken (g) } & \multirow{2}{*}{$\mathrm{U}$ found $(\mathrm{g})$} & \multirow{2}{*}{ Solution no. } & \multicolumn{2}{|c|}{ Amount taken $(\mathrm{g})$} & \multirow{2}{*}{ U found (g) } \\
\hline & $\mathrm{U}$ & $\mathrm{Ni}$ & & & U & $\mathrm{Ni}$ & \\
\hline $\begin{array}{l}1 \\
0 \\
3 \\
5 \\
6 \\
7 \\
8 \\
0\end{array}$ & $\begin{array}{l}0.1561 \\
.1561 \\
.1561 \\
.1561 \\
.1561 \\
.1561 \\
.1561 \\
.1561 \\
.1561 \\
.1561 \\
.1561 \\
.1561 \\
.1561 \\
.1561 \\
.1561 \\
.1561 \\
.1561\end{array}$ & $\begin{array}{l}0.15 \\
.15 \\
.15 \\
.15 \\
.15 \\
.15 \\
.15 \\
.15 \\
.15 \\
.15 \\
.15 \\
.15 \\
.15 \\
.15 \\
.15 \\
.15 \\
.15\end{array}$ & 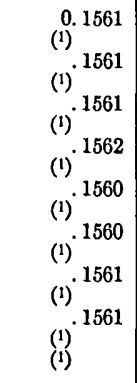 & $\begin{array}{l}18 \\
19 \\
20 \\
21 \\
22 \\
23 \\
24 \\
25 \\
26 \\
27 \\
28 \\
30 \\
31 \\
32 \\
33 \\
34\end{array}$ & $\begin{array}{l}0.1561 \\
.1561 \\
.1561 \\
.1561 \\
.1561 \\
.1561 \\
.1561 \\
.1561 \\
.1561 \\
.1561 \\
.1561 \\
.1561 \\
.1561 \\
.1561 \\
.1561 \\
.1561 \\
.1561\end{array}$ & $\begin{array}{l}0.15 \\
.15 \\
.15 \\
.15 \\
.15 \\
.15 \\
.15 \\
.15 \\
.15 \\
.15 \\
.15 \\
.15 \\
.15 \\
.15 \\
.15 \\
.15 \\
.15\end{array}$ & 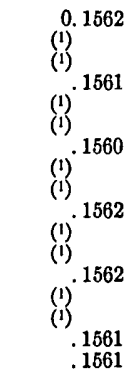 \\
\hline
\end{tabular}

1 Not titrated.

The results show that the reductor was not poisoned even after more than $5 \mathrm{~g}$ of nickel had passed through, it. This corresponds to the reduction of more than 100 samples of the kind of uranium ore 
normally analyzed. It must be noted also that the amount of nickel used in each experiment was at least three times the amount usually found and that with these amounts no poisoning of the reductor ensued. No gas evolved even with sample 34. After the experiments the reductor looked like new.

To determine if any nickel had actually plated out on the reductor, the top inch of amalgam was removed and dissolved in aqua regia. A qualitative test with dimethylglyoxime showed no nickel.

\section{NONPOISONING OF THE "10 PERCENT'” JONES REDUCTOR IN HYDROCHLORIC ACID SOLUTIONS}

The 10 percent Jones reductor was further tested on solutions containing hydrochloric acid as the only acid. Eleven test samples were made up; each contained exactly $0.1117 \mathrm{~g}$ iron, $0.15 \mathrm{~g}$ nickel, and $4.5 \mathrm{ml}$ hydrochloric acid in a total volume of $45 \mathrm{ml}$. These solutions were reduced with the "10 percent" reductor and titrated as before. Again no poisoning resulted as shown in table 3.

TABLE 3.-Test of the "10 percent" reductor with hydrochloric acid solutions

\begin{tabular}{|c|c|c|c|c|c|c|c|}
\hline \multirow{2}{*}{ Solution no. } & \multicolumn{2}{|c|}{ Amounts taken (g) } & \multirow{2}{*}{$\mathrm{U}$ found $(\mathrm{g})$} & \multirow{2}{*}{ Solution no. } & \multicolumn{2}{|c|}{ Amounts taken (g) } & \multirow{2}{*}{$\mathrm{U}$ found $(\mathrm{g})$} \\
\hline & U & $\mathrm{Ni}$ & & & $\mathbf{U}$ & $\mathrm{Ni}$ & \\
\hline $\begin{array}{l}1 \\
2 \\
3 \\
4 \\
5\end{array}$ & $\begin{array}{l}0.1117 \\
.1117 \\
.1117 \\
.1117 \\
.1117 \\
.1117\end{array}$ & $\begin{array}{l}0.15 \\
.15 \\
.15 \\
.15 \\
.15 \\
.15\end{array}$ & $\begin{array}{l}(1) \\
(1) \\
(1) \\
(1) \\
(1) \\
(1)\end{array}$ & $\begin{array}{l}7 \\
8 \\
9 \\
10 \\
11\end{array}$ & $\begin{array}{r}0.1117 \\
.1117 \\
.1117 \\
.1117 \\
.1117\end{array}$ & $\begin{array}{l}0.15 \\
.15 \\
.15 \\
.15 \\
.15\end{array}$ & $\begin{array}{r}\text { (1) } \\
0.1117 \\
.1118 \\
.1117 \\
.1117\end{array}$ \\
\hline
\end{tabular}

1 Not titrated.

BEHAVIOR OF VANADIUM, TITANIUM, AND MOLYBDENUM ON REDUCTION IN THE "10 PERCENT'” JONES REDUCTOR

Tests made on sulfuric acid solutions showed that the 10 percent Jones reductor reduces vanadium to the bivalent state, titanium and molybdenum to the trivalent state. These valenco changos are identical with those obtained by use of a standard Jones reductor; thus elements may be determined by the usual procedures after roduction with a 10 percent Jones reductor.

\section{PREPARATION OF THE "10 PERCENT" JONES REDUCTOR}

Preparation of the "10 percent" amalgam.-Dissolve $23.6 \mathrm{~g}$ mercuric chloride in $400 \mathrm{ml}$ of water containing about $10 \mathrm{ml}$ of nitric acid. Transfer the solution to a $500-\mathrm{ml}$ separatory funnel. Add $180 \mathrm{~g}$ of 20-mesh zinc and immediately shake. Shake for about 2 minutes; 
release any gas pressure from time to time. Wash the amalgam with dilute sulfuric acid, and then wash thoroughly with water.

Preparation of the reductor column.-The reductor used for all tests described had an inside diameter of $11 \mathrm{~mm}$ and was filled with $12 \frac{1 / 2}{2}$ inches of zinc amalgam. To prepare, first add a little water to the tube and introduce about an inch of the amalgam at a time, gently tamping it in place with a glass rod. 



\title{
Part 6. THE VISUAL FLUORIMETRIC DETERMINATION OF URANIUM IN LOW-GRADE ORES
}

\author{
By F. S. Grimaldi and Harry Levine
}

\section{CONTENTS}

$\begin{array}{ll}\text { Abstract } & 43 \\ \text { Introduction } & \\ \text { Discussion and procedure } & \end{array}$

TABLES

TABLE 1. Comparison of results of uranium determinations by three

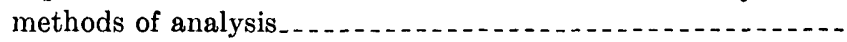

2. Comparison of results of uranium determinations obtained by fluorimetric and colorimetric procedures.............. 48

3. Extraction of some other elements with ethyl acetate....... 48

\section{ABSTRACT}

A simple visual fluorimetric procedure is described for the determination of 0.001 to about 0.04 percent uranium in low-grade shale and phosphate ores. Using aluminum nitrate as the salting agent, the procedure employs batch extraction of uranyl nitrate by ethyl acetate. The uranium is fused with a fluoridecarbonate flux and the fluorescence intensity of the cooled melt is compared visually with standards. The initial decomposition of the sample by fusion with a sodium hydroxide-sodium nitrate flux is rapid, and the extraction is made from acid solution without removing silica and other hydrolytic precipitates. Aluminum nitrate effectively complexes fluoride, sulfate, and phosphate ions and thus eliminates the need for their removal.

\section{INTRODUCTION}

The exceedingly sensitive fluorescence of uranium fluoride phosphors under ultraviolet light has been used extensively for the quantitative estimation of uranium in a variety of materials. It is desirable to isolate the uranium first because many elements interfere seriously by quenching the fluorescence. For example, less than 10 micro- 
grams of chromium reduces the fluorescence of uranium. The critical factor in the quenching phenomenon was found by Price ${ }^{1}$ to be the concentration of the quenching element in the flux, not the ratio of the concentrations of quencher to uranium in the sample.

Two types of procedures have appeared in the project literature to circumvent quenching interferences. One developed by Price and coworkers employs a dilution technique that depends on reducing the quenching to a negligible factor by using a sufficiently small sample for the analysis. As the intensity of fluorescence measured in the procedure usually is weak, a sensitive fluorimeter is necessary. Also with such low levels of fluorescence contamination by airborne dust may be significant; rigid controls designed to minimize contamination are therefore desirable.

The second procedure involves the separation of uranium from interfering elements before estimation by the fluorescence method. This separation generally involves the extraction of uranyl nitrate with organic solvents after the addition of a salting agent. The distribution of uranyl nitrate depends both on the solvent employed and on the salting agent selected, and a particular procedure may lend itself to either batch or continuous extraction.

A batch extraction is employed using aluminum nitrate as the salting agent and ethyl acetate as the solvent. Aluminum nitrate was selected because moderate amounts of aluminum (about $50 \mathrm{mg}$ ) have shown no quenching action on the uranium-fluoride phosphors. Also aluminum effectively complexes phosphate, sulfate, and fluoride ions that normally interfere with the quantitative extraction of uranium. Ethyl acetate was chosen as the solvent because it is easily obtainable and presents relatively little fire hazard. At first it was thought that the ethyl acetate might hydrolyze to some extent and that the acetate ions formed could conceivably complex the uranium and prevent its complete extraction. In practice, however, little if any ethyl acetate hydrolyzes and no interference of this kind results, but it is doubtful whether ethyl acetate can be used for continuous extractions.

\section{DISCUSSION AND PROCEDURE}

The sample $(0.15 \mathrm{~g})$ is completely decomposed by fusion with a sodium hydroxide-sodium nitrate mixture. This flux will decompose shales and phosphate rocks. After fusion the melt is leached with water, acidified with nitric acid, and $7.5 \mathrm{ml}$ of nitric acid ${ }^{2}$ are added in excess. Silica does not separate out if the acid is added to

1 Price, G. R., Ferretti, R. J., and Schwartz, S., 1945. The microfluorometric determination of uranium: AECD 2282.

2 Present practice is to employ $3.5 \mathrm{ml}$ excess $\mathrm{HNO}_{8}$ (part 1, extraction method). 
the cool solution. Any hydrolytic precipitate that may form is not filtered off. The solution is then made up to $50 \mathrm{ml}$ and a $5-\mathrm{ml}$ aliquot is transferred to a test tube. To this are added $9.5 \mathrm{~g}$ of aluminum nitrate (enough to saturate $5 \mathrm{ml}$ of solution) and $10 \mathrm{ml}$ of ethyl acetate, and the mixture shaken for 30 seconds. After the layers have separated, about $8 \mathrm{ml}$ of the ethyl acetate layer is drawn off and filtered through a dry filter paper. Five milliliters of the filtered ethyl acetate are removed by pipette, transferred to a clean platinum crucible, and evaporated off. The fluoride flux is then added to the crucible and the flux is melted for about 2 minutes. After cooling, the fluorescence is compared with a series of standards also contained in platinum crucibles. The standards are prepared from known amounts of a uranium solution transferred to platinum crucibles and finally heated with the fluoride flux in the same manner and for the same length of time as for the samples. To bring the flux in contact with any of the sample that may have crept up during the evaporation, it is necessary to play the melt around the sides of the crucible. It is preferable to prepare the standards in the same manner. Proper heating is an important factor in the results obtained. Too much heating, especially at an elevated temperature, will dissolve some platinum, which causes quenching; too little heating may also give low results because insufficient time has been allowed to incorporate the sample into the flux. With a little experience, the proper method of heating is easily determined. Each operator should make his own set of standards.

The fluoride flux used in the procedure consists of 9 parts by weight of sodium fluoride, 45.5 parts by weight of sodium carbonate, and 45.5 parts by weight of potassium carbonate, intimately ground and mixed. Standards made with this flux are kept in a desiccator and should be prepared daily.

The extraction of uranium nitrate by $10 \mathrm{ml}$ of ethyl acetate according to the above procedure has given good quantitative recoveries of $0.15,0.3,0.45,0.60,0.75,300$, and 5,000 micrograms of uranium. The extraction data on a few other elements are described on pages 47 and 48 . For the concentration of thorium tested about 60 percent of the thorium is extracted.

The results of the analyses of a placer sample and a shale (table 1) using ethyl acetate extraction and colorimetric instead of fluorimetric estimation show the feasibility of batch extraction for colorimetric amounts.

A blank should be run on each bottle of aluminum nitrate to be used in the analysis. If the nitrate contains uranium, it may be purified by batch extraction with ether using the proportions $9.5 \mathrm{~g}$ 
of aluminum nitrate, $5 \mathrm{ml}$ of 15 percent nitric acid and $10 \mathrm{ml}$ of ether. It is then crystallized at room temperature after some of the water has evaporated.

\section{PROCEDURE}

The final fluorimetric estimation is made in the range 0.075 to 0.75 microgram of uranium. For ores containing 0.001 to 0.01 percent uranium, the uranium from a $7.5-\mathrm{mg}$ sample is fused in the fluoride flux; for higher percentages of uranium a proportionately smaller sample is fused.

1. Grind about $2 \mathrm{~g}$ of $40-80$ mesh sample in an agate mortar to a fine powder to insure that a representative sample will be taken for analyris.

2. Weigh $0.15 \mathrm{~g}$ of the sample and transfer it to a clean $25-\mathrm{ml}$ iron crucible. Roast if organic matter is present.

3. Add $1.5 \mathrm{~g}$ of $\mathrm{NaOH}$ (15 pellets) and about $0.1 \mathrm{~g} \mathrm{NaNO}_{3}$ and fuse at the lowest possible temperature. The fusion should be as brief as possible to minimize the introduction of iron into the sample.

4. Allow the melt to cool. Add $15 \mathrm{ml}$ of water and heat on the steam bath to disintegrate the melt.

5. Transfer the solution to a $100-\mathrm{ml}$ beaker, scrubbing the crucible thoroughly.

6. Allow the solution to cool to about $30 \mathrm{C}$. Add $\mathrm{HNO}_{3}$ dropwise to neutrality and then $7.5 \mathrm{ml}$ in excess. ${ }^{2}$ Any hydrolytic precipitate that forms is not filtered off.

7. Heat the solution just to boiling. Cool.

8. Transfer the solution to a $50-\mathrm{ml}$ volumetric flask. Add water to make $50 \mathrm{ml}$ and pipette a $5-\mathrm{ml}$ aliquot into a $30-\mathrm{ml}$ glass-stoppered test tube.

9. Add $9.5 \mathrm{~g}$ of $\mathrm{Al}\left(\mathrm{NO}_{3}\right)_{3} \cdot 9 \mathrm{H}_{2} \mathrm{O}$ and dissolve the salt by heating over a flame. Mix the solution and cool under the tap. When a large number of samples are run at one time, it is more convenient to place the test tubes in a beaker of boiling water to effect the solution of aluminum nitrate and in a beaker of cold water to cool the solutions.

10. Add $10 \mathrm{ml}$ of ethyl acetate from a pipette, stopper the tube, and shake for at least 60 seconds. Release the pressure and allow the layers to separate for about 5 minutes.

11. Pour off about $8 \mathrm{ml}$ of the ethyl acetate layer through a dry 5.5-cm Whatman No.42 filter paper fitted into a dry test tube.

12. By means of a clean dry pipette transfer $5 \mathrm{ml}$ of the filtered ethyl acetate to a clean $25-\mathrm{ml}$. platinum crucible. Both the filtration and aliquoting may be made with the volumetric filtering pipette (part 7).

2 Present practice is to on ploy $3.5 \mathrm{ml}$ excess $\mathrm{HNO}_{3}$ (part 1, extraction method). 
13. Place the crucible on 4 layers of water-soaked absorbent paper and set fire to the ethyl acetate with a lighted splinter held just above. the solution.

14. Dry the residue on a steam bath. Add $3 \mathrm{~g}$ of the fluoride flux and heat over a low burner. After the flux melts, heat for 2 minutes playing the melt around the sides of the crucible to dissolve any sample that creptup during the evaporation. The temperature should be kept below $700 \mathrm{C}$. Allow the melt to cool and solidify.

15. View under ultraviolet light and match the fluorescence against a series of standards made to correspond to the following percentages of uranium based on a $7.5-\mathrm{mg}$ sample: $0.000,0.002,0.004,0.006$, 0.008 , and 0.010 . These contain, respectively, 0.00, 0.15, 0.30, 0.45, 0.60 , and 0.75 micrograms of uranium in $3 \mathrm{~g}$ of flux. For this work the source of ultraviolet light was the 110-volt, 60-cycle, Mineralight lamp. However, a long wavelength ultraviolet light (3650A) is preferable. Ultraviolet radiation may be dangerous to the eyes. Goggles transmitting 5200 to $6400 \mathrm{~A}$ radiation should be worn when visual comparison is made.

The short wavelength lamp is a cold quartz mercury lamp, 90 percent of its radiation is in the $2537 \mathrm{~A}$ mercury line. The Corning red-purple Corex filter no. 9863 transmits the ultraviolet light and absorbs visible light.

\section{ANALYTICAL RESULTS AND EXTRACTION BEHAVIOR OF OTHER ELEMENTS}

Several representative samples were analyzed by the Geological Survey cupferron-colorimetric procedure and by the fluorescence procedure described in this paper. Two samples were also analyzed colorimetrically using the batch extraction of uranium with aluminum nitrate as the salting agent and ethyl acetate as the solvent. The results are shown in table 1.

Table 2 gives the results of fluorimetric analyses of a series of samples of shales and phosphates whose uranium content was not known to the two analysts. These results compare favorably with the results obtained by using the Geological Survey cupferron-colorimetric method.

To $5 \mathrm{ml}$ of a 15 percent nitric acid solution containing the nitrate of the element under test, $9.5 \mathrm{~g}$ of aluminum nitrate were added and shaken 30 seconds with $10 \mathrm{ml}$ of ethyl acetate. The ethyl acetate layer was drawn off and filtered and then tested quantitatively for the particular element. The results are given in table 3. 
TABLE 1.-Comparison of results of uranium determinations by three methods of analysis

\begin{tabular}{|c|c|c|c|c|c|c|c|}
\hline \multirow[b]{2}{*}{ Sample } & \multicolumn{3}{|c|}{$\begin{array}{l}\text { Percentage uranium deter- } \\
\text { mined by- }\end{array}$} & \multirow[b]{2}{*}{ Sample } & \multicolumn{3}{|c|}{$\begin{array}{l}\text { Percentage uranium deter- } \\
\text { mined by- }\end{array}$} \\
\hline & $\begin{array}{c}\text { Cupfer- } \\
\text { ron-col- } \\
\text { orimetric } \\
\text { method }\end{array}$ & $\begin{array}{l}\text { Extrac- } \\
\text { tion-col- } \\
\text { orimetric } \\
\text { method }\end{array}$ & $\begin{array}{l}\text { Fluori- } \\
\text { metric } \\
\text { method }\end{array}$ & & $\begin{array}{l}\text { Cupier- } \\
\text { ron-col- } \\
\text { orimetric } \\
\text { method }\end{array}$ & $\begin{array}{l}\text { Extrac- } \\
\text { tion-col- } \\
\text { orimetric } \\
\text { method }\end{array}$ & $\begin{array}{l}\text { Fluori- } \\
\text { metric } \\
\text { method }\end{array}$ \\
\hline $\begin{array}{l}\text { Phosphate rock... } \\
\text { Do } \\
\text { Do } \\
\text { Do } \\
\text { Do } \\
\text { Silicate containing } \\
\text { fluorite. } \\
\text { Shale } \\
\text { Do } \\
\text { Do }\end{array}$ & $\begin{array}{l}0.012 \\
.023 \\
.022 \\
.011 \\
.017 \\
\\
.032 \\
.0075 \\
.0055 \\
.002\end{array}$ & 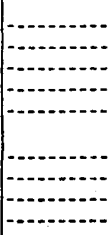 & $\begin{array}{l}0.012 \\
.022 \\
.023 \\
.011 \\
.016 \\
\\
.032 \\
.007 \\
.005 \\
.002\end{array}$ & $\begin{array}{l}\text { Shale } \\
\text { Do } \\
\text { Do } \\
\text { Do } \\
\text { Do } \\
\text { Placer } \\
\text { Zircon concentrate } \\
\text { Do } \\
\text { Monazite......... }\end{array}$ & $\begin{array}{l}0.007 \\
.007 \\
.0025 \\
.008 \\
.009 \\
.12 \\
.019 \\
.09 \\
.19\end{array}$ & \begin{tabular}{c}
0.009 \\
012 \\
\hdashline \\
\hdashline
\end{tabular} & $\begin{array}{l}0.007 \\
.007 \\
.002 \\
.008 \\
.009 \\
.1 \\
.02 \\
.09 \\
.2\end{array}$ \\
\hline
\end{tabular}

TABLE 2.-Comparison of results of uranium determinations obtained by fluorimetric and colorimetric procedures

\begin{tabular}{|c|c|c|c|c|c|c|c|}
\hline \multirow{3}{*}{ Sample no. } & \multicolumn{3}{|c|}{ Percentage uranium determined by- } & \multirow{3}{*}{ Sample no. } & \multicolumn{3}{|c|}{ Percentage uranium determined by- } \\
\hline & \multicolumn{2}{|c|}{ Fluorimetric method } & \multirow{2}{*}{$\begin{array}{l}\text { Cupferron- } \\
\text { colorimetric } \\
\text { method }\end{array}$} & & \multicolumn{2}{|c|}{ Fluorimetric method } & \multirow{2}{*}{$\begin{array}{l}\text { Cupferron- } \\
\text { colorimetric } \\
\text { method }\end{array}$} \\
\hline & (Analyst $A$ ) & (Analyst $B$ ) & & & (Analyst $A$ ) & (Analyst $B$ ) & \\
\hline $\begin{array}{l}1 \\
2 \\
3 \\
4\end{array}$ & $\begin{array}{r}0.015 \\
.017 \\
.022 \\
.003\end{array}$ & $\begin{array}{r}0.015 \\
.015 \\
.020 \\
.003\end{array}$ & $\begin{array}{r}0.012 \\
.014 \\
.020 \\
.003\end{array}$ & $\begin{array}{l}5 \ldots \\
6-\ldots \\
7-\ldots\end{array}$ & $\begin{array}{l}0.002 \\
.0085 \\
.020\end{array}$ & $\begin{array}{r}0.002 \\
.008 \\
0 .\end{array}$ & $\begin{array}{l}0.002 \\
.008 \\
.022\end{array}$ \\
\hline
\end{tabular}

TABLE 3.-Extraction of some other elements with ethyl acetate

\begin{tabular}{|c|c|c|c|c|c|}
\hline Compound taken & $\underset{(\mathrm{g})}{\operatorname{Amount}}$ & $\begin{array}{l}\text { Amount ex- } \\
\text { tracted with } \\
10 \text { ml ethyl } \\
\text { acetate }(\mathrm{g})\end{array}$ & Compound taken & $\underset{(\mathrm{g})}{\operatorname{Amount}}$ & $\begin{array}{l}\text { Amount ex- } \\
\text { tracted with } \\
10 \text { ml ethyl } \\
\text { acetate (g) }\end{array}$ \\
\hline $\begin{array}{l}\mathrm{ThO}_{2} \ldots \ldots \ldots \\
\mathrm{ZrO}_{2} \ldots \ldots \ldots \\
\mathrm{V}_{2} \mathrm{O}_{3} \ldots \ldots \ldots\end{array}$ & $\begin{array}{l}0.0025 \\
.0025 \\
.025\end{array}$ & $\begin{aligned} & 0.0015 \\
& (1) \\
2 & <.00001\end{aligned}$ & $\begin{array}{l}\mathrm{Fe}_{2} \mathrm{O}_{3} \\
\mathrm{Al}\left(\mathrm{NO}_{3}\right)_{2} \cdot 9 \mathrm{H}_{2} \mathrm{O}\end{array}$ & $\begin{array}{l}0.2 \\
9.5\end{array}$ & $\begin{array}{l}0.00005 \\
8.00004\end{array}$ \\
\hline
\end{tabular}

1 Ethyl acetate layer was tested with phosphoric acid. No precipitate for zirconium phosphate formed after 2 days.

Recent experiments indicate that vanadium is partially extracted when larger volumes of ethyl acetate

are used. 


\title{
Part 7. A VOLUMETRIG FILTERING PIPETTE
}

\author{
By F. S. Grimaldi
}

During chemical analysis it is often necessary to filter a solution and later to take a measured aliquot of the filtrate for analysis. The volumetric filtering pipette (fig. 1) was designed to provide a tool whereby the filtration and aliquoting may be made in one step. It was designed specifically for use in the extraction procedure for the determination of uranium (part 6).

The volumetric filtering pipette consists of two parts:

1. The male part (fig. $2 A$ ) made of a standard taperedglass joint (the one shown is standard taper $7 / 25$ ) is fused to a glass tube (fig. $2 B$ ) calibrated to deliver a prescribed amount of solution. This constitutes the pipette proper.

2. The female part (fig. $2 C$ ), or cap, also made of a standard tapered-glass joint, fits snugly over the male joint. This filtering cap contains the filtering medium, such as absorbent cotton. The tip of the pipette proper is covered by the cotton plug in the cap as illustrated in figure 2 .

A cotton plug or other suitable filtering medium is inserted in the cap, which is attached to the pipette proper, so that the tip is embedded in the cotton plug. The filtering pipette is inserted into the solution, and the solution is withdrawn by gentle suction at the mouth of the pipette. The solution is thus filtered and any desired amount may be delivered after removal of the cap.

This pipette has been used successfully to filter both gelatinous and crystalline precipitates. 
This simple apparatus, although designed primarily for laboratory procedure, should be useful also for a variety of chemical tests for use in the field. For such purposes, it could serve as either a filter or a pipette, or both. The constituent parts are easily obtainable, inexpensive, and should add little weight to portable field kits.
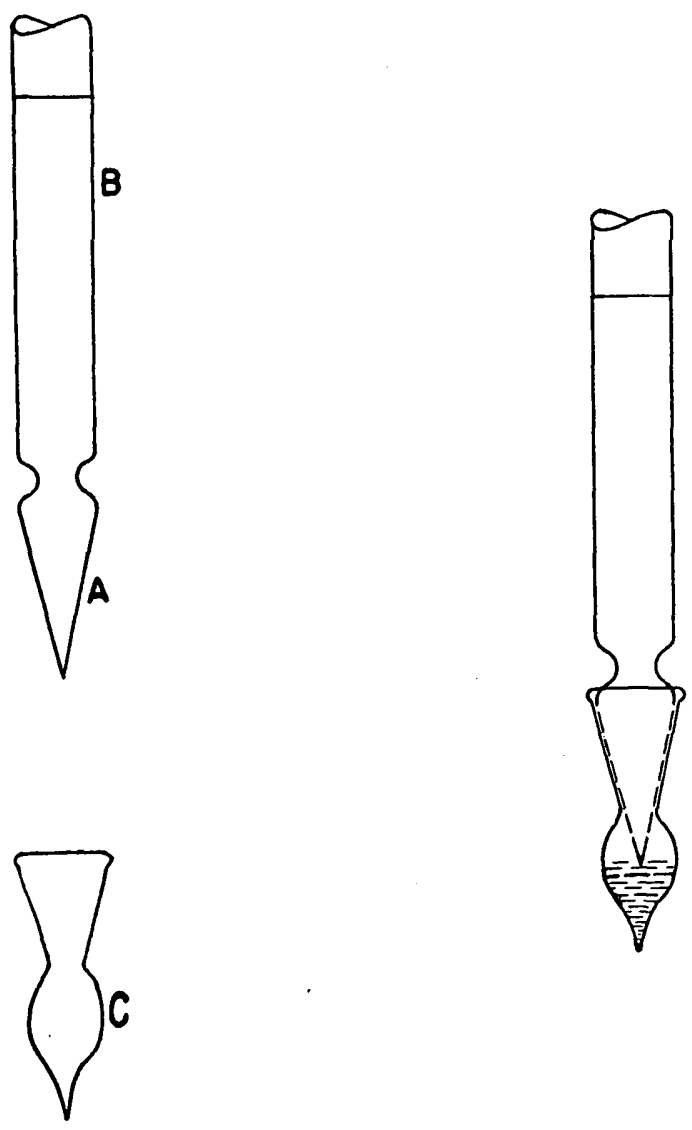

FIGURE 1.-Volumetric filtering pipette. Figure 2--Details of volumetric filtering pipette. 


\title{
Part 8. A STUDY OF GRITICAL FACTORS IN THE "DIRECT" FLUORIMETRIC DETERMINATION OF URANIUM
}

\author{
By Mary H. Fletcher
}

\section{CONTENTS}

Abstract.

Introduction ............. 52

Experimental data and discussion

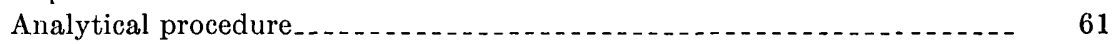

New data on time-temperature study

\section{ILLUSTRATIONS}

Plate 1. Assembly of Model II transmission fluorimeter......... 62

2. Model II transmission fluorimeter

Frgure 3. Effect of fusion conditions on fluorescence of blank samples_.. $\quad 57$

4. Effect of fusion conditions on fluorescence of standard samples. $\quad 57$

5. Effect of fusion conditions on sensitivity

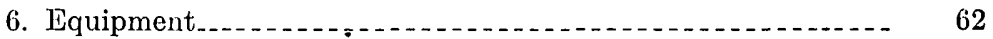

7. Effect of fusion conditions on fluorescence of standard samples

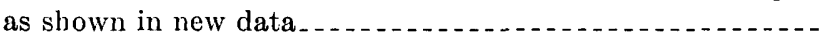

\section{TABLES}

TABLE 1. Attack on platinum lid by flux as a function of fusion temperature.

2. Time-temperature study for blanks._._. 56

3. Time-temperature study for standard samples...

4. Effect of fusion conditions on sensitivity ......... 56

5. Reproducibility of fluorescence of blanks heated in a small

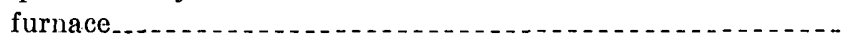

6. Reproducibility of fluorescence of blanks heated in a large

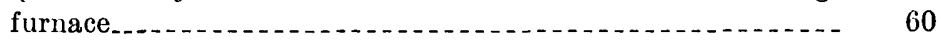

7. Inadequacy of fusion mixture prepared by ball-milling . . . 61

8. Replicate analyses of standard shale sample GST-1_...... 62

9. Replicate analyses of standard shale sample GST-2 _....... 65

10. Comparison of results obtained by different methods of analysis

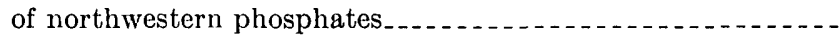

1.1. Determination of uranium by the "direct" method using

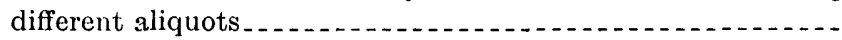

12. Time-temperature study of standard samples containing 0.005

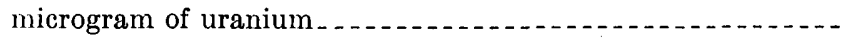

13. Comparison of fluorescence readings for melts fused at $800 \mathrm{C}$ in different platinumware 
ABSTRACT

A study was made of some of the important factors in the "direct" fluorimetric determination of uranium in the range 0.0005 to 0.08 microgram, and a modified procedure based on these results is given. Detailed time-temperature studies showed that the sensitivity of the fluorescent method decreased rapidly when the fusion temperature was greater than $650 \mathrm{C}$, and that at temperatures above $650 \mathrm{C}$ the sensitivity decreased with increased time of heating. Inhomogeneity of the carbonate fluoride flux led to erratic results.

Highly reproducible results were obtained by fusing at $650 \mathrm{C}$ for 25 minutes, using a carbonate fluoride flux that had been fused and then ground. Phosphors prepared by this procedure are reproducible to about \pm 5 percent day after day, thus allowing the use of a permanent standard curve. Standard samples are unnecessary once the standard curve has been prepared.

\section{INTRODUCTION}

Many of the chemical laboratories that analyze large numbers of samples for traces of uranium use a "direct" fluorimetric method for many of the determinations. In the direct fluorimetric method the sample or sample aliquot is fused with sodium fluoride or an alkali carbonate fluoride mixture, and the fluorescence of the melt is measured. The use of Price's "dilution" technique ${ }^{1}$ and the development ${ }^{234}$ of extremely sensitive fluorimeters (discussed in parts 11,12 , and 13) have eliminated almost entirely the necessity for chemical separations. Although the manipulative details and the equipment used in the different laboratories differ, the general method for the direct determination of uranium has been well established.

All the instruments referred to, and perhaps others, have greater sensitivity than can be used to full advantage. At present, the size and reproducibility of the blanks set the lower sensitivity limit. The errors that occur in readings of replicate blanks or standards usually are greater than the instrumental error, which may be measured by replicate readings on a single blank or standard. Further improvement of instrumental sensitivity or precision should be secondary to the production of more reproducible phosphors and to obtaining a fusion mixture that will give lower blank readings.

In setting up a standard procedure for the direct determination of uranium in this laboratory, a method was sought for phosphor preparation that was reproducible day after day, and one that would allow for the duplication of the fluorescence to \pm 5 to 10 percent for melts of any given uranium content. Such a phosphor would make it

\footnotetext{
1 Price, G. R., Ferretti, R. J., and Schwartz, Samuel, 1945, The microfluorometric determination of uranium: AECD 2282.

2 Pickel, O. B., 1946, A ECD 2433.

- Price, G. R., Ferrettl, R. J., and Schwartz, Samuel, 1948, The design and construction of sensitive fluorophotometers, part 1, principles: ANL 4113.

- Smith, S. B., and Neil, H. G., 1946, Y-407.
} 
unnecessary to fuse standards with each batch of unknowns. One standard curve could be prepared and used permanently with only infrequent checks, for example when a new batch of flux was prepared. A transmission fluorimeter (part 11) was chosen for the measurement of the fluorescence. This instrument is set to a "standard deflection" which is a measure of filter leakage; therefore, once the standard curve is prepared, standard samples of any kind are unnecessary.

Several investigators have reported the effects of different methods of heating on the fluorescence of fluoride melts. Some have pointed out the variations in results that occur when the fusions are made in oxidizing as contrasted to reducing atmospheres, ${ }^{6}$ or at high temperatures as contrasted to lower temperatures, ${ }^{6}$ or in atmospheres of various gases. ${ }^{7}$ Others ${ }^{8}{ }^{8}$ have stated that fusions with a similar flux should not be made at temperatures greater than $750 \mathrm{C}$ because of the solution of platinum at higher temperatures (part 6).

Early work in the laboratory indicated that temperature, period of fusion, and homogeneity of flux were the most important factors affecting the reproducibility of the method. It was thought that a homogeneous flux could be prepared by fusion of the ingredients, followed by grinding and mixing, and that furnace fusions at controlled temperatures for a standard length of time would give reproducible phosphors.

These ideas proved correct, and a satisfactory method has been found for the preparation of reproducible phosphors. Quenching by platinum dissolved from the fusion vessel by the flux is probably the chief cause for nonreproducibility in earlier work. Controlled lowtemperature fusions practically eliminate this error.

\section{EXPERIMENTAL DATA AND DISCUSSION}

Many substances were considered, and several mixtures were tested before the final choice of a fusion mixture was made. A one-component flux such as sodium fluoride should be ideal for homogeneity; however, this substance has a very high melting point, and if used alone adheres strongly to the platinum fusion vessel. Several different mixtures of sodium fluoride and sodium carbonate were tested, and either they had a tendency to stick to the fusion vessel or they gave discs that were too fragile. The three-component mixture used

O Grimes, W. R., and Clark, F. E., 1948, Clinton Eng. Works, Tenn. Eastman Corp., H. 1.740,10.

- Simpson, S. D., 1948, The photofluorometric determination of uranium: Nat. Research Council, Atomic Energy Project, Chalk River, Ontario, Canada; R. M. C. 14 [abstract no. 26] or no. 263/26 (paper presented at the London Conference).

7 Price, G. R., Ferretti, R. J., and Schwartz, Samuel, 1947, ANL 4002 and addenda.

8 Bartlett, T. W., and others, 1945, Fluorescent methods: Tenn. Eastman Corp., C-4.100.19, p. 9.

- Clinton Eng. Works, Tenn. Eastman Corp., Div. of Chem. Research and Devel. Anal. Div. P. P. R. period ending July 1945, Doc. O.4.360.11, Ser. A, p. 38 . 
by Grimaldi and Levine (personal communication) had the requisite physical characteristics. The composition of this flux is 9 parts of sodium fluoride, 45.5 parts of sodium carbonate, and 45.5 parts of potassium carbonate by weight. To remove any uncertainty concerning the uniformity of the fusion mixture, a large batch was prepared by fusing the ingredients in a platinum vessel, hand-grinding the cool melts in a mullite mortar, and thoroughly mixing the combined batches by rolling on a mixing cloth.

The melting point of this flux was determined by the standard method of making melting and cooling curves. The mixture started to melt at $575 \mathrm{C}$ and was completely molten at $605 \mathrm{C}$. On cooling, the flux started to solidify at $605 \mathrm{C}$ and seemed to be completely solidified at $575 \mathrm{C}$. No sharp break was observed in either curve. The fusion was made in a J. L. Smith crucible heated in a small electric pot furnace. The temperatures were determined by measuring the voltage developed in a platinum-platinum +rhodium thermocouple placed in the molten material.

For the time-temperature studies, replicate blank samples and standard samples containing 0.005 microgram of uranium were fused with $1.5 \mathrm{~g}$ of flux in the platinum lids of $25-\mathrm{ml}$ crucibles. The fusions were made at $800,750,700,650$, and $620 \mathrm{C}$ for different intervals of time. Two to four replicates were made for each period at each temperature. The fusions were made in a small muffle furnace that accommodated two lids at a time; the melts were mixed by swirling about three times during the fusion period. The furnace temperature was controlled at the higher temperatures by manual operation of a rheostat; for the tests made at 650 and $620 \mathrm{C}$ the temperature was regulated with an automatic controller. When the lids were removed from the furnace, they were held by tongs until the melts crystallized. They were then cooled in a desiccator for 30 minutes before the fluorescence was measured.

The groups of melts, fused at $800 \mathrm{C}$ and at $750 \mathrm{C}$, each formed a graduated color series when compared under white light. The melts of each group increased in the intensity of their yellow color with the length of the fusion period; those that were fused at $800 \mathrm{C}$ were darker yellow than the corresponding melts fused at $750 \mathrm{C}$. For example, the intensity of the yellow of a melt fused at $800 \mathrm{C}$ for 3 minutes corresponded to that of a melt fused at $750 \mathrm{C}$ for 10 minutes; and the fluorescence of these two phosphors ulso was comparable. Tho melts that were fused for 5 to 10 minutes at 800 and 750 C showed 2 decided murkiness just before they solidified; however, when the melts were rempyed from the lids in which they were fused, the lids were relatively clean. By way of contrast, even 40-minute fusions at $650 \mathrm{C}$ and less gave melts that appeared to be perfectly white but 
the lids used for these fusions showed a dark stain. This stain increased with the length of the fusion and was very heavy after the 20- and 40-minute fusions. At temperatures of $650 \mathrm{C}$ and less, the platinum lid seemed to be attacked, but only a small part dissolved in the melt.

The degree of attack on the lid by the flux was determined for fusions made at different temperatures. Samples of a fusion mixture weighing $1.5 \mathrm{~g}$ each were fused for 10 minutes in the small furnace. Portions were fused at $650,700,750$, and $800 \mathrm{C}$. Two were fused at $800 \mathrm{C}$ and then re-fused for an additional 10 minutes at $650 \mathrm{C}$. The melts were dissolved in a little water and hydrochloric acid, and the solutions evaporated to dryness. The residues were dissolved in water and analyzed for platinum by the stannous chloride colorimetric method. ${ }^{10}$ The standards used for comparison contained $1.5 \mathrm{~g}$ of fusion mixture treated in the same manner. The lids that were used for these fusions were boiled with $(1+1)$ hydrochloric acid until the stain disappeared. The lids then were removed and the solutions evaporated to dryness. Platinum was determined on these residues by the same colorimetric method except that a new set of standards that contained no fusion mixture was used for comparison. The density measurements were made at $420 \mathrm{~m} \mu$ with a Beckman spectrophotometer.

The results of these analyses are given in table 1. The platinum content of the melts is a direct function of the fusion temperature.

The results of the time-temperature study have been summarized in graphs. Figure 3 shows the fluorescence of blanks plotted against total time in the furnace at different temperatures. Figure 4 shows the same for standard samples that contained 0.005 microgram of uranium. In figure 5 the data presented in figures 3 and 4 are combined and the sensitivity is plotted against total time in the furnace at different temperatures. Tables 2,3 , and 4 present the data from which these graphs were prepared.

TABLE 1.-Attack on platinum lid by flux as a function of fusion temperature

[10-minute fusion in small furnace]

\begin{tabular}{|c|c|c|c|c|c|}
\hline \multirow{2}{*}{ Temperature of fusion $\left({ }^{\circ} \mathrm{C}\right)$} & \multicolumn{2}{|c|}{$\begin{array}{l}\text { Micrograms of } \\
\text { platinum found- }\end{array}$} & \multirow{2}{*}{ Temperature of fusion $\left({ }^{\circ} \mathrm{C}\right)$} & \multicolumn{2}{|c|}{$\begin{array}{l}\text { Micrograms of } \\
\text { platinum found- }\end{array}$} \\
\hline & In melts & On lids ${ }^{1}$ & & In melts & On lids ${ }^{1}$ \\
\hline $\begin{array}{l}650 \\
700 \\
750\end{array}$ & $\begin{array}{r}9 \\
33 \\
76\end{array}$ & $\begin{array}{l}156 \\
113 \\
148\end{array}$ & $8000^{2}$ & $\begin{array}{l}155 \\
174 \\
174\end{array}$ & $\begin{array}{l}125 \\
218 \\
250\end{array}$ \\
\hline
\end{tabular}

1 Soluble in hydrochloric acid.

2 Re-fused for an additional 10 minutes at $650 \mathrm{C}$.

10 Sandell, E. B., 1944, Colorimetric determination of traces of metals, p. 358, New York, Interscience Publishers, Inc. 
TABLE 2.-Time-temperature study for blanks

[1.5 grams of flux]

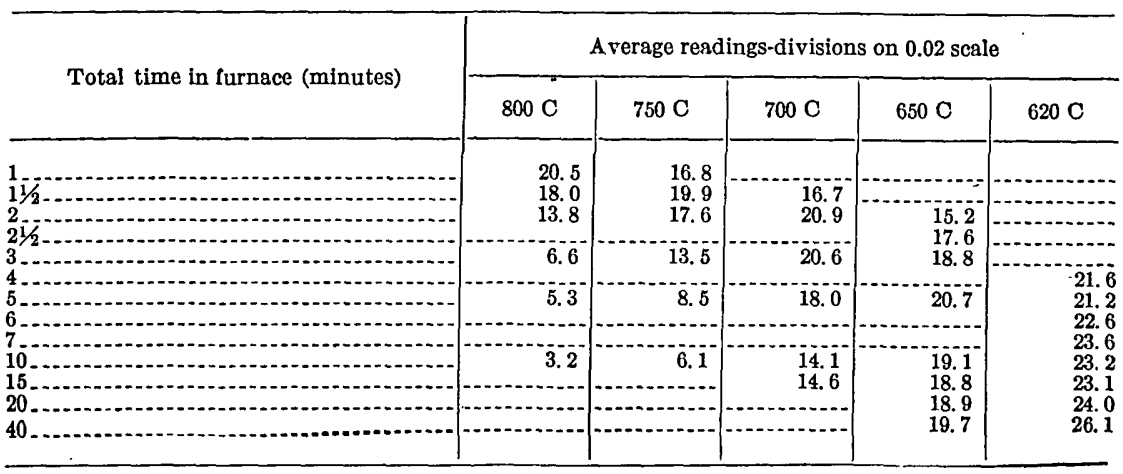

TABLE 3.-Time-temperature study for standard samples containing 0.005 microgram of uranium

[1.5 $\mathrm{g}$ of flux]

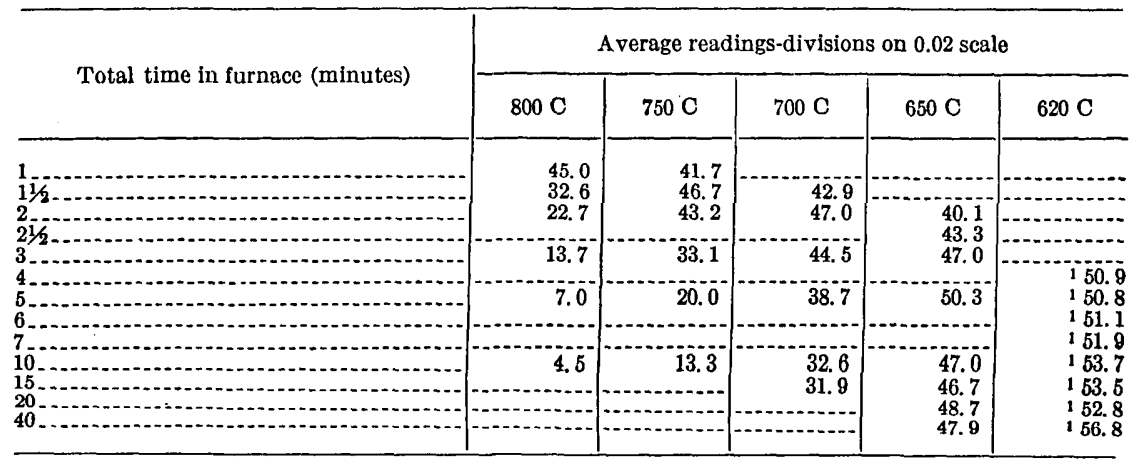

1 Data calculated from readings on 0.05 scale.

TABLE 4.-Effect of fusion conditions on sensitivity

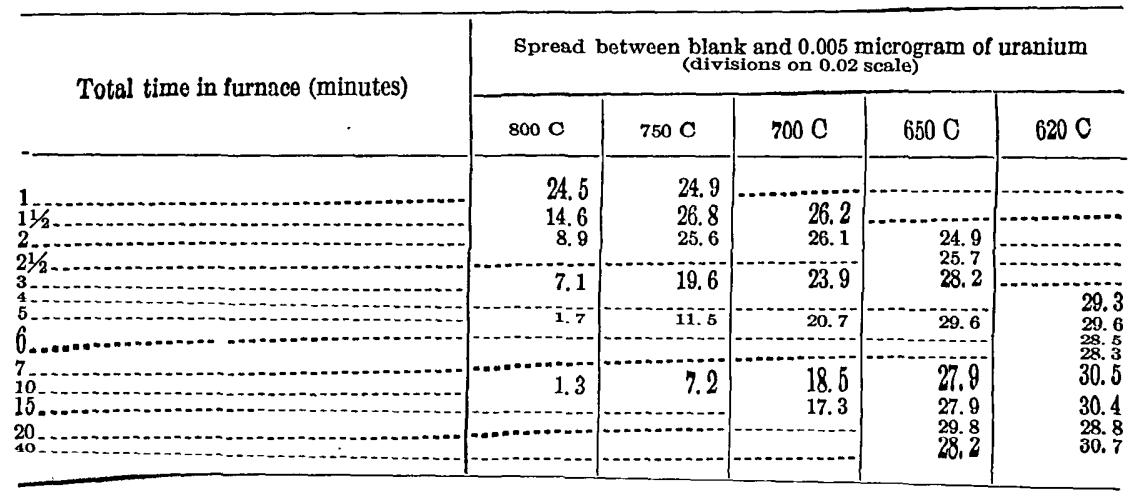




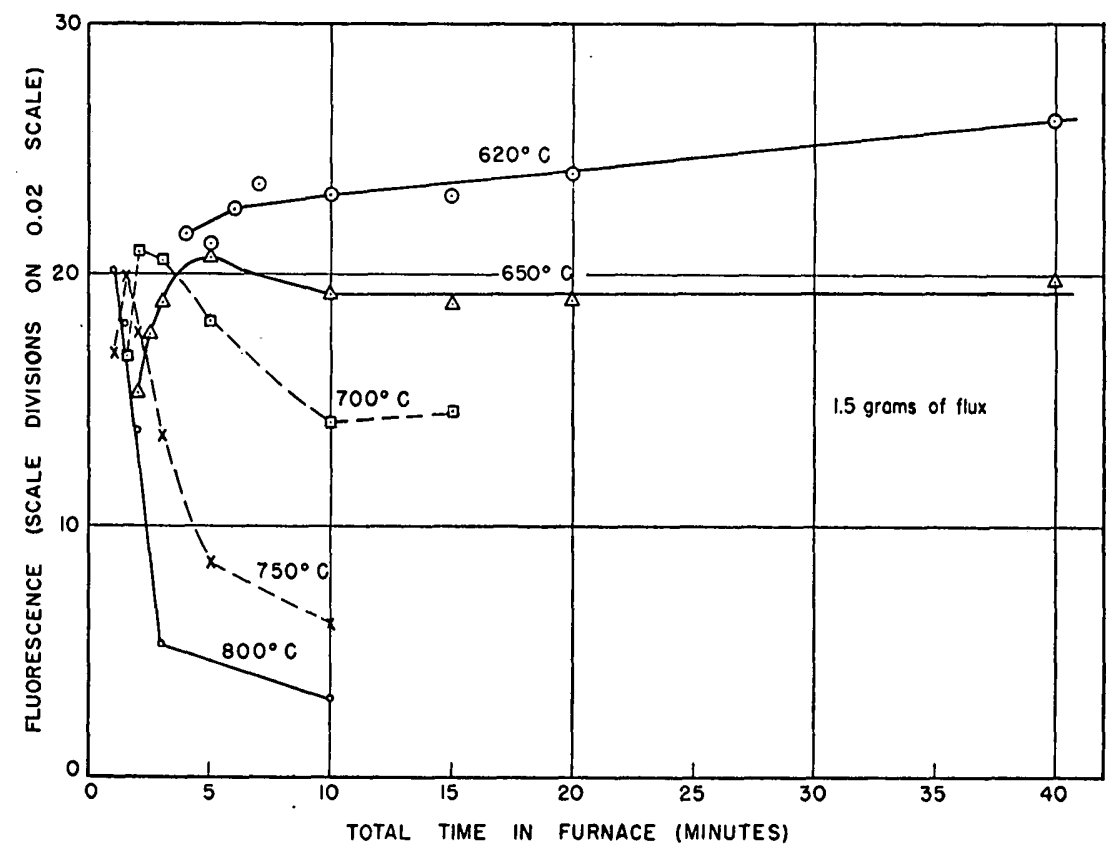

FIGURE 3.-Effect of fusion conditions on fuorescence of blank samples.

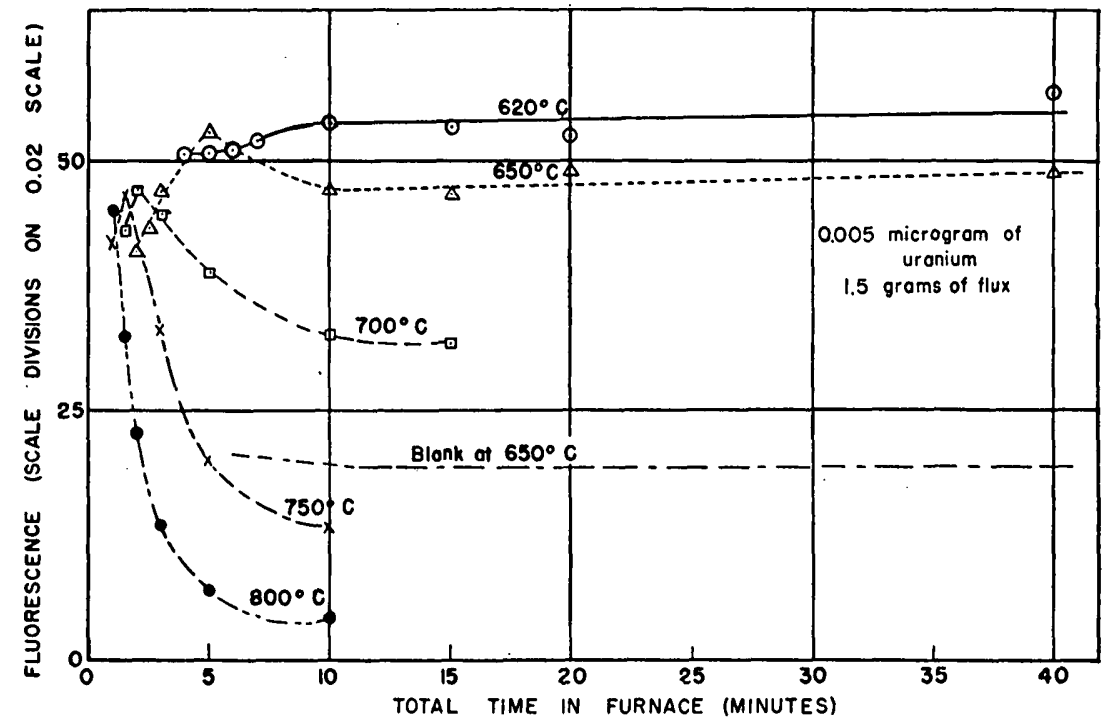

Fiaure 4.-Effect of fusion conditions on fluorescence of standard samples. 


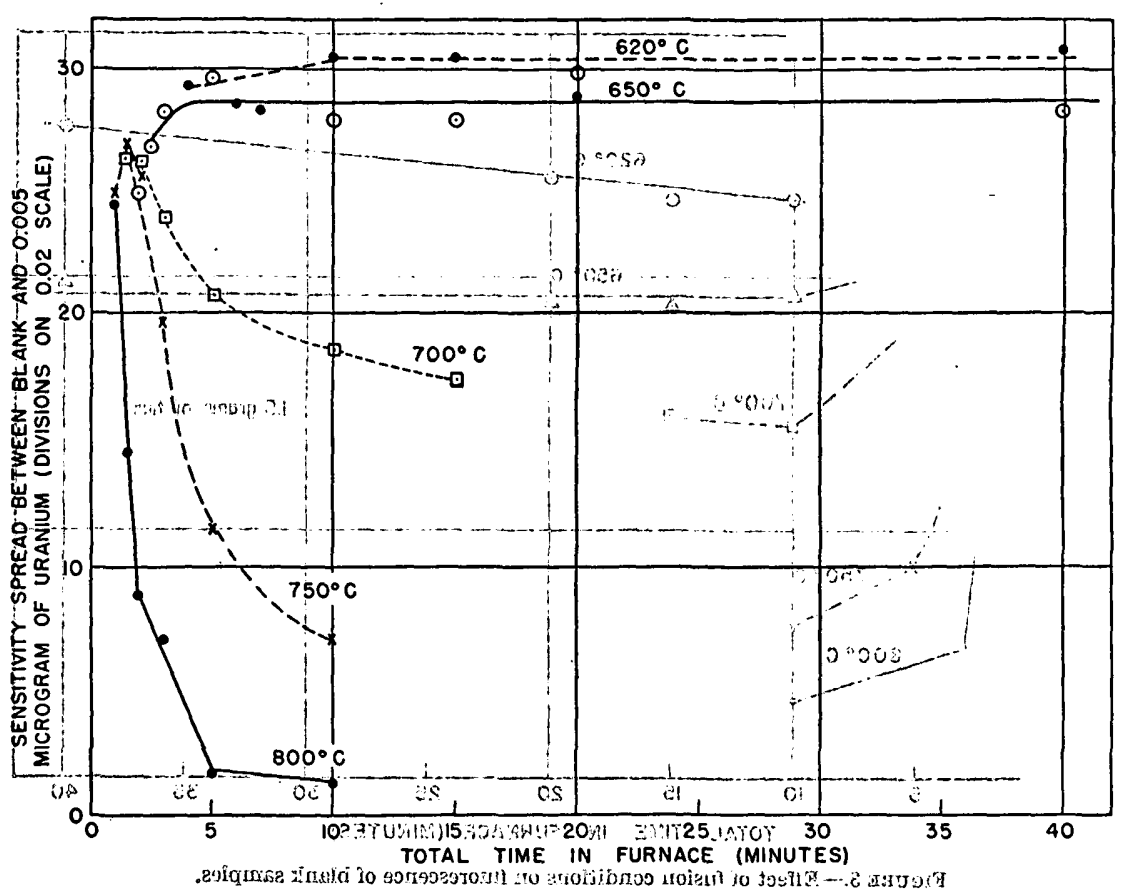

Figure 5.-Effect of fusion conditions on sensitivity.

These graphs and tables show the effects of uncontrolled heating and the necessity for_low-temperature fusions. The fluorescence of alkali_carbonate fluoride melts with or without added ưranium is affected tremendously by the conditions-of -the-fusion. The fluorescencerof individual melts and the sensitivity of the determination decrease witherencesing fusion temperature, and with incréasing periogd of fusion when the temperature is greater than $650 \mathrm{C}$. For very short fusions (that is, just long enough to melt the flux and quickly mix it) the fluorescence at all_témperatures_is near the maximum; and for low-temperature fusions, the fluorescence is the same for all periods of fusion provided the maximum has been reached. The graphs indicate that the best fusion conditions are a temperature of $650 \mathrm{C}$ for a period of at least 10 minutes in the furnace ysed for this study.

in This furnace is small and the thermocouple not-enclosed;-as-a résult, it gives excellent response to the controller. The total variation from the desired temperature Was about 8 , and although the furnace cooled when the door was opened, it heated up again almost immediately. This small furnace was ideal for a study where careful temperature control was the principal consideration, but a larger 
furnace is necessary for analytical purposes when large numbers of samples must be handled.

The best conditions for fusion in a large furnace are harder to define than are those for a smaller furnace. In a large furnace, there is usually a large temperature gradient from the front to the back of the furnace. There is also an appreciable lag which results in a lower or higher temperature than that at which the controller is set. When the door is opened to insert samples or to agitate them, the furnace cools and takes much longer to heat up again than a small one. Therefore, the temperature conditions within each furnace should be determined. A controller setting should be chosen that will not allow the temperature to rise above $650 \mathrm{C}$. Any part of the furnace that is always cooler than $605 \mathrm{C}$ cannot be used.

The temperature controller for the large furnace used in this laboratory was set at $650 \mathrm{C}$, and 10 lids, on two racks in rows of 5 each, were placed in the furnace at one time. The front one-third section of the furnace was too cool to fuse the samples and could not be used. The melts were mixed by shaking the rack three times during the fusion (the melts usually solidified at the end of the period of shaking). A period of 15 to 25 minutes was required to obtain reproducible maximum fluorescence in the melts. The 25-minute period finally was adopted as the standard fusion time although some of the data presented were obtained at the shorter period.

Later, the furnace chamber was tested with a National Bureau of Standards chromel-alumel thermocouple used in conjunction with a potentiometer. The temperature at the position of the back lids ranged from 600 to $630 \mathrm{C}$, and at the position of the front lids from 585 to $610 \mathrm{C}$. About 7 minutes were required to fuse the samples after they were inserted in the furnace; whereas, only $1 \frac{1}{2}$ minutes at $1650 \mathrm{C}$ and 3 minutes at $620 \mathrm{C}$ were required in the small furnace. The unexpectedly low temperatures in the large furnace and the consequent longer fusion time made necessary the 25-minute fusion period required to obtain reproducible fluorescence in the melts.

are effient temperature control results in better reproduction

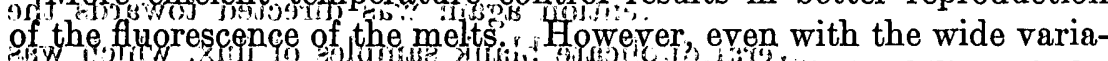
tions that existed in the larger furnace the reproducibility of the tons that existenin ine larger furnace, the reproducibility of the fuorescence was well within tolerable limits Thab 5 gives fuorescance radings on replicate blank samples fused in the small furnace, and table 6 gives readings for fusions made in the large furnace. The average devation from the mean is 0.6 division on the 0.02 scale

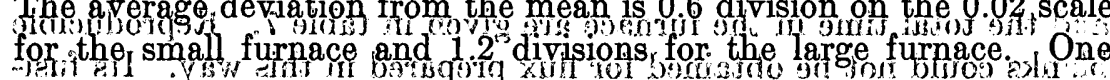

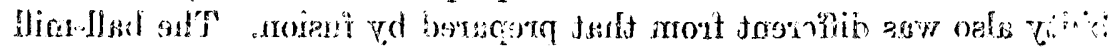

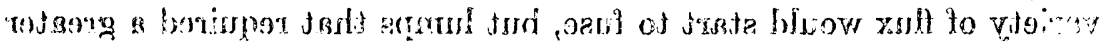


division on the 0.02 scale was equivalent to 0.000144 microgram of uranium.

Tests by Norma Guttag (personal communication) of this laboratory have shown that careful fusions over a Meker burner give results comparable to those obtained in the small furnace. The fusions over a burner were made at the minimum temperature required to melt the flux. The molten material was constantly agitated for about 1 minute. This procedure is quicker than furnace fusions, but demands that overheating be prevented. Analyses of several melts fused in this manner showed 3 to 10 micrograms of platinum.

TABLE 5.-Reproducibility of fluorescence of blanks heated in a small furnace

[Fusions made at $650 \mathrm{C}$ for 5 minutes]

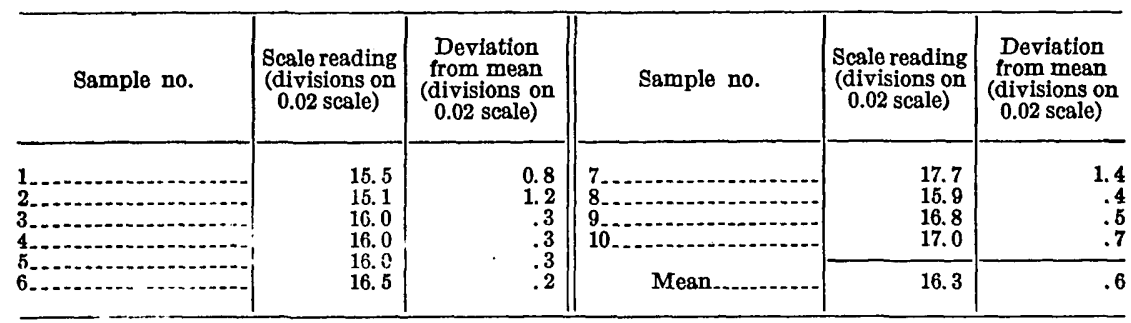

$\mathrm{T}_{\mathrm{AE} L \mathrm{E}}$ 6.-Reproducibility of fluorescence of blanks heated in a large furnace [Controller set for $650 \mathrm{O}$; actual temperature fluctuated from 585 to $630 \mathrm{C}$. Period of fusion: 15 minutes]

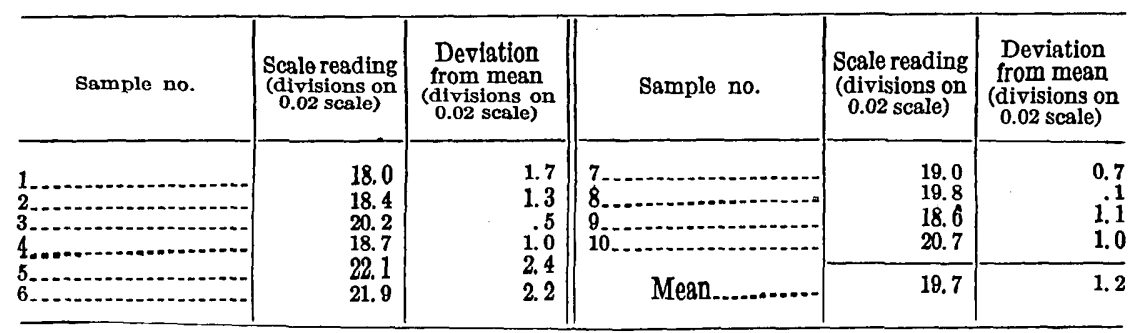

The best fusion conditions for the preparation of the phosphors having been determined, attention again was directed towards the fusion mixture. Several duplicate blank samples of flux, which was prepared by mixing the components in a ball mill without prior fusion, were fused in the small furnace and their fluorescence measured to determine whether this simpler means could be used for preparing the flux. The readings obtained, the time required to melt the mixture, and the total time in the furnace are given in table 7. Reproducible blanks could not be obtained for flux prepared in this way. Its fusibility also was differant from that prepared by fusion. The ball-mill variety of flux would start to fuse, but lumps that required a greater 
length of time to melt usually were present. Sometimes as much as 10 minutes were necessary to obtain complete fusion. Furthermore, many air bubbles formed next to the lid, and it was virtually impossible to get rid of them. In contrast to this, the mixture prepared by fusion always melted in about the same length of time ( 1 to $1 \frac{1}{2}$ minutes at $650 \mathrm{C})$; moreover, no lumps and scarcely any air bubbles were present.

The details of the method finally adopted for the preparation of the fusion mixture follow:

Heat a mixture of $9 \mathrm{~g} \mathrm{NaF}, 45.5 \mathrm{~g}$ of $\mathrm{Na}_{2} \mathrm{CO}_{3}$, and $45.5 \mathrm{~g}$ of $\mathrm{K}_{2} \mathrm{CO}_{3}$ in a large platinum dish in a furnace at $650 \mathrm{C}$ for 15 to 20 minutes or until most of the material has fused. Complete the fusion over a Meker burner and swirl the melt until it is well mixed. Fuse as many $100-\mathrm{g}$ lots of the mixture as desired. Then break up the cakes in a large mortar with a pestle until all of the fused material will pass through a 5-mesh screen. Place the lumps of flux in a dry warm ball mill, and tumble it for about 3 hours or until the mixture will pass through a 65 -mesh screen. Remove the pebbles and again tumble in the ball mill for several hours. Store the stock in a large tight bottle. Transfer to smaller bottles as required for use. The mixture is hygroscopic in damp weather; consequently, when not in use, the containers must be kept tightly closed.

TABLE 7.-Inadequacy of fusion mixture prepared by ball-milling

[Fusions made in small furnace at $650 \mathrm{O}$-blank samples]

\begin{tabular}{|c|c|c|c|c|c|c|c|}
\hline Sample no. & $\begin{array}{c}\text { Time } \\
\text { required } \\
\text { to melt } \\
\text { (minutes) }\end{array}$ & $\begin{array}{l}\text { Totsl time } \\
\text { in furnace } \\
\text { (minutes) }\end{array}$ & $\begin{array}{l}\text { Reading } \\
\text { (divisions } \\
\text { on } 0.02 \\
\text { scale) }\end{array}$ & Sample no. & $\begin{array}{c}\text { Time } \\
\text { required } \\
\text { to melt } \\
\text { (minutes) }\end{array}$ & $\begin{array}{l}\text { Total time } \\
\text { in furnace } \\
\text { (minutes) }\end{array}$ & $\begin{array}{l}\text { Reading } \\
\text { (divisions } \\
\text { on } 0.02 \\
\text { scale) }\end{array}$ \\
\hline $\begin{array}{l}1 \\
2 \\
4 \\
5\end{array}$ & $\begin{array}{r}3-4 \\
3-4 \\
3-4 \\
10 \\
8\end{array}$ & \begin{tabular}{c|}
5 \\
5 \\
6 \\
10.5 \\
10.5
\end{tabular} & $\begin{array}{r}42.0 \\
39.2 \\
46.0 \\
37.8 \\
(1)\end{array}$ & $\begin{array}{l}6 \\
7 \\
8 \\
0 \\
0\end{array}$ & $\begin{array}{r}8 \\
6 \\
6 \\
10 \\
8\end{array}$ & $\begin{array}{l}10.5 \\
10.5 \\
10.5 \\
10.5 \\
10.5\end{array}$ & (3) $\begin{array}{r}40.2 \\
41.8 \\
41.2 \\
34.6\end{array}$ \\
\hline
\end{tabular}

1 Off scalo-36.1 on 0.05 scale.

2 Off scalo-23.0 on 0.05 scale.

\section{ANALYTICAL PROCEDURE}

The chief differences in the analytical procedure adopted by this laboratory and that used elsewhere are (1) the use of a transmission fluorimeter for the measurement of the fluorescence of the melts; (2) the use of controlled low-temperature fusions with the consequent elimination of standard samples.

Most other laboratories fuse about six standards and several blanks along with the samples for each fusion operation, and prepare a new curve for each set of samples fused. 

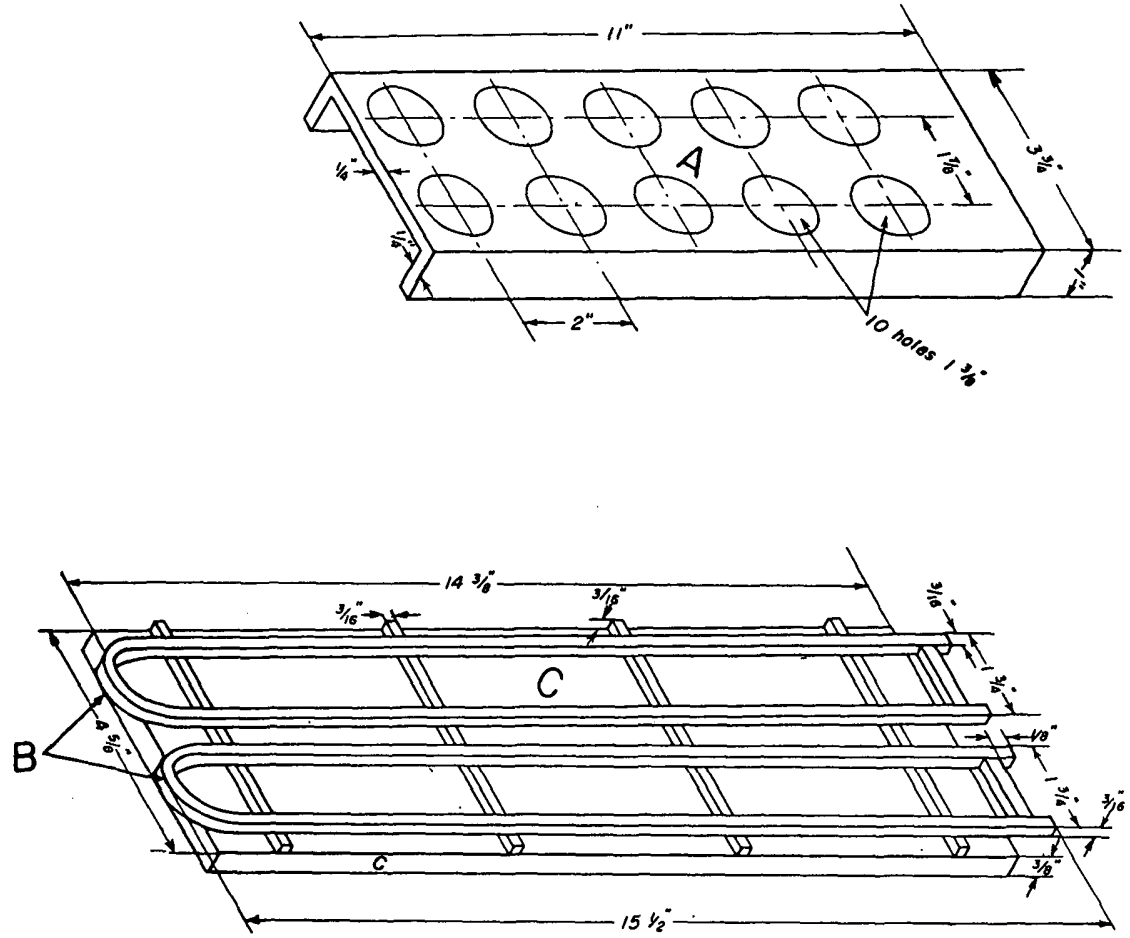

Figure 6.-Equipment.

The equipment used here is shown in plates 1 and 2 and figure 6 . Plates 1 and 2 are photographs of the Model II transmission fluorimeter and d-c amplifier described in part 11 which were used for the work described in this report. A Model V has now been built and is described in part 12. Figure $6(A)$ shows the stainless steel racks that hold 10 lids each. The lids are placed on these racks, the sample solutions pipetted onto the lids and dried in place on the racks. Figure $6(B)$ shows chromel racks made from furnace-heating elements that are used to hold the lids in the furnace during the fusion period. Figure $6(C)$ shows a transite plato with attached chromel rods placed on the bottom of the furnace to serve as a support for the racks and samples during fusion. The sample solutions are transferred to the lids with graduated $0.2-\mathrm{ml}$ pipettes. The platinum lids are from 25 -ml crucibles,

For the determination of the uranium in any sample, a small amount of the sample was weighed onto the lid, or a small amount of the sample solution was pipetted onto the lid. When liquid, the sample was dried under an infrared lamp or on a hotplate, and ignited briefly. For both solids and liquids, $1.5 \mathrm{~g}$ of fusion mixture was added to the lid. The lids were transferred to the chromel racks and placed in the furnace, which was set for $650 \mathrm{C}$; the samples were 


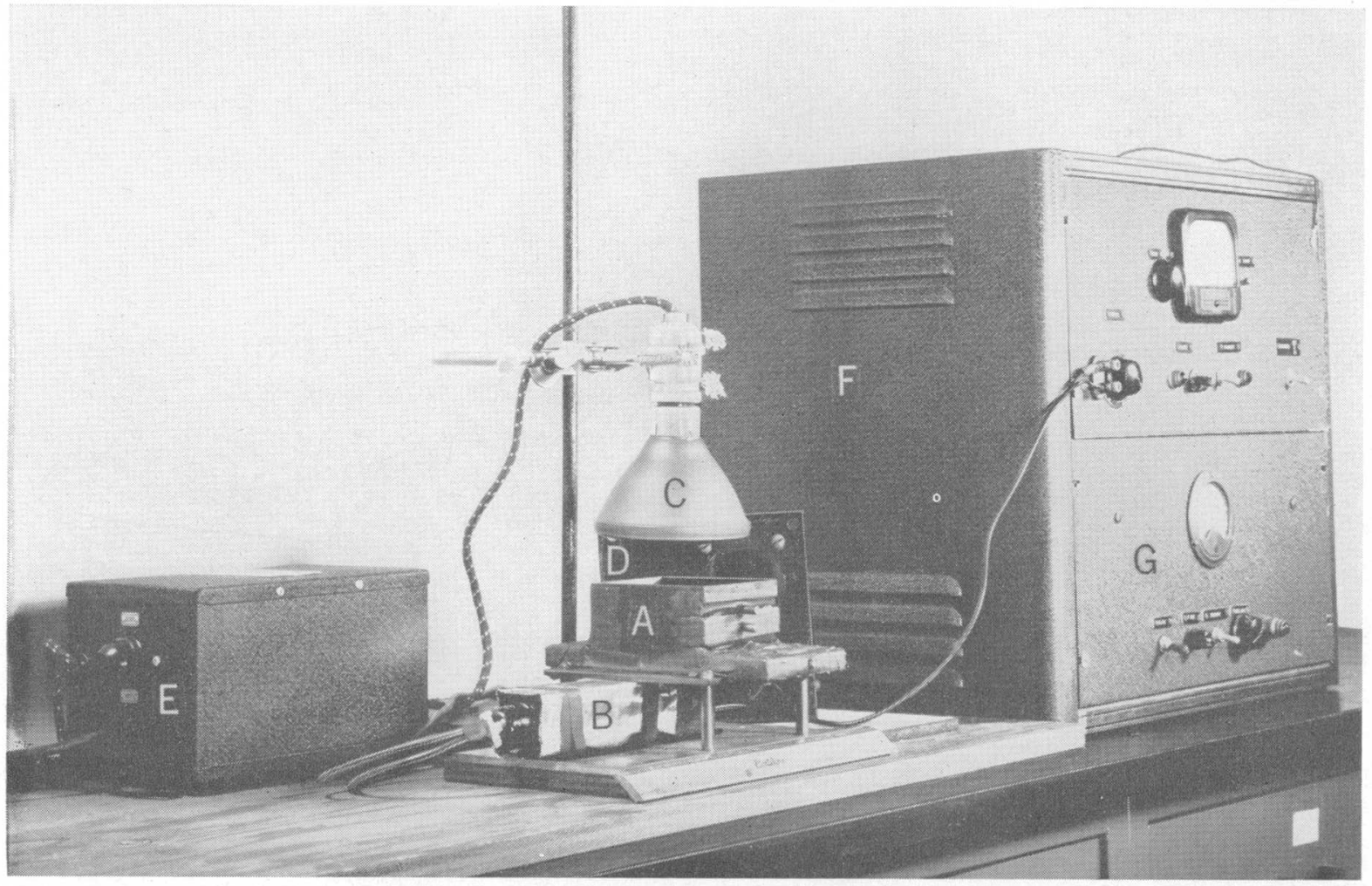

ASSEMBLY OF MODEL II TRANSMISSION FLUORIMETER. $A$, fluorimeter; $B$, phototube; $C$, ultraviolet lamp; $D$ ventilating fan $E$, voltage regulator; $F, \mathrm{~d}-\mathrm{c}$ amplifier; $G$, power source. 


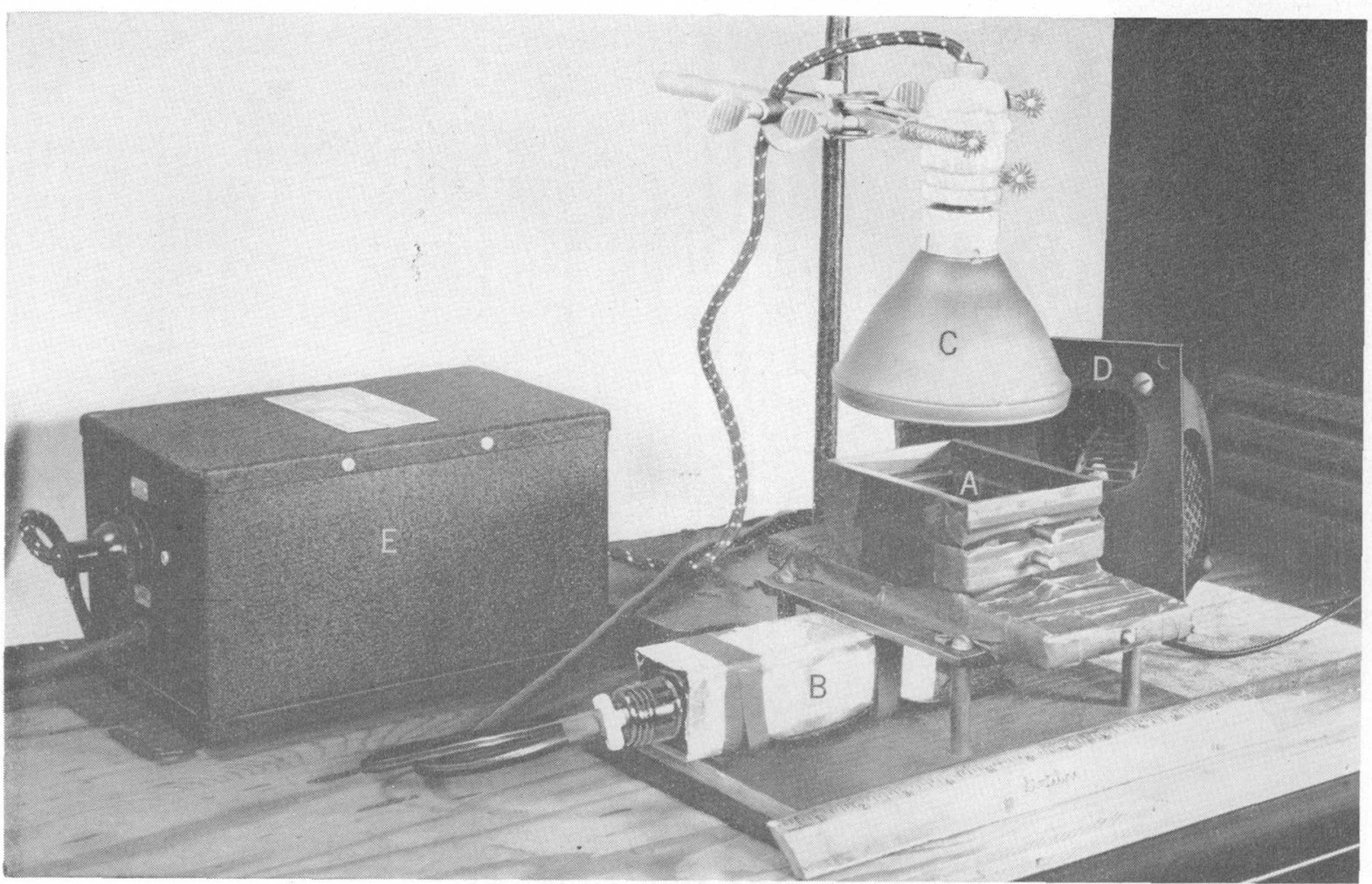

MODEL II TRANSMISSION FLUORIMETER. $A$, fluorimeter; $B$, phototube; $C$, ultraviolet lamp; $D$, ventilating fan; $E$, voltage regulator. 


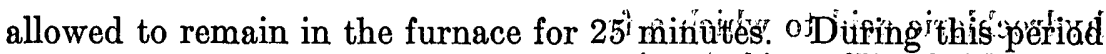
they were mixed three times by shaking 'the riacks

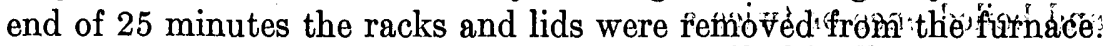
The lids were placed in a desiccator and allowed tón col 30 'minutes; after this period the fluorescence of the melts was measured:"

The size of the sample used for the final determination, and the methods of preparation of the sample solution are flexible and are determined by the nature of the sample and the quantity available. For average samples, the final aliquot was chosen to contain 0.001 to 0.08 microgram of uranium, and usually represented 50 micrograms of sample although much smaller and much larger samples have been used successfully.

When the amount of sample is limited, the uranium content low, and the amount of quenchers negligible, the solid sample can be used directly. For example, with plant-ash samples that contain from a few hundredths of a part per million to a few parts per million of uranium and only small amounts of quenching elements, $5 \mathrm{mg}$ of the solid sample are fused directly. When the sample is readily soluble in acid, $50 \mathrm{mg}$ are weighed into a flask, $100 \mathrm{ml}$ of 18 percent nitric acid measured into the flask, the flask covered with a watch glass and heated until it just boils. It is then cooled and a 50-microgram $(0.10-\mathrm{ml})$ aliquot is pipetted onto the lid, and the determination continued as outlined. Samples not readily soluble in acid usually are decomposed by fusion with a mixture of sodium carbonate and sodium borate $(4+1)$. This flux has the advantage of keeping silica in solution. For decomposition with the carbonate borax flux, 10 to $50 \mathrm{mg}$ of the sample are weighed into a small platinum crucible and fused with $500 \mathrm{mg}$ of the flux. The crucible then is placed in a $100-\mathrm{ml}$ beaker which contains $30 \mathrm{ml}$ of 30 percent hydrochloric acid, and the beaker is placed on a hotplate for a few minutes. The fusion melt dissolves in about 3 minutes to give a clear solution. When the melt is completely dissolved, the crucible is removed from the beaker and rinsed with water. The solution is transferred to a $100-\mathrm{ml}$ volumetric flask and diluted to volume. (Further dilutions of this solution are made if the percentage of uranium in the sample is greater than about 0.1.) A $0.1-\mathrm{ml}$ aliquot then is taken for the determination. Hydrochloric acid instead of nitric acid was used to prepare these sample solutions because there is danger of attack on the platinum by sodium nitrate and because less creeping of the borate residue occurred with hydrochloric acid. An aliquot of $0.1 \mathrm{ml}$ of sample solution was chosen because it evaporates quickly and the residue is confined to a small spot; thus the flux is always in contact with the sample during fusion.

The lids used for the determination are cleaned by acid washing. The melts are removed, and the lids boiled for a short time in 1:1 
hydrochloric acid to which a few milliliters of hydrofluoric acid have been added. The acid then is drained off, the lids rinsed with water, and boiled once or twice again with 1:1 hydrochloric acid. They are then rinsed well with distilled water, and dried over a bunsen burner.

Results of determinations carried out by this method are given in tables $8,9,10$, and 11 . In table 8 the results of replicate analyses on standard shale sample GST-1 are given. The average amount of uranium found was 0.0087 percent $U$ with an average deviation from the mean of 0.00018 percent $U$. The average amount found by six laboratories was 0.0086 percent $U \pm 0.00017$ percent $U$. Table 9 shows the results on the standard shale sample GST-2. The percent uranium found was 0.0127 percent $U$ with an average deviation from the mean of 0.00038 percent $U$, whereas the average value from six laboratories was 0.0123 percent $U \pm 0.00008$ percent $U$. Table 10 gives comparative determinations of uranium by the direct method, by the extraction procedure (see part 6 ), and by radiometric count. Each result represents a single determination. The correlation is good. Table 11 shows comparative results for determinations by the direct method using 100- and 20-microgram aliquots. Each value again corresponds to a single determination, and the results agree.

The method as outlined has sufficient sensitivity and accuracy to determine a few thousandths of a percent of uranium in a $0.02-\mathrm{mg}$ sample. Through the use of small aliquots, quenching from foreign ions is reduced to a minimum, and chemical separations generally are unnecessary. Low-temperature fusions eliminate platinum quenching. Standards of any kind are unnecessary once the standard curve has been prepared. The method is especially useful where the amount of material is small, and it is invaluable where the sample is small and the uranium content is low.

$\mathrm{T}_{\mathrm{ABLE}}$ 8.-Replicate analyses of standard shale sample GST-1.1 Uranium present $0.0086 \pm 0.00017$ percent

[100-microgram aliquots of sample]

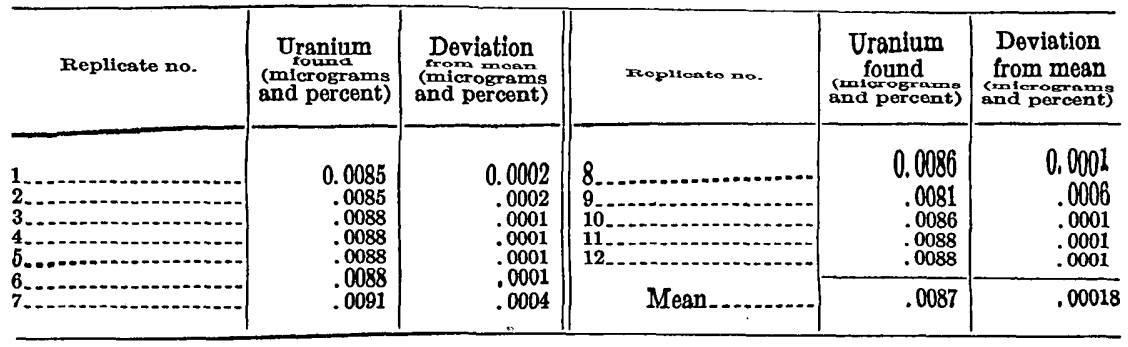

1 See part 11, table 5. 
TARLE 9.-Replicate analyses of standard shale sample GST-2. Uranium content $0.0128 \pm 0.00008$ percent

[100-microgram aliquots of sample]

\begin{tabular}{r|r|r||r|r|r}
\hline Replicate no. & $\begin{array}{r}\text { Uranium } \\
\text { found } \\
\text { (mfcrograms } \\
\text { and percent) }\end{array}$ & $\begin{array}{r}\text { Deviation } \\
\text { from mean } \\
\text { (micrograms } \\
\text { and percent) }\end{array}$ & Replicate no. & $\begin{array}{c}\text { Uranium } \\
\text { found } \\
\text { (micrograms } \\
\text { and percent) }\end{array}$ & $\begin{array}{c}\text { Deviation } \\
\text { from mean } \\
\text { (micrograms } \\
\text { and percent) }\end{array}$ \\
\hline 1 & $\begin{array}{r}0.0133 \\
.0128\end{array}$ & $\begin{array}{r}0.0006 \\
.0001 \\
.0001\end{array}$ & 4.60128 & 0.0007 \\
\hline
\end{tabular}

TABLE 10.-Comparison of results obtained by different methods of analysis of northwestern phosphates

\begin{tabular}{|c|c|c|c|c|c|c|c|}
\hline \multirow[b]{2}{*}{ Sample no. } & \multicolumn{3}{|c|}{ Percent uranium found } & \multirow[b]{2}{*}{ Sample no. } & \multicolumn{3}{|c|}{ Percent uranium found } \\
\hline & $\begin{array}{l}\text { "Direct" } \\
\text { method, } \\
\text { 100-micro- } \\
\text { grsm } \\
\text { aliquot }\end{array}$ & $\begin{array}{c}\text { Extraction, } \\
\text { 3.6-milli- } \\
\text { gram } \\
\text { aliquot }\end{array}$ & $\begin{array}{l}\text { Radio- } \\
\text { metric } \\
\text { count }\end{array}$ & & $\begin{array}{l}\text { "Direct" } \\
\text { method, } \\
\text { 100-micro- } \\
\text { gram } \\
\text { aliquot }\end{array}$ & $\begin{array}{l}\text { Extraction, } \\
\text { 3.6-milli- } \\
\text { gram } \\
\text { aliquot }\end{array}$ & $\begin{array}{l}\text { Radio- } \\
\text { metric } \\
\text { count }\end{array}$ \\
\hline 1 & $\begin{array}{l}0.009 \\
.008 \\
.010 \\
.010 \\
.007\end{array}$ & $\begin{array}{l}0.010 \\
.007 \\
.008 \\
.010 \\
.007\end{array}$ & $\begin{array}{l}0.011 \\
.009 \\
.009 \\
.011 \\
.008\end{array}$ & $\begin{array}{l}6 \\
7 \\
8 \\
9\end{array}$ & $\begin{array}{l}0.004 \\
.013 \\
.011 \\
.008 \\
.010\end{array}$ & $\begin{array}{l}0.004 \\
.013 \\
.010 \\
.008 \\
.008\end{array}$ & $\begin{array}{l}0.008 \\
.013 \\
.013 \\
.008 \\
.010\end{array}$ \\
\hline
\end{tabular}

TABLE 11.-Determination of uranium by the "direct" method using different aliquots

[Samples 1 through 12 are Florida phosphates; samples 13 through 20 are northwestern phosphates]

\begin{tabular}{|c|c|c|c|c|c|}
\hline \multirow{2}{*}{ Sample no. } & \multicolumn{2}{|c|}{ Percent uranium found } & \multirow{2}{*}{ Sample no. } & \multicolumn{2}{|c|}{ Percent uranium found } \\
\hline & $\begin{array}{c}\text { 100-micro- } \\
\text { gram sliquot }\end{array}$ & $\begin{array}{l}\text { 20-micro- } \\
\text { gram aliquot }\end{array}$ & & $\begin{array}{c}\text { 100-micro- } \\
\text { gram aliquot }\end{array}$ & $\begin{array}{l}\text { 20-micro- } \\
\text { gram aliquot }\end{array}$ \\
\hline 1 & $\begin{array}{l}0.023 \\
.005 \\
.012 \\
.009 \\
.012 \\
.010 \\
.010 \\
.007 \\
.016 \\
.006\end{array}$ & $\begin{array}{l}0.022 \\
.007 \\
.015 \\
.008 \\
.013 \\
.010 \\
.010 \\
.011 \\
.015 \\
.006\end{array}$ & 10 & $\begin{array}{l}0.013 \\
.017 \\
.013 \\
.008 \\
.010 \\
.013 \\
.009 \\
.013 \\
.006 \\
.013\end{array}$ & $\begin{array}{l}0.014 \\
.019 \\
.013 \\
.008 \\
.007 \\
.012 \\
.009 \\
.014 \\
.006 \\
.013\end{array}$ \\
\hline
\end{tabular}

\section{NEW DATA ON TIME-TEMPERATURE STUDY}

The time-temperature study, figure 4 and table 3 , was repeated 3 years after the original work. The standard (May) dish with $2.0 \mathrm{~g}$ of flux was used in this new study because these dishes are now in regular use in this Geological Survey laboratory (part 13). Otherwise the conditions of the tests were identical with those of the original work. As before, the fluorescence of the carbonate fluoride melts varied with the temperature and period of heating, and the degree of quenching depended upon the amount of platinum dissolved from the fusion vessel. 


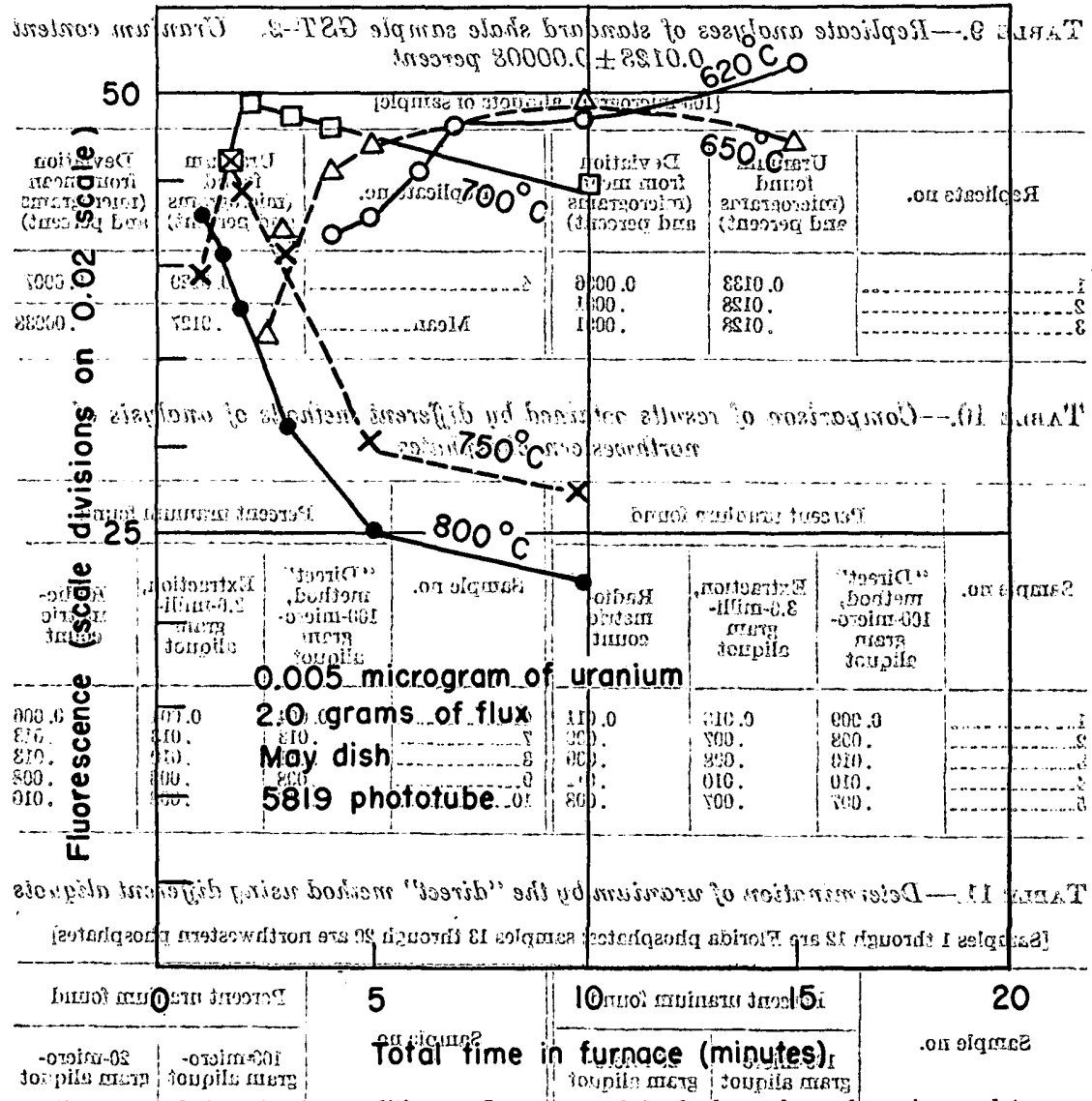

\section{-FIGURE 7 - Effect-of fusion-conditions-on-fluorescence-of-standard-samples-as-shown-in.new_data}

The newidata, presented here in figure 7 and table 12 , show lês guenching than occurred in the original study and also that the melts: êntained less dissolved-platinum ther running the tests, one set of fusions was repeated using the crucibleilids employed in the earlier investigation. Accordingly, the series fused at $800 \mathrm{C}$ were run again in the original lids with $1.5 \mathrm{~g}$ of flux. Less quenching

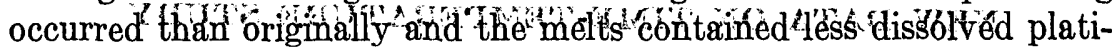

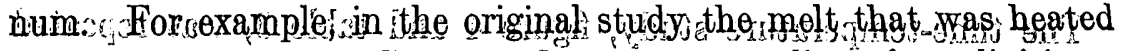

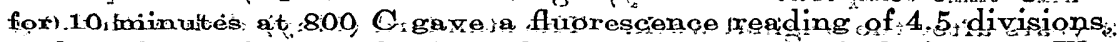
and analysis of the melt showed 155 micrograms of platinum. The corresponding melt in the new study gavo a fluorescence reading of 25.0 divisions, and analysis of the melt showed pnply 74 imicrograms of

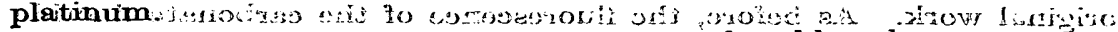
sitherfluorescence readings obtained from the old and new tests at

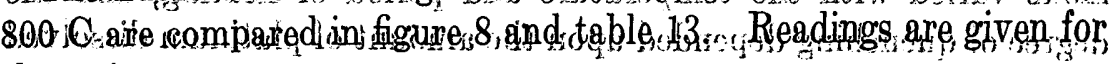
the series. 
TABLE 12.-Time-temperature study of standard samples containing 0.005 microgram of uranium

[Fluorescence readings on 0.02 scale with ROA 5819 multiplier phototube]

\begin{tabular}{|c|c|c|c|c|c|c|c|c|c|c|c|c|}
\hline \multirow{3}{*}{$\begin{array}{l}\text { Total } \\
\text { time in } \\
\text { furnace } \\
\text { (min- } \\
\text { utes) }\end{array}$} & \multicolumn{10}{|c|}{ Standard dishes and $2.0 \mathrm{~g}$ of flux } & \multirow{2}{*}{\multicolumn{2}{|c|}{$\begin{array}{c}\begin{array}{c}\text { Crucible llds } \\
1.6 \mathrm{~g} \text { flux }\end{array} \\
800 \mathrm{O}\end{array}$}} \\
\hline & \multicolumn{2}{|c|}{$620 \mathrm{O}$} & \multicolumn{2}{|c|}{$650 \mathrm{O}$} & \multicolumn{2}{|c|}{7000} & \multicolumn{2}{|c|}{7500} & \multicolumn{2}{|c|}{8000} & & \\
\hline & $\begin{array}{l}\text { Fluo- } \\
\text { res- } \\
\text { cence } \\
\text { (divi- } \\
\text { sions) }\end{array}$ & $\begin{array}{l}\text { Pt } \\
\text { micro- } \\
\text { grams }\end{array}$ & $\begin{array}{l}\text { Fluo- } \\
\text { res- } \\
\text { cence } \\
\text { (divi- } \\
\text { sions). }\end{array}$ & $\begin{array}{l}\mathrm{Pt} \\
\text { micro- } \\
\text { grams }\end{array}$ & $\begin{array}{l}\text { Fluo- } \\
\text { res- } \\
\text { cence } \\
\text { (divi- } \\
\text { sions) }\end{array}$ & $\begin{array}{c}\text { Pt } \\
\text { micro- } \\
\text { grams }\end{array}$ & $\begin{array}{l}\text { Fluo- } \\
\text { res- } \\
\text { cence } \\
\text { (divi- } \\
\text { sions) }\end{array}$ & $\begin{array}{c}\text { Pt } \\
\text { micro- } \\
\text { grams }\end{array}$ & $\begin{array}{l}\text { Fluo- } \\
\text { res- } \\
\text { cence } \\
\text { (divi- } \\
\text { sions) }\end{array}$ & $\begin{array}{l}\text { Pt } \\
\text { micro- } \\
\text { grams }\end{array}$ & $\begin{array}{l}\text { Fluo- } \\
\text { res- } \\
\text { cence } \\
\text { (divi- } \\
\text { sions) }\end{array}$ & $\begin{array}{l}\text { Pt } \\
\text { micro- } \\
\text { grams }\end{array}$ \\
\hline & & & & & $\begin{array}{l}46.0 \\
49.5\end{array}$ & $\begin{array}{r}16 \\
7\end{array}$ & $\begin{array}{l}40.0 \\
46.1 \\
44.2\end{array}$ & $\begin{array}{r}6 \\
7 \\
110\end{array}$ & $\begin{array}{l}43.0 \\
40.8 \\
37.8\end{array}$ & $\begin{array}{r}5 \\
10 \\
21\end{array}$ & $\begin{array}{l}45.0 \\
40.0 \\
36.8\end{array}$ & $\begin{array}{r}7 \\
8 \\
13\end{array}$ \\
\hline & & & $\begin{array}{l}36.0 \\
41.5\end{array}$ & $\begin{array}{r}8 \\
18\end{array}$ & 491 & 10 & 410 & 121 & 312 & 34 & 0 & 24 \\
\hline 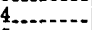 & 42.0 & 4 & 45. 4 & 113 & & & & & & & 20.0 & 24 \\
\hline & 42.5 & 6 & 47.0 & 111 & 47.8 & 12 & 30.0 & 135 & 25.0 & 64 & 22.8 & $\ddot{60}$ \\
\hline$\cdots$ & 48.2 & 11 & & 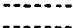 & & & & & & & 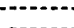 & \\
\hline 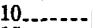 & 48. 2 & 9 & 49.2 & 116 & 45.0 & 40 & 27.4 & 172 & 22.2 & 82 & 19.1 & 74.0 \\
\hline & 52 & 16 & 47.0 & 123 & & & & & & & & \\
\hline
\end{tabular}

1 Fusion in now May dishes. TABLE 13.-Comparison of fluorescence readings for melts fused at $800 \mathrm{C}$ in

[Readings on 0.02 scale with RCA 1P21 photomultiplier tube]

\begin{tabular}{|c|c|c|c|c|c|c|c|}
\hline \multirow{2}{*}{$\begin{array}{l}\text { Total time in } \\
\text { furnace (minutes) }\end{array}$} & \multicolumn{2}{|c|}{ Crucible lfds } & \multirow{2}{*}{$\begin{array}{l}\text { Standard } \\
\text { dish new } \\
\text { study }\end{array}$} & \multirow{2}{*}{$\begin{array}{l}\text { Total time in } \\
\text { furnace (minutes) }\end{array}$} & \multicolumn{2}{|c|}{ Crucible lids } & \multirow{2}{*}{$\begin{array}{l}\text { Standatd } \\
\text { dish nề } \\
\text { study. } \\
<\end{array}$} \\
\hline & $\begin{array}{l}\text { Original } \\
\text { study }\end{array}$ & $\begin{array}{l}\text { New } \\
\text { study }\end{array}$ & & & $\begin{array}{l}\text { Original } \\
\text { study }\end{array}$ & $\begin{array}{l}\text { New } \\
\text { study }\end{array}$ & \\
\hline 1313 & $\begin{array}{l}45.0 \\
32.6 \\
22.7\end{array}$ & $\begin{array}{l}51.0 \\
48.0 \\
43.0\end{array}$ & $\begin{array}{l}39.5 \\
39.5 \\
35.0\end{array}$ & $\begin{array}{l}3 \\
5 \\
10\end{array}$ & $\begin{array}{r}13.7 \\
7.0 \\
4.5\end{array}$ & $\begin{array}{l}31.0 \\
27.5 \\
25.0\end{array}$ & $\begin{array}{r}30.0 \\
+24.0 \\
220\end{array}$ \\
\hline
\end{tabular}

Beside the differences already discussed, examination of figure 8 shows, as would be expected, that the rate of quenching is great: $\mathrm{r}$ when a smaller amount of flux is used. The amounts of platinu角 in the melts in the new tests were about the same for melts fused lids and dishes under corresponding conditions. Whenever differences in platinum content did occur, there was a little mo?e platinum present in the melts fused in dishes.

When the original study was:made, the lids used for the fusions were almost new; they have now been used continuously for 3 years. The continuous use and repeated cleanings of these lids have probably left the vessels less susceptible to attack. This seems to be proved by the fact that analysis of the new melts shows only about half as much platinum in them as found in melts used in the original study.

It is possible that the composition of the platinum in the standard dishes is different from that in the lids because the age of these dishes made no significant difference in the results obtained. Some of the 
dishes used in these tests were new whereas others have been used constantly for about 2 years.

These new data are presented not as a correction to the original study but rather to point out the differences in fluorescence that may occur from time to time even though identical fusion conditions are used. This indicates that such factors as the condition, age, and composition of the platinumware determine to a large extent the amount of platinum going into solution in the melts. The amount of platinum in the melts determines the amount of quenching that occurs and consequently the intensity of fluorescence.

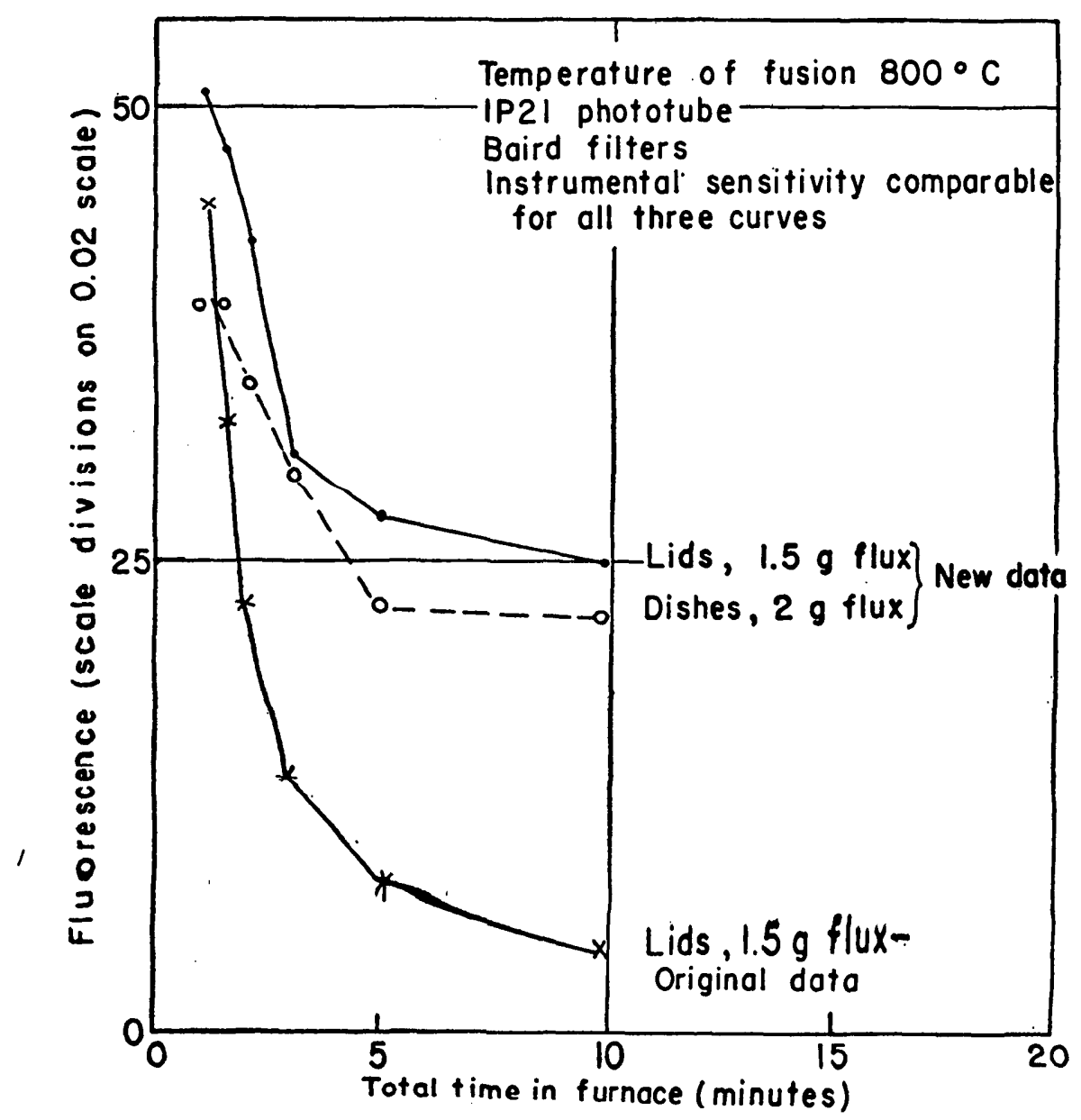

FrodRe 8.-Effect of fusion time and type of platimumware on fluprescence-or standard samples. 


\title{
Part 9. A DIRECT FLUORIMETRIC METHOD FOR THE DETERMINATION OF SMALL AMOUNTS OF URANIUM IN THE FIELD AND LABORATORY
}

\author{
By F. S. Grimaldi, F. N. Ward, and Ruth Kreher Fưat
}

\section{CONTENTS}

Abstract

Introduction

Discussion of the method

Procedure

Results of analyses

Experiments

\section{TABLES}

TABLD 1. Fluorimetric uranium analyses of Florida phosphate samples; comparison of direct and extraction methods . ...........

2. Fluorimetric uranium analyses of northwestern phosphate samples; comparison of direct and extraction methods.........

3. Fluorimetric uranium analyses of black shale samples; comparison of direct and extraction methods.......................

4. Fluorimetric uranium analyses of carnotite samples of the Colorado Plateaus; comparison of direct and extraction

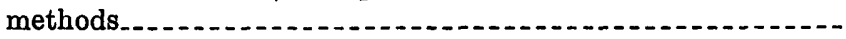

5. Determination of uranium, in percent, to show homogeneity of two samples containing segregated uranium minerals........ -

6. Effect of sample weight in the direct method.....

7. Equivalent fluorescence of elements other than uranium.......

\section{ABSTRACT}

This paper describes a quantitative fluorimetric method to determine sinall amounts of uranium ( 0.001 percent to 0.01 percent on a $3-\mathrm{mg}$ sample) which is useful for field and for laboratory screening. A small solid sample is fused with a fluoride flux, and the fluorescence of the uranium melt is measured photometrically.

The method has been tested on a large number of phosphate rocks, shales, and carnotite-bearing deposits. The results are sufficiently accurate to warrant use of the method for screening purposes.

Nore.-This report was issued as Trace Elements Inv. Rept. 98 and AEOD 2825, 1946. 


\section{INTRODUCTION}

The methods most commonly used for the field estimation of small amounts (from 0.001 to 0.01 percent) of uranium are purely physical. The most important technique is a radiometric method using an instrument such as a portable Geiger counter. As radioactivity measurements do not discriminate between the radioactivity associated with uranium and that due to other elements such as thorium and potassium, it is highly desirable to supplement this method with an independent technique specific for uranium.

Field tests based on the fluorescence of sodium fluoride uranium phosphors have been used; these methods are qualitative in nature and have not been used for the quantitative determination of small amounts of uranium.

The simplest method for the analysis of uranium is to fuse a sample of the rock directly with one of the standard fluoride fluxes and to measure the fluorescence intensity of the resulting melt. This procedure was applied to shales, to other rocks high in silica, and to phosphate rocks from different localities. The reliability of the results obtained by this method was surprisingly good and better than we had anticipated. Although quenching of the uranium fluorescence occurred in many samples, it did not impair seriously the utility of the method for screening purposes. The method should be especially useful either in the field or laboratory for the rapid selection of samples that deserve more refined analyses.

In the laboratory the fluorescence is measured with a Modified Model $R$ fluorimeter described by Fletcher and May in part 10. This instrument may also be used in the field provided an outlet of 110 volts $a-c$ is available. Work is in progress to develop a small portable battery-powered unit so that the instrument will be completely self-contained and independent of an external power source. After this report was issued to the Atomic Energy Commission, a battery-powered fluorimeter was developed by Irving May and Mary Fletcher, and is described in part 13 of this bulletins.

\section{DISCUSSION OF THE METhOD}

The procedure involves a direct fusion of $3.0 \mathrm{mg}$ of sample with $3 \mathrm{~g}$ of flux in a platinum container. This size sample was selected for the following reasons:

1. It may be conveniently weighed in the field with $a$ Roller-smith (5-mg capacity) balance. 


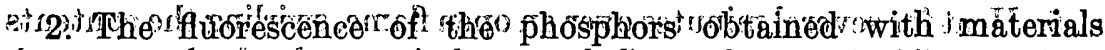

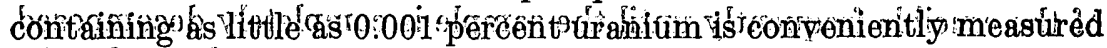

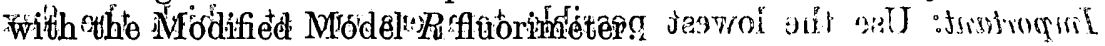

3. This ratio of rock sample to flux was the largest ratio practicable

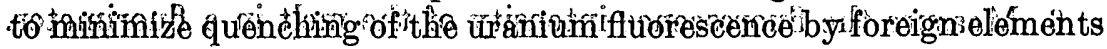
in the sample.

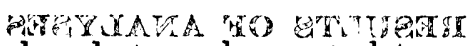

With shales and phosphate rocks ground to -100 mesh, a $3.0-\mathrm{mg}$

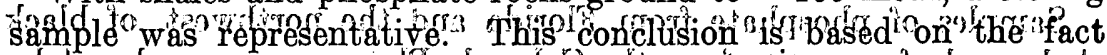
that the results on most of the samples run by this directi methold

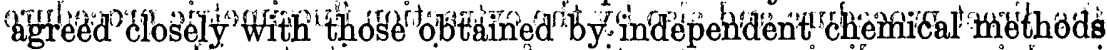

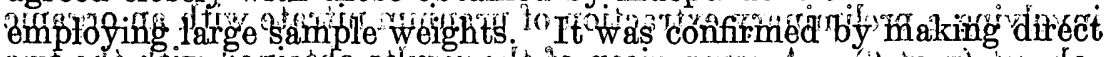

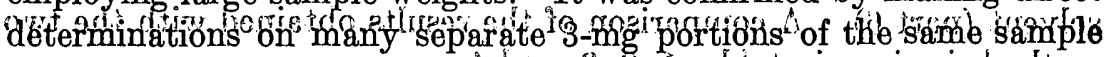

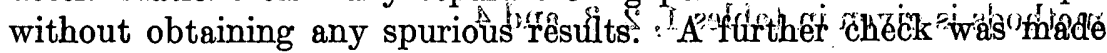
by grinding several large samples very finely and comparing the results on these samplestwith those obtained on the original $-100 \mathrm{mesh}$ material. - These results are consistent-with the fact that no discrete wrianium

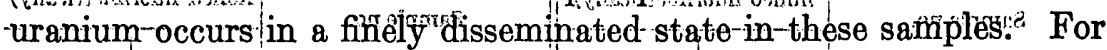
sanples that contain segregated uranitum ininiofrals a satisfactory procedure is to grind a representative $1-\mathrm{g}$ sample to a powder in a mortar before withdrawing the 30 -n' sample for analyses (see p- 74 ahd tablefor). E Severallo elements have been reported as interfering in the-fluori metric procedure by virtue of their of on fluorescence in fluoride meltss These, as: well as several others were tested to determine the -post Sistility of interference in the-direct procedure: Under excitation of

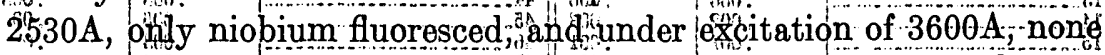
of the eliments tested-showed-tany fifluorescence. These-results ard

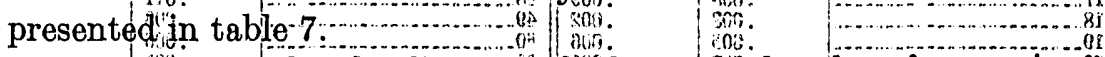

A few anglyses by the-direct-nethód gave high values for uranum For example, the results on-Florid phosphiate samples - $28-a n d-30$ table 1, were significantly higher than those $e^{r}$ obtained-by extraction fluorimetric and radiometric analysess:

1. Grind sample to - -100 mesh and-mix.

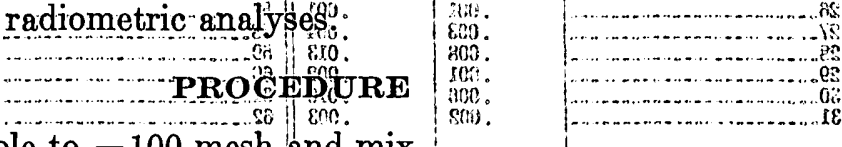

2. Weigh out $3.0 \mathrm{mg}$ of sample and transfer to a $25-\mathrm{ml}$ platinum crucible.

3. Burn off organic matter if present.

4. Add $3 \mathrm{~g}$ of fluoride flux (made by grinding together $9 \mathrm{~g} \mathrm{NaF}$, $45.5 \mathrm{~g} \mathrm{Na}_{2} \mathrm{CO}_{3}, 45.5 \mathrm{~g} \mathrm{~K}_{2} \mathrm{CO}_{3}$ ). 
5. Heat for several minutes over an open flame, swirling the contents of the crucible frequently until the sample is completely decomposed. Important: Use the lowest possible temperature at which the flux remains fluid. Cool.

6. Measure the fluorescence intensity of the melt in a fluorimeter.

\section{RESULTS OF ANALYSES}

Samples of phosphate from Florida and the northwest, of black shale, and of carnotite from the Colorado Plateaus were analyzed by the direct procedure and also by the extraction fluorimetric procedure involving a preliminary extraction of uranium nitrate with an organic solvent (part 6). A comparison of the results obtained with the two methods is given in tables $1,2,3$, and 4 .

TABLE 1.-Fluorimetric uranium analyses of Florida phosphate samples; comparison of direct and extraction methods

\begin{tabular}{|c|c|c|c|c|c|}
\hline \multirow{2}{*}{ Sample no. } & \multicolumn{2}{|c|}{$\begin{array}{l}\text { Percent uranium (deter- } \\
\text { mined fluorimetrically) }\end{array}$} & \multirow{2}{*}{ Sample no. } & \multicolumn{2}{|c|}{$\begin{array}{l}\text { Percent uranium (deter- } \\
\text { mined fluorimetrically) }\end{array}$} \\
\hline & Extraction & Direct & & Extraction & Direct \\
\hline $\begin{array}{l}1 \\
2 \\
3 \\
4\end{array}$ & $\begin{array}{l}0.002 \\
.001 \\
.004 \\
.013 \\
.006 \\
.006 \\
.003 \\
.002 \\
.004 \\
.005 \\
.003 \\
.006 \\
.002 \\
.001 \\
.001 \\
.008 \\
.005 \\
.002 \\
.005 \\
.004 \\
.005 \\
.001 \\
.003 \\
.001 \\
.003 \\
.008 \\
.001 \\
.006 \\
.002\end{array}$ & $\begin{array}{l}0.001 \\
.001 \\
.004 \\
.015 \\
.007 \\
.005 \\
.003 \\
.001 \\
.006 \\
.003 \\
.005 \\
.002 \\
.006 \\
.003 \\
.001 \\
.001 \\
.009 \\
.006 \\
.001 \\
.004 \\
.003 \\
.005 \\
.002 \\
.003 \\
.001 \\
.004 \\
.013 \\
.002 \\
.010 \\
.003\end{array}$ & 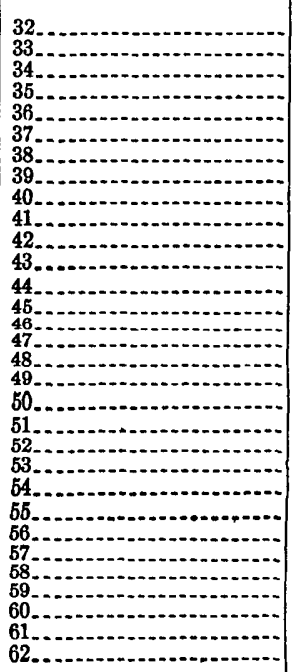 & $\begin{array}{l}0.000 \\
.006 \\
.003 \\
.001 \\
.003 \\
.002 \\
.003 \\
.004 \\
.005 \\
.002 \\
.002 \\
.002 \\
.008 \\
.005 \\
.003 \\
.006 \\
.011 \\
.008 \\
.001 \\
.005 \\
.009 \\
.009 \\
.001 \\
.007 \\
.016 \\
.018 \\
.015 \\
.014 \\
.012 \\
.015\end{array}$ & $\begin{array}{l}0.000 \\
.008 \\
.004 \\
.003 \\
.001 \\
.002 \\
.003 \\
.005 \\
.004 \\
.005 \\
.003 \\
.001 \\
.008 \\
.004 \\
.004 \\
.001 \\
.010 \\
.007 \\
.002 \\
.005 \\
.011 \\
.010 \\
.001 \\
.008 \\
.015 \\
.017 \\
.015 \\
.011 \\
.016\end{array}$ \\
\hline
\end{tabular}


TABLE 2.-Fluorimetric uranium analyses of northwestern phosphate samples; comparison of direct and extraction methods

\begin{tabular}{|c|c|c|c|c|c|}
\hline \multirow{2}{*}{ Bample no. } & \multicolumn{2}{|c|}{$\begin{array}{l}\text { Percent uranium (deter- } \\
\text { mined fluorimetrically) }\end{array}$} & \multirow{2}{*}{ Sample no. } & \multicolumn{2}{|c|}{$\begin{array}{l}\text { Percent uranium (deter- } \\
\text { mined fluorimetrically) }\end{array}$} \\
\hline & Extraction & Direct & & Extraction & Direct \\
\hline 51 & $\begin{array}{l}0.001 \\
.000 \\
.001 \\
.021 \\
.005 \\
.004 \\
.001 \\
.001 \\
.001 \\
.004 \\
.005 \\
.005 \\
.001 \\
.001 \\
.001 \\
.001 \\
.001 \\
.008 \\
.004 \\
.000 \\
.000 \\
.001 \\
.000 \\
.001 \\
.002 \\
.003 \\
.002 \\
.000 \\
.001 \\
.002 \\
.001 \\
.001\end{array}$ & $\begin{array}{l}0.001 \\
.000 \\
.001 \\
.018 \\
.006 \\
.004 \\
.000 \\
.000 \\
.000 \\
.004 \\
.003 \\
.006 \\
.000 \\
.000 \\
.000 \\
.000 \\
.000 \\
.008 \\
.006 \\
.000 \\
.000 \\
.000 \\
.000 \\
.000 \\
.002 \\
.003 \\
.001 \\
.000 \\
.000 \\
.001 \\
.002 \\
.001\end{array}$ & $\begin{array}{l}33 \\
35 \\
36 \\
35 \\
38\end{array}$ & $\begin{array}{l}0.001 \\
.003 \\
.001 \\
.001 \\
.001 \\
.005 \\
.011 \\
.008 \\
.011 \\
.007 \\
.009 \\
.007 \\
.001 \\
.002 \\
.003 \\
.002 \\
.001 \\
.002 \\
.001 \\
.005 \\
.002 \\
.004 \\
.003 \\
.004 \\
.002 \\
.001 \\
.002 \\
.002 \\
.001 \\
.013 \\
.015\end{array}$ & $\begin{array}{l}0.001 \\
.001 \\
.000 \\
.000 \\
.000 \\
.002 \\
.009 \\
.009 \\
.011 \\
.004 \\
.007 \\
.006 \\
.001 \\
.001 \\
.003 \\
.001 \\
.001 \\
.004 \\
.002 \\
.005 \\
.004 \\
.005 \\
.002 \\
.005 \\
.003 \\
.000 \\
.001 \\
.002 \\
.000 \\
.012 \\
.015\end{array}$ \\
\hline
\end{tabular}

TABLE 3.-Fluorimetric uranium analyses of black shale samples; comparison of direct and extraction methods

\begin{tabular}{|c|c|c|c|c|c|}
\hline \multirow{2}{*}{ Sample no. } & \multicolumn{2}{|c|}{$\begin{array}{l}\text { Percent uranium (deter- } \\
\text { mined fluorimetrically) }\end{array}$} & \multirow{2}{*}{ Sample no. } & \multicolumn{2}{|c|}{$\begin{array}{l}\text { Percent uranium (deter- } \\
\text { mined fluorimetrically) }\end{array}$} \\
\hline & Extraction & Direct & & Extraction & Direct \\
\hline $\begin{array}{l}1 \\
2 \\
3\end{array}$ & $\begin{array}{l}0.005 \\
.001 \\
.006 \\
.007 \\
.007 \\
.004 \\
.003 \\
.001 \\
.001 \\
.002 \\
.003 \\
.002 \\
.005 \\
.004 \\
.002 \\
.003 \\
.004 \\
.005 \\
.002 \\
.001 \\
.003 \\
.002 \\
.003 \\
.002 \\
.002 \\
.001 \\
.001\end{array}$ & $\begin{array}{l}0.005 \\
.001 \\
.004 \\
.006 \\
.003 \\
.001 \\
.000 \\
.000 \\
.000 \\
.001 \\
.002 \\
.002 \\
.004 \\
.004 \\
.003 \\
.003 \\
.003 \\
.004 \\
.003 \\
.002 \\
.002 \\
.002 \\
.001 \\
.002 \\
.000 \\
.002\end{array}$ & \begin{tabular}{|l}
29 \\
30 \\
31 \\
32 \\
33 \\
34 \\
36
\end{tabular} & $\begin{array}{l}0.002 \\
.001 \\
.002 \\
.001 \\
.004 \\
.002 \\
.003 \\
.001 \\
.004 \\
.002 \\
.002 \\
.002 \\
.002 \\
.005 \\
.003 \\
.001 \\
.003 \\
.003 \\
.005 \\
.004 \\
.003 \\
.001 \\
.001 \\
.001 \\
.002 \\
.002 \\
.001\end{array}$ & $\begin{array}{l}0.001 \\
.001 \\
.002 \\
.001 \\
.002 \\
.001 \\
.002 \\
.003 \\
.001 \\
.002 \\
.001 \\
.002 \\
.006 \\
.003 \\
.001 \\
.003 \\
.004 \\
.004 \\
.002 \\
.001 \\
.001 \\
.001 \\
.001 \\
.001 \\
.001\end{array}$ \\
\hline
\end{tabular}


TABLE 4.-Fluorimetric uranium analyses of carnotite samples of the Côtorâdo Plateaus; comparison of direct and extraction methods

\begin{tabular}{|c|c|c|c|c|c|}
\hline \multirow{2}{*}{ Sample no. } & \multicolumn{2}{|c|}{$\begin{array}{l}\text { Percent uranium (deter- } \\
\text { mined fluorimetrically) }\end{array}$} & \multirow{2}{*}{ Sample no. } & \multicolumn{2}{|c|}{$\begin{array}{l}\text { Percent uranium (deter- } \\
\text { mined fluorimetrically) }\end{array}$} \\
\hline & Extraction & Direct & & Extraction & Direct \\
\hline 12 & $\begin{array}{l}0.001 \\
.001 \\
.001 \\
.001 \\
.001 \\
.005 \\
.006 \\
.006 \\
.002 \\
.004 \\
.002 \\
.005 \\
.013 \\
.006 \\
.001 \\
.001 \\
.001 \\
.001 \\
.001 \\
.005\end{array}$ & $\begin{array}{l}0.000 \\
.000 \\
.001 \\
.000 \\
.000 \\
.005 \\
.003 \\
.004 \\
.001 \\
.003 \\
.001 \\
.004 \\
.012 \\
.008 \\
.004 \\
.000 \\
.000 \\
.001 \\
.001 \\
.004 \\
.004\end{array}$ & $\begin{array}{l}23 \\
25 \\
26 \\
27 \\
28 \\
29 \\
30 \\
32\end{array}$ & $\begin{array}{l}0.004 \\
.004 \\
.006 \\
.004 \\
.002 \\
.014 \\
.002 \\
.001 \\
.002 \\
.014 \\
.009 \\
.002 \\
.000 \\
.001 \\
.000 \\
.001 \\
.001 \\
.001 \\
.001 \\
.008 \\
.002\end{array}$ & 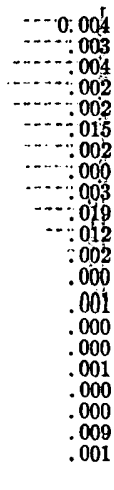 \\
\hline
\end{tabular}

\section{EXPERIMENTS}

Materials containing segregated uranium minerals such as carnotite.A 1-g portion of each of two samples was ground in a mullite mortar and ten 3.0-mg portions of each sample were taken for direct analysis to determine whether a sample prepared in this manner would be homogeneous. Table 5 gives the results obtained. These results indicate that such a procedure yields representative samples.

Effect of sample weight.-Uranium was determined in three samples by the direct method using for each sample weights of $1.88,3.75,7.5$, and $14.0 \mathrm{mg}$. The results shown in table 6 indicate that $3.0 \mathrm{mg}$ as a sample weight is sufficiently small to minimize quenching of the uranium fluorescence.

Fluorescence of other elements in the $\mathrm{NaF}-\mathrm{Na}_{2} \mathrm{CO}_{3}-\mathrm{K}_{2} \mathrm{CO}_{3} \mathrm{flux}$ Salts or oxides of six elements were weighed, ignited, and fused with $3 \mathrm{~g}$ of flux. These discs were read on the fluorimeter, employing excitation of $3600 \mathrm{~A}$. The fluorescence intensities measured were calculated in terms of equivalent percent uranium based on a $3.0-\mathrm{mg}$ sample. As shown in table 7 none of the elements in the amounts tested gave fluorescence intensities distinguishable from a blank. 
TABLE 5.-Determination of uranium, in percent, to show homogeneity of two samples containing segregated uranium minerals

[Samples from the Colorado Plateaus]

\begin{tabular}{r|r||r|r}
\hline Sample no. 1 & Sample no. 2 & Sample no. 1 & Sample no. 2 \\
\hline 0.017 & 0.015 & 0.020 & 0.013 \\
.018 & .014 & .019 & .014 \\
.019 & .012 & .019 & .013 \\
.020 & .014 & .019 & .015 \\
.019 & .016 & .023 & .013 \\
\hline
\end{tabular}

TABLE 6.-Effect of sample weight in the direct method

\begin{tabular}{|c|c|c|c|}
\hline \multirow{2}{*}{ Sample } & \multirow{2}{*}{ Weight (mg) } & \multicolumn{2}{|c|}{ Percent uranium } \\
\hline & & Extraction & Direct \\
\hline Florida phosphate....................... & $\begin{array}{r}1.88 \\
3.75 \\
7.50 \\
14.00 \\
1.88 \\
3.75 \\
7.50 \\
14.00 \\
1.83 \\
3.75 \\
7.50 \\
14.00\end{array}$ & $\begin{array}{r}0.007 \\
.010 \\
.009\end{array}$ & $\begin{array}{l}0.005 \\
.006 \\
.004 \\
.004 \\
.011 \\
.009 \\
.008 \\
.007 \\
.008 \\
.008 \\
.007 \\
.006\end{array}$ \\
\hline
\end{tabular}

TABLE 7.-Equivalent fluorescence of elements other than uranium

\begin{tabular}{|c|c|c|c|c|c|}
\hline Material & $\begin{array}{l}\text { Weight of } \\
\text { oxide (mg) }\end{array}$ & $\begin{array}{c}\text { Equivalent } \\
\text { uranium } \\
\text { (percent) }\end{array}$ & Material & $\begin{array}{l}\text { Weight of } \\
\text { oxide (mg) }\end{array}$ & $\begin{array}{l}\text { Equivalent } \\
\text { uranium } \\
\text { (percent) }\end{array}$ \\
\hline $\begin{array}{l}\mathrm{La}_{2}\left(\mathrm{SO}_{4}\right)_{3} \cdot \mathrm{HH}_{2} \mathrm{O} \\
\mathrm{Ta}_{2} \mathrm{O}_{8} \\
\mathrm{Nb}_{2} \mathrm{O}_{3} \\
\left(\mathrm{NH}_{4}\right)_{2} \mathrm{Ce}\left(\mathrm{NO}_{3}\right)_{8} \cdot 4 \mathrm{H}_{2} \mathrm{O}\end{array}$ & $\begin{array}{r}6.7 \\
15.0 \\
15.0 \\
5.4\end{array}$ & $\begin{array}{r}0.000 \\
.000 \\
.000 \\
.000\end{array}$ & $\begin{array}{l}\mathrm{Nd}\left(\mathrm{NO}_{3}\right)_{3} \cdot 6 \mathrm{H}_{2} \mathrm{O} \\
\mathrm{Y}(\mathrm{NO})_{2} \cdot 6 \mathrm{H}_{2} \mathrm{O} \\
\text { Blank }\end{array}$ & $\begin{array}{r}12.0 \\
8.8 \\
0\end{array}$ & $\begin{array}{r}0.000 \\
.000 \\
.000\end{array}$ \\
\hline
\end{tabular}





\section{Part 10. AN IMPROVED FLUORIMETER FOR THE DETER- MINATION OF URANIUM IN FLUORIDE MELTS}

By Mary H. Fletcher and Irving May

\section{CONTENTS}

Introduction ............ 77

Description of the instrument.

Performance of the instrument.

\section{ILLUSTRATIONS}

Plate 3. Rear-view assembly and expanded details of the modified fluorimeter............ In pocket

Fiadre 9. Complete assembly of the modified fluorimeter......... 79

10. Standardization curves for 3.0-g discs prepared by fusion in

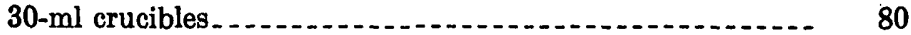

11. Standardization curves for $1.5-\mathrm{g}$ discs prepared by fusion in

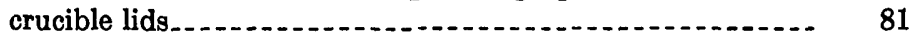

12. Calibration curve for routine work . .

\section{INTRODUCTION}

The Model $R$ fluorimeter has been modified to increase its stability and sensitivity. The new instrument is about 10 times as sensitive as the original fluorimeter, but it can also be employed conveniently at a sensitivity level comparable to or less than that of the Model $R$ fluorimeter.

The Oak Ridge Model $R$ fluorimeter (Coleman, C. F., C-4.381.4, 1946) was in constant use at the Geological Survey for 6 months and proved to be very useful. When it became apparent that a more sensitive and stable instrument would better meet the particular needs of this laboratory, an improved fluorimeter for use in the analysis of low-grade samples was constructed. The new instrument has the following advantages over the Model $R$ fluorimeter:

1. Greater sensitivity.

2. Increased electrical stability.

3. Greater flexibility, by which a wider range of fluorescence can be measured.

Nork.-This report was Issued as Trace Elements Inv. Rept, 120, 1950. 
In the Model $R$ fluorimeter, the ultraviolet lamp is fastened directly to the instrument and there is no provision for cooling, although it is characteristic of high-pressure mercury lamps that their intensity is, among other things, a function of their ambient temperature. As a result, when the instrument is used for 30 to 40 minutes after a 10-minute warmup period, there is a decrease of about 30 . percent in the instrumental sensitivity because of increased lamp temperature. It is, therefore, frequently necessary to turn the lamp off, allow it to cool, and restart it to maintain a usable range of sensitivity. This is not only a time-consuming process, but it is a poor practice inasmuch as such lamps undergo the greatest wear during the starting period. Furthermore, the high operating temperature of the unventilated lamp, as it is used in the Model $R$ instrument, raises the temperature of the phototube and causes a constant drift of the zero of about four or five divisions after each reading. Such a change introduces some uncertainty in the readings. It also necessitates resetting the zero point after each reading.

In the first model of the new fluorimeter, the minimum changes consistent with our requirements were made, and several parts of the Model $R$ instrument were incorporated in the modified fluorimeter. The substitution of the more intense General Electric E-H4 or $\mathrm{C}-\mathrm{H} 4$ lamp in the new instrument increases its sensitivity yet allows the continued use of the Photovolt Electronic Photometer (Model 512). A constant wattage transformer designed for use with $\mathrm{H} 4$ lamps is required. The lamp is supported on a stand and is ventilated by a ventilating fan (obtainable at photographic stores). After a 30minute initial warmup the operating temperature remains constant, and the lamp can be left on all day if desired; furthermore, the phototube remains cool, and most of the drift is eliminated.

A feature of the new fluorimeter is a convenient sensitivity control beyond the 25-percent change in sensitivity possible with the photometer unit. As the lamp is not mounted directly on the instrument, the distance between the lamp and sample may be changed readily. Extra sensitivity control results from the variation in intensity of illumination according to the inverse square law as the distance between the sample and lamp is changed. For instance, with the E-H4 lamp 12 inches above the sample ( $8 \% \frac{1}{2}$ inches above the primary filter) and the photometer unit set for lowest sensitivity, the standard glass supplied with the Model $R$ fluorimeter will give a reading of 1000 . This is about twice the usable sensitivity of the Model $R$ fluorimeter. When the damp 18 moved to within 6 inches of the sample (3 inches from the primary filter), the sensitivity is increased to eight times tho sensitivity of the Model $R$ instrument. For still greater sensitivity a C-H4 lamp is used about $1 \frac{\mathrm{H}}{2} \mathrm{~m}$ inches above the primary filter; this 
arrangement gives a sensitivity about 10 times that of Sthe $^{-1}$ Model $R$ flyorimeter.

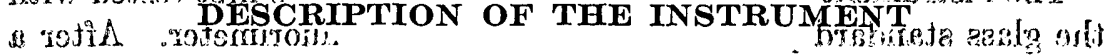

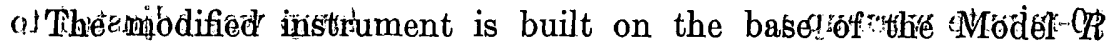

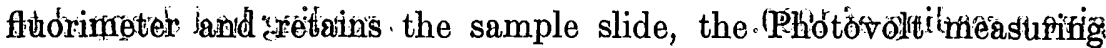

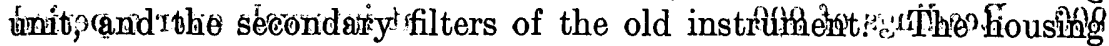

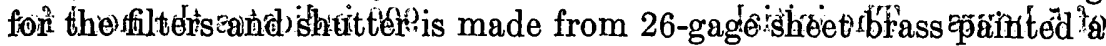

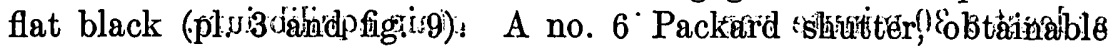

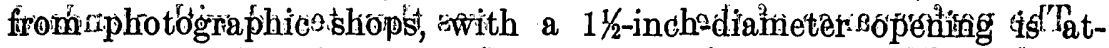

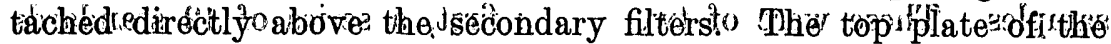

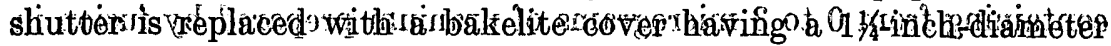
hole in the center. One end of a brass collar is held in this hole by a friction fit, and the other end is threaded to screw directly into the search unit--Alt joints are secure-and-light-tight a The secondary

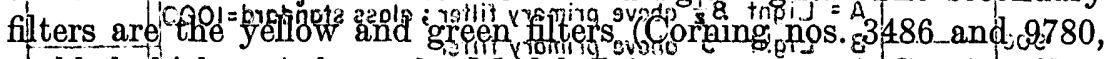
molded thickness) from the Model $k$ oinstraments $=A$ Corning filter no. $5874,3 \%$ inches square, serves as 7 the primary filter. A sheetmetal shield provided_with_air_vents is. placed around the-instrument, and the enclosure is ventilated with a ventilating fan.

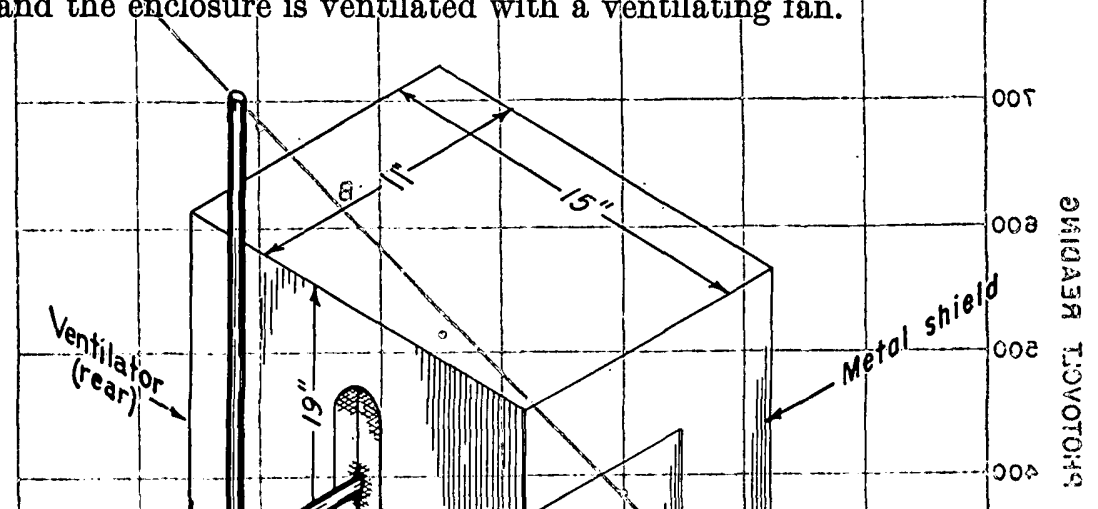

o.

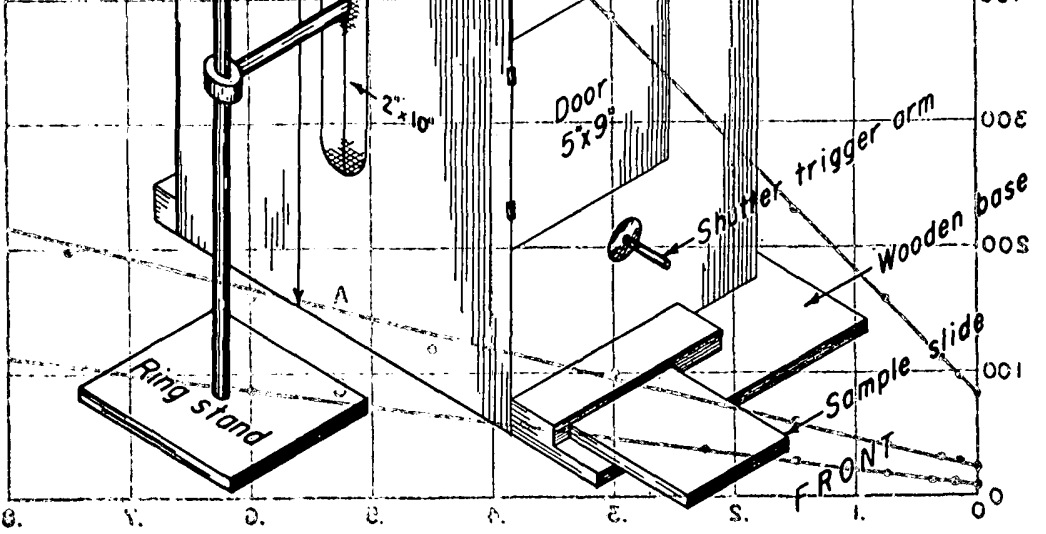

FIaURE 9.tiquopplete, assembly

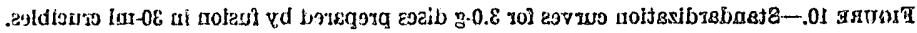




\section{PERFORMANCE OF THE INSTRUMENT}

The instrument equipped with an E-H4 lamp was first tested with the glass standard provided with the Model $R$ fluorimeter. After a 10-minute warmup period the distance of the lamp was adjusted to give a reading of 1000 . After 20 minutes the reading had dropped to 900. Readings of 900 were then obtained at intervals over a period of 5 hours. The initial drop from 1000 to 900 indicates the need for at least a 30-minute warmup period to obtain equilibrium.

The performance of the instrument was then tested with standard samples. These were of two kinds: first, a series of 12 standards containing from 0 to 3 micrograms of uranium prepared by fusion in

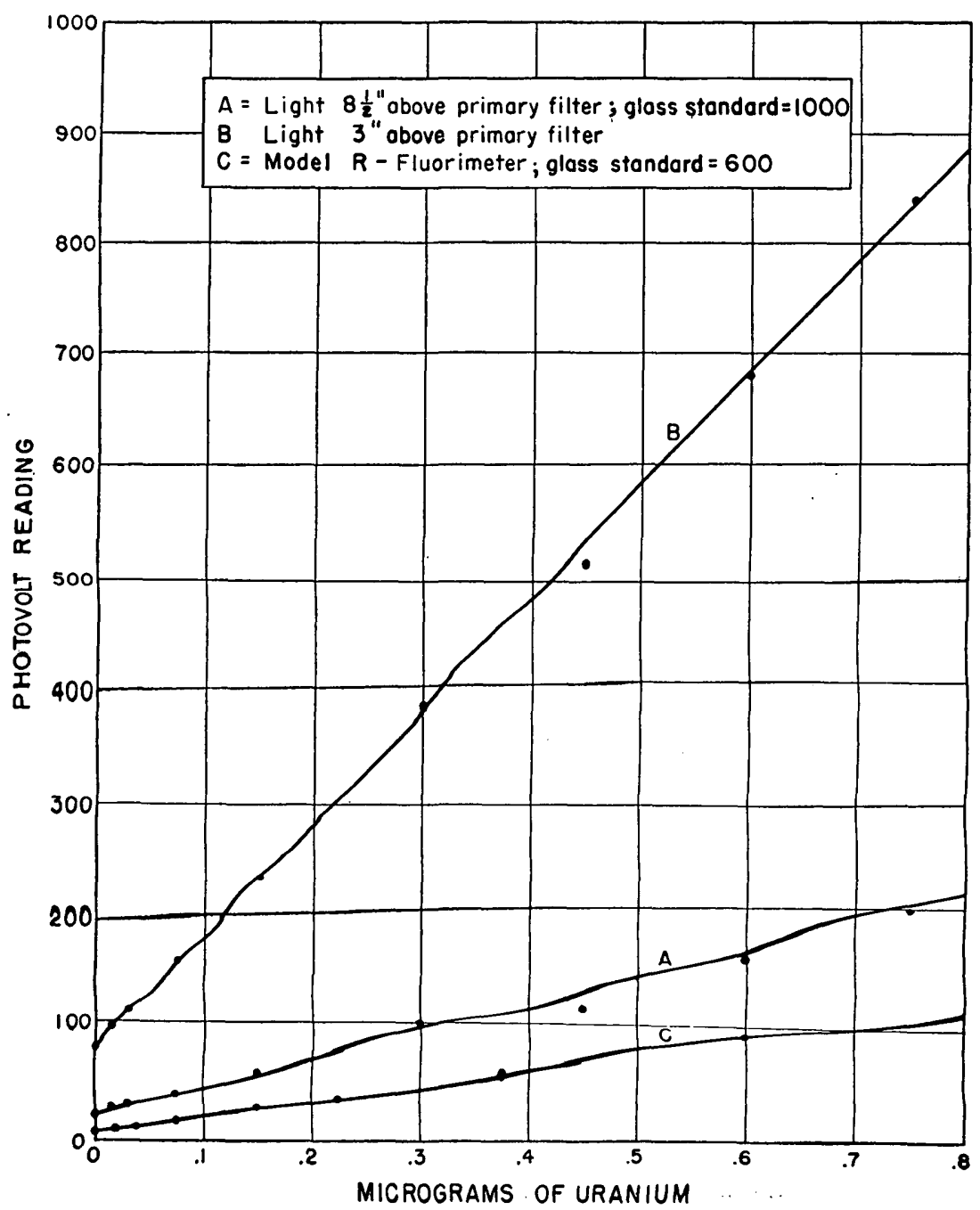

FiguRe 10.-Standardization curves for 3.0-g discs prepared by fusion in 30-ml crucibles. 
30-ml platinum crucibles with 3 grams of fusion mixture; ${ }^{1}$ second, a series of 8 standards containing from 0 to 0.15 microgram of uranium prepared by fusion in platinum lids with 1.5 grams of the same flux. Each of these two sets of standards was read in the instrument with the lamp $81 / 2$ and 3 inches above the primary filter. As many as 10 to 20 discs could be read without resetting the dark current. The curves obtained in these experiments as well as a comparison curve obtained with the Model $R$ fluorimeter are given in figures 10 and 11 .

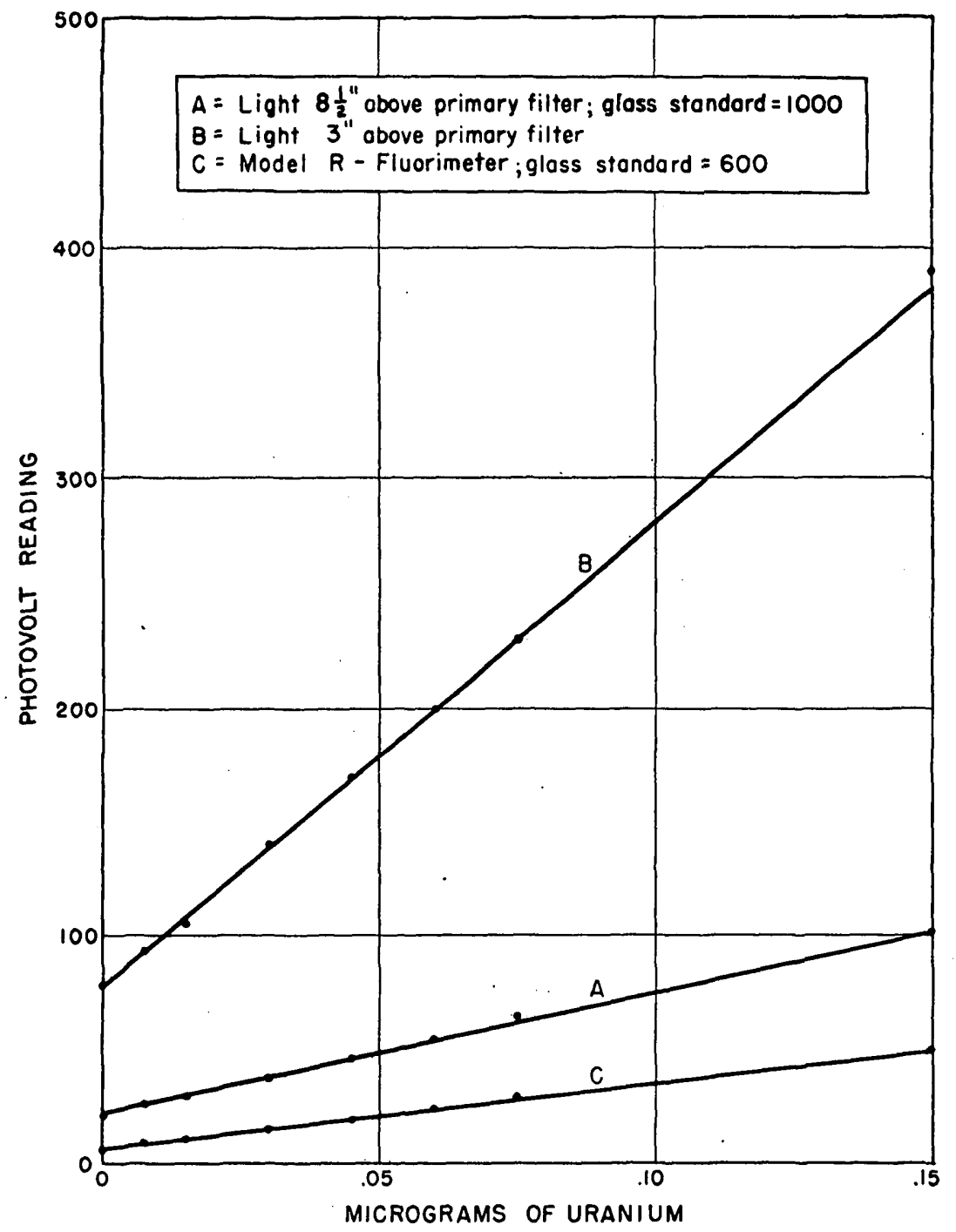

Fiadre 11.-Standardization curves for 1.5-g discs prepared by fusion in crucible lids.

18 percent $\mathrm{NaF}$ in $\mathrm{Na}_{3} \mathrm{CO}_{2}, \mathrm{~K}_{2} \mathrm{CO}_{3}(1+1$ by weight). The pellets were removed from the crucibles be fore the measurements were made. 
The modified fluorimeter has now been in constant use for almost 2 years and has proved to be very satisfactory. However, future models ${ }^{2}$ may incorporate such changes as a different lamp support to give better and easier lamp adjustment, a built-in slide for cutting the intensity of the exciting light, and possibly a different base and sample holder. The photometers can be purchased with additional $2 \mathrm{X}$ and $5 \mathrm{X}$ ranges added to the original "Hi" and "Lo" scales. These new ranges increase the precision for those readings just beyond the range of the Hi scale.

Many of the samples analyzed in this laboratory contain less than 0.02 percent of uranium, and few contain more than 0.04 percent. These determinations are usually made by the method described by Grimaldi and Levine (part 6). An aliquot which contains $3.75 \mathrm{mg}$ of sample is used for the preparation of the phosphors. One of the instruments has been adapted specifically for the convenient handling of these samples.

For this purpose a C-H4 lamp 11/2 inches above the primary filter is the source of exciting light, 'and only 'the Lo scale of' the' photometer is used. Standard curves are drawn to give direct readings in percent of uranium (fig. 12). Curve $A$ (0 to 0.019 percent uranium) was obtained when the glass standard (a Corning polished glass filter, no. 3384 , melt $600,{ }^{3} 2$ inches square, masked down to a 0.8 -inchdiameter circle) read 80 divisions; in this curve one scale division is equivalent to 0.00022 percent uranium. For curve $B$ (0 to 0.066 percent uranium) the intensity of the exciting light was cut down by interposing 2 nichrome gauze squares between the lamp and the instrument. With this arrangement the glass standard read 25 divisions, and one scale division was equivalent to 0.00068 percent uranium. Once the curves are prepared, it is necessary only to set the instrument to give the proper reading with the glass standard. Occasional checks of the curve are made with uranium standards, particularly when a new batch of flux is used

\footnotetext{
8 New models have been construeted but when this bulletin was sent to the printer descriptions and shop drawings of them were not yet avallable.

- Different melts of fliters bearing the same number vary grontly in fuorescence. No. 3384 flters purchased in recent years have shown very little fluorescence and cannot be used as glass standards.
} 
CURVE B, PERCENT URANIUM IN A 3.75-mg ALIQUOT

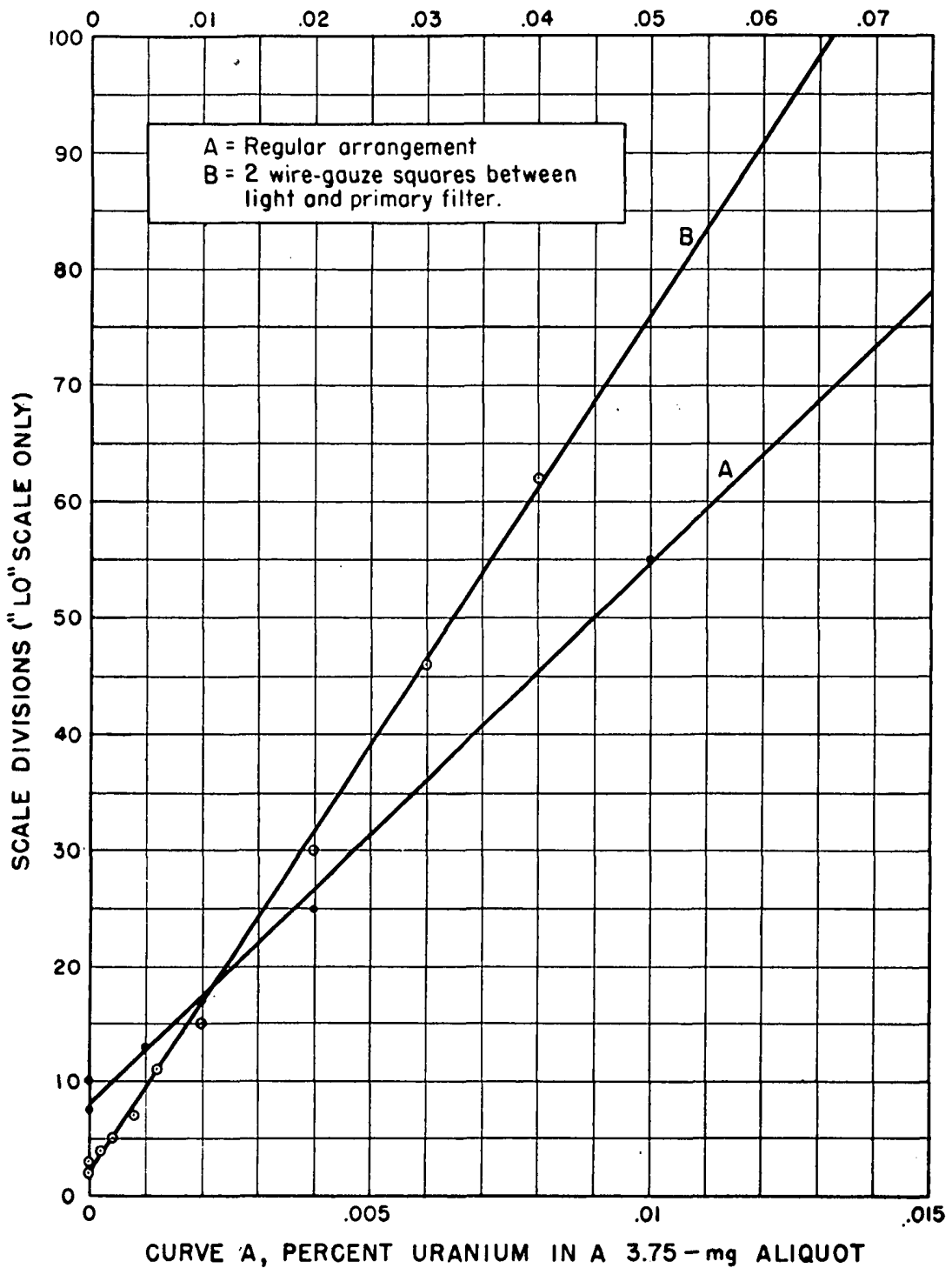

Figure 12.-Calibration curve for routine work. 



\title{
Part 11. A TRANSMISSION FLUORIMETER FOR USE IN THE FLUORIMETRIC METHOD OF ANALYSIS FOR URANIUM
}

\author{
By Marí H. Fletcher, Irving May, and Morris Slavin
}

\section{CONTENTS}

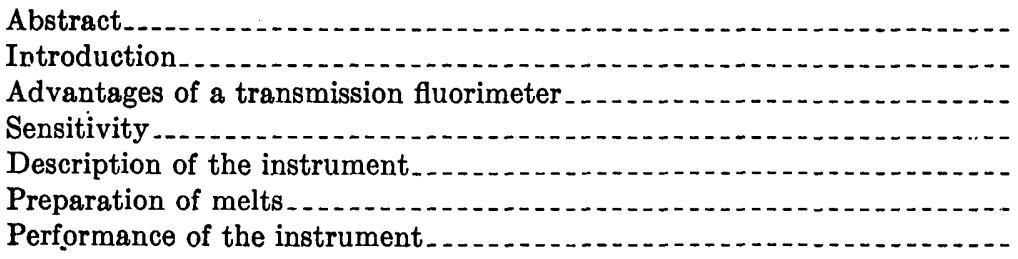

\section{ILLUSTRATIONS}

FraUre 13. Schematic diagram of a "reflection"-type fluorimeter.

14. Schematic diagram of a transmission-type fluorimeter......-

\section{TABLES}

TABLE 1. Effect of melt thickness on instrument response . .

2. Performance of the "pick-up" units ... 91

3. Readings of replicate blank samples......... 92

4. Readings of replicate standard samples........ 92

5. Replicate analyses of standard sample GST-1

\section{ABSTRACT}

A fluorimeter has been built which measures fluorescence by transmission rather than by the usual "reflection" methods. The consequence of the adoption of this new principle is a large gain in simplicity, compactness. ruggedness, sensitivity, cheapness of construction, and efficient use of light energy.

When used with an uncooled 1P21 photomultiplier tube operated at 50 volts per stage and a d-c amplifier, the instrument has a sensitivity of one scale division equivalent to $1.7 \times 10^{-10} \mathrm{~g}$ of uranium in $1.5 \mathrm{~g}$ of flux. However, in practice the lower limit is set by the blank reading. As a consequence of compactness and compartmentalization, stray light, which contributes to this blank reading, is reduced to a very small amount.

Reproducibility is such that a few thousandths of 1 percent of uranium can be determined on a $\mathbf{0 . 0 5}-\mathrm{mg}$ sample with an error of about 5 percent of the amount present.

Efficiency of light use is so great that commercial photometers using simple phototubes may be substituted for the photomultiplier tube and $\mathrm{d}-\mathrm{c}$ amplifier.

NoTE.-This report was'issued as."Trace Elements Inv. Rept. 104, 1949. 


\section{INTRODUCTION}

Fluorescence of solids of the type exemplified by the alkali carbonate-fluoride melts used in the fluorimetric determination of uranium is generally measured by irradiating the surface of the melt with ultraviolet light and picking up the fluorescent light from the same surface by means of a phototube. A typical arrangement is shown schematically in figure 13. The Argonne fluorimeter, ${ }^{12}$ the Oak Ridge Model $R$ fluorimeter, ${ }^{3}$ and others are based on this principle.

In the transmission fluorimeter, by way of contrast, the lamp and phototube are on opposite sides of the melt. Figure 14, is a schematic drawing of this arrangement. Transmission measurements were probably overlooked by earlier workers because they considered their melts opaque, because of mechanical difficulties in the removal of the inelts from the containers in which they had been fused, or simply

$$
\text { Q.8 }
$$

06

18

28

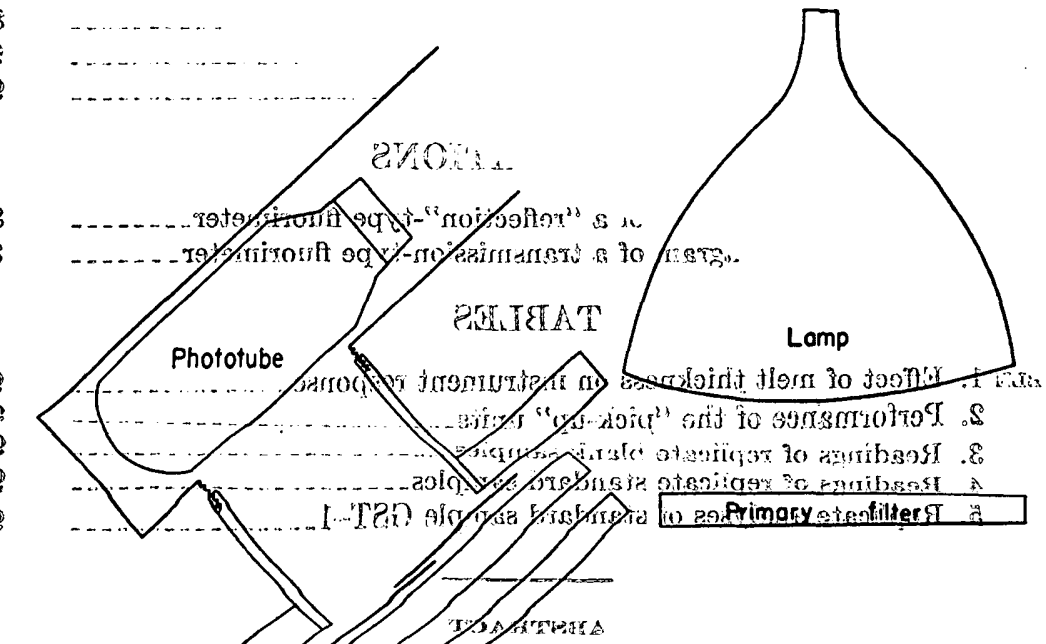

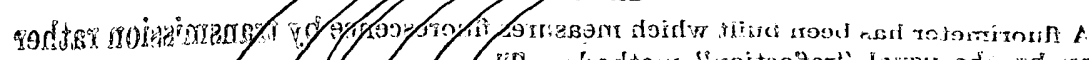

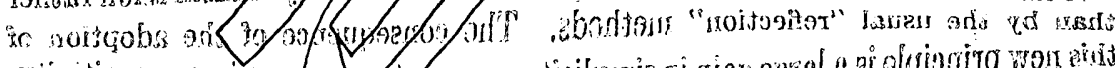

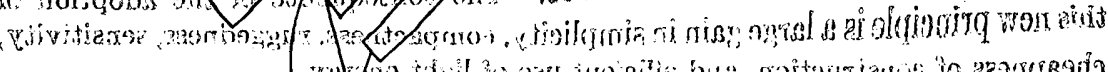

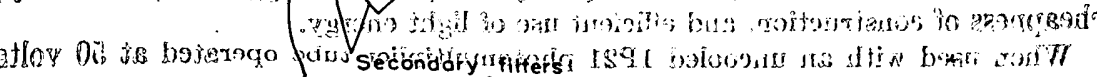

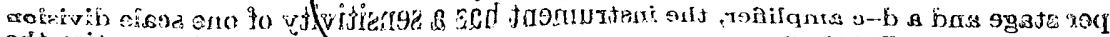

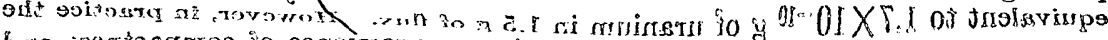

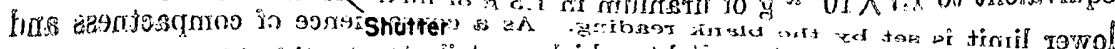

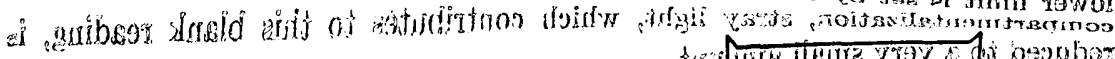

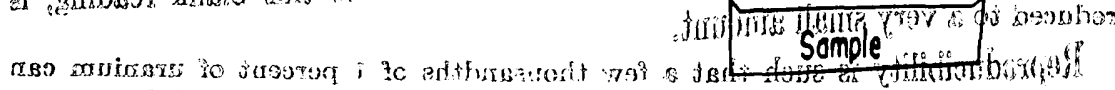

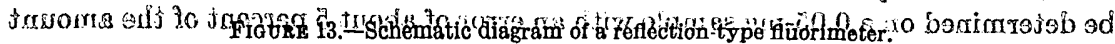
. Iraseng

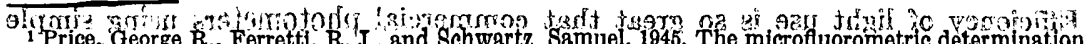
1 Price, Ceorge $\mathbf{R}$ Ferretti, $\mathbf{R}$, J., and Schwart 2 , Samuel, 1945, The microfuorometric determination 0 urantum. AEED-2282.

2 Price, G. R., Ferretti, R. J., and Schwartz, 8., 1948, ANL-4113.

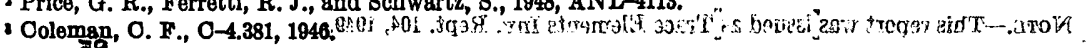
दै 
because the other system worked satisfactorily. Transmission methods are entirely feasible because tests have shown that the melts are translucent, not opaque and that proper choice of a fusion mixture gives a melt which is easily removable from its container and strong enough to be handled.

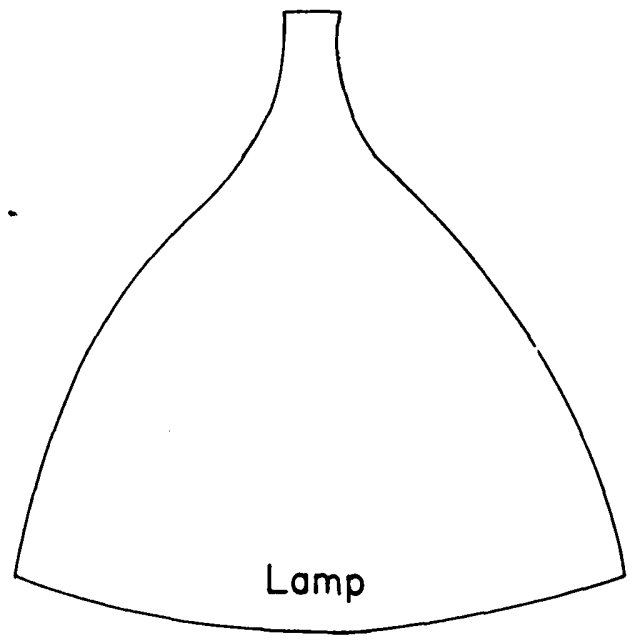

Primary filter
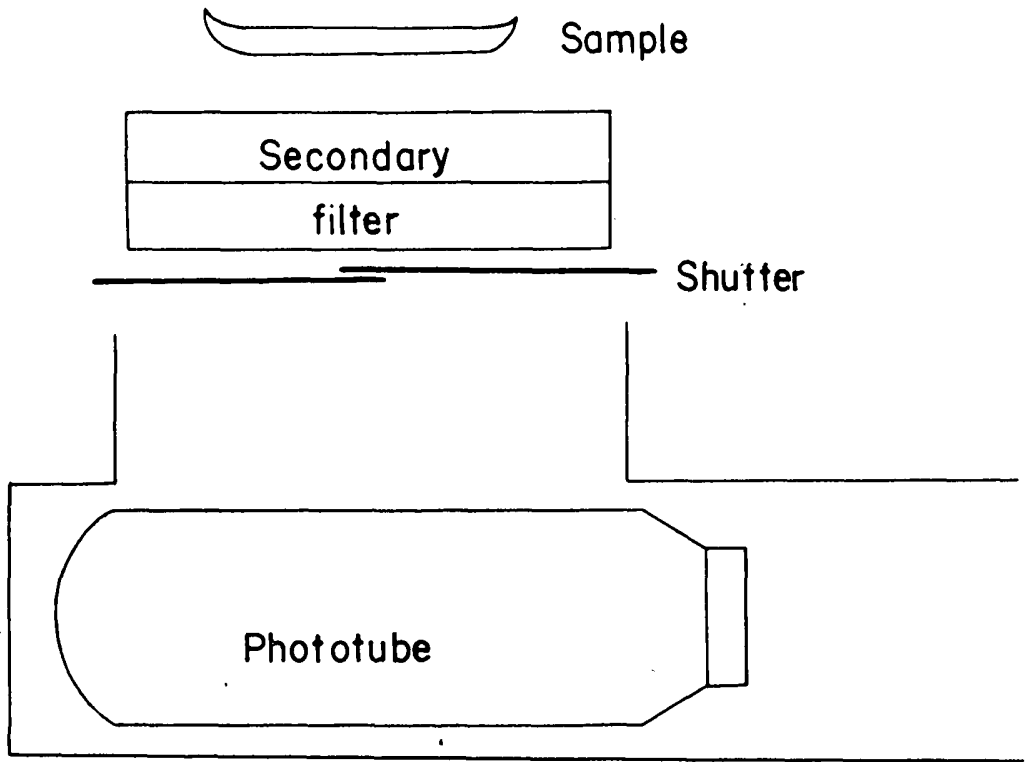

FroUki 14.-Schematio diagram of a transmission-type fluorimeter. 


\section{ADVANTAGES OF A TRANSMISSION FLUORIMETER}

Compactness and simplicity are the first and obvious advantages of an instrument based on the transmission principle. The linear arrangement of parts, with the ultraviolet source and phototube on opposite sides of the sample, makes it possible to bring both the ultraviolet light and the phototube very close to the sample. Thus maximum use is made of the exciting light, and a relatively large part of the transmitted fluorescence reaches the phototube. This is an efficient arrangement that greatly reduces losses in light intensity due to the inverse square law.

When a sample is in position in the transmission fluorimeter, 95 to 98 percent of the initial ultraviolet light is reflected upward from the surface of the sample. Of the remaining 2 to 5 percent, about eighttenths is absorbed; consequently, not more than 0.5 to 2 percent of the original exciting radiation can pass to the lower part of the instrument where it might cause stray fluorescence. This results in a low instrument blank. In contrast to this, the entire inner surface of a simple reflection fluorimeter (one without an optical system) is irradiated by the full intensity of the exciting light, and the inner surface is very large in comparison to that of the transmission fluorimeter. In a reflection fluorimeter, the reading obtained for a blank melt corresponds to the fluorescence of the melt plus about an equal or greater response from the instrument itself. But in a transmission fluorimeter the reading obtained for a blank melt is due almost wholly to the melt alone.

Simplicity of the instrument results in ruggedness and cheapness of construction. There are no lenses or mirrors and no need for delicately adjusted parts.

\section{SENSITIVITY}

The sensitivity of the Argonne and Oak Ridge fluorimeters, as well as the one described here, is such that all give a measurable blank reading. Consequently it is meaningless to express limiting sensitivity in such terms as galvanometer deflection per unit weight of uranium, for it is the blank which limits further improvement, not inefficiency of exciting light nor insensitivity of phototube. The main factors contributing to the blank are impure flux, fluorescent or leaky filters, and stray light in the instrument. The first is a chemical problem in purification of reagents; the second is a problem for the filter makers; only the third is amenable to reduction by good design of instrument. The transmission fluorimeter, therefore, with its compact linear arrangement of parts and consequent very low stray light, is inherently very sensitive. 


\section{DESCRIPTION OF THE INSTRUMENT}

The Model II transmission fluorimeter described in this paper was designed to give maximum flexibility for research purposes and is intended as an intermediate model. More specifically, all filters are readily removable and exchangeable, the exciting light is on a sepate stand so that lamps may be interchanged, and the "pick-up" units of different measuring devices are in separate and identical housings that are threaded to screw into the bottom of the fluorimeter proper. Future models will not require this amount of flexibility and will undoubtedly be more compact; also, there are obvious changes that will be necessary. For example, the Model II as built was not as light tight as later proved to be necessary so that masking tape had to be used around the joints and extra light traps were added to prevent light leakage around the front and back shutter rods.

The basic design of the instrument resembles a miniature chest of drawers. The housing is made of brass and the drawers of maple and brass. The uppermost drawer carries the primary or ultraviolet filters; the middle drawer contains a disc of nonfluorescing glass over the bottom aperture and is equipped with an adaptor to hold the sample; the lower drawer holds the secondary filters.

The filter combination finally adopted for general use consists of two Corning No. 5874 2-inch polished squares as the primary filters, and a 2-inch square interference filter peaked at 5550A for the secondary. The exciting light is furnished either by a General Electric $\mathrm{C}-\mathrm{H} 4$ or E-H4 lamp. Lamp voltages are regulated by a constant wattage transformer specifically designed for use with the $\mathrm{H}-4$ lamps. Temperature of the lamps is controlled by ventilation with a darkroom ventilating fan.

The measuring devices are either a photometer equipped with a simple phototube, or a 1P21 photomultiplier tube in combination with a d-c amplifier. Voltage for the 1P21 photomultiplier tube is supplied by a regulated power supply with voltage divider of conventional design. The d-c amplifier design is slightly modified from that used by Schulman, Battey, and Jelatis, ${ }^{4}$ with their polarograph and is based on the fundamental design of Roberts. ${ }^{5}$

The modification consists in deletion of the circuit for applied voltage, reversal of polarity, and appropriate changes in the sensitivity ranges.

( Schulman, J. H., Battey, Bruce H., and Jelatis, D. G., 1947, A new polarograph: Rev. Sci. Instruments, v. 18, p. 226-231.

- Roberts, Shepard, 1939, A feedback micromicroammeter: Rev. Sci. Instruments, v. 10, p. 181-183.

$268681-54-7$ 


\section{PREPARATION OF MELTS}

The fusion mixture used for the preparation of the melts is that described by Grimaldi and Levine (part 6) and consists of 9 percent sodium fluoride in equal parts by weight of sodium carbonate and potassium carbonate. This mixture melts at a little below $650 \mathrm{C}$ and shrinks slightly on cooling so that the melt pulls away from its container. The melts are strong and can be handled without danger of breaking. The fusion mixture is prepared by fusing several $100-\mathrm{g}$ portions which are then ground and mixed. This procedure was necessary to obtain a uniform mixture that would give reproducible blanks. Melts were prepared by fusion of $1.5 \mathrm{~g}$ of this mixture in platinum lids from $30-\mathrm{ml}$ crucibles. The fusions were made in a furnace at $650 \mathrm{C}$.

Although, as might have been expected, fluorescence varies inversely with thickness of the melt, these variations of thickness present no practical difficulties. Standard size lids are chosen for the fusions, hence, the weight of the flux controls the thickness. Differences in weight as large as $5 \mathrm{mg}$ introduce an error in the fluorescence reading of only 0.2 percent. Variations in thickness with weight and the corresponding changes in the instrument response are given in table 1. It should be stressed that even relatively thick melts are translucent. Also the greatest sensitivity occurs with the thinnest melts. This could be predicted from mathematical considerations.

TABLE 1.-Effect of melt thickness on instrument response

[Measurements made with the 1P21 photomultiplier tube and d-c amplifler]

\begin{tabular}{|c|c|c|c|c|}
\hline \multirow{2}{*}{ Weight of flux (grams) } & \multirow{2}{*}{$\begin{array}{l}\text { Thickness of } \\
\text { melt (inches) }\end{array}$} & \multicolumn{2}{|c|}{$\begin{array}{l}\text { Scale divisions }(0,02 \\
\text { scale) }\end{array}$} & \multirow{2}{*}{$\begin{array}{l}\text { Sensitivity } \\
\text { (microgram } \\
\text { of uranium } \\
\text { per scale } \\
\text { division) }\end{array}$} \\
\hline & & $\underset{\text { ing }}{\text { Blank read- }}$ & $\begin{array}{l}0.003 \text { micro- } \\
\text { gram of } \\
\text { uranium }\end{array}$ & \\
\hline $\begin{array}{l}0.5 \\
1.0 \\
2.0 \\
2.50\end{array}$ & $\begin{array}{r}0.017 \\
.027 \\
.040 \\
.049 \\
.058 \\
.070\end{array}$ & $\begin{array}{l}21.8 \\
20.8 \\
20.4 \\
22.5 \\
20.6 \\
18.6\end{array}$ & $\begin{array}{l}43.5 \\
40.4 \\
38.0 \\
36.5 \\
33.6 \\
29.8\end{array}$ & $\begin{array}{r}0.000138 \\
.000153 \\
.000171 \\
.000214 \\
.000231 \\
.000268\end{array}$ \\
\hline
\end{tabular}

It is difficult to cover the lids evenly with 0.5 to $1.0 \mathrm{~g}$ of flux, and for this reason $1.5 \mathrm{~g}$ was the most convenient to use. The larger amount of flux will also allow for the presence of larger amounts of quencher elements, as Prico has shown that tho ratio weight of quencher to weight of flux is the important factor in quenching phenomena.

o Price, George R., Ferretti, R. J., and Scbwartz, Samuel, 1945, The microfluorometric determination of uranium: AECD-2282. 


\section{PERFORMANCE OF THE INSTRUMENT}

A standard curve is obtained by measuring a series of melts which contain known amounts of uranium. At the same time a reading is made with no sample in place. This reading is called the "standard deflection" and represents filter leakage or fluorescence and is a constant of the instrument. Once a standard curve has been drawn, the conditions under which it was made can be reproduced by adjusting the voltage applied to the phototube, or the distance of the lamp to give this standard deflection. The uranium content of unknown is obtained by interpolation in the standard curve.

The performance of the instrument with two different pick-up units, the photomultiplier tube with the $d-c$ amplifier and the Photovolt photometer (no. 512) with a "C" search unit, is shown in table 2. It will be seen from the table that the two may be used for the same amounts of uranium. However, the Photovolt photometer is operated at capacity but the more elaborate system of a 1P21 photomultiplier tube and $\mathrm{d}-\mathrm{c}$ amplifier still has a large reserve of unused sensitivity. For instance, if the voltage per stage were increased from 50 to 100 the amplification would be increased about one hundredfold.?

TABLE 2.-Performance of the "pick-up" units

\begin{tabular}{|c|c|c|c|c|c|}
\hline Lamp type & $\begin{array}{c}\text { Lamp dis- } \\
\text { tance } \\
\text { (inches) }\end{array}$ & "Pick-up" unit & $\begin{array}{l}\text { Volts } \\
\text { per } \\
\text { stage }\end{array}$ & $\begin{array}{l}\text { Blank } \\
\text { reading } \\
\text { (scale } \\
\text { div.) }\end{array}$ & $\begin{array}{l}\text { Sensitivity } \\
\text { (microgram } \\
\text { equivalent } \\
\text { to one div.) }\end{array}$ \\
\hline C-H4 & $\mathbf{1}$ & $\begin{array}{l}\text { Photovolt unit. } \\
\text { 1P21 d-c amplifier... }\end{array}$ & 45 & $\begin{array}{l}222.0 \\
220.0\end{array}$ & $\begin{array}{l}10.00015 \\
\quad .000171\end{array}$ \\
\hline
\end{tabular}

11 scale.

0.02 scale.

The sensitivity of the instrument with either pick-up unit is roughly equivalent to that of the Argonne instrument, although the available data are insufficient to make an exact comparison. However, Price ${ }^{8}$ operated his photomultiplier tube at 80 volts per stage (compared to 50 volts in this instrument) and used dry-ice cooling for the phototube.

Results obtained with the transmission fluorimeter are shown in tables 3,4 , and 5 . The $\mathrm{E}-\mathrm{H} 4$ lamp was used at a distance of 3 inches from the primary. filter, and volts per stage on the 1P21 tube were 50. The scale setting with no melt in the holder was 46.0 divisions on the 0.02 scale.

\footnotetext{
I Engstrom, Ralph W., 1947, Multiplier phototube characteristics; application to low light levels: Jour. Optical Soc. Am., vol. 37, p. 421.

B Price, G. R., Ferretti, R. J., and Schwartz, S., 1948, ANL-4113.
} 
The data in these tables show that performance of the instrument is adequate for analytical purposes. The errors are no greater than those inherent in the chemical manipulations of sampling, weighing, and pipetting that precede the photometry of the fluorescence.

TABLE 3.-Readings of replicate blank samples

\begin{tabular}{|c|c|c|c|c|c|}
\hline - Sample no. & $\begin{array}{c}\text { Scale } \\
\text { divisions } \\
(0.02 \text { scale })\end{array}$ & $\begin{array}{l}\text { Deviation } \\
\text { from mean }\end{array}$ & Sample no. & $\begin{array}{c}\text { Scale } \\
\text { divisions } \\
\text { (0.02 scale) }\end{array}$ & $\begin{array}{l}\text { Deviation } \\
\text { from mean }\end{array}$ \\
\hline \multirow{2}{*}{ 3 } & $\begin{array}{r}21.0 \\
22.0 \\
21.0 \\
21.5 \\
20.1\end{array}$ & $\begin{array}{r}0.2 \\
1.2 \\
.2 \\
.7\end{array}$ & 9 & $\begin{array}{r}20.0 \\
20.2 \\
21.1 \\
20.9 \\
\end{array}$ & $\begin{array}{r}0.8 \\
.6 \\
.3 \\
.1 \\
\end{array}$ \\
\hline & 20.2 & .6 & Mean. & 20.8 & .54 \\
\hline
\end{tabular}

TABLE 4.-Readings of replicate standard samples

[Uranium content $=0.005$ microgram]

\begin{tabular}{|c|c|c|c|c|c|}
\hline Sample no. & $\begin{array}{c}\text { Scale } \\
\text { divisions } \\
(0.05 \text { scale })\end{array}$ & $\begin{array}{l}\text { Deviation } \\
\text { from mean }\end{array}$ & Sample no. & $\begin{array}{c}\text { Scale } \\
\text { divisions } \\
(0.05 \text { scale })\end{array}$ & $\begin{array}{l}\text { Deviation } \\
\text { from mean }\end{array}$ \\
\hline \multirow{2}{*}{ 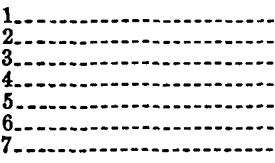 } & \multirow{2}{*}{$\begin{array}{l}20.5 \\
19.9 \\
20.9 \\
20.8 \\
20.8 \\
20.7 \\
21.0\end{array}$} & \multirow{2}{*}{$\begin{array}{r}0.3 \\
.9 \\
.1 \\
.0 \\
.0 \\
.1 \\
.2\end{array}$} & \multirow{2}{*}{$\begin{array}{r}\text { Mean. } \\
\text { Blank. }\end{array}$} & $\begin{array}{l}21.2 \\
21.0 \\
21.0\end{array}$ & $\begin{array}{r}0.4 \\
.2 \\
.2\end{array}$ \\
\hline & & & & $\begin{array}{r}20.8 \\
8.1\end{array}$ & 1. 24 \\
\hline
\end{tabular}

10.24 scale divisions on 0.05 scale is equivalent to 0.6 scale divisions on 0.02 scale. The ratio of the 0.02 scale to the 0.05 scale is $1: 2.5$.

TABLE 5.-Replicate analyses of standard sample GST-1 (Uranium content $=0.009$ perçent)

[100-microgram aliquots of sample]

\begin{tabular}{|c|c|c|c|c|c|}
\hline Replicate no. & $\begin{array}{c}\text { Oranium } \\
\text { (micro- } \\
\text { grams and } \\
\text { percent) }\end{array}$ & $\begin{array}{l}\text { Deviation } \\
\text { from mean }\end{array}$ & Replicate no. & \begin{tabular}{|c} 
Uranium \\
(micro- \\
grams and \\
percent)
\end{tabular} & $\begin{array}{l}\text { Deviation } \\
\text { from mean }\end{array}$ \\
\hline \multirow[t]{2}{*}{$\begin{array}{l}1 \\
2 \\
3 \\
4 \\
6\end{array}$} & \multirow[t]{2}{*}{$\begin{array}{l}0.0085 \\
.0085 \\
.0088 \\
.0088 \\
.0088 \\
.0088 \\
.0091\end{array}$} & \multirow[t]{2}{*}{$\begin{array}{l}0.0002 \\
.0002 \\
.0001 \\
.0001 \\
.0001 \\
.0001 \\
.0004\end{array}$} & \multirow[t]{2}{*}{$\begin{array}{r}10 \\
11 \\
9 \\
\quad \text { Mean }\end{array}$} & $\begin{array}{r}0.0086 \\
.0081 \\
.0086 \\
.0088 \\
.0088 \\
\end{array}$ & $\begin{array}{l}0.0001 \\
.0006 \\
.0001 \\
.0001 \\
.0001\end{array}$ \\
\hline & & & & .0087 & .00018 \\
\hline
\end{tabular}




\section{Part 12. THE DESIGN OF THE MODEL V TRANSMISSION FLUORIMETER}

By Mary H. Fletcher, Irving May, and Joseph W. Anderson

\section{CONTENTS}

Abstract

Introduction

Acknowledgments

\section{ILLUSTRATIONS}

Plate 4. Fluorimeter assembly

[In pocket]

5. Cutaway view, cross section, and details of parts of "fluorimeter"

6. Details of parts of fluorimeter assembly shown in plate 4

7. Details for construction of shield

8. Details for construction of type- $B$ phototube housing

\section{ABSTRACT}

A transmission fluorimeter for the measurement of the fluorescence of uranium in fluoride melts is described. The instrument incorporates several improved features that have not been published previously. Unlike the earliest models, the design of the new fluorimeter, with its close machining of parts, reduces the possibility of light leakage and also increases considerably the ease with which the various components of the instrument may be assembled and adjusted. The Model $\mathrm{V}$ fluorimeter is a very rugged instrument with a compact arrangement of parts. It possesses great flexibility so that various phototubes, measuring devices, light sources, and filter combinations may be used interchangeably.

Detailed shop drawings are given for the construction of the fluorimeter.

\section{INTRODUCTION}

The use of transmission fluorimeters for the measurement of the fluorescence of uranium in fluoride melts has been discussed in other papers (parts $8,11,13)^{1}$

The Model II fluorimeter was described (parts 8 and 11) without detailed drawings inasmuch as it was an experimental model.

Note.-This report was issued as Trace Elements Inv. Rept. 133, 1950.

1 May, Irving, and Fletcher, Mary H., 1948, A preliminary report on a transmission fluorimeter: U. 8. Geol. Survey (unpublished report) 
Newer models have been built, and the Model V instrument described in this paper incorporates the various improved features of these instruments. No further marked changes in design are contemplated, and therefore we are presenting detailed drawings of the instrument.

Like earlier models, the Model $\mathrm{V}$ was designed to be a sturdy, light-tight instrument, having compact arrangement of parts and great flexibility. Various phototubes, measuring devices, light sources, and filter combinations may be used interchangeably. The chief difference between the two fluorimeters is that the Model II is rectangular whereas the Model $\mathrm{V}$ is cylindrical.

For clarity the word "fluorimeter," in quotation marks, as used in this paper refers to that part of the complete fluorimeter that houses the filters, sample slide, and shutter.

The Model V "fluorimeter" is machined from solid brass. The "fluorimeter" head includes the sample slide, shutter, and a holder for the primary filters. The sample slide is provided with adaptors so that several sizes of fluoride melts may be accommodated. The secondary filters are in the bottom plate which screws into the "fluorimeter" head. The bottom plates are of two types- $A$ and $B$. Type $A$ is used with an RCA 1P21 photomultiplier tube or with the Photovolt Electronic Photometer (Model 512). It is threaded to fit the Photovolt search unit. Housings for the 1P21 photomultiplier tubes have the same thread as the search unit so that either phototube can be used with the type- $A$ plate. The type- $A$ plate is constructed so that phototube housings can be removed or installed while the "fluorimeter" is in position on the supporting stand. The type- $B$ bottom plate is used with the RCA 5819 photomultiplier tube. The Cinch no. 3M14 socket with mounting ring 3R14 is used with this tube.

The filter holders are made for 2-inch-square filters. An adaptor ring for each filter holder permits the use of filters of different thicknesses.

The instrument is shown in detail in plates 4-8. In plate 4 onehalf of drawing $A$ is a section showing the fluorimeter assembly with type- $A$ bottom plate and search unit in place; in plate 4 drawing $B$ shows the arrangement with type- $B$ bottom plate and 5819 photomultiplier tube. The stand, lamp support, and shield are the same for both arrangements. Plate 5 is a cutaway drawing showing additional details of the "fluorimeter." The remaining plates are detailed shop drawings for the construction of parts shown in plates 4-5. All parts of the "fluorimeter" shown in plate 5 must be machined to a class-4 fit or better; those shown in plate 5 require only a class-3 fit.

A thin glass disc (not shown in the illustrations) is required in the sample slide under the adaptor ring. The purpose of this disc is to 
prevent flakes of the sample from falling into the fluorimeter. This glass must be nonfluorescent. Discs cut from photographic plates used in spectrum analysis are satisfactory.

The lamp shown in plate 4 is a General Electric $\mathrm{E}-\mathrm{H} 4$ or $\mathrm{C}-\mathrm{H} 4$ lamp. This lamp requires a porcelain socket with an "admedium" base. It is operated with a constant wattage transformer designed especially for $\mathrm{H}-4$ lamps. The lamp temperature is controlled by ventilation with a darkroom ventilator.

The primary filters are 2-inch-square Corning no. 5874 ultraviolet filters, polished thickness. Two of these filters are generally used. The secondary filters may be either a combination of Corning filters nos. 3486 and 9780 , molded or polished thickness, or an interference filter peaked for maximum transmission at $5550 \mathrm{~A}$.

Various combinations of phototubes, and current amplifying and measuring devices that may be used with this "fluorimeter" have been described elsewhere (part 11 and 13).

\section{ACKNOWLEDGMENTS}

We gratefully acknowledge the contributions to this project by our associates at the Geological Survey.

We are especially indebted to Alexander E. Herold, Jr., who did all of the machine work and made many valuable contributions to the final design.

Special thanks are also due to Joseph Ramisch who assisted in the original design. 


\title{
Part 13. A BATTERY-POWERED FLUORIMETER FOR THE DETERMINATION OF URANIUM
}

\author{
By Irving May and Mary H. Fletcher
}

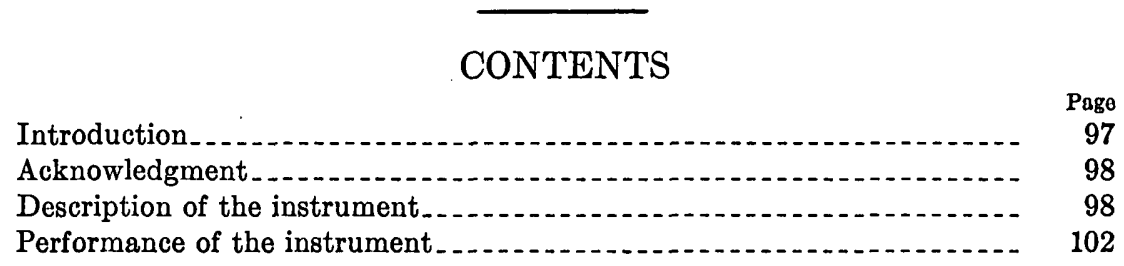

\section{ILLUSTRATIONS}

Figure 15. Lamp circuit used in the instrument

16. Reflecting support for the lamp............. 101

17. Power circuit for the photomultiplier tube $\ldots 1$

18. Standard curve._.

19. Platinum dish used for fusion

\section{INTRODUCTION}

This report describes a transmission fluorimeter that is completely battery-powered and suitable for use in the laboratory, in field stations, or in mobile units. The source of the ultraviolet light is a 3-watt RP-12 lamp. The instrument is sufficiently sensitive for the determination of 0.001 percent uranium in a $0.4-\mathrm{mg}$ sample.

The determination of uranium by measuring the fluorescence of fluoride melts has been used extensively in the past few years as a laboratory procedure. With an appropriate fluorimeter this technique could be developed into a field method for the determination of uranium.

A fluorimeter for field use, either in a mobile laboratory or at a field station, would have to be completely battery-powered. Although there are a number of fluorimeters in general use that employ battery-powered current-amplifying and measuring devices, they all require house current as a source of power for the ultraviolet light. The fundamental problem in designing a field fluorimeter therefore resolves itself into finding a suitable ultraviolet lamp that can be operated with batteries.

Nork.-This report was issued as Trace Elements Inv. Rept. 135, 1960. 
The instrument described in this paper uses an inexpensive 3-watt $d-c$ lamp as the source of ultraviolet light. The arrangement of the sample support, filters, and shutter is the same as the one used in the transmission fluorimeter described in a previous paper (part 12). The fluorescent light is converted to electrical energy by a batterypowered photomultiplier tube, and the resulting current is read directly with a sensitive but sturdy microammeter.

\section{ACKNOWLEDGMENT}

We thank Dr. Francis J. Davis, Division of Health Physics, Oak Ridge National Laboratory, for his recommendations about phototubes and meters, and for assembling a prototype current-measuring unit.

\section{DESCRIPTION OF THE INSTRUMENT}

The ultraviolet lamp.-The source of the ultraviolet light is a small d-c RP-12 lamp, manufactured by the General Electric Co. for lighting fluorescent instrument dials on aircraft. The lamp is coated on the inner surface with a phosphor having a radiation peak at $3500 \mathrm{~A}$. The RP-12 lamps are available in two wattage ratings, 3 watts, 12-16 volts, and 4 watts, $24-28$ volts. The lamp has a length of $23 / 3$ inches, a maximum diameter of $1 \frac{1}{2}$ inches, and a regular double-contact bayonet base with indexed pins. The lamp circuit used in this fluorimeter is shown in figure 15.

Despite its lower light output, the 3-watt lamp has been adopted for this instrument because of the greater convenience in working with lower voltage batteries. The light produced by the 3-watt lamp is much less intense than that from 100-watt lamps or larger that normally are employed in fluorimeters. Therefore the 3-watt lamp might seem unsuitable for use in a very sensitive fluorimeter. The overall sensitivity of the transmission fluorimeter (parts 11 and 12) is so great, however, that for normal use in uranium analyses the lamp is raised about 10 inches from the primary filter and the photomultiplier tube is operated at only 450 volts rather than at its maximum voltage. In the field fluorimeter, however, the low light output of the 3-watt lamp is compensated for largely by placing the lamp nearly in contact with the primary filter and operating the photomultiplier tube at 900 volts.

The lamp generates very little heat; even when it is close to the filter and covered with a reflecting dome, there is no necessity for cooling with a fan. The light output of the lamp becomes reasonably stable less than 5 minutes after lighting.

Power supply for the lamp,-Two types of batteries have been investigated to supply current for the lamp: mercury dry-cell batteries 
for portable instruments, and lead storage batteries for use in a laboratory, field station, or mobile unit.

Mercury batteries, recently developed, provide several times more current per unit volume than conventional dry cells. Batteries providing a starting voltage under load of 16 volts are available.

Performance tests of the batteries were made in which 500 milliamperes were drawn in the lamp circuit. Under continuous drain, the battery delivered this current for 90 minutes. After an overnight rest, an additional 50 minutes of service was obtained. Two such batteries, connected in parallel, provided 5 hours' service at the same current drain, followed by $1 \frac{1}{4}$ hours' service after resting. This current drain represents an appreciable overload on the batteries and results in poorer performance compared to the rated capacity of $3000 \mathrm{ma}-\mathrm{hr}$.

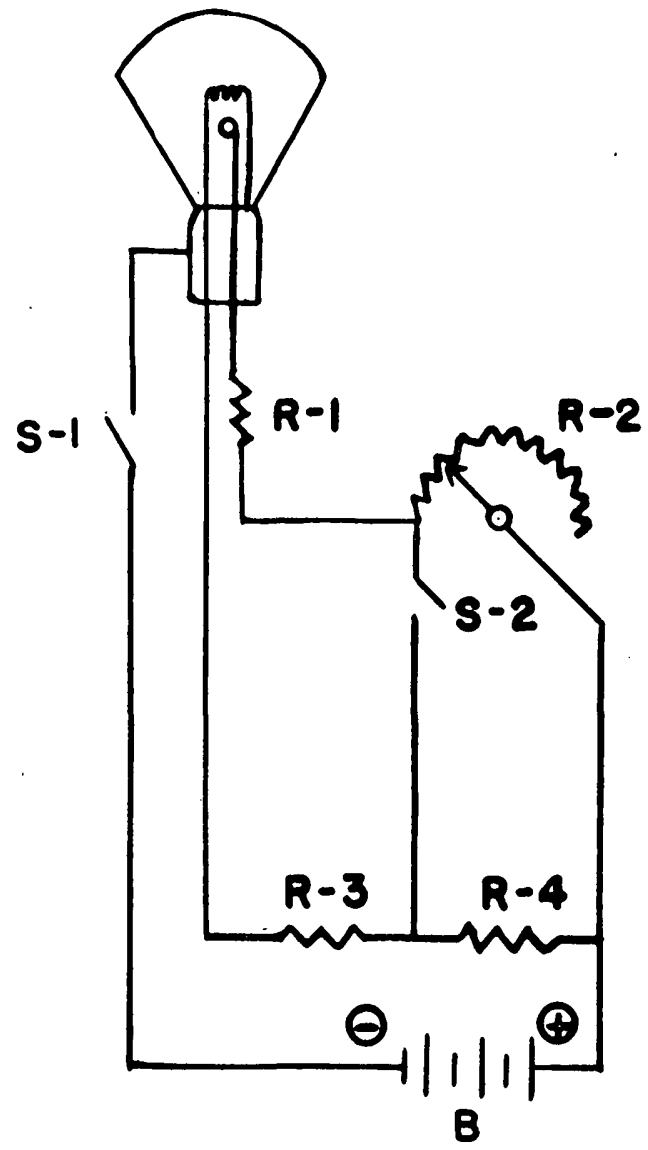

FigURe 15.-Lamp circuit used in the instrument. $S-1$, on-off switch; $S-2$, starting switch, normal posi: tion open; $R-1$, resistor, 16 ohms; $R-2$, variable resistor, 25 ohms; $R-3$, resistor, 60 ohms; $R-4$, resistor, 24 ohms; $B$, battery, $12-16$ volts. 
A storage battery is the most convenient power supply for the lamp where ease of portability is not important. The battery, only 18 inches long, consists of seven radio storage-type cells in series. The cells have transparent nonspillable polystyrene cases with built-in indicator floats. The dimensions of the unit cell are $2 \frac{5116}{6}$ by $2 \frac{1}{2}$ by 6 inches. The capacity of these cells is 26.5 ampere hours which is equivalent to about 50 hours of current-supply for the lamp per battery charge.

A voltage regulator is not required because the storage battery generally provides a steadier current than the voltage-regulated house current.

A convenient charging unit for the storage batteries-consisting of a variable transformer, a selenium rectifier stack (output of 18 volts), and an ammeter-was assembled. Convenient control of the charging rate can be obtained by varying the output voltage of the variable transformer.

The current flowing through the lamp circuit can be changed by varying resistance $R-2$ (fig. 15). Variation of the resistance produces a change in the light output of the lamp. This adjustment is employed for standardizing the overall sensitivity of the instrument. (Larger changes in the sensitivity may be made by changing the voltage on the photmultiplier tube as described below.)

Sample-support, filter, and shutter assembly.-The arrangement of the sample-support, filters, and shutter is the transmission type previously described (part 12). The ultraviolet-lamp support seats directly on the unit (fig. 16). The assembly is so constructed that it may be used interchangeably with either the 5819 or the 1P21 photomultiplier tube. The primary filter is the Corning no. 5874 (2-inchsquare, polished thickness); the secondary filters consist of one each of Corning nos. 3486 and 9780 (2-inch-square) filters.

Photomultiplier tube and circuit.-The 5819 photomultiplier tube is used in the instrument. The power source for the photomultiplier tube consists of three 300-volt miniature " $\mathrm{B}$ " batteries in series. The power circuit for the tube is shown in figure 17 . With a total voltage of 900 volts the amplification given by the tube is about 200,000 times. The amplification may be doubled, as desired, by increasing the voltage to 1,000 volts. Switch $S$ (fig. 17) provides for a stepwise application of voltage to the photomultiplier tube. Thus the tube may be operated over a considerable range of sensitivity. When reading the fluorescence during the analysis of a sample of unknown composition, readings are taken at the lowest voltage and then at progressively higher voltages, if necessary, to avoid damage to the photomultiplier tube. Arerage anode currents of more than 750 microamperes will damage the tube. For maximum stability, the anode current should not exceed 100 microamperes. 


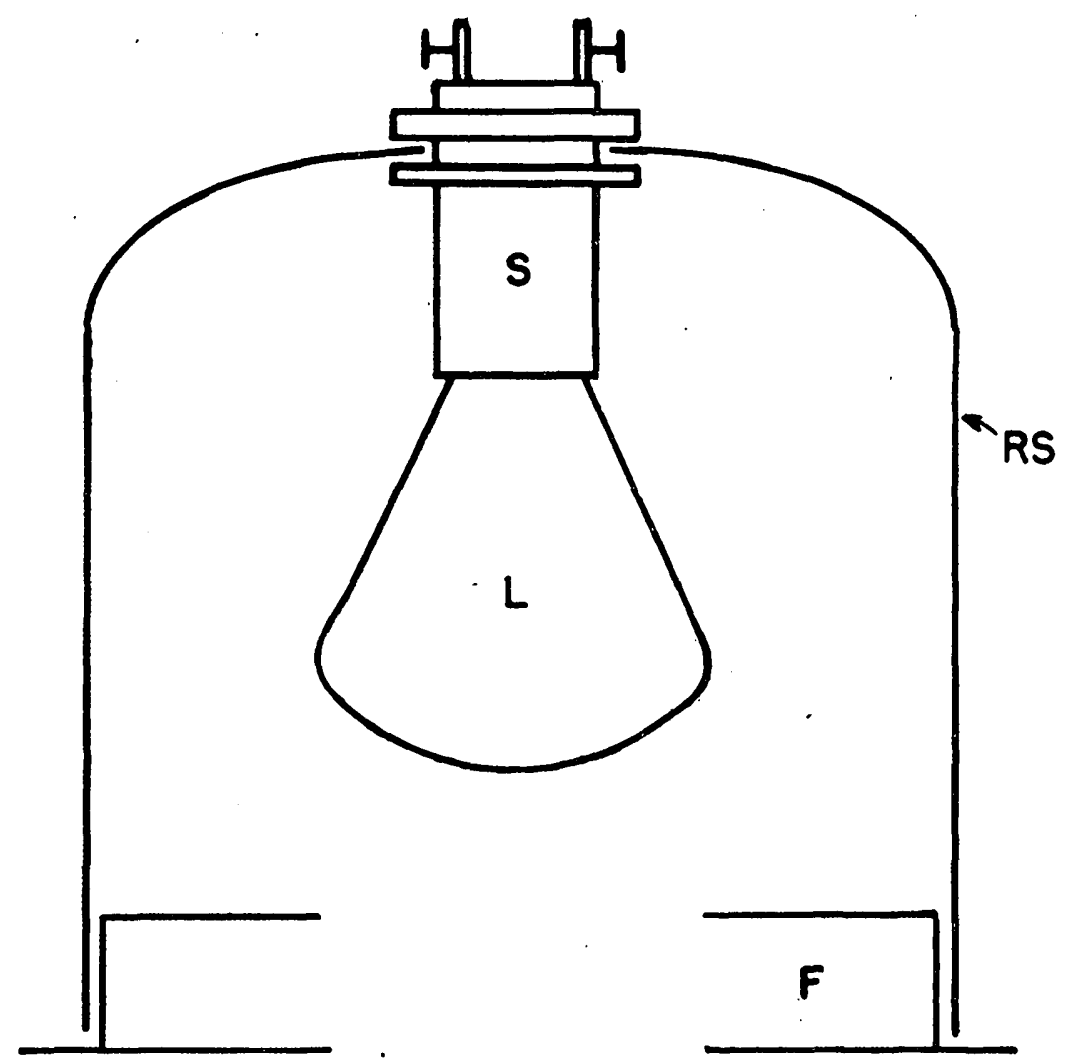

FigURE 16.-Reflecting support for the lamp. $R S$, reflecting shleld; $L$, lamp; $S$, lamp socket; $F$, primary fllter holder.
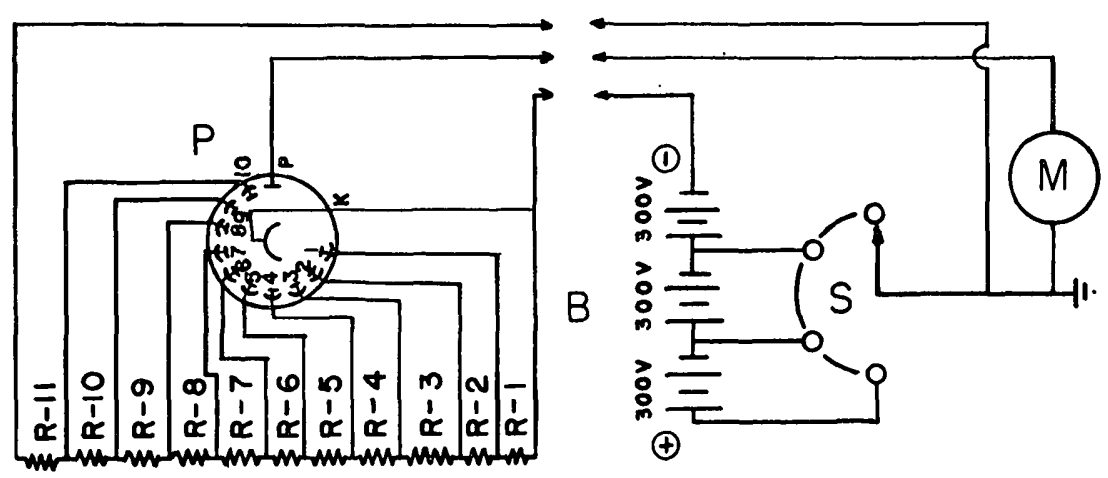

$\oplus$

FIGURE 17.-Power circuit for the photomultiplier tube. $P, \mathrm{RCA}$ photomultiplier tube 5819; $M$, microammeter; $S$, selector switch; $B$, “B" batteries, 300 volts each; $R 1-11$, resistors, 1 megohm, $1 / 2$ watt. 
As an alternative arrangement the 1P21 photomultiplier tube may be used in place of the 5819 tube. The smaller size of the 1P21 tube is advantageous where maximum portability is desirable.

Microammeter.-The currents generated by the photomultiplier tube are read directly with a microammeter. The meter in use until recently was a microammeter that gave full-scale readings of 4,40 , 400, and 4,000 microamperes. Recently we replaced this with another meter having full-scale readings of $5,15,50$, and 150 microamperes. The scales on this new meter give a convenient gradation of sensitivities within the useful range of the photomultiplier-tube output.

\section{PERFORMANCE OF THE INSTRUMENT}

The instrument gives good stability over a very wide range of sensitivity. At the sensitivities normally used, the instrument is standardized by adjusting the standard deflection (reading obtained with no sample in position and with the shutter open) to full-scale deflection on the most sensitive scale of the microammeter (4 microamperes) (part 11). This adjustment is made by varying the current supply of the ultraviolet lamp with resistance R-2 (fig. 15).

A standard curve for the instrument is shown in figure 18 . The fluoride melts were prepared by techniques described in parts 8 and 11 and the melts were fused in specially designed platinum dishes (fig. 19).

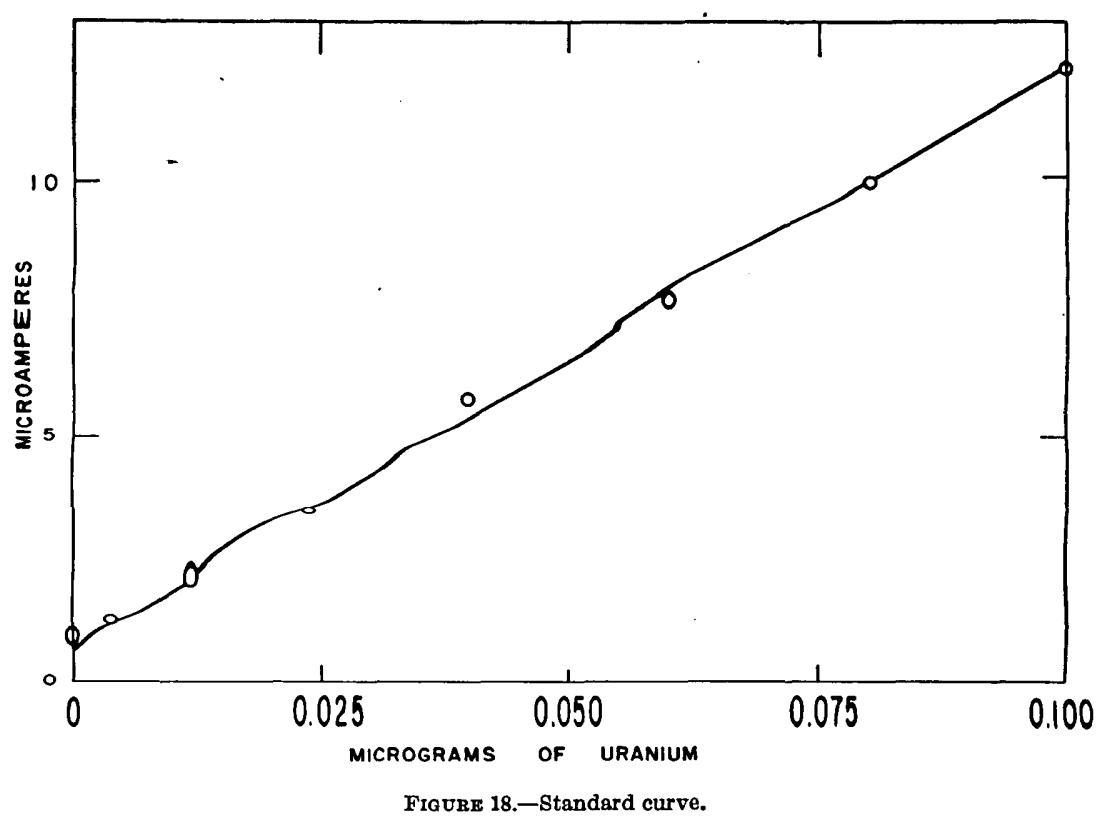




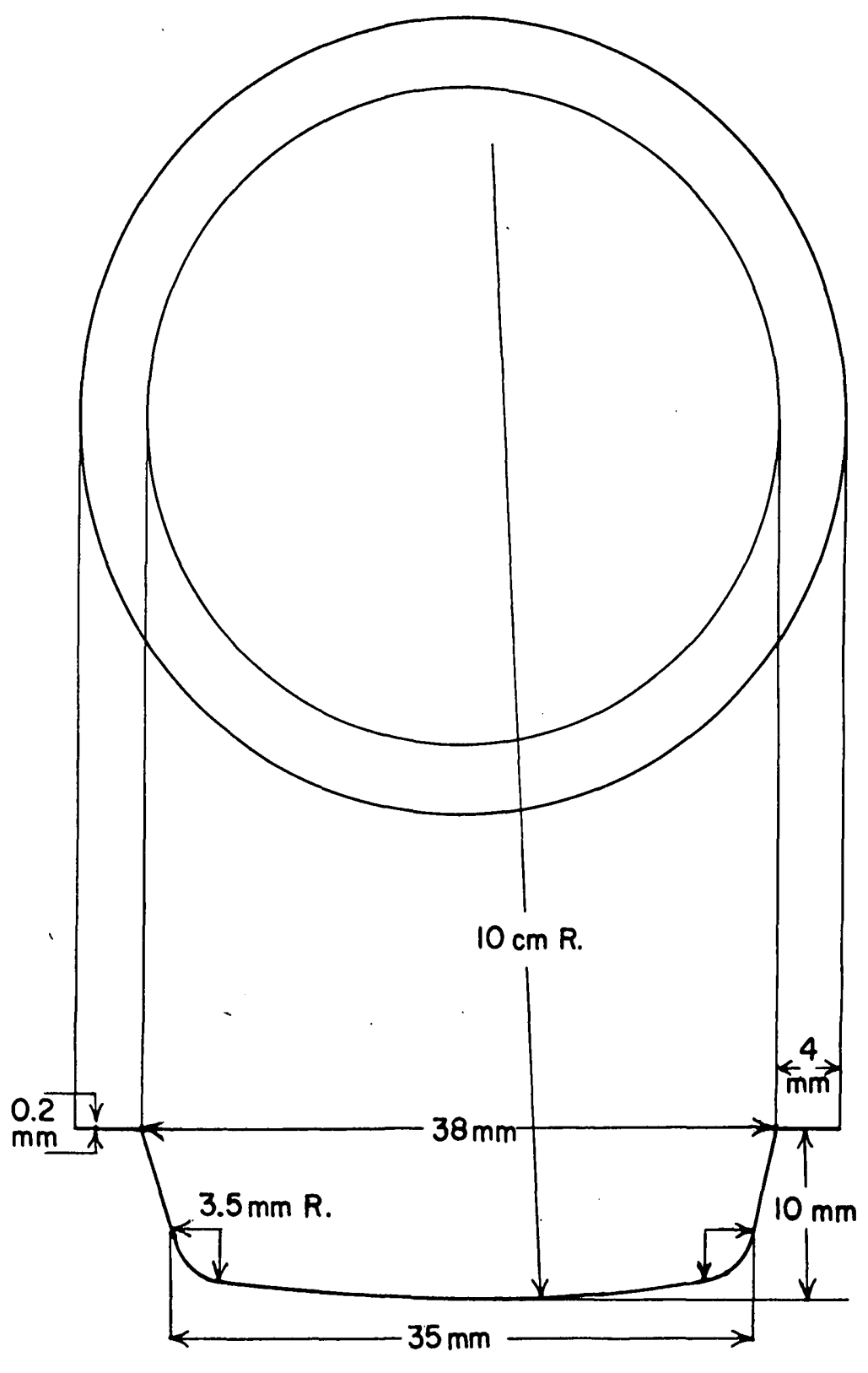

Figore 19.-Platinum dish used for fusion. 
The ultraviolet lamp was powered by the storage-battery unit and the photomultiplier-tube voltage was 900 volts. The sensitivity is about 1 microampere for 0.01 microgram of uranium. As the meter can be read to the nearest 0.01 microampere on the 4-microampere scale, the sensitivity is adequate for this range of uranium concentrations.

The tabulation below shows the precision with which fluorescence measurements may be made with the fluorimeter. The fluorescence of melts prepared in the routine analysis of rocks for uranium was measured with the fluorimeter. Each melt was measured four times, and was rotated $90^{\circ}$ between successive measurements. The overall variance of the measurements is 0.028 .

Precision of fluorescence measurements

\begin{tabular}{|c|c|c|c|c|}
\hline Sample & Scale & Readings (microamperes) & $\begin{array}{l}\text { Mean of } \\
\text { readings }\end{array}$ & Variance \\
\hline (6) & $\begin{array}{r}40 \\
40 \\
40 \\
40 \\
40 \\
40 \\
4\end{array}$ & $\begin{array}{l}30.3,30.4,30.6,30.7 \\
22.8,22.8,22.8,22.9 \\
31.4,31.6,31.6,31.8 \\
29.5,29.5,30.0,29.4 \\
21.0,21.4,21.0,21.1 \\
24.7,24.7,24.8,24.6 \\
1.18,1.18,1.17,1.20\end{array}$ & $\begin{array}{r}30.5 \\
22.8 \\
31.6 \\
29.6 \\
21.1 \\
24.7 \\
1.18\end{array}$ & $\begin{array}{l}0.033 \\
.0033 \\
.027 \\
.073 \\
.037 \\
.0067 \\
.017\end{array}$ \\
\hline Overall variance & & & & .028 \\
\hline
\end{tabular}




\title{
Part 14. SHORT ROUTINE DIRECT METHOD FOR THE FLUORIMETRIC DETERMINATION OF URANIUM IN PHOSPHATE ROCKS
}

\author{
By F. S. Grimaldi and Norma S. Guttag
}

\section{CONTENTS}

$\begin{array}{lll}\text { Abstract } & \text { Page } \\ \text { Introduction } & & 105 \\ \text { Experimental work } & & 106\end{array}$

\section{ILLUSTRATION}

Figure 20. Working curve

109

(4)

\section{ABSTRACT}

A short routine direct fluorimetric procedure for the determination of as much as 0.06 percent uranium in phosphate rocks is described. The procedure employs a simple acid leach for preparing the solution, and the uranium is determined directly on a 1.8-mg aliquot. The results obtained by using this simple procedure on several thousand samples are discussed. The quenching of the uranium fluorescence by foreign elements was found to be negligible, for all practical purposes, and results on western phosphates may be corrected by using an empirically determined quenching factor.

\section{INTRODUCTION}

Need for faster routine uranium analyses of phosphate rocks made it necessary to reappraise previous methods for the purpose of introducing as many short cuts as possible consistent with the accuracy sought.

The fastest procedure used in the Geological Survey is the dilution technique that employs microgram amounts of samples in conjunction with very sensitive fluorimeters (part .8). This dilution technique is necessary for most types of materials to avoid quenching of the uranium fluorescence by foreign elements in the sample. However, microgram amounts of samples are unnecessary for the analysis of

NOTE.-This report was tssued as Trace Elements Inv. Ropt. 134, 1950.

$268681-64-8$ 
phosphate rocks because in them the concentration of quenching elements is relatively small.

The use of larger samples has definite advantages for routine analysis because the ratio of fluorescence intensities to the blank value is greater. Consequently, variations in the blank value of ballmill ground flux result in no significant uncertainty in the analysis. Also, a higher level of accidental contamination resulting from improperly cleaned glassware or airborne dust may be tolerated. The ideal direct method should employ a sample large enough to avoid the enumerated difficulties but small enough that quenching of the uranium fluorescence by foreign elements will not be significant.

In the preparation of the solution for analysis the complete decomposition of the sample is necessary. Lacking any information to the contrary it is the only safe procedure to follow. However, the uranium in phosphate rocks yields to simpler and faster methods of attack. The fastest solution procedure for a large number of samples is a simple acid leach. This method was investigated and gave excellent dissolution of all the uranium-bearing components of the rock.

The final procedure evolved for testing phosphate rocks integrates all the foregoing considerations and simplifications. An aliquot of the $(18+82)$ nitric acid leach representing a $1.8-\mathrm{mg}$ sample is evaporated in a $30-\mathrm{ml}$ platinum crucible or other suitable container and fused directly over a burner with $3 \mathrm{~g}$ of fluoride-carbonate flux previously described (part 8). The fluorescence of the disc is measured in the reflection fluorimeter described by Fletcher and May (part 10). These measurements may also be made with the transmission instrument (part 11).

\section{EXPERIMENTAL WORK}

Preliminary tests on about 30 samples indicated that the short procedure described in this paper was applicable to phosphate rock. The method was then adopted tentatively for routine uranium determination on phosphate rock. Several thousand samples typical of the deposits being tested by the Geological Survey were analyzed for uranium by this procedure over an extended period of time.

Concurrent with the chemical analyses, the uranium content of these samples was determined by independent methods. The results by beta-gamma count of total radioactivity were used as the main criteria for a "correct" analysis. This counting was done in the laboratory of the Geological Survey and has proved to be a very reliable method for uranium determinations on phosphato rocks. About 10 percent of the samples counted were spot-checked by one 
or more of the refined chemical methods described by Grimaldi and Levine (part 6) and by Fletcher (part 8).

Data for the feasibility of simple acid attack were obtained by determining uranium in 100 samples by more conventional methods after complete decomposition of the sample and after simple acid leach. The acid-insoluble residues from 600 samples were also tested and found to be free from uranium.

The short procedure is not perfect by any means, but represents the best compromise at this time for speed, accuracy sought, simplicity, and convenience. Analysis of the results obtained with the short procedure on several thousand samples from the Florida phosphate deposits has shown that quenching of the uranium fluoresence by foreign elements has not been eliminated altogether.

1. In 90 percent of these samples the quenching amounted to less than 10 percent, and most samples showed no detectable quenching.

2. In 8 percent of the Florida samples the quenching was between 10 and 20 percent; in most it was less than 15 percent.

3. The last 2 percent of the samples showed quenching of the order of 20 to 25 percent.

Phosphate rocks rarely contain more than 0.02 percent $U$, therefore errors due to quenching certainly can be tolerated, when they are of the magnitude cited. For example, a sample containing 0.015 percent $U$ would be reported as 0.012 percent $U$ if the quenching amounted to 20 percent.

Analysis of the results obtained with the short procedure on more than a thousand samples of western phosphate deposits showed the following:

1. In 90 percent the quenching amounted to 15 percent or less; the average quenching in this group amounted to 12 percent.

2. In 8 percent the quenching amounted to 15 to 20 percent.

3 . In the last 2 percent the quenching amounted to 20 to 25 percent.

Quenching is more serious in western phosphates, but it is also relatively constant in amount. Advantage may be taken of this to correct results on western phosphates by use of an empirical factor. The factor used in this laboratory is 1.18. Thus:

Percent U given by short procedure $\times 1.18=$ "true" percent $U$.

The empirical correction factor was used to improve the results on 500 more samples of western phosphates and the corrected figures were indistinguishable from results obtained by more reliable methods.

Experience in our laboratory with simple acid leaching of phosphate rocks for the preparation of the solution for analysis has been 
very successful. Out of 4,000 samples of Florida and western phosphate deposits, only 4 samples so far have failed to yield completely to attack by $(18+82)$ nitric acid. These four samples were unusual (the uranium-bearing mineral proved to be a different mineral than the one usually associated with phosphate rocks), but they yielded to attack by $(1+1)$ nitric acid.

When thousands of samples have to be analyzed routinely by relatively unskilled technicians and speed is important, a certain fraction of the analyses reported will be in error no matter what procedure is used, and the irreducible minimum of errors will increase with the complexity of the analytical procedure. The results obtained here by this short procedure have been better on the whole than when more refined methods of analysis were used.

\section{DETAILED PROCEDURE}

1. Weigh out a $0.15-\mathrm{g}$ sample into a $125-\mathrm{ml}$ Erlenmeyer flask.

2. Add, by means of a graduate, $50 \mathrm{ml}$ of carefully measured $(18+82) \mathrm{HNO}_{3}$.

3. Cover the flask with a small glass and heat the solution just to boiling on a hotplate. Boil gently for 2 minutes. Cool.

4. Take a $0.6-\mathrm{ml}$ aliquot of the supernatant liquid by means of a $1-\mathrm{ml}$ graduated pipette and transfer this amount to a clean $30-\mathrm{ml}$ platinum crucible.

5. Evaporate the solution to dryness on the steam bath. Gently ignite the residue.

6. Add $3 \mathrm{~g}$ of the carbonate fluoride flux (9 parts $\mathrm{NaF}, 45.5$ parts $\mathrm{K}_{2} \mathrm{CO}_{3}$, and 45.5 parts $\mathrm{Na}_{2} \mathrm{CO}_{3}$ by weight).

7. Heat on a low burner flame until the flux melts. The crucible should not be heated at any time above incipient red heat.

8. Heat for an additional 2 minutes at the lowest temperature at which the flux stays molten, swirling and mixing the contents of the crucible to obtain a uniform melt. Place the crucible on an asbestos pad to cool and store in a desiccator for $\mathbf{3 0}$ minutes.

9. Read the fluorescence on the fluorimeter. Obtain the percent uranium by reference to the standard curve, figure 20.

10. For Florida phosphates, report what is obtained. For western phosphates, multiply the percent $U$ by 1.18 . 
FLUORIMETRIC DETERMINATION OF URANIUM-PHOSPHATE ROCK 109

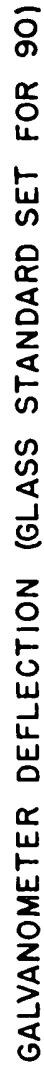

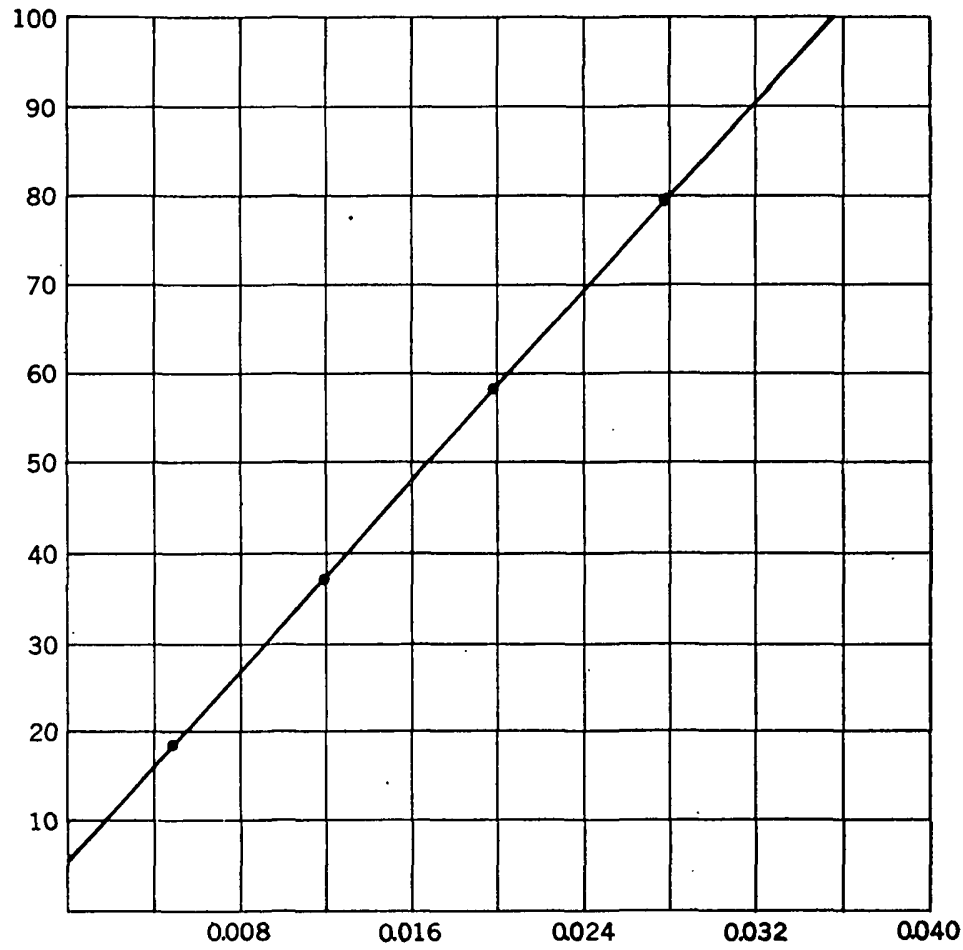

PERCENT U BASED ON I.8-mg SAMPLE

Figure 20.-Working curve. 


\section{.}




\title{
Part 15. FLUORIMETRIC DETERMINATION OF URANIUM IN SHALES, LIGNITES, AND MONAZITES AFTER ALKALI GARBONATE SEPARATION
}

\author{
By Norma S. Guttag and F. S. Grimaldi
}

\section{CONTENTS}

Introduction

Experimental data and discussion

Procedure for shales and lignites

Procedure for monazite.

Results of analysis

\section{TABLES}

TABLE 1. Efficiency of the carbonate separation method under various test

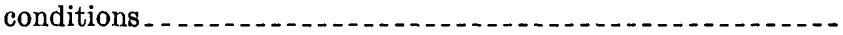

2. Elimination of interference of copper with hydroxylamine hydrochloride.

3. Comparison of uranium analyses of shale by the carbonatefluorimetric procedure and by the uranyl nitrate extraction procedure

4. Comparison of uranium analyses of lignites by the carbonatefluorimetric procedure and by the uranyl nitrate extraction procedure

5. Results of uranium analyses of monazites

\section{INTRODUCTION}

Comparative data are presented on separations of microgram amounts of uranium from milligram amounts of various metal ions with $\mathrm{Na}_{2} \mathrm{CO}_{3}-\mathrm{K}_{2} \mathrm{CO}_{3}, \mathrm{Na}_{2} \mathrm{CO}_{3}-\mathrm{K}_{2} \mathrm{CO}_{3}-\mathrm{H}_{2} \mathrm{O}_{2}$, and $\mathrm{Na}_{2} \mathrm{CO}_{3}-\mathrm{NaClO}$. The $\mathrm{Na}_{2} \mathrm{CO}_{3}-\mathrm{K}_{2} \mathrm{CO}_{3}$ separation procedure is applied to the analysis of shales, lignites, and monazites. This method will determine as little as 0.001 percent uranium in shales and lignites and 0.01 percent uranium in monazites.

Several fluorimetric procedures, based essentially on two techniques, have been developed in the Geological Survey and are used for the analysis of uranium in a wide variety of materials. One technique 
(part 6) involves a preliminary isolation of uranyl nitrate by solvent extraction from milligram amounts of sample. The second technique (part 8) based on Price's dilution method ${ }^{1}$ involves no preliminary isolation of uranium and uses microgram amounts of sample. Each method has its advantages and disadvantages for routine work that need not be discussed here.

The Geological Survey is constantly searching for new methods or modifications that can be used in the determination of small amounts of uranium, even if applicable only to certain types of samples. This investigation of methods of analysis for uranium involves, among other things, evaluating known techniques and methods and devising new applications of known facts for special purposes.

Precipitation with alkali carbonate is a standard procedure for the separation of iron and other elements, that form insoluble hydroxides or carbonates, from uranium that stays in solution as a complex carbonate. It is a popular method of separation in procedures for the determination of macro amounts of uranium but is rarely used when micro amounts are to be determined. The neglect of this method in trace analyses is partly due to the lack of available data on the performance of this separation when small amounts of uranium are involved.

The purpose of this study was to obtain data on the carbonate separation method that might be applicable to work of the Geological Survey. The separation method was remarkably efficient and, in conjunction with fluorimetric estimation of uranium, provided the basis of a simple method for determination of small amounts $\left(1 \times 10^{-8} \mathrm{~g}\right.$ and more) of uranium in shales, lignites, and monazites. This method will determine as little as 0.001 percent uranium, as the lower limit, in shales and lignite samples and 0.01 percent uranium as the lower limit in monazite samples.

\section{EXPERIMENTAL DATA AND DISCUSSION}

Preliminary tests were made to determine the efficiency of the carbonate separation of uranium from various metal ions. In these tests sulfates of the test metals were used in amounts equivalent to $15 \mathrm{mg}$ or less of each metal oxide. This amount was determined by the fact that the carbonate precipitation method proposed in this report uses solutions containing no more than $15 \mathrm{mg}$ of each sample.

The procedures used on the test samples follow:

In the first experiments (method 1) a 5-ml aliquot of a solution, containing a known weight of metal sulfate, $0.05 \mathrm{ml}$ of $\mathrm{H}_{2} \mathrm{SO}_{4}$, and

1 Price, G. R., Ferrettl, R. J., and Schwartz, 8., 1945, The microfluorimetrio determination of uranium: AECD 2282 . 
$2.25 \gamma$ of U, was transferred to a glass-stoppered test tube. Five milliliters of mixed carbonate solution (made by dissolving $10 \mathrm{~g}$ $\mathrm{Na}_{2} \mathrm{CO}_{3}$ and $10 \mathrm{~g}$ of $\mathrm{K}_{2} \mathrm{CO}_{3}$ in $100 \mathrm{ml}$ of $\mathrm{H}_{2} \mathrm{O}$ ) were added from a pipette and the glass-stoppered tube shaken to give a uniform mixture. The tube was placed in a beaker of hot water for half an hour at a temperature of about $80 \mathrm{C}$. The tube was removed and the solution allowed to cool to room temperature for 1 hour. The solution was filtered through a dry filter paper (Whatman no. 42) and collected in a dry test tube. An 0.8-ml aliquot of the filtered solution was transferred to a platinum container $(3.5-\mathrm{cm}$ diameter) and the solution evaporated on the steam bath. Two grams of fluoride flux ( 9 parts by weight $\mathrm{NaF}, 45.5$ parts by weight $\mathrm{Na}_{2} \mathrm{CO}_{3}$, and 45.5 parts by weight $\mathrm{K}_{2} \mathrm{CO}_{3}$ ) were added and the mixture fused over a burner at a temperature not exceeding $700 \mathrm{C}$. Heating and mixing were continued for 2 minutes after the flux melted. The fluorescence of the disc was then measured in a fluorimeter designed by Fletcher and May (part 10). The carbonate precipitate was dissolved in $\mathrm{HNO}_{3}$ and tested for occluded uranium by the uranyl nitrate extraction procedure (part 6).

In another set of experiments (method 2) the carbonate precipitation was made after the addition of 1 drop of 30 percent $\mathrm{H}_{2} \mathrm{O}_{2}$ to the test solutions that had been made as before. In still another set of experiments (method 3) the carbonate precipitation was made with $5 \mathrm{ml}$ of mixed carbonate solution containing 0.5 percent by weight of $\mathrm{NaClO}$. The $\mathrm{NaClO}$ was added to test the behavior of those elements that are oxidized to higher valence states.

Table 1 shows the results obtained. None of the low results obtained (method $1, \mathrm{Na}_{2} \mathrm{CO}_{3}-\mathrm{K}_{2} \mathrm{CO}_{3}$ ) was due to loss of uranium by occlusion in the carbonate precipitate but rather was due to quenching of the uranium fluorescence by the small amounts of the test elements escaping precipitation. Most of the carbonate filtrates were colored when low results were obtained.

Some additional observations relating to the data in table 1 should be pointed out. We note that the elements $\mathrm{Y}, \mathrm{Zr}, \mathrm{V}, \mathrm{As}, \mathrm{Sm}$, and $\mathrm{Gd}$ are completely soluble and that $\mathrm{Co}, \mathrm{Ce}, \mathrm{Nd}, \mathrm{Pr}$, and $\mathrm{Al}$ are slightly soluble in carbonate solutions. This solubility is not due solely to the complexing action of carbonate. The amount of sulfate present in the solutions tested increased the solubility of some metals. For example, in the absence of sulfate, most of the zirconium is precipitated as well as most of the cobalt. 


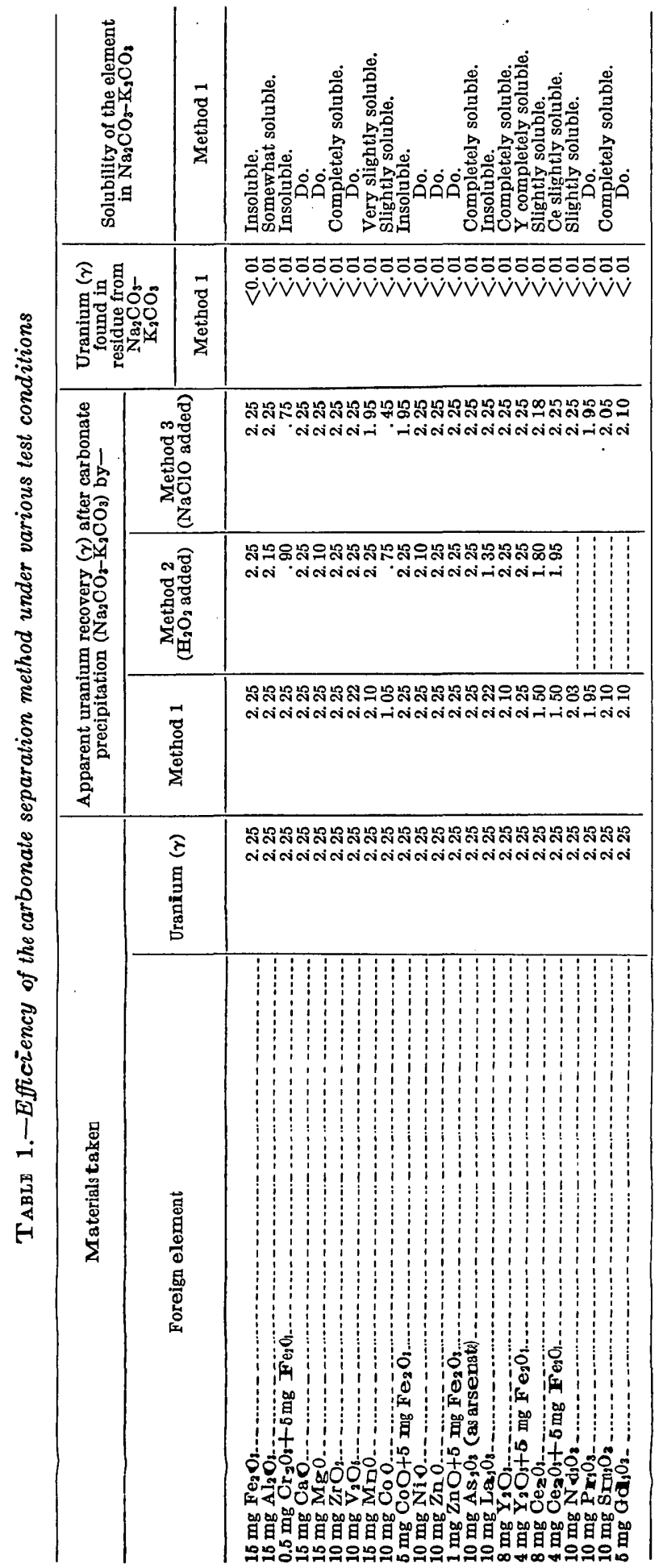


Of the elements that are not precipitated, $\mathrm{Y}, \mathrm{Zr}, \mathrm{V}, \mathrm{As}, \mathrm{Sm}, \mathrm{Gd}$, and $\mathrm{Al}$ do not quench the uranium fluorescence. It might be generalized that the cerium earths are bad quenchers, whereas the yttrium earths do not quench the uranium fluorescence seriously. $\mathrm{Mn}, \mathrm{Co}$, and $\mathrm{Cr}$ are elements which apparently seriously quench the uranium fluorescence.

The behavior of copper (cupric) in the carbonate precipitation is erratic. In a few of our tests, copper was completely precipitated as $\mathrm{CuO}$. However, the conditions for complete precipitation of copper appear to be exceedingly critical, and the precipitation is usually incomplete with much of the copper remaining in solution as a blue complex. To insure complete precipitation, the copper can be reduced to cuprous oxide with hydroxylamine hydrochloride. This reagent is introduced only if a blue solution persists after the boiling with alkali carbonate.

The blue color of the soluble copper complex is barely perceptible at about $50 \gamma$ of copper in $10 \mathrm{ml}$ of solution. Tests summarized in table 2 show that if the quantity of copper is insufficient to yield a blue color after the carbonate precipitation (that is, $<50 \gamma \mathrm{Cu}$ ) no hydroxylamine need be added; this amount of copper will not result in any quenching of the uranium fluorescence using the general procedure. If hydroxylamine is used, the data in tables 2 and 3 show that no loss of uranium occurs by occlusion in the cuprous oxide precipitate. It has also been confirmed that the introduction of hydroxylamine causes no significant change in the behavior of the elements listed in table 1.

The data in table 2 were obtained as follows: $5 \mathrm{ml}$ portions of solutions containing $4.5 \gamma \mathrm{U}$ (uranyl nitrate), varying amounts of copper sulfate, and $0.1 \mathrm{ml}$ of $(1+1)$ sulfuric acid were treated as previously described (p. 112, method 1). After heating for 10 minutes in the bath, $0.05 \mathrm{ml}$ of a 20 percent aqueous solution of $\mathrm{NH}_{2} \mathrm{OH} \cdot \mathrm{HCl}$ ( $20 \mathrm{~g}$ per $100 \mathrm{ml}$ of $\mathrm{H}_{2} \mathrm{O}$ ) was added to some of the samples. The heating was continued for 20 minutes for all the samples; they were then cooled for 1 hour. The uranium content was determined as before.

TABLE 2.-Elimination of interference of copper with hydroxylamine hydrochloride

\begin{tabular}{|c|c|c|c|c|c|c|c|}
\hline \multicolumn{2}{|c|}{ Materials taken } & \multirow{2}{*}{$\begin{array}{c}\mathrm{NH}_{2} \mathrm{OH} \cdot \mathrm{HCl} \\
\text { added (ml of } \\
20 \text { percent solu- } \\
\text { tion) }\end{array}$} & \multirow{2}{*}{$\begin{array}{c}\text { Uranium } \\
\text { found } \\
(\gamma)\end{array}$} & \multicolumn{2}{|c|}{ Materials taken } & \multirow{2}{*}{$\begin{array}{l}\mathrm{NH}_{2} \mathrm{OH} \cdot \mathrm{HCl} \\
\text { added (ml of } \\
20 \text { percent solu- } \\
\text { tion) }\end{array}$} & \multirow{2}{*}{$\begin{array}{l}\text { Uranium } \\
\text { found } \\
(\gamma)\end{array}$} \\
\hline$\underset{(\gamma)}{\mathrm{CuO}}$ & $\underset{(\gamma)}{\operatorname{Uranium}}$ & & & $\underset{(\gamma)}{\mathrm{CuO}}$ & $\underset{(\gamma)}{\operatorname{Uranium}}$ & & \\
\hline 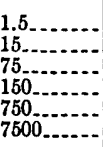 & $\begin{array}{l}4.5 \\
4.5 \\
4.5 \\
4.5 \\
4.5 \\
4.5\end{array}$ & $\begin{array}{l}0.05 \\
.05 \\
.05 \\
.05 \\
.05 \\
.05\end{array}$ & $\begin{array}{l}4.5 \\
4.5 \\
4.5 \\
4.6 \\
4.6 \\
4.6\end{array}$ & 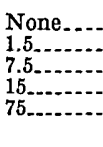 & $\begin{array}{l}4.5 \\
4.5 \\
4.5 \\
4.5 \\
4.5\end{array}$ & $\begin{array}{l}0 \\
0 \\
0 \\
0 \\
0\end{array}$ & $\begin{array}{l}4.5 \\
4.6 \\
4.6 \\
4.7 \\
4.6\end{array}$ \\
\hline
\end{tabular}


Of the three methods used to obtain data in table 1 , fluorimetric results based on carbonate-peroxide separation (method 2) are poorest. The carbonate-hypochlorite method (method 3) is better than the simple carbonate method (method 1) for samples containing rare earths and would be the method of choice were it not for the serious interference of chromium. Of the elements tested in the simple carbonate method (method 1) only cerium, cobalt, and copper can interfere when uranium is determined fluorimetrically. The interference of copper is readily overcome by use of hydroxylamine.

In determining uranium in shales, lignites, and monazites the simple carbonate separation was selected for the following reasons:

1. Shale and lignite samples do not contain sufficient cerium or cobalt to interfere in a fluorescence method based on $1.2 \mathrm{mg}$ of sample.

2. Although cerium normally would quench the uranium fluorescence in a $1.2-\mathrm{mg}$ sample of monazite, the fact that the uranium content of monazite is usually greater than 0.1 percent enables us to use a sufficiently small sample $(0.12 \mathrm{mg})$ to eliminate any quenching due to cerium. For the $0.12 \mathrm{-mg}$ sample used in the procedure for monazite, the smallest amount of uranium that may be determined without interference is 0.01 percent if the reflection fluorimeter is used and 0.001 percent if the transmission instrument is used.

\section{PROCEDURE FOR SHALES AND LIGNITES}

1. Weigh $0.15 \mathrm{~g}$ of sample (minus $80 \mathrm{mesh}$ ) into a 70 -ml platinum dish.

2. Ignite the sample gently to remove organic matter. Cool and moisten the sample with water.

3. Add $1 \mathrm{ml}(1+1) \mathrm{H}_{2} \mathrm{SO}_{4}$ and cautiously add 5-10 ml HF. Digest sample on the steam bath and then evaporate the solution to remove water.

4. Heat the sample until fumes of sulfuric acid evolve and allow to fume for several minutes. Cool.

5. Cautiously add $25 \mathrm{ml}$ of water, digest the sample on steam bath stirring to effect solution. Cool to room temperature.

6. Transfer the contents of the dish to a 50-ml glass-stoppered graduated cylinder. Increase to $50 \mathrm{ml}$ with water. Mix.

7. Take a $5-\mathrm{ml}$ aliquot and transfer the solution to a $25-\mathrm{ml}$ glassstoppered test tube.

8. Add $5 \mathrm{ml}$ of mixed carbonate solution (10 g Na $\mathrm{Na}_{2} \mathrm{CO}_{3}+10 \mathrm{~g}$ $\mathrm{K}_{2} \mathrm{CO}_{3}$ per $100 \mathrm{ml}$ of water) and mix.

9. Place the stoppered tube in a beaker of hot water and let stand for 30 minutes at $80-90 \mathrm{C}$. If, after 10 minutes of heating, a blue solution is evident, cool, add $0.05 \mathrm{ml}$ of 20 percent hydroxylamine hydrochloride solution (made by dissolving $20 \mathrm{~g} \mathrm{NH} \mathrm{NH}_{2} \mathrm{OH} \cdot \mathrm{HCl}$ in 100 $\mathrm{ml} \mathrm{H}_{2} \mathrm{O}$ ) and resume the heating for another 20 minutes. 
10. Remove the tube from the bath and allow the solution to cool for 1 hour at room temperature.

11. Filter part of the solution through a dry filter paper (Whatman no. 42) into a dry test tube. The filter paper may be conveniently held in place by the test tube itself. Instead of filtration, the precipitate is preferably centrifuged at $1700 \mathrm{rpm}$ for $10-15$ minutes.

12. Take an $0.80-\mathrm{ml}$ aliquot and transfer the solution to a standard platinum container (part 13) and evaporate the solution on the steam bath.

13. Add $2 \mathrm{~g}$ of flux ( 9 parts by weight $\mathrm{NaF}, 45.5$ parts by weight $\mathrm{Na}_{2} \mathrm{CO}_{3}$, and 45.5 parts by weight $\mathrm{K}_{2} \mathrm{CO}_{3}$ ).

14. Heat over a burner until the flux melts and then for an additional 2 minutes, mixing and swirling the contents to assure a uniform melt. The temperature of the container should not be allowed to exceed $700 \mathrm{C}$ during the heating period.

15. Place the dish on an asbestos pad to cool.

16. Measure fluorescence of the disc in the fluorimeter (part 10) and convert to percent uranium by reference to a standard curve. The standard curve is prepared by fusing various amounts of uranium with the fluoride flux and measuring the fluorescence intensity of the discs.

\section{PROCEDURE FOR MONAZITE}

The procedure for monazite differs from the procedure for shale and lignite only in the method of preparing the solution and in the final size of sample taken.

1. Weigh $0.0800 \mathrm{~g}$ of representative finely ground monazite into a platinum crucible.

2. Add $0.6 \mathrm{~g}$ of flux ( 2 parts by weight $\mathrm{NaF}$ and 3 parts by weight $\mathrm{K}_{2} \mathrm{~S}_{2} \mathrm{O}_{7}$ ).

3. Fuse the sample over a low burner until a clear melt is obtained (about 30 seconds). Cool.

4. Add $0.4 \mathrm{ml}$ of concentrated sulfuric acid. Heat gently at a low temperature until all the fluorine is removed and a clear pyrosulfate melt is obtained. This fusion proceeds through several stages. In the first stage some frothing is apparent until the pad disintegrates. The melt is usually colored and muddy. In the second stage the melt thickens appreciably and becomes lighter in color. In the final stage a clear pyrosulfate melt is obtained. The total time for the complete process takes about $3 \frac{1}{2}$ minutes. Cool.

5. Add $10-15 \mathrm{ml}$ of water and $2 \mathrm{ml}$ concentrated sulfuric acid. Digest the melt on the steam bath. Stir occasionally until the melt is completely disintegrated.

6. Transfer the sample to a $100-\mathrm{ml}$ glass-stoppered graduated cylinder and increase to $100 \mathrm{ml}$ with water. Mix. A complete solution 
generally is obtained within 5 minutes. Sometimes a cloud (presumably anhydrous rare-earth sulfates) persists after 5 minutes. This is not important as long as the sample has been completely decomposed.

7. Disperse the mixture by shaking. Immediately draw off a $5-\mathrm{ml}$ aliquot and transfer to a glass-stoppered test tube.

8. Proceed according to steps 8-11 of the procedure for shales.

9. Take an $0.3-\mathrm{ml}$ aliquot and proceed as in the procedure for shales steps $12-16$.

\section{RESULTS OF ANALYSIS}

Tables 3, 4, and 5 list the results obtained by the carbonatefluorimetric procedure on shales, lignites, and monazites, respectively. The results for the shales and lignites agree closely with those obtained by the uranyl nitrate extraction procedure (part 6). The results on monazites agree with those obtained by colorimetric analysis (part 3). The carbonate precipitates from shales and lignites were also tested for uranium by the extraction procedure; uranium was not occluded.

TABLE 3.-Comparison of uranium analyses of shale by the carbonate-fluorimetric procedure and by the uranyl nitrate extraction procedure

\begin{tabular}{|c|c|c|c|c|c|c|c|}
\hline \multirow[b]{2}{*}{ Sample no. } & \multicolumn{2}{|c|}{ Analyses by- } & \multirow{2}{*}{$\begin{array}{c}\text { Percent } \\
\text { uranium } \\
\text { occluded } \\
\text { by car- } \\
\text { bonate } \\
\text { precipitate }\end{array}$} & \multirow[b]{2}{*}{ Sample no. } & \multicolumn{2}{|c|}{ Analyses by- } & \multirow{2}{*}{$\begin{array}{c}\text { Percent } \\
\text { uranium } \\
\text { occluded } \\
\text { by car- } \\
\text { bonate } \\
\text { precipitate }\end{array}$} \\
\hline & $\begin{array}{c}\text { Carbonate- } \\
\text { fluorimetric } \\
\text { procedure } \\
\text { (percent U) }\end{array}$ & $\begin{array}{c}\text { Uranyl } \\
\text { nitrate } \\
\text { extraction } \\
\text { (percent U) }\end{array}$ & & & $\begin{array}{l}\text { Carbonate. } \\
\text { fluorimetric } \\
\text { procedure } \\
\text { (percent U) }\end{array}$ & $\begin{array}{c}\text { Uranyl } \\
\text { nitrate } \\
\text { extraction } \\
\text { (percent U) }\end{array}$ & \\
\hline & 0.006 & 0.005 & 0.000 & 9. & 0.005 & 0.005 & 0,000 \\
\hline & .008 & .008 & .000 & 10. & .004 & .005 & .000 \\
\hline 3... & .005 & 005 & & & .005 & .005 & .000 \\
\hline & .007 & .00 & .000 & $\frac{12}{13 i}$ & .004 & .004 & .000 \\
\hline $6 . . .$. & .005 & .005 & .000 & $14 i^{\circ}$ & .014 & .015 & .000 \\
\hline & .006 & .00 & .000 & 151 & .005 & .005 & .000 \\
\hline & .003 & .0 & .000 & & .003 & .003 & \\
\hline
\end{tabular}

1 These samples are mineralized shales containing from 4 to 10 percent $\mathrm{CuO}$. Results for uranium obtained by the procedure using hydroxylamine hydrochloride.

TABLE 4.--Comparison of uranium analyses of lignites by the carbonate-fluorimetric procedure and by the uranyl nitrate extraction procedure

\begin{tabular}{|c|c|c|c|c|c|c|c|}
\hline \multirow[b]{2}{*}{ Sample no. } & \multicolumn{2}{|c|}{ Analyses by- } & \multirow{2}{*}{$\begin{array}{c}\text { Percent } \\
\text { uranium } \\
\text { occluceded } \\
\text { by car- } \\
\text { bonate } \\
\text { precipitate }\end{array}$} & \multirow[b]{2}{*}{ Sample no. } & \multicolumn{2}{|c|}{ Analyses by- } & \multirow{2}{*}{$\begin{array}{c}\text { Percent } \\
\text { uranium } \\
\text { occluded } \\
\text { by car- } \\
\text { bonate } \\
\text { precipitate }\end{array}$} \\
\hline & $\begin{array}{c}\text { Carbonate- } \\
\text { fluorimetric } \\
\text { procedure } \\
\text { (percent U) }\end{array}$ & $\mid \begin{array}{c}\text { Uranyl } \\
\text { nitrate } \\
\text { extraction } \\
\text { (percent U) }\end{array}$ & & & $\begin{array}{c}\text { Carbonate- } \\
\text { fluorimetric } \\
\text { procedure } \\
\text { (percent U) }\end{array}$ & $\begin{array}{c}\text { Uranyl } \\
\text { nitrate } \\
\text { extraction } \\
\text { (percent U) }\end{array}$ & \\
\hline 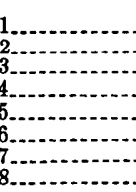 & $\begin{array}{r}0.015 \\
.011 \\
.012 \\
.012 \\
.011 \\
.010 \\
.018 \\
.017\end{array}$ & \begin{tabular}{r|}
0.016 \\
.011 \\
.011 \\
.013 \\
.011 \\
.010 \\
.016 \\
.018
\end{tabular} & $\begin{array}{l}0.000 \\
.000 \\
.000 \\
.000 \\
.000 \\
.000 \\
.000 \\
.000\end{array}$ & $\begin{array}{l}9 \\
10 \\
112 \\
12 \\
13 \\
15\end{array}$ & $\begin{array}{r}0.018 \\
.015 \\
.024 \\
.027 \\
.014 \\
.024 \\
.027\end{array}$ & $\begin{array}{r}0.019 \\
.015 \\
.025 \\
.029 \\
.013 \\
.025 \\
.029\end{array}$ & $\begin{array}{r}0.000 \\
.000 \\
.000\end{array}$ \\
\hline
\end{tabular}


DETERMINATION URANIUM-SHALES, LIGNITES, MONAZITES 119

TABLE 5.-Results of uranium analyses"of monazites

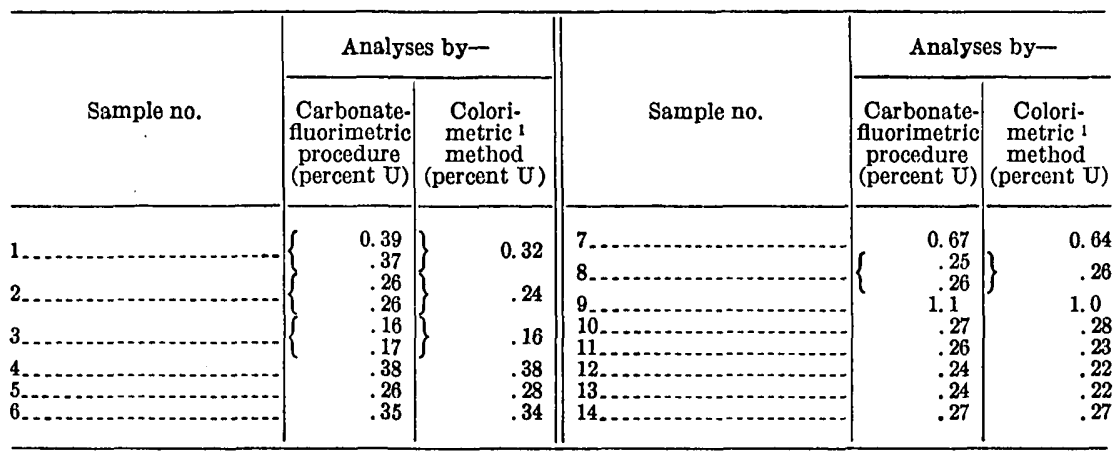

1 Analyst, Henry Mela, U. S. Geological Survey. 


\section{Part 16. NONINTERFERENCE OF ARSENATE ION IN THE VOLUMETRIC DETERMINATION OF URANIUM USING THE JONES REDUCTOR}

By JAck J. Rowe

\section{CONTENTS}

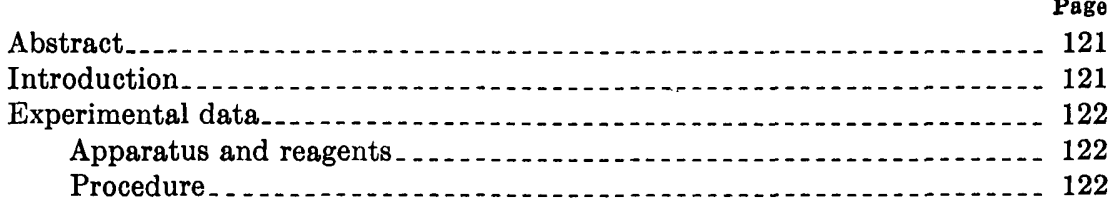

\section{TABLES}

TABLE 1. Consumption of permanganate after passage of arsenate ion through Jones reductors and aeration..................

2. Lack of interference of arsenate ion in the volumetric determination of uranium using zinc amalgams

3. Effect of aeration on the consumption of permanganate...... 123

\section{ABSTRACT}

Arsenate ions in sulfuric acid solution do not interfere in the volumetric determination of uranium if zinc amalgam reductors are used. Tests on zinc reductors amalgamated with 2,3 , and 10 percent, by weight, of mercury indicate that the arsenate ion is reduced slightly but this interference is almost eliminated during the aeration of the solutions after passage through the reductors and before titration.

\section{INTRODUCTION}

Most chemists consider that arsenic interferes in determining uranium and other elements that are commonly determined by means of reduction-oxidation reactions involving the use of zinc amalgams. ${ }^{12}$

Nork.--This report was issued as Trace Elements Memo. Rept. 316, 1951.

1 Hillebrand, W. F., and Lundell, G. E. F., 1929, Applied inorganic analysis, p. 102, New York, John Wiley and Sons.

2 Kolthoff, I. M., and Sandell, E. B., 1948, Textbook of quantitative inorganic analysis, p. 599, New York, The Macmillan Co.

$268681-54-9$ 
Many procedures for the volumetric determination of uranium make provision for the initial removal of arsenic by volatilizing it as the trichloride or tribromide or by precipitating it as the sulfide. ${ }^{3}$ In the course of an investigation to determine the extent of arsenic interference, it was found that arsenate is not appreciably reduced in the reactions and does not interfere seriously in the volumetric determination of uranium.

\section{EXPERIMENTAL DATA}

\section{APPARATUS AND REAGENTS}

Jones reductors: $\quad 1$. One filled with zinc amalgam containing 2 percent by weight of mercury.

2. One containing 3 percent by weight of mercury.

3. One containing 10 percent by weight of mercury.

The reductor tubes had a diameter of $5 / 8$ of an inch, and the amalgam was packed in each to a column height of 12 inches.

Arsenate solution: Sodium arsenate solution was made by dissolving pure $\mathrm{As}_{2} \mathrm{O}_{3}$ in sodium hydroxide solution, acidifying with sulfuric acid, and oxidizing with permanganate solution using a trace of $\mathrm{KIO}_{3}$ as a catalyst. The final solution contained 10 percent by volume sulfuric acid.

Uranium solution: This solution was made from $\mathrm{U}_{3} \mathrm{O}_{8}$ (99.96 percent pure) (standard)

fused with $\mathrm{K}_{2} \mathrm{~S}_{2} \mathrm{O}_{7}$ and the melt dissolved in 10 percent by volume $\mathrm{H}_{2} \mathrm{SO}_{4}$.

\section{PROCEDURE}

To determine whether arsenate would consume permanganate after passage through the Jones reductor and aeration, 50-ml volumes of sodium arsenate solution, 10 percent by volume in sulfuric acid, were passed through the three reductors (2, 3, and 10 percent). Each solution was then aerated for 5 minutes. After the addition of one drop of $0.002 \mathrm{M}$ potassium iodate as a catalyst, the solutions were titrated with standard potassium permanganate, $0.03 \mathrm{~N}$. The results are given in table 1 . We cannot conclude from these results that arsenate ion is not reduced at all. It is possible that some arsenate was reduced to $\mathrm{As}^{+++}$and subsequently reoxidized by air or that some was reduced to arsine and oxidized or removed from solution by the air stream.

- Rodalen, Cloment $J_{\text {.. }}$ 1050. Analytionl ehemistry of the Manhattan project, p. 56, 138, 142, New York, McGraw-Hill Book Co., Inc. 
TABLE 1.-Consumption of permanganate after passage of arsenate ion through Jones reductors and aeration

\begin{tabular}{|c|c|c|c|c|c|c|c|}
\hline $\begin{array}{l}\text { Reductor } \\
\text { (percent) }\end{array}$ & $\begin{array}{c}\text { Sodium } \\
\text { arsenate } \\
\text { taken, } \\
\text { calculated } \\
\text { as As (g) }\end{array}$ & $\underset{(\mathrm{ml})}{\mathrm{KMnO}}$ & $\begin{array}{c}\text { Equivalent } \\
U_{3} \mathrm{O}_{8} \text { (g) } \\
\text { (corrected } \\
\text { for blank) }\end{array}$ & $\underset{\text { (percent) }}{\text { Reductor }}$ & $\begin{array}{l}\text { Sodium } \\
\text { arsenate } \\
\text { taken, } \\
\text { calculated } \\
\text { as As (g) }\end{array}$ & $\underset{(\mathrm{ml})}{\mathrm{KMnO}}$ & $\begin{array}{l}\text { Equivalent } \\
U_{3} \mathrm{O}_{3}(\mathrm{~g}) \\
\text { (corrected } \\
\text { for blank) }\end{array}$ \\
\hline & $\begin{array}{l}0.05 \\
\quad .5\end{array}$ & $\begin{array}{r}0.3 \\
.3 \\
1\end{array}$ & $\begin{array}{r}0.0008 \\
.0008\end{array}$ & 10 & $\begin{array}{r}0.05 \\
.5\end{array}$ & $\begin{array}{l}0.2 \\
.25\end{array}$ & $\begin{array}{r}0.0004 \\
.0006\end{array}$ \\
\hline 3... & (1) .05 & $\begin{array}{l}.3 \\
.3 \\
.05\end{array}$ & .0008 & & & & \\
\hline
\end{tabular}

1 Blank.

To determine whether the presence of arsenate ions would interfere when uranium is determined by these methods, solutions were made containing various amounts of sodium arsenate and uranium in $(1+9)$ sulfuric acid. Fifty milliliters of each solution were passed through the reductors. The solutions were then aerated for 5 minutes, one drop of $0.002 \mathrm{M}$ potassium iodate was added to each, and they were then titrated with permanganate. The results are shown in table 2.

TABLE 2.-Lack of interference of arsenate ion in the volumetric determination of uranium using zinc amalgams

\begin{tabular}{|c|c|c|c|c|c|c|c|}
\hline $\begin{array}{l}\text { Reductor } \\
\text { (percent) }\end{array}$ & $\begin{array}{c}\mathrm{U}_{3} \mathrm{O}_{8} \text { taken } \\
(\mathrm{g})\end{array}$ & $\begin{array}{l}\text { Sodium } \\
\text { arsenate } \\
\text { taken, } \\
\text { calculated } \\
\text { as As (g) }\end{array}$ & $\underset{(\mathrm{ml})}{\mathrm{KMnO}_{4}}$ & $\begin{array}{l}\text { Reductor } \\
\text { (percent) }\end{array}$ & $\begin{array}{c}\mathrm{U}_{3} \mathrm{O}_{8} \text { taken } \\
(\mathrm{g})\end{array}$ & $\begin{array}{c}\text { Sodium } \\
\text { arsenate } \\
\text { taken, } \\
\text { calculated } \\
\text { as As (g) }\end{array}$ & $\underset{(\mathrm{ml})}{\frac{0.03 \mathrm{~N}}{\mathrm{KMnO}}}$ \\
\hline 3..... & $\begin{array}{r}0.05 \\
.05 \\
.05 \\
.10 \\
.10 \\
.10 \\
.15 \\
.15\end{array}$ & $\begin{array}{c}\text { None } \\
0.05 \\
.5 \\
\text { None } \\
.05 \\
.5 \\
\text { None } \\
.05\end{array}$ & $\begin{array}{l}11.70 \\
11.90 \\
11.90 \\
23.50 \\
23.75 \\
23.75 \\
35.10 \\
35.00\end{array}$ & $10 \ldots$ & $\begin{array}{l}0.05 \\
.05 \\
.05 \\
.10 \\
.10 \\
.10\end{array}$ & $\begin{array}{c}\text { None } \\
0.05 \\
.5 \\
\text { None } \\
.05 \\
.5\end{array}$ & $\begin{array}{l}11.70 \\
11.75 \\
11.80 \\
23.40 \\
23.40 \\
23.40\end{array}$ \\
\hline
\end{tabular}

To determine the influence of aeration on the consumption of permanganate, four separate arsenate solutions were passed through the 3-percent reductor. Two of the solutions were aerated and two were not before the titration with permanganate. The results of this experiment are given in table 3.

TABLE 3.-Effect of aeration on the consumption of permanganate

\begin{tabular}{|c|c|c|c|}
\hline Solution no. & $\begin{array}{l}\text { Sodium } \\
\text { arsenate } \\
\text { taken, } \\
\text { calculated } \\
\text { as As (g) }\end{array}$ & Procedure & $\underset{(\mathrm{ml})}{0.03 \mathrm{~N}}$ \\
\hline 1 & $\begin{array}{r}0.1 \\
.1 \\
.5 \\
.5\end{array}$ & 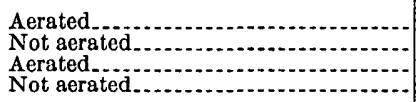 & $\begin{array}{r}0.25 \\
.60 \\
.30 \\
2.00\end{array}$ \\
\hline
\end{tabular}


This experiment shows that some reduction of arsenate ion is obtained (solutions 2 and 4) but that the interference is minimized by aeration. It would be of interest to determine the actual valence state or states of the reduced arsenic. As aeration, an essential step in the volumetric determination of uranium, eliminates interference by the reduced forms of arsenic, no attempt was made to pursue the problem.

It would be reasonable to assume that:

1. Most of the arsenate is not reduced. This was indicated qualitatively by the formation of a sulfide precipitate (subsequent to the passage of arsenate through the reductors) with hydrogen sulfide at an acidity favorable for the precipitation of arsenic pentasulfide and unfavorable for the precipitation of arsenic trisulfide. Furthermore the size of the precipitate indicated that arsenic had been completely recovered.

2. Little if any of the arsenate is reduced to the trivalent state. Were this to occur, a high consumption of the permanganate would be obtained in the unaerated solutions. It is also doubtful that air could oxidize trivalent arsenic in 10 percent (by volume) sulfuric acid solutions.

3. A small amount of the arsenic is reduced to arsine. This would account for the small titration obtained in the unaerated solutions. The smaller titration obtained after aeration could be explained by mechanical removal of arsine by air. The small residual titration obtained after aeration is probably due either to the incomplete removal of arsine or to the slight oxidation of arsine to the arsenite during the aeration.

4. Arsenate is not reduced to metallic arsenic. This was indicated by the lack of darkening of the reductors even after the passage of more than $5 \mathrm{~g}$ of arsenic. 


\title{
Part 17. THE FLUORIMETRIC DETERMINATION OF URANIUM IN NONSALINE AND SALINE WATERS
}

\author{
By Audrey Pietsch Smith and F. S. Grimaldi
}

\section{CONTENTS}

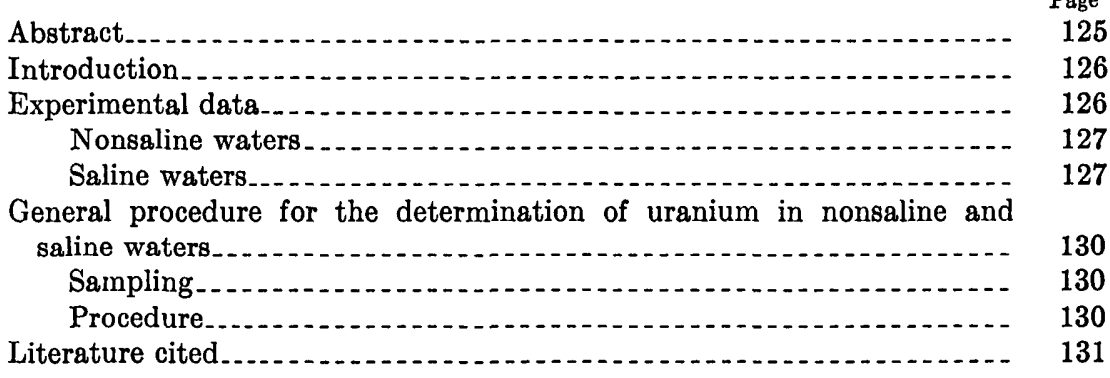

\section{TABLES}

TABLE 1. Uranium found in distilled water after the addition of known amounts of uranium

2. Comparison of results of two methods of fluorimetric uranium determination of naturally occurring nonsaline waters....... -

3. Uranium analyses of synthetic sea-water solutions containing

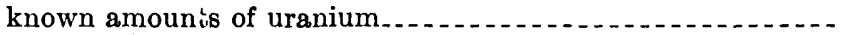

4. Test of procedure on a sea-water sample from the surf at Ocean City, Md.

5. Uranium found in sea water from Ocean City, Md., after addition of known amounts of uranium

6. Uranium found in water samples from the coast of Florida....-

\section{ABSTRACT}

The procedure determines about $10^{-8}$ percent uranium using $500-\mathrm{ml}$ samples of water. Uranium is concentrated by precipitating uranyl phosphate using aluminum phosphate as a carrier. The aluminum phosphate is dissolved in nitric acid, salted with aluminum nitrate, and the uranium is extracted with ethyl acetate. A portion of the ethyl acetate is evaporated in a standard platinum dish and a fluorescing disc is prepared with a mixed fluoride flux. Fluorescence measurements are made with a fluorimeter. One precipitation with aluminum phosphate collects more than 95 percent of the uranium. The uranium content of various ocean waters tested ranged from $2.3 \times 10^{-7}$ to $3.4 \times 10^{-7}$ percent uranium.

Note.-This report was issued as Trace Elements Inv. Rept. 181, 1952. 


\section{INTRODUCTION}

In the determination of uranium in waters containing slightly more than $10^{-8}$ percent uranium, it is frequently necessary to concentrate the uranium before its estimation by the fluorescence method using fluoride phosphors. The uranium in waters of low salinity can be concentrated by simple evaporation of the water, but this method is not as useful for saline waters, where the problem is not only to concentrate the uranium but to separate it from large amounts of salts that would cause subsequent analytical difficulties.

Hernegger and Karlik (1934) isolated uranium from sea water by precipitating the uranium with ammonium hydroxide using a small amount of ferric iron as a carrier. This carrier has also been used by others (Lahner, 1939; Hoffman, 1939; and Urry, 1941) for concentrating uranium from rocks and from ocean sediments. Other useful collectors for uranium include aluminum hydroxide (Urry, 1941, and Orlemann, 1945) and aluminum phosphate (Tschernichow and Guldina, 1934).

Aluminum phosphate has certain advantages as a carrier for uranium. Especially important is the ease with which aluminum phosphate can be dissolved with dilute acids even after it is aged or ignited. We have found aluminum phosphate to be an efficient collector even for less than microgram amounts of uranium.

This paper presents a simple fluorimetric method for the determination of uranium in naturally occurring waters. Preliminary concentration of uranium is made by precipitating uranyl phosphate using aluminum phosphate as the carrier. After dissolving the aluminum phosphate in nitric acid and salting the solution with aluminum nitrate, the uranyl nitrate is isolated by extraction with ethyl acetate (part 6). The relative fluorescence of the disc is measured in a fluorimeter (part 10). The procedure is designed to determine $10^{-8} \mathrm{~g}$ of uranium as a lower limit and uses $100-$ to $500-\mathrm{ml}$ samples of water.

EXPERTMENTAY DATA

The procedure recommended is based on two operations-the coprecipitation of uranium with aluminum phosphate, and the isolation of uranyl nitrate by ethyl acetate extraction from solutions salted with aluminum nitrate. The reliability of the extraction process has been domonstrated and is a standard procoduro in tho laboratory of the Geological Survey for the isolation of uranium from many naturally occurring materials before the estimation of uranium by the fluorescence method. The major aim is to show that aluminum phosphate is an efficient collector for uranium.

Data on the efficiency of aluminum phosphate as a carrier for uranium were obtained by several more or less independent techniques. 


\section{NONSALINE WATERS}

The following techniques were used in testing nonsaline waters:

1. Known amounts of uranium were added to separate $500-\mathrm{ml}$ aliquots of distilled water. Analysis for uranium was then made according to the recommended procedure of this report. The recoveries obtained are given in table 1, column 3 .

2. The amount of uranium left in the filtrates after the precipitation and filtration of the aluminum phosphate was determined. This was accomplished in the following manner: The filtrates were evaporated to dryness and the ammonium salts were destroyed by aqua regia. Chlorides were converted to nitrates by evaporation with nitric acid, and the nitric acid solutions obtained were extracted with ethyl acetate after adding the requisite amount of aluminum nitrate for salting. The uranium in the ethyl acetate layers was determined fluorimetrically and the results corrected for the small amount of uranium introduced by the reagents are given in table 1 , column 4 . The tests on the filtrates show that more than 95 percent of the uranium is collected by the aluminum phosphate. Some samples, table 1, showed slightly low overall recoveries of uranium. These errors are inherent in the fluorimetric procedure. For instance, it is sometimes difficult to burn the ethyl acetate without a slight loss. Some quenching of the uranium fluorescence occurs because platinum may be dissolved from the fusion vessel. This may occur if there is accidental overheating during the preparation of the standard disc.

3. Naturally occurring waters were used in $500-\mathrm{ml}$ aliquots and uranium was determined by alternate methods. In one method the procedure of this report was used. In the other, concentration of uranium was made by simple evaporation of the water and the uranium was extracted directly without prior precipitation with aluminum phosphate. The results by the two methods are given in table 2. The agreement is close and differences are no greater than the reproducibility of either method.

\section{SALINE WATERS}

In testing saline waters, the following techniques were used:

1. To 500-ml aliquots of a synthetic solution made to approximate the composition of ocean water known amounts of uranium were added. Uranium was then determined by the recommended procedure, and the amounts found are given in table 3 .

2. In another set of experiments, actual ocean waters were used. Quadruplicate uranium determinations were made on a sample of water obtained from the surf at Ocean City, Md. (table 4). The filtrates from the aluminum phosphate precipitates were further treated as follows: On filtrates 1 and 2 the aluminum phosphate precipitation was repeated and the precipitate analyzed for uranium to 
determine if the second precipitation would recover more uranium. Known amounts of uranium were added to filtrates 3 and 4 , the aluminum phosphate precipitation repeated, and the precipitate analyzed for uranium. The results of determinations on these four filtrates are given in table 4 . The results of tests on Ocean City water after the addition of known amounts of uranium are given in table 5 .

Table 6 gives the location and uranium content of waters collected off the coast of Florida.

The uranium content of the Ocean City water and the waters from the Gulf of Mexico is greater than the content generally found in other ocean waters by earlier investigators (Hernegger and Karlik, 1934, and Koczy, 1950). This may be a purely local condition. Our results are in line with the recent results of Nakanishi (1951).

TABLE 1.-Uranium found in distilled water after the addition of known amounts of uranium

\begin{tabular}{|c|c|c|c|c|c|c|c|}
\hline Sample no. & $\begin{array}{l}\text { Uranium } \\
\text { added } \\
\text { (micro- } \\
\text { grams) }\end{array}$ & $\begin{array}{l}\text { Uranium } \\
\text { found } 1 \\
\text { (micro- } \\
\text { grams) }\end{array}$ & $\begin{array}{l}\text { Uranium } \\
\text { found in } \\
\text { fltrates } \\
\text { from AlPO، } \\
\text { separation } \\
\text { (micro- } \\
\text { grams) }\end{array}$ & Sample no. & $\begin{array}{l}\text { Uranium } \\
\text { added } \\
\text { (micro- } \\
\text { grams) }\end{array}$ & $\begin{array}{l}\text { Uranium } \\
\text { found } 1 \\
\text { (micro* } \\
\text { grams) }\end{array}$ & $\begin{array}{l}\text { Uranium } \\
\text { found in } \\
\text { fltrates } \\
\text { from AlPO } \\
\text { separation } \\
\text { (micro- } \\
\text { grams) }\end{array}$ \\
\hline $\begin{array}{l}1 \\
1 \\
4 \\
5 \\
6 \\
7\end{array}$ & $\begin{array}{l}0.09 \\
.09 \\
.30 \\
.45 \\
.45 \\
1.2 \\
1.8\end{array}$ & $\begin{array}{l}0.11 \\
.09 \\
.32 \\
.44 \\
.40 \\
1.4 \\
1.6\end{array}$ & $\begin{array}{r}<0.01 \\
<.01 \\
.02 \\
.01\end{array}$ & $\begin{array}{l}8 \\
9 \\
10 \\
11 \\
13\end{array}$ & $\begin{array}{l}1.8 \\
9.0 \\
9.0 \\
18 \\
36 \\
36\end{array}$ & $\begin{array}{l}1.7 \\
8.3 \\
8.5 \\
17 \\
34 \\
35\end{array}$ & $\begin{array}{r}0.01 \\
04 \\
01\end{array}$ \\
\hline
\end{tabular}

1 In samples 7-13 a correspondingly smaller alfquot of the ethyl acetate extract was used for the determina. tion of uranium because the normal aliquot yields fluorescence intensities beyond the range of the working curve.

TABLE 2.-Comparisons of results of two methods of fluorimetric uranium determination on naturally occurring nonsaline waters

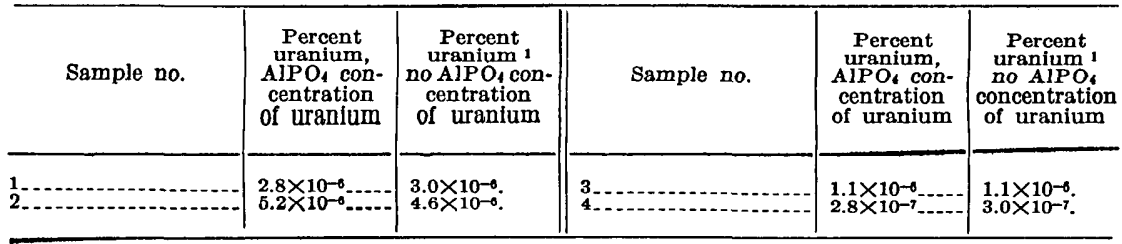

1 Analyst, A. M. Sherwood, U. S. Geological Survey.

TАвт. 3-Uranium analyses of synthetic sea-water solutions containing known

\begin{tabular}{|c|c|c|c|c|c|}
\hline Sample no. & $\begin{array}{c}\text { Uranium } \\
\text { added } \\
\text { (micro- } \\
\text { grams) }\end{array}$ & $\begin{array}{l}\text { Uranium } \\
\text { found } \\
\text { (micro. } \\
\text { grams) }\end{array}$ & Sample no. & $\begin{array}{l}\text { Uranium } \\
\text { added } \\
\text { (micro- } \\
\text { grams) }\end{array}$ & $\begin{array}{l}\text { Uranium } \\
\text { found } \\
\text { (micro- } \\
\text { grams) }\end{array}$ \\
\hline 1 & $\begin{array}{l}0.36 \\
.72 \\
1.80 \\
1.80\end{array}$ & $\begin{array}{l}0.35 \\
.70 \\
1.77 \\
1.79\end{array}$ & $\begin{array}{l}5 \\
6 \\
7 \\
7\end{array}$ & $\begin{array}{l}1.80 \\
3.60 \\
3.60\end{array}$ & $\begin{array}{l}1.80 \\
3.30 \\
3.34\end{array}$ \\
\hline
\end{tabular}


TABLE 4.-Test of procedure on a sea-íwater sample from the suirf át: Ocean City, Md.

\begin{tabular}{|c|c|c|c|}
\hline Sample no. & 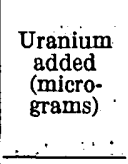 & $\begin{array}{ll} & \\
& \end{array}$ & $\begin{array}{l}\text { Uranium } \\
\text { found in } \\
\text { 2d AlPO, } \\
\text { precipitatlon } \\
\text { (micro- } \\
\text { grams) }\end{array}$ \\
\hline 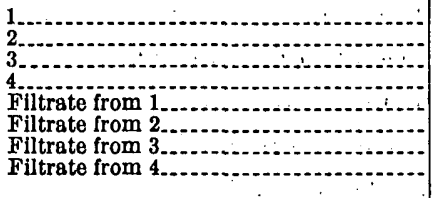 & 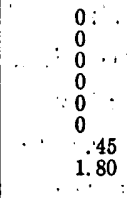 & $\begin{array}{l}1.1 \\
1.2 \\
1.1\end{array}$ & $\begin{array}{r}0.01 \\
0.01 \\
0 \quad 48 \\
1.74\end{array}$ \\
\hline
\end{tabular}

TABLE 5.-Uranium found in sea water from Ocean City, Md., after addition of known amounts of uranium.

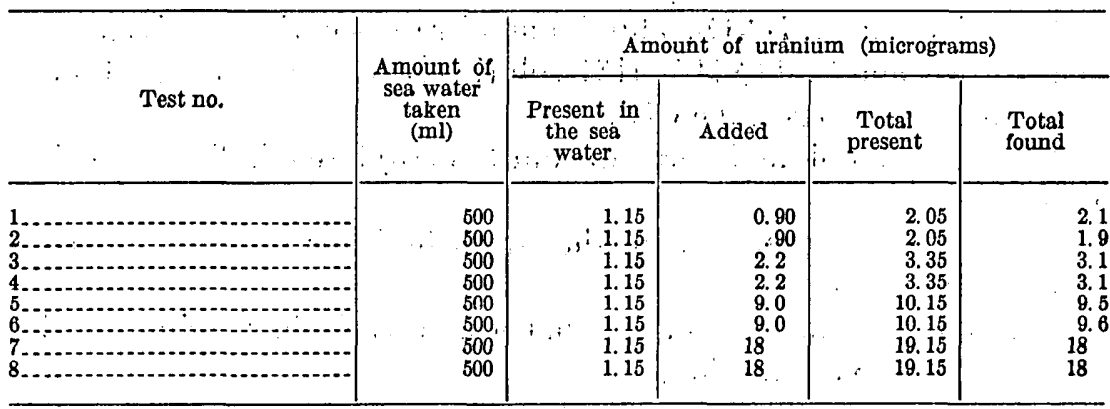

TABLE 6.-Uranium found in water samples from coast of Florida (Gulf of Mexico and near the Indian River estuary) ${ }^{1}$

\begin{tabular}{|c|c|c|c|c|}
\hline \multirow{2}{*}{ Sample no. } & \multicolumn{2}{|c|}{ Location } & \multirow{2}{*}{$\begin{array}{l}\text { Depth of } \\
\text { water } \\
\text { (fathoms) }\end{array}$} & \multirow{2}{*}{$\begin{array}{l}\text { Uranium } \\
\text { (percent) }\end{array}$} \\
\hline & Latitude & Longitude ${ }^{\circ}$ & & \\
\hline 1 & $\begin{array}{l}26^{\circ} 31^{\prime} \mathrm{N} \\
26^{\circ} 39^{\prime} \mathrm{N} \\
28^{\circ} 1.5^{\prime} \mathrm{N} \\
28^{\circ} 2.5^{\prime} \mathrm{N} \\
\mathrm{N}\end{array}$ & $\begin{array}{l}83^{\circ} 10^{\prime} \mathrm{W} \\
82^{\circ} 31^{\prime}, \ldots . . . \\
80^{\circ} 32.5^{\prime} \mathrm{W} \\
80^{\circ} 32.2^{\prime} \mathrm{W}\end{array}$ & $\begin{array}{r}25 \\
11 \\
5 \\
8\end{array}$ & $\begin{array}{l}3.2 \times 10^{-7} \\
3.4 \times 10^{-7} \\
3.0 \times 10^{-7} \\
3.0 \times 10^{-1}\end{array}$ \\
\hline
\end{tabular}

Filtrates from simples 1 and 3

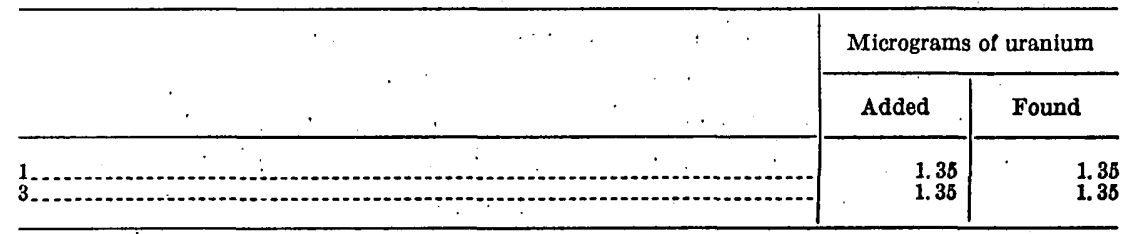

1 Collected by Albert Collier, U. S. Fish and Wildlife Service.

2 Surface samples. 


\section{GENERAL PROCEDURE FOR THE DETERMINATION OF URANIUM IN NONBALINE AND SALINE WATERS}

\section{SAMPIING}

In sampling waters it is good practice to add acid (about $8 \mathrm{ml}$ of nitric acid per gallon of water) immediately after collection. If the water sample contains sediment, the sediment should be separated by decantation or by filtration through a porous filter before adding acid to the water. Unacidified water samples tend to decrease in uranium concentration during storage because some of the uranium may be precipitated or adsorbed on the glass (Koczy, 1950).

\section{PROCEDURE}

1. Transfer a 500-ml aliquot of water to an $800-\mathrm{ml}$ beaker.

2. Add $3 \mathrm{ml}$ of $\mathrm{HNO}_{3}$, aluminum nitrate solution equivalent to $20 \mathrm{mg} \mathrm{Al} \mathrm{O}_{3}$, and $5 \mathrm{ml}\left(\mathrm{NH}_{4}\right)_{2} \mathrm{HPO}_{6}$ solution [1 $\mathrm{cc}=12 \mathrm{mg}\left(\mathrm{NH}_{4}\right)_{2} \mathrm{HPO}_{4}$ ]. Heat to boiling to remove $\mathrm{CO}_{2}$.

3. Add ammonium hydroxide until methyl red indicator is just yellow.

4. Digest the precipitate on the steam bath for about 10 minutes. Stir in paper pulp.

5. Filter the solution on a fast paper and wash the precipitate with 1 percent $\mathrm{NH}_{4} \mathrm{NO}_{3}$ solution.

6. Transfer the precipitate and paper to a clean $25-\mathrm{ml}$ porcelain crucible and ignite at low temperature to remove carbon.

7. Add $5 \mathrm{ml}$ of $(15+85) \mathrm{HNO}_{3}{ }^{1}$ and warm gently to dissolve the salts (avoid significant evaporation of the solution).

8. Add $9.5 \mathrm{~g} \mathrm{Al}\left(\mathrm{NO}_{3}\right)_{3} \cdot 9 \mathrm{H}_{2} \mathrm{O}$ and warm to dissolve the salt.

9. Pour the solution into a dry $30-\mathrm{ml}$ glass-stoppered graduated test tube. Do not wash the crucible.

10. Add $10 \mathrm{ml}$ of ethyl acetate by pipette or buret and shake the mixture for about 1 to 2 minutes. Allow the layers to separate for a few minutes.

11. Filter about $8 \mathrm{ml}$ of the ethyl acetate through a dry Whatman no. 42 filter paper into a dry test tube.

12. Transfer a 2-ml aliquot (more or less may be necessary depending on the uranium content of the water) of the filtered ethyl acetate into a standard platinum container, part 13. Place the dish on four layers of water-soaked paper that rest in a pan containing about $1 / 16$ inch of water and ignite the ethyl acetate with a lighted splinter. After the ethyl acetate has burned off, evaporate the residue on steam bath.

\footnotetext{
1 Present practice is to use $5 \mathrm{ml}$ of $(7+93) \mathrm{HNO}$ (part 1, extraction method).
} 
13. Add $2 \mathrm{~g}$ of the mixed fluoride flux (prepared by grinding or mixing together 9 parts $\mathrm{NaF}, 45.5$ parts $\mathrm{Na}_{2} \mathrm{CO}_{3}$ and 45.5 parts $\mathrm{K}_{2} \mathrm{CO}_{3}$, by weight).

14. Heat over a burner until the flux melts and then for an additional 2 to 4 minutes, mixing and swirling the contents to assure a uniform melt. All heating should be done at the lowest temperature at which the flux stays molten. The temperature of the melt should not be allowed to exceed $700 \mathrm{C}$ during the heating period.

15. Measure the relative fluorescence of the melt with a fluorimeter.

\section{LITERATURE CITED}

Hernegger, F., and Karlik, B., 1934, Die quantitative Bestimmung sehr kleiner Uranmengen und der Urangehalt des Meerwassers: Akad. Wiss. Wien, Math.-naturwiss. Kl., Sitzungsber., Abt. IIa, 144 Band, p. 217.

Hoffman, J., 1939, Uran in Gesteinen und Sedimenten des Erzbesbirgsbruches: Akad. Wiss. Wien, Math.-naturwiss. Kl., Sitzungsber., Abt. IIa, 148 Band, p. 189.

Koczy, Gerta, 1950, Weitere Uranbestimmungen an Meerwasserproben: Akad. Wiss. Wien, Math.-naturwiss. Kl., Sitzungsber., Abt. IIa, 158 Band, 1-5 Heft, p. 113-122.

Lahner, I., 1939, Uran und Thorium Bestimmungen an Kalken und Dolomiten und die Frage des radioaktiven Gleichgewichtes in diesen Gesteinen: Akad. Wiss. Wien, Math.-naturwiss. Kl., Sitzungsber., Abt. IIa, 148 Band, p. 149.

Nakanishi, M., 1951, Fluorometric microdetermination of uranium. V. The uranium content of sea water: Chem. Soc. Japan Bull., v. 24, no. 1, p. 36.

Orlemann, E. F., 1945, Progress report, Clinton Engineering Works, CEW-TEC CD 2244.

Tschernichow, J. A., and Guldina, E., 1934, Colorimetrische Bestimmung von Uran in uranarmen Erzen: Zeitschr. anal. Chemie., v. 96, p. 260.

Urry, W. D., 1941, The radioactive determination of small amounts of uranium: Am. Jour. Sci., v. 239, p. 191-203. 


\title{
Part 18. THE GEOLOGICAL SURVEY PHOSPHATE-FLUO- RIDE-IODATE METHOD FOR THE DETERMINATION OF VERY SMALL AMOUNTS OF THORIUM IN NATURALLY OCGURRING MATERIALS
}

\author{
By F. S. Grimaldi and J. G. Fairchild
}

\section{CONTENTS}

Abstract

Introduction

Outline of procedure 135

Discussion of general procedure

Discussion of special procedure 138

General procedure

The chemical concentration of thorium 139

The estimation of thorium

Method A. Nephelometrically as the iodate............... 141

Method B. Photometrically with $p$-dimethylaminoazophenylar-

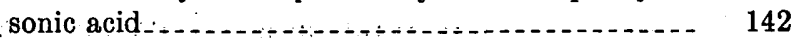

Method C. Gravimetrically with ammonia and peroxide...... 142

Special procedure for monazite

Experiments . . . .

1. Analysis of synthetic mixtures

2. Occlusion of rare earths with the phosphate precipitate

3. Failure of hydrofluoric acid separation of thorium from zirconium in the presence of alkaline earths and alkalies . . . . . . . . .

4. Nonocclusion of zirconium, titanium, and iron by thorium fluoride when mercurous chloride is used as carrier

5. Optimum conditions for the precipitation of thorium with $\dot{p}$-di-

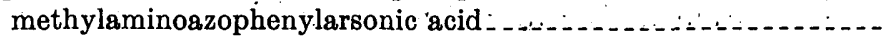

6. Interference of oxidizing agents in the photometric determination of thorium -

7. Spectral transmittancy and standard curves for the photometric determination of thorium with $p$-dimethylaminoazophenylarsonic acid ... . . .

8. Inhomogeneity of the reagent $p$-dimethylaminoazophenylarsonic acid _...

Literature cited....... 


\section{ILLUSTRATIONS}

Figure 21. Spectral transmittancy curve for the determination of tho-

rium with $p$-dimethylaminoazophenylarsonic acid..........

Page 150

22. Fisher electrophotometer readings for the photometric determination of thorium with $p$-dimethylaminoazophenylarsonic

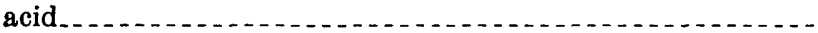

151

\section{TABLES}

TABLE 1. Analysis of synthetic mixtures.

2. Analysis of synthetic mixtures

\section{ABSTRACT}

Detailed procedures are presented for the determination of very small percentages of thorium. The methods are designed to determine 0.001 percent of thorium oxide as the lower limit and are applicable to silicate and phosphate rocks. For quantities below $1 \mathrm{mg}$ of thorium oxide, the thorium is determined nephelometrically as the iodate or photometrically with $p$-dimethylaminoazophenylarsonic acid. For quantities of thorium above $1 \mathrm{mg}$ of thorium oxide, the thorium is determined gravimetrically. A discussion of the important features of the methods and a summary of the more important experimental work that led to the adoption of the procedures are given.

\section{INTRODUCTION}

In the work of the Trace Elements project of the U. S. Geological Survey it was necessary to know the thorium content of samples for which measurements of total radioactivity and uranium content had been made. Methods had to be developed by which accurate determinations of very small percentages of thorium could be made on rocks and ores of widely varying types. This report presents some of the procedures developed in the chemical laboratory of the Geological Survey that are now in use.

In any method for the determination of thorium, the thorium must be separated from other elements, of which titanium, zirconium, and rare earths are particularly troublesome. In addition, a suitable means of measurement is required for quantities of thorium less than $1 \mathrm{mg}$. The problem is complicated by the wide variety of materials to be analyzed, which included many types of rocks, and metallic and nonmetallic ores. The high phosphate content of some samples (as much as 35 percent $\mathrm{P}_{2} \mathrm{O}_{6}$ ) is particularly troublesome. The methods found in the literature were found wanting in one or more respects.

These methods are outlined, with some discussion, by Hillebrand and Lundell (1929). The thiosulfate (Fresenius and Hintz, 1896, p. 525) and peroxide (Wyrouboff and Verneuil, 1898, p. 340) separations fail in the presence of phosphate. The precipitation of thorium 
as fluoride and as iodate are used under conditions modified from those in the literature. Thus, in the iodate method (Meyer, 1911, p. 65), the acidity recommended in the literature is too high for complete precipitation of small amounts of thorium.

The procedure given below is complex and slow. However, it can be simplified considerably for the analysis of less complex materials than those dealt with by us.

\section{OUTLINE OF PROCEDURE}

The essential features of the method are as follows:

1. Complete decomposition of the sample. It cannot be assumed that no thorium is present in undecomposed material.

2. Precipitation of thorium phosphate using zirconium or titanium as carrier, the precipitation being made at an acidity of $0.3 \mathrm{~N}$ hydrochloric acid. (Separation from the bulk of constituents.)

3. Concentration of thorium as fluoride by two treatments with hydrofluoric acid, mercurous chloride being used as carrier. (Separation from titanium, zirconium, iron, niobium, tantalum, and phosphate.)

4. Solution of the thorium fluoride in sulfuric acid.

5. Precipitations as thorium iodate. (Separation from rare earths.)

6. Estimation of thorium (a) nephelometrically as the iodate, or (b) photometrically with $p$-dimethylaminoazophenylarsonic acid, or (c) gravimetrically with ammonia and hydrogen peroxide.

In the general procedure monazite and rare-earth mineral concentrates yield large fluoride precipitates that tend to occlude small amounts of zirconium. If the first hydrofluoric acid precipitate is large, the procedure is modified by changing the order of the separations. The precipitations as iodate are interposed between the first and second fluoride precipitations. The rare earths are thus removed before the final hydrofluoric acid precipitation and a better separation of the zirconium is obtained. (Special procedure for monazite.)

\section{DISCUSAION OF GENERAL PROCEDURE}

Separation.-The sample is completely decomposed and a hydrochloric acid solution of the sample is made (part 2). Use of sulfuric acid or bisulfate fusions in preparing the solution is avoided if much calcium is present, as with phosphate and carbonate rocks, because any calcium sulfate precipitated will interfere with the isolation of thorium. Any insoluble products, such as hydrolytic precipitates of tantalum, niobium, tin, titanium, zirconium, tungsten, especially in the presence of phosphate, will carry down thorium and so must be kept with the solution during the analysis, or if filtered off should be combined with the phosphate precipitate when it is burned (step 7). 
The phosphate precipitation (step 5) is made in $0.3 \mathrm{~N}$ hydrochloric acid solution. Under these conditions, thorium is coprecipitated with zirconium or titanium phosphate and with some iron phosphate. Thorium is separated from moderate amounts of rare earths by this treatment (Experiments, 2). If the rare earths in the sample exceed about $10 \mathrm{mg}$ of oxides, a part of the rare earths may be coprecipitated.

If the sample contains heavy metals, an acid hydrogen sulfide separation should be made before making the phosphate precipitation.

The phosphate precipitate is burned and treated with hydrofluoric acid to dissolve the phosphates of zirconium, titanium, and iron, and all the hydrolytic precipitate. Thorium is converted to the insoluble fluoride. If the total amount of fluoride precipitate obtained is less than a few milligrams, mercurous chloride is precipitated from the solution to serve as a bulky carrier for the thorium fluoride precipitate. ${ }^{1}$ Other carriers that were tried occluded titanium and zirconium; thus with calcium fluoride, as much as 6 percent of the zirconium added was coprecipitated. ' It was hoped that sodium fluoride would inhibit the precipitation of zirconium by stabilizing the fluozirconate ion, but we found that the coprecipitation of zirconium with the calcium fluoride was greatly increased by the addition of sodium fluoride (Experiments, 3). The amount of zirconium and titanium carried down by mercurous chloride is less than $0.01 \mathrm{mg}$ of each as found by spectrographic analyses (Experiments, 4). The ease of filtration of mercurous chloride and its easy removal are further advantages.

The precipitate of mercurous chloride may be dark. This is probably because minute amounts of platinum, or possibly gold, palladium, selenium, tellurium, and arsenic are reduced to the elemental condition on the surface of the mercurous chloride. (Pierson, 1934, p. 437.)

The mercurous chloride is volatilized, leaving the concentrate of thorium fluoride in the crucible. Caution is necessary to avoid loss of thorium by dusting, both while burning and wetting the fluffy residue. The thorium fluoride should be heated to a low temperature to prevent the formation of the less soluble thorium oxide. The usual precautions must be taken against mercury poisoning. A second precipitation as thorium fluoride ensures the removal of the last traces of titanium and zirconium; the residue then contains little impurity except possibly a little lead fluoride and some rare-earth fluorides or oxides.

The thorium fluoride is converted to sulfate; any ceric ion formed in the ignition of the fluoride precipitate is reduced by adding sul-

\footnotetext{
3 Mercurous chloride is not a carrier in the accepted sense of the word. Its sole function is to provide bulk. If the thorium fluoride has not already precipitated, the mercurous chloride will serve no useful function. If the thorium fluoride has precipitated out, the mercurous chloride is a convenient collector of the thorium fluoride.
} 
furous acid. Any lead present is precipitated and filtered off. The excess sulfuric acid is then removed because it interferes with the precipitation of thorium iodate. In removing free sulfuric acid, care must again be taken to prevent the formation of thorium oxide by overheating.

The thorium sulfate is dissolved in nitric acid and the thorium separated from any remaining traces of rare earths by precipitation as thorium iodate. It may be directly determined nephelometrically, or further treated and determined photometrically with $p$-dimethylaminoazophenylarsonic acid, or determined gravimetrically as thorium oxide.

The photometric method of determination has the advantages of greater objectivity and reproducibility than the nephelometric method, but the latter is simpler and more direct. However, the stability of the cloud of thorium iodate may be markedly affected by the presence of small amounts of impurities. For example, a few tenths of a milligram of zirconium causes very rapid clotting of the iodate precipitate, leading to low results nephelometrically.

The iodate precipitation may not be necessary for samples containing less than a few milligrams of rare-earth oxides (Experiments, 2). The thorium may then be determined directly by the photometric method by adjusting the acidity and adding $p$-dimethylaminoazophenylarsonic acid. Other such simplifications and shortened procedures will occur to the analyst dealing with materials of more restricted composition than those provided for here.

Determination as thorium iodate.-The cloud of thorium iodate is stable enough for nephelometric estimation up to $0.7 \mathrm{mg}$ thorium oxide. There is a good spread from zero to $0.3 \mathrm{mg}$ thorium oxide, $0.05 \mathrm{mg}$ being readily detected. A drop of hydrogen peroxide is added to insure against the presence of quadrivalent cerium, which would also precipitate as iodate. If the sample contains at this point more than a few milligrams of rare earths, the thorium must be further purified by filtering and dissolving the iodate in nitric acid and reprecipitating as the iodate.

Determination with p-dimethylaminoazophenylarsonic acid.-The precipitation of thorium by $p$-dimethylaminoazophenylarsonic acid is quantitative from buffered solutions such as acetate solutions. The acidity must be controlled (Experiments, 5). The reagent is not very specific, as it precipitates to some extent many elements (such as zirconium, titanium, rare earths, uranium, and iron) at this acidity. However, the thorium obtained by the procedure has been freed from interfering elements.

The iodate precipitate is dissolved in hydrochloric acid and the solution evaporated. Strong oxidizing agents that are released $268681-54-10$ 
would disturb the photometric determination and are here removed by sulfurous acid (Experiments, 6). The acidity is adjusted and the thorium is precipitated by the dye. The precipitate is filtered and washed to remove excess dye. The arsonic acid precipitate of thorium could be ignited to thorium oxide and weighed. For photometric determination, the precipitate is decomposed on the filter with dilute sodium hydroxide solution, releasing dye equivalent to the amount of thorium in the precipitate. The relation between the amount of dye precipitated with the thorium and the amount of thorium present is exact and reproducible. Other applications of $p$-dimethylaminoazophenylarsonic acid in colorimetry are shown by Hayes and Jones (1941, p. 603) and Nazarenko (1937, p. 1696).

The dye solutions closely follow Beer's Law up to about $0.45 \mathrm{mg}$ thorium oxide and the standard curve is reproducible for even larger amounts (Experiments, 8). If the weight of thoria exceeds $0.5 \mathrm{mg}$, it is better to dilute so that the sample is in the range of Beer's Law.

We found that the commercial $p$-dimethylaminoazophenylarsonic acid reagent is likely to be inhomogeneous; not only does it vary from lot to lot, but different parts of the same lot may vary in composition. A new standard reference curve should be made with every new solution of the arsonic acid reagent, even when successive batches are made from the same bottle of reagent (Experiments, 9). The experiments show that if the dye is not completely dissolved, the residue differs in composition from the material in solution.

Gravimetric determination.-If the thoria content exceeds $1 \mathrm{mg}$, as indicated by the size of the iodate precipitate, the iodate precipitate is dissolved in hydrochloric acid and the thorium precipitated with ammonia in the presence of hydrogen peroxide. The precipitate is filtered and ignited to thorium oxide. The peroxide provides a delicate test for the presence of cerium. If the precipitate shows discoloration, it is best to filter without washing, redissolve in nitric acid, and reprecipitate as iodate.

\section{DISCUSSION OF SPECIAL PROCEDURE}

The general procedure must be modified for the analysis of samples, such as monazite, that have a high content of rare earths. These yield large precipitates of rare-earth fluorides at step 8 of the general procedure that tend to occlude zirconium. For example, the analysis of a monazite by the general procedure gave 10.40 percent thorium oxide, by the special procedure 10.02 percent thorium oxide, the 0.38 percent difference was found spectrographically to be due to the presence of zirconium.

The special procedure differs from the general procedure only in the order of the separation steps. After one fluoride precipitation, 
the rare earths are removed by repeated iodate precipitations, then the second fluoride precipitation is made to remove the last traces of zirconium. The special procedure is included in this report to illustrate these principles; simpler methods for the determination of thorium in monazite are given in parts 19 and 20.

\section{GENERAL PROCEDURE}

\section{THE CHEMICAL CONCENTRATION OF THORIOM}

Special reagents:

Potassium iodate, 7\%/2 percent solution.

Mercurous nitrate solution, $8 \mathrm{mg} \mathrm{HgCl}$ equivalent per $\mathrm{ml}$.

Dissolve $0.952 \mathrm{~g}$ of reagent-grade mercurous nitrate in water containing a few frops of nitric acid and adjust the volume to $100 \mathrm{ml}$ with water.

1. For samples containing less than 0.04 percent thorium, take $5.00 \mathrm{~g}$, proportionally less for samples of higher thorium content. Prepare a hydrochloric acid solution of the sample as outlined in part 2. Any hydrolytic precipitate should be left in the solution, or if filtered should be added to the phosphate precipitate when it is burned (step 7).

2. Evaporate the solution to dryness to eliminate the free acid.

3. With a pipette add $10 \mathrm{ml}$ of $(1+1)$ hydrochloric acid solution. Digest about 15 minutes on the steam bath and then add $130 \mathrm{ml}$ of water. Digest until the soluble salts are dissolved.

4. While stirring, slowly add $\left.10 \mathrm{ml}(1 \mathrm{ml}=2 \mathrm{mg} \mathrm{ZrO})_{2}\right)$ of zirconium nitrate solution. ${ }^{2}$ Warm to about $90 \mathrm{C}$.

5. Add $4 \mathrm{~g}$ of diammonium phosphate dissolved in about $20 \mathrm{ml}$ of water. Dilute with water to $200 \mathrm{ml}$. Cover the beaker and digest on the steam bath for at least 4 hours.

6. Add paper pulp, stir, and filter on an 11-cm $S$ and $S 589$ white ribbon filter paper. Wash with 4 percent ammonium nitrate solution.

7. Transfer the filter paper with precipitate to a porcelain crucible. Burn gently, starting at a low heat and gradually raising the temperature until the carbon is burned off.

8. Transfer the residue to a $100-\mathrm{ml}$ platinum dish or crucible. Moisten with a little water and add $20 \mathrm{ml}$ of hydrofluoric acid. Cover with a platinum cover and digest until soluble constituents dissolve. Evaporate the sample on the steam bath until about $8 \mathrm{ml}$ remain. Add $10 \mathrm{ml}$ of hydrofluoric acid and evaporate again to about $8 \mathrm{ml}$. Dilute with $30 \mathrm{ml}$ of water. Warm on the bath. If

\footnotetext{
${ }^{2}$ In this procedure zirconium phosphate formed in step 5 acts as a collector for the thorium phosphate. Alternately the zirconium may be omitted and the acidity of the solution after the addition of ammonium phosphate (step 5) carefully adjusted with ammonium hydroxide until a fair-sized phosphate precipitate is obtained from the still acid solution.
} 
less than a few milligrams of fluoride precipitate is obtained, proceed to step 9. If more than a few $\mathrm{mg}$ of fluoride precipitate is obtained, omit step 9 and proceed to step 10 .

9. Add $10 \mathrm{ml}$ of the mercurous nitrate solution. Next add $1 \mathrm{ml}$ of dilute hydrochloric acid $(7+100)$ and stir with a platinum rod. Warm on the bath for a few minutes and then allow to stand at room temperature for about 4 hours, keeping the dish covered.

10. Filter on a no. 40 Whatman 9-cm filter paper in a hard rubber funnel and wash twice with 10 to $15 \mathrm{ml}$ of approximately 5 percent hydrofluoric acid wash solution, making the wash solution directly in the dish that contained the precipitate and scrubbing the inside of the dish thoroughly with a rubber policeman wetted by the solution. Wash twice with water.

11. Transfer the paper and precipitate to a $20-\mathrm{ml}$ platinum crucible, shield from drafts and burn gently below $500 \mathrm{C}$ in a well-ventilated hood until the paper is burned off and the mercurous chloride volatilized. The precipitate must be burned carefully and slowly; if the mercurous chloride is volatilized too fast, thorium may be lost by dusting. Also, burning at too high a temperature may convert some of the thorium fluoride to thorium oxide which is harder to dissolve.

12. Carefully moisten the fluoride residue with a few drops of water. Add about $8 \mathrm{ml}$ of hydrofluoric acid. Cover the crucible and digest on the steam bath for 20 minutes. Transfer the contents of the crucible to a platinum dish. Wet and scrub the inside of the crucible thoroughly with a rubber policeman, rinsing into the dish. Dilute with water to $40 \mathrm{ml}$. Add $10 \mathrm{ml}$ of mercurous nitrate solution, warm, add $1 \mathrm{ml}$ of dilute $(7+100)$ hydrochloric acid solution and stir. Let stand at room temperature for about 4 hours.

13. Filter on a no. 40 Whatman 9-cm filter paper in a hard rubber funnel and wash twice with hydrofluoric acid wash solution and twice with water.

14. Transfer the paper and precipitate to a small $(20 \mathrm{ml})$ platinum crucible and again carefully burn at below $500 \mathrm{C}$ in a well-ventilated hood until the paper is burned off and the mercurous chloride is volatilized.

15. Wet the residue in the crucible with a few drops of water; dry on the steam bath. Carefully add $0.5 \mathrm{ml}$ of sulfuric acid. Allow to fume on the hotplate for about 15 minutes, keeping the crucible covered. Cool. Cautiously add water until the crucible is about three-fourths full. Add a few drops of 6 percent sulfurous acid solution to decolorize any quadrivalent cerium, and ovaporate until water is removed. Bring to fumes of sulfuric acid and fume 15 minutes. Cool. Add about $10 \mathrm{ml}$ of water and transfer the contents to a $50-\mathrm{ml}$ beaker. Police the crucible and wash with water, adding 
the washings to the beaker. At this point, the volume of the solution should be 25 to $30 \mathrm{ml}$. Warm gently, then allow to stand for about 4 hours.

16. Filter off any lead sulfate on a no. 427 -cm Whatman paper and wash a few times with 1 percent sulfuric acid solution. Collect the filtrate in a $50-\mathrm{ml}$ platinum dish.

17. Evaporate the solution nearly to dryness and then bring to fumes. Drive off all the free sulfuric acid at a low temperature. This is conveniently done by heating on a hotplate until dry and then rotating the dish above a low bunsen flame until no more fumes appear. The temperature should be kept below $450 \mathrm{C}$ to avoid formation of thorium oxide, which in the next step may not dissolve completely in the nitric acid. The removal of free sulfuric acid is essential because excess sulfate interferes with the precipitation of thorium iodate (step 19).

18. Add $6 \mathrm{ml}$ of $(1+1)$ nitric acid solution from a pipette. Add 1 drop of 30 percent hydrogen peroxide, warm gently and then add 10 $\mathrm{ml}$ of water. Cover the dish and digest on the steam bath for a few minutes until the thorium is dissolved.

19. Transfer with a jet of water to a $100-\mathrm{ml}$ beaker, policing the dish thoroughly. Adjust the volume to $42 \mathrm{ml}$ with water. Cool to room temperature. Add by pipette $8 \mathrm{ml}$ of $7 \frac{1}{2}$ percent potassium iodate solution. If less than $1 \mathrm{mg}$ of thorium is indicated by the cloud of thorium iodate, the thorium may be determined either nephelometrically as the iodate (step 20), or photometrically with $p$-dimethylaminoazophenylarsonic acid (step 21); and if more than $1 \mathrm{mg}$ thorium oxide is present, determine it gravimetrically (step 28).

\section{THE ESTIMATION OF THORIUM}

\section{METHOD A. NEPHELOMETRICALLY AS THE IODATE}

20. Let the thorium iodate precipitate stand 15 minutes (30 minutes for $\mathrm{ThO}_{2}$ content of $0.1 \mathrm{mg}$ or less) and compare against a series of standards containing known amounts of thorium with the same amounts of nitric acid and iodate in the same volume, and prepared at the same time as the unknown sample.

If the iodate precipitate indicates a thorium content greater than $0.3 \mathrm{mg}$ and less than $1 \mathrm{mg}$ thorium oxide, an aliquot is taken, as follows, without filtering off the thorium iodate. Add $12 \mathrm{ml}$ of $(1+1)$ nitric acid solution to dissolve the thorium iodate. Transfer one-third of the solution into another $100-\mathrm{ml}$ beaker. Adjust the volume with water to $45 \mathrm{ml}$ and add $51 / 3 \mathrm{ml}$ of $7 \frac{1}{2}$ percent potassium iodate solution from a graduated pipette. Match against a series of standards. The match is made by placing the beakers on a dark plate in front of a window and looking into the beakers. 


\section{METHOD B. PHOTOMETRICALLY WTTH $p$-DIMETHYLAMINOAZOPHENYL- ARSONIC ACID}

Special reagents:

$p$-Dimethylaminoazophenylarsonic acid solution. Dissolve $0.1 \mathrm{~g}$ of the finely powdered reagent in $50 \mathrm{ml}$ of $(1+1)$ alcohol solution containing $10 \mathrm{~g}$ of ammonium acetate. Filter.

Buffered wash solution. Dissolve $10 \mathrm{~g}$ ammonium acetate and $12 \mathrm{ml}$ of $(7+100)$ hydrochloric acid solution in $488 \mathrm{ml}$ of water.

21. Let the thorium iodate precipitate stand overnight. Filter on a 7-cm no. 42 Whatman paper. Do not wash.

22. Dissolve the iodate precipitate off the filter with alternate washes of hot $(1+1)$ hydrochloric acid solution and hot $(7+100)$ hydrochloric acid solution, three portions of each. Collect the filtrate in the same $100-\mathrm{ml}$ beaker that contained the iodate precipitate.

23. Evaporate to dryness on the bath. Add about $8 \mathrm{ml}$ of fresh 6 percent sulfurous acid and evaporate to dryness again.

24. Dissolve in 4 drops of hydrochloric acid and $43 \mathrm{ml}$ of water. Add 2 drops of methyl red indicator and neutralize with ammonia until the methyl red turns yellow. Add dropwise a solution of hydrochloric acid $(7+100)$ until the methyl red just turns red. Add $1.2 \mathrm{ml}$ excess. Now add $5 \mathrm{ml}$ of a solution of $p$-dimethylaminoazophenylarsonic acid. Cover the beaker and allow to digest on the steam bath until the precipitate clots (10 to 20 minutes).

25. Filter on a $10-\mathrm{ml}$ asbestos Gooch filter and wash 4 times with $10-\mathrm{ml}$ portions of the ammonium acetate wash solution.

26. Pour over the Gooch filter $30 \mathrm{ml}$ of a warm 4 percent solution of sodium hydroxide and collect the washings in a clean receiver. Wash once with water.

27. Make the filtrate up to $250 \mathrm{ml}$. Read the optical density on a filter photometer using a blue filter or on a spectrophotometer at 460 millimicrons (Experiments, 7). Obtain the thoria equivalent by reference to a standard curve (Experiments, 8).

If there is more than $0.5 \mathrm{mg} \mathrm{ThO}_{2}$, it is better to make the dilution so that the sample is in the range of Beer's Law. The standard curve should be checked at intervals; two known concentrations usually are enough.

28. If the thoria content exceeds $1 \mathrm{mg}$, the determination is made gravimetrically. Allow the iodate precipitate (step 19) to stand overnight. Filter on a 7-cm no. 42 Whatman paper, but do not wash. Dissolve the iodate precipitate off the filter with alternate washes of hot $(1+1)$ hydrochloric acid solution and hot $(7+100)$ hydrochloric acid solution, three portions of each. Collect the filtrate in the same $100-\mathrm{ml}$ beaker that contained the iodate precipitate. 
Evaporate the solution to dryness. Add 5 drops of hydrochloric acid and 15 to $20 \mathrm{ml}$ of water. Warm and add 1 drop of 30 percent hydrogen peroxide; neutralize with ammonia, adding a few drops of ammonia in excess. Digest on the steam bath about 15 minutes, add paper pulp and filter on a no. $407-\mathrm{cm}$ Whatman paper. Wash with 4 percent ammonium nitrate solution. Ignite to thorium oxide and weigh.

\section{SPECIAL PROCEDURE FOR MONAZITE}

29. Fuse $0.5 \mathrm{~g}$ of finely ground sample in a porcelain crucible with $3 \mathrm{~g}$ of sodium peroxide. Cool the melt and transfer to a $250-\mathrm{ml}$ beaker containing 100-150 ml of water. Add hydrochloric acid in excess and evaporate to dryness. Dissolve with dilute hydrochloric acid and filter, reserving the filtrate. Gently ignite the residue in platinum and volatilize the silica with hydrofluoric acid and sulfuric acid. Remove excess sulfuric by fuming the sample to dryness on the hotplate. Sinter the residue with a little sodium carbonate, cool, leach with dilute hydrochloric acid, and add the total to the reserved solution. Make an ammonium hydroxide precipitation with about $2 \mathrm{ml}$ of excess ammonium hydroxide, clot precipitate on steam bath and filter, washing with 0.1 percent ammonium chloride solution made alkaline to phenolphthalein. Burn the precipitate gently in a platinum dish and proceed to steps 8-11, inclusive, of the general procedure.

30. To the ignited fluoride precipitate in the platinum crucible add $1 \mathrm{ml}$ of sulfuric acid, cover, and gently simmer the sample on the hotplate for about 20 minutes. The rare-earth fluorides are slowly attacked by this fuming with sulfuric acid. Cool, add a little water and transfer the mixture to a $100-\mathrm{ml}$ beaker. Add a few drops of sulfurous acid to reduce cerium and evaporate the solution on the steam bath. Cover the beaker and allow the sample to digest overnight. This overnight digestion generally converts the fluorides to the soluble sulfates. In the morning, add water, and if a complete solution is not obtained, filter. Reserve the filtrate. Gently ignite the residue and treat again with sulfuric acid and heat until fumes evolve. These steps are repeated until a complete solution is obtained.

31. Evaporate the solution in a platinum dish on the steam bath to remove water. Cover the dish and place on a hotplate raising the dish slightly by a porcelain ring so that the bottom of the dish is not in actual contact with the hotplate. When the sulfuric acid fumes, remove cover and evaporate to dryness. Remove the last traces of excess sulfuric acid by heating gently over a burner at low heat (the temperature should not exceed $450 \mathrm{C}$ ). 
32. Add $6 \mathrm{ml}$ of $(1+1)$ nitric acid, 2 drops of 30 percent hydrogen peroxide, and $10 \mathrm{ml}$ of water, and digest on the steam bath a few minutes keeping the dish covered. A complete solution will be obtained at this point. Transfer the solution to a $100-\mathrm{ml}$ beaker and adjust the volume to $42 \mathrm{ml}$ with water. Cool. Add $8 \mathrm{ml}$ of $7 \frac{1}{2}$ percent potassium iodate solution and let stand for 1 to 2 hours.

33. Filter off the iodate precipitate. The iodate precipitate is dissolved, and enough iodate precipitations are made from nitric acid solutions to remove completely the rare earths (four will generally suffice). To test the complete removal of rare earths, add excess ammonia and a few drops of 30 percent hydrogen peroxide to the filtrate from the iodate precipitation. The rare earths show their presence as insoluble yellow hydroxides, the yellow is due to cerium.

The analyst must use his judgment on how to dissolve the iodate precipitates for reprecipitation. If the iodate precipitate is small, it may be dissolved off the filter paper with $6 \mathrm{ml}(1+1)$ nitric acid so that precipitation becomes relatively easy. For monazite samples, the iodate precipitate is generally too large to be handled in this manner. The iodate is dissolved off the filter paper with a minimum of hot $(1+1)$ hydrochloric acid solution. As the iodate precipitations must be made from nitric acid solution, the hydrochloric acid is next eliminated by precipitating the thorium with excess ammonia and peroxide. The precipitate is filtered but not washed. It is dissolved off the filter with $6 \frac{1}{2} \mathrm{ml}$ of $(1+1)$ nitric acid and reprecipitated with ammonia and peroxide. The second ammonia precipitate is sufficiently free from chloride so that after solution in $6.5 \mathrm{ml}$ of $(1+1)$ nitric acid, the solution is adjusted to $42 \mathrm{ml}$ with water, a few drops of 30 percent hydrogen peroxide and $8 \mathrm{ml}$ of $71 / 2$ percent potassium iodate solution are added to give the second iodate precipitation.

34. Dissolve the final iodate precipitate off the filter with hydrochloric acid. The hydrochloric acid and the reduction products of the iodate are next removed by precipitating thorium with ammonium hydroxide plus hydrogen peroxide. The ammonia precipitate is then gently ignited in a 100 -ml platinum dish.

35. Add hydrofluoric acid and repeat the fluoride precipitation as before (steps 8-11). The thorium fluoride obtained at this point should be free from all contaminants.

36. Dissolve the thorium fluoride in sulfuric acid and add a few drops of 30 percent hydrogen peroxide and precipitate with 1 to $2 \mathrm{ml}$ excess of ammonia. Ignite and weigh.

\section{EXPERIMENTS}

\section{Analysis or synthetic mixtures}

The methods described above were tested by analysis of solutions whose thorium content was not known to the analyst. The standard 
thorium solution was made from reagent-grade thorium nitrate that contained less than 0.1 percent of any other metal as determined spectrographically. The solution was standardized by evaporating to dryness and igniting to oxide, and by precipitating with ammonia and peroxide and igniting to oxide.

The solutions for analysis were made by adding various amounts of thorium nitrate to $50 \mathrm{ml}$ of either of two stock solutions. All reagents used were evidently free enough from thorium for the purpose, because the results with solutions of the lowest thorium contents analyzed were not significantly higher than the amount of thorium added: The synthetic stock solutions, labeled solution $S$ and solution $P$, were made so that $50 \mathrm{ml}$ of solutions $S$ and $P$ contain the following:

\begin{tabular}{|c|c|c|c|c|}
\hline & $\underset{\text { (grams) }}{\text { Solution } \mathbf{S}}$ & $\underset{\text { (grams) }}{\text { Solution }} \mathbf{P}$ & Salt used & \\
\hline 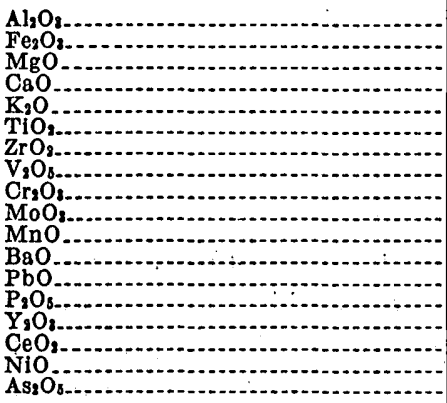 & $\begin{array}{l}0.75 \\
.50 \\
.05 \\
.50 \\
.30 \\
.05 \\
.005 \\
.02 \\
.02 \\
.005 \\
.005 \\
.005 \\
.005 \\
.010 \\
.005 \\
\text {.005 } \\
\text { None } \\
\text { None }\end{array}$ & $\begin{array}{l}0.20 \\
.20 \\
.05 \\
1.50 \\
.20 \\
.05 \\
.005 \\
.02 \\
.02 \\
.005 \\
.005 \\
.005 \\
.005 \\
1.25 \\
1.01 \\
1.01 \\
.005 \\
.005\end{array}$ & $\begin{array}{l}\text { Aluminum chloride. } \\
\text { Ferric chloride. } \\
\text { Magnesium chloride. } \\
\text { Calcium chloride. } \\
\text { Potassium chloride. } \\
\text { Titanium tetrachloride. } \\
\text { Zirconium nitrate. } \\
\text { Ammonium metavanadate. } \\
\text { Potassium dichromate. } \\
\text { Ammonium molybdate: } \\
\text { Manganese chloride. } \\
\text { Barium chloride. } \\
\text { Lead carbonate. } \\
\text { Ammonium phosphate. } \\
\text { Yttrium nitrate. } \\
\text { Cerous nitrate. } \\
\text { Nickel chloride. } \\
\text { Sodium arsenate. }\end{array}$ & $\begin{array}{c}. \\
\therefore \\
. \\
.\end{array}$ \\
\hline
\end{tabular}

1 These solutions were added separately just before the analysis was begun.

Table 1 gives the analytical results obtained.

TABLE 1.-Analyses of synthetic mixtures

\begin{tabular}{|c|c|c|c|c|c|}
\hline $\begin{array}{c}\text { : } \\
\text { Sample no. }\end{array}$ & $\begin{array}{c}\text { Type } \\
\text { sample }\end{array}$ & $\begin{array}{l}\text { ThO } \\
\text { taken } \\
\text { (mg) }\end{array}$ & $\begin{array}{l}\mathrm{ThO}_{2} \text { found } \\
\text { nephelo- } \\
\text { metrically } \\
\text { (mg) }\end{array}$ & $\begin{array}{l}\mathrm{ThO}_{2} \text { found } \\
\text { photomet- } \\
\text { rically } \\
\text { (mg) }\end{array}$ & $\begin{array}{l}\mathrm{ThO}_{2} \text { found } \\
\text { gravimet- } \\
\text { rically } \\
\text { (mg) }\end{array}$ \\
\hline $\begin{array}{l}\text { P2 } \\
\text { P4 } \\
\text { P6 } \\
\text { Q4 } \\
\text { P1 } \\
\text { B1 } \\
\text { J2 } \\
\text { Q2 } \\
\text { P2 } \\
\text { Q1 }\end{array}$ & $\begin{array}{l}\text { S } \\
\mathbf{P} \\
\mathbf{S} \\
\mathbf{S} \\
\mathbf{S} \\
\mathbf{P} \\
\mathbf{P} \\
\mathbf{P} \\
\mathbf{S} \\
\mathbf{S} \\
\mathbf{S} \\
\mathbf{P} \\
\mathbf{P} \\
\mathbf{S} \\
\mathbf{S} \\
\mathbf{P} \\
\mathbf{P} \\
\mathbf{S} \\
\mathbf{P}\end{array}$ & $\begin{array}{r}0.05 \\
.10 \\
.25 \\
.30 \\
.30 \\
.50 \\
.55 \\
.60 \\
.70 \\
.90 \\
.90 \\
.95 \\
1.00 \\
1.10 \\
1.60 \\
1.70 \\
1.80 \\
3.30 \\
5.40\end{array}$ & $\begin{array}{r}0.07 \\
.09 \\
\hdashline .27 \\
.20 \\
.70 \\
.65 \\
.66 \\
.80 \\
1.0 \\
.70 \\
1.1 \\
1.0 \\
\hdashline \\
\hdashline \\
\hdashline \\
\hdashline\end{array}$ & 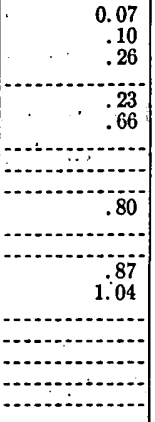 & \begin{tabular}{|r|r|} 
& \\
& 1.1 \\
& 0 \\
& 1.5 \\
& 1.9 \\
1.9 \\
2.6 \\
5.2
\end{tabular} \\
\hline
\end{tabular}


The procedures were further tested by analysis of eight synthetic mixtures by W. G. Schlecht. The results given in table 2 indicate what might be expected on a first trial by an analyst unfamiliar with the procedures. Probably the discrepancies in the photometric results for samples $S 6$ and $S 5$ are caused mainly by imperfect separation of zirconium, which can cause small positive or negative errors in the nephelometric determination and larger positive errors in the photometric determination. Additional data applying this method to ores are given in parts 20 and 21.

TABLE 2.-Analyses of synthetic mixtures

\begin{tabular}{|c|c|c|c|c|c|}
\hline Sample no. & $\begin{array}{c}\text { Type } \\
\text { sample }\end{array}$ & $\begin{array}{c}\mathrm{ThO}_{2} \text { taken } \\
(\mathrm{mg})\end{array}$ & $\begin{array}{l}\mathrm{ThO}_{2} \text { found } \\
\text { nephelomet- } \\
\text { rically } \\
\text { (mg) }\end{array}$ & $\begin{array}{l}\mathrm{ThO}_{2} \text { found } \\
\text { photomet- } \\
\text { rically } \\
\text { (mg) }\end{array}$ & $\begin{array}{l}\text { Tho, found } \\
\text { gravimet- } \\
\text { rically } \\
\text { (mg) }\end{array}$ \\
\hline $\begin{array}{l}\text { S6 } \\
\text { S1 } \\
\text { S3 } \\
\text { S8 } \\
\text { S5 } \\
\text { S7 }\end{array}$ & $\begin{array}{l}\mathbf{P} \\
\mathbf{S} \\
\mathbf{P} \\
\mathbf{S} \\
\mathbf{P} \\
\mathbf{S} \\
\mathbf{P} \\
\mathbf{S}\end{array}$ & $\begin{array}{r}0.00 \\
.10 \\
.25 \\
.40 \\
.65 \\
.80 \\
1.20 \\
1.45\end{array}$ & $\begin{array}{l}0.18 \\
.10 \\
.3 \\
.35 \\
.7 \\
.6 \\
1.0\end{array}$ & $\begin{array}{r}0.52 \\
1.05 \\
1.65 \\
1.25\end{array}$ & 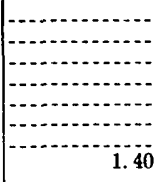 \\
\hline
\end{tabular}

2. Occlusion of rare earths with the phosphate precipitate

To $50 \mathrm{ml}$ of solution $P$, which contains $10 \mathrm{mg} \mathrm{Y}_{2} \mathrm{O}_{3}$ and $10 \mathrm{mg}$ $\mathrm{CaO}, 0.95 \mathrm{mg}(A), 0.25(B)$ and $0.6 \mathrm{mg}(C)$ of $\mathrm{ThO}_{2}$ were added. These were analyzed according to the procedure through step 16. Precipitation with excess ammonia in the presence of a few drops of 30 percent hydrogen peroxide gave the following weights when ignited:
(A) $3.4 \mathrm{mg}$
(B) $2.3 \mathrm{mg}$
(C) $2.5 \mathrm{mg}$

The ignited oxides were dissolved and the thorium content determined nephelometrically as the iodate. The thorium contents found werle:
(A) $1.1 \mathrm{mg} \mathrm{ThO}_{2}$
(B) $.36 \mathrm{mg} \mathrm{ThO}_{2}$
(C) $.66 \mathrm{mg} \mathrm{ThO}$

The samples showed therefore the following quantity $(\mathrm{mg})$ of rareearth oxides occluded:
(A) $2.3 \mathrm{mg}$
(B) $1.9 \mathrm{mg}$
(C) $1.8 \mathrm{mg}$

When the experiments were repeated with solution $S$ that contained only half the amounts of rare earths in solution $P$, no rare earths were found to accompany the thorium. 


\section{Fallure of hydronuoric acid separation of thorlum from zirconium in the presence of alkallne earths and alkalles}

To each of four platinum dishes were added $50 \mathrm{mg}$ of zirconium oxide as the pyrophosphate, $0.3 \mathrm{mg}$ thorium oxide as the nitrate, and $60 \mathrm{mg}$ calcium chloride. The mixtures were evaporated to dryness and $20 \mathrm{ml}$ of hydrofluoric acid solution was added to each. After digestion the solutions were evaporated to $8 \mathrm{ml}$ and then $10 \mathrm{ml}$ of hydrofluoric acid added. The solutions were evaporated again to 8 $\mathrm{ml}$ and then diluted with water to $50 \mathrm{ml}$ and allowed to stand at room temperature for 4 hours. They were then filtered and washed with 4 percent hydrofluoric acid solution. The residues were burned in platinum and dissolved by fuming with perchloric acid. The solutions were diluted with water and exactly $100 \mathrm{mg}$ of alumina (as the chloride) was added to each. Ammonia was now added until the solutions were neutral to methyl red, and the precipitates obtained were ignited and weighed. The weights of the ignited precipitates were $0.1032,0.1031,0.1029,0.1031 \mathrm{~g}$. The excess of about $3 \mathrm{mg}$ was found to be due to zirconium.

In another series, $0.5 \mathrm{~g}$ sodium fluoride was added in addition to calcium in an effort to fix the fluozirconate ion, but the results were even worse than above as about 10 percent of the final ignited precipitate was zirconium oxide.

4. Nonocclusion of zirconium, titanium, and iron by thorium fluoride when mercurous chloride is used as carrier

To each of four beakers were added $50 \mathrm{mg}$ zirconium oxide as the nitrate, $50 \mathrm{mg}$ titanium oxide as the chloride, $1 \mathrm{~g}$ ferric oxide as the chloride, and $0.5 \mathrm{mg}$ thorium oxide as the nitrate. A phosphate precipitation was made according to the procedure outlined in step 5 . After filtration, the phosphate precipitates were burned and treated with hydrofluoric acid, as in step 8.

The thorium fluoride was filtered off with the aid of $80 \mathrm{mg}$ of mercurous chloride as carrier. The fluoride precipitate was dissolved with fuming sulfuric acid, exactly $100 \mathrm{mg}$ of alumina was added and an ammonia precipitation made. This was filtered off, burned and examined spectrographically by J. C. Rabbitt for zirconium, titanium, and iron. The results obtained with only one hydrofluoric acid treatment are as follows:

\begin{tabular}{|c|c|c|c|c|c|c|c|}
\hline No. & $\begin{array}{l}\mathrm{TiO}, \\
(\mathrm{mg})\end{array}$ & $\begin{array}{l}\mathrm{ZrO}{ }_{2} \\
(\mathrm{mg})\end{array}$ & $\begin{array}{l}\mathrm{Fe}_{2} \mathrm{O}_{3} \\
(\mathrm{mg})\end{array}$ & No. & $\begin{array}{l}\mathrm{TiO}, \\
\text { (mg) }\end{array}$ & $\underset{(\mathrm{mg})}{\mathrm{ZrO}}$ & $\underset{(\mathrm{mg})}{\mathrm{Fe}_{2} \mathrm{O}_{3}}$ \\
\hline 1 & $\begin{array}{l}0.01 \\
.008\end{array}$ & $\begin{array}{l}0.01 \\
.006\end{array}$ & $\begin{array}{r}0.008 \\
.005\end{array}$ & 4 & $\begin{array}{l}0.02 \\
.008\end{array}$ & $\begin{array}{l}0.005 \\
.01\end{array}$ & $\begin{array}{r}0.006 \\
.005\end{array}$ \\
\hline
\end{tabular}


6. Optimum conditions for the precipitation of thorium with $p$-dimethylaminoazophenylarsonic acid

Effect of acid concentration: To each of six beakers were added a solution of thorium nitrate equivalent to $0.4 \mathrm{mg}$. $\mathrm{ThO}_{2}, 0.2 \mathrm{ml}$ of hydrochloric acid, $1 \mathrm{~g}$ of ammonium acetate, and distilled water to make the volume to $43 \mathrm{ml}$. Ammonia was next added until the solutions were alkaline to methyl red. Dilute $(7+100)$ hydrochloric acid was then added dropwise until the solutions were just acid to methyl red, followed by a known excess of dilute hydrochloric acid $(7+100)$. Five milliliters of a saturated solution of $p$-dimethylaminoazophenylarsonic acid in alcohol was added to each to precipitate the thorium. After digestion on the steam bath for 15 minutes, the thorium precipitates were filtered on Gooch crucibles and washed 4 times with $10-\mathrm{ml}$ portions of ammonium acetate wash solution. The precipitates were dissolved off the Gooch crucibles with $30 \mathrm{ml}$ of 4 percent sodium hydroxide and the filtrates made to $250 \mathrm{ml}$. The solutions were then read in the electrophotometer. The readings obtained are listed below.

\begin{tabular}{|c|c|c|c|c|c|}
\hline No. & $\begin{array}{c}\text { Excess of } \\
7 \text { percent } \\
\text { HCl added } \\
\text { (milligrams) }\end{array}$ & $\begin{array}{l}\text { Optical } \\
\text { density }\end{array}$ & No. & $\begin{array}{c}\text { Excess of } \\
7 \text { percent } \\
\text { HCladded } \\
\text { (milligrams) }\end{array}$ & $\begin{array}{l}\text { Optical } \\
\text { density }\end{array}$ \\
\hline 1 12 & $\begin{array}{r}\text { None } \\
0.1 \\
.7\end{array}$ & $\begin{array}{r}0.21 \\
.38 \\
.54\end{array}$ & $\begin{array}{l}4 \\
5 \\
6 \\
6\end{array}$ & $\begin{array}{l}1.2 \\
3 \\
6\end{array}$ & $\begin{array}{r}0.55 \\
.57 \\
.90\end{array}$ \\
\hline
\end{tabular}

1 Solution just acid to methyl red.

The results obtained show that the acidity must be controlled. The optimum acidity taken is that given by a solution containing $1 \mathrm{~g}$ of ammonium acetate and $1.2 \mathrm{ml}$ of $(7+100)$ hydrochloric acid in a total volume of $50 \mathrm{ml}$.

Effect of concentration of $p$-dimethylaminoazophenylarsonic acid: Using the optimum acidity, the amount of $p$-dimethylaminoazophenylarsonic acid was varied in two tests. Using $2.5 \mathrm{ml}$ of the arsonic acid reagent, the optical density obtained was 0.525 ; using $10 \mathrm{ml}$ of the arsonic acid reagent, the optical density was 0.575 .

The concentration of $p$-dimethylaminoazophenylarsonic acid used in the precipitation of thorium is evidently not important. The small discrepancy noted above is probably due to the fact that the precipitate was washed only four times in each experiment, so that washing was probably not complete for the more concentrated solution. No attempt is made to wash all excess dye from the precipitate. Four washings are enough for practical purposes when $5 \mathrm{ml}$ of reagent is used. 
6. Interference of oxdalzing agents in the photometric determination of thorium

Various amounts of thorium were precipitated as the iodate as in the procedure (step 19). The precipitates were filtered 24 hours later, dissolved off the filter with $25 \mathrm{ml}$ of $(1+1)$ hydrochloric acid and the paper washed with water. The solutions were evaporated to dryness, taken up with 4 drops of hydrochloric acid and $42 \mathrm{ml}$ of water. The photometric procedure was then applied for the estimation of thorium. The results obtained are given below.

$\begin{array}{ccc}\begin{array}{c}\mathrm{ThO}_{2} \\ \text { taken } \\ (m g)\end{array} & \begin{array}{c}\mathrm{ThO}_{2} \text { found } \\ \text { photometrically } \\ (\mathrm{mg})\end{array} & \begin{array}{c}\text { Percent } \\ \text { recooery } \\ \text { of ThO, }\end{array} \\ 0.15 & 0.135 & 90 \\ .40 & .37 & 92 \\ .75 & .67 & 90 \\ 1.4 & 1.23 & 88\end{array}$

The above experiments were repeated except that, after the hydrochloric acid solution of the iodate was evaporated to dryness, $8 \mathrm{ml}$ of 6 percent sulfurous acid was added and the solution again evaporated to dryness. The residue was taken up with 4 drops of hydrochloric acid and $42 \mathrm{ml}$ of water and the thorium estimated photometrically. The results given below show excellent recoveries.

$\begin{array}{cc}\begin{array}{c}\mathrm{ThO}_{2} \\ \text { taken } \\ (m g)\end{array} & \begin{array}{c}\mathrm{ThO}_{2} \text { found } \\ \text { photometrically } \\ (\text { mg) }\end{array} \\ 0.15 & 0.155 \\ .40 & .395 \\ .80 & .80 \\ 1.40 & 1.41\end{array}$

7. Spectral transmittancy and standard curves for the photometric determination of thorium with $p$-dimethylaminoazophenylarsonic acid

The spectral transmittancy curve for the $p$-dimethylaminoazophenylarsonic acid solution obtained in the thorium determination is given in figure 21. The data were obtained with the Coleman Universal spectrophotometer Model II against water as reference, the concentration of thorium used being $0.1 \mathrm{mg} \mathrm{ThO}_{2}$ per $100 \mathrm{ml}$. The standard curve, figure 22, was obtained with a Fisher electrophotometer, using a 425-millimicron filter. The solutions were prepared according to the procedure outlined in steps 24-27, page 142.

\section{Inhomogenelty of the reagent $p$-dimethylaminoazophenylarsonic acld}

Two saturated alcoholic solutions of the reagent were made in this way: 1. Excess of $p$-dimethylaminoazophenylarsonic acid was digested with alcohol to make a saturated solution. Excess reagent was filtered from the solution which was labeled no. 1 . 


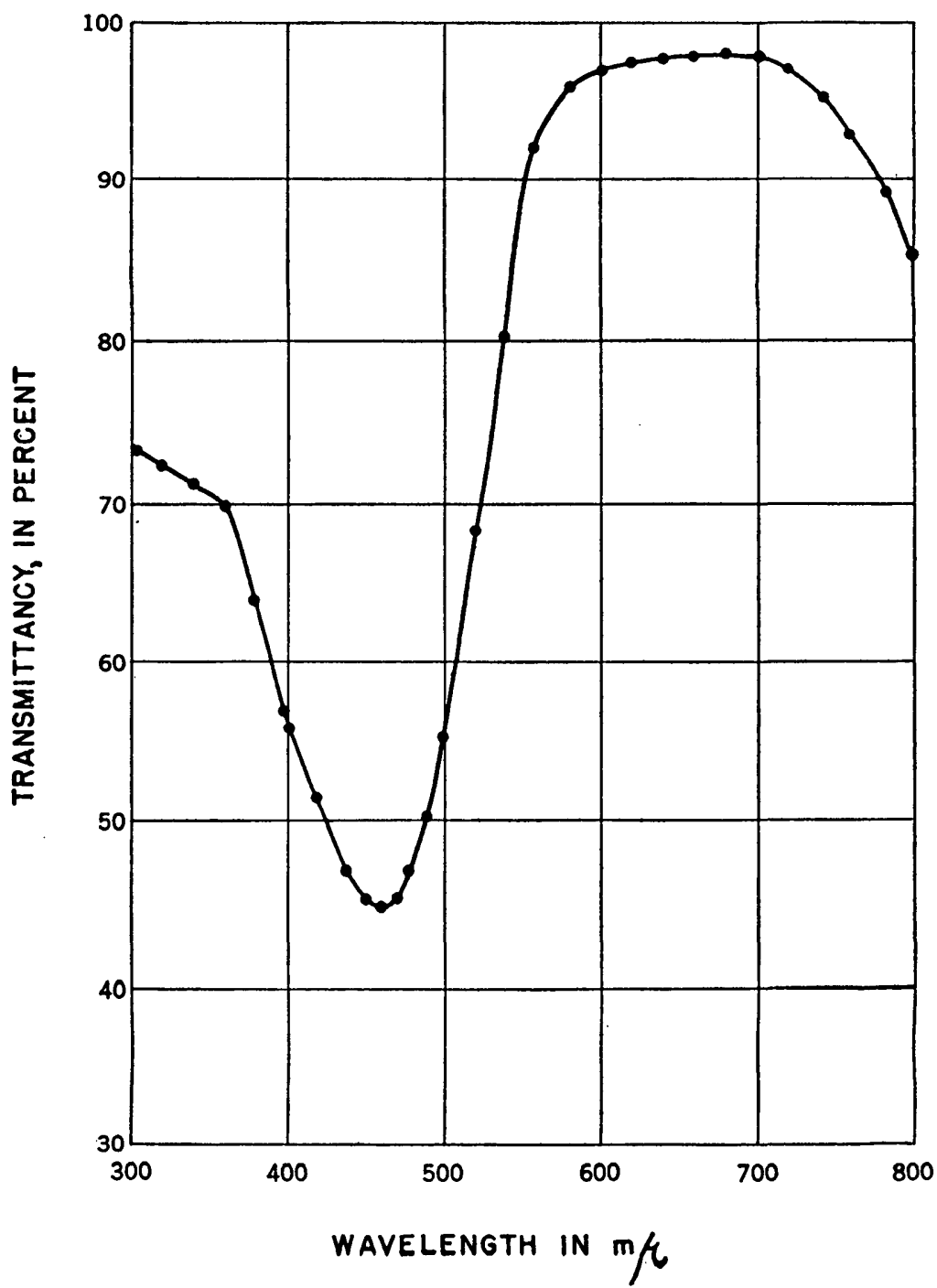

FIGURE 21.-Spectral transmittancy curve for the photometric determination of thorium with p-dimethylaminoazophenylarsonic acid. 


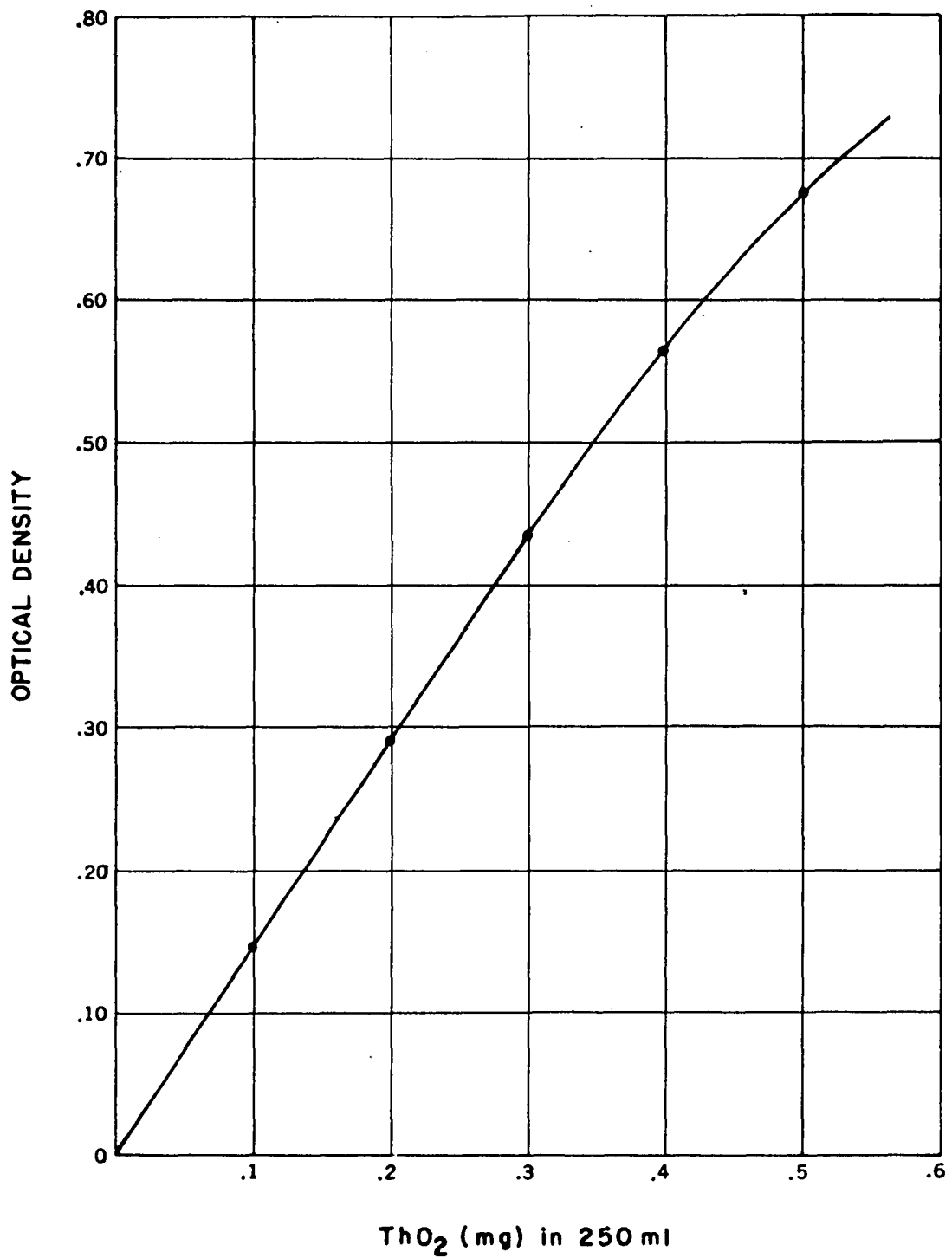

Figure 22.-Fisher electrophotometer readings for the photometric determination of thorium with a $p$-dimethylaminoazophenylarsonic acid. 
2. The excess reagent obtained in the paper from (1) was treated with more alcohol to form a second saturated solution. This was filtered and labeled no. 2.

Various amounts of thorium were determined photometrically using the optimum conditions of excess acid and ammonium acetate, using alcoholic solutions nos. 1 and 2 for precipitation. The electrophotometer readings obtained are given below:

\begin{tabular}{ccc}
$\underset{\text { ThO }}{\text { mg })}$ & \multicolumn{2}{c}{ Optical density } \\
\cline { 2 - 3 } & Solution 1 & Solution 2 \\
0.15 & 0.17 & 0.21 \\
.30 & .34 & .42 \\
.45 & .50 & .58 \\
.60 & .64 & .73
\end{tabular}

Both solutions follow Beer's Law up to about $0.4 \mathrm{mg} \mathrm{ThO}_{2}$, but they do not give the same density. for the same amount of thorium.

In another experiment, $2 \mathrm{~g}$ of $p$-dimethylaminoazophenylarsonic acid was ground to an impalpable powder in an agate mortar. Three $0.1 \mathrm{~g}$ portions were weighed and to each were added $10 \mathrm{~g}$ of ammonium acetate, $25 \mathrm{ml}$ water, and $25 \mathrm{ml}$ of alcohol; they were warmed until solutions were obtained. This made three identical dye solutions. The results obtained when $0.4 \mathrm{mg} \mathrm{ThO}_{2}$ was determined photometrically by each solution are given below.

\begin{tabular}{|c|c|c|}
\hline $\begin{array}{l}\mathrm{ThO}_{2} \\
\text { taken } \\
\text { (mg) }\end{array}$ & $\begin{array}{l}\text { Optical } \\
\text { density } \\
\text { reading }\end{array}$ & $\begin{array}{c}\text { Reagent } \\
\text { solution } \\
\text { used } \\
(5 \text { ml of each })\end{array}$ \\
\hline 0.4 & 0.60 & no. 1 \\
\hline .4 & .60 & no. 2 \\
\hline .4 & .60 & no. 3 \\
\hline
\end{tabular}

Consistent results will therefore be obtained if a complete solution of thoroughly mixed reagent is used.

\section{LITERATURE CITED}

Fresenius, R., and Hintz, E., 1896, Uber die Untersuchung der Thornitrate des Handels und die Tremmung von Thorerde und Ceroxyd: Zeitschr. anal. Chemie, v. 35 , p. 525.

Hayes, W. G., and Jones, - E. W:, 1941, Determination of zirconium in steel: Indus. Eng. Chem., Anal. Ed. v. 13, p. 603-604.

Hillebrand, W. F., and Lundell, G. E. F., 1929, Applied inorganic analysis, p. 416-425, New York, John Wiley and Sons.

Meyer, R. J., 1911, Der Nachweis und die Bestimmung des Thoriums mit Jodsaure: Zeitschr. anorg. Chemie, v. 71, p. 65.

Nazarenko, V. A., 1937, Méthode colorimétrique determiner le zirconium: Jour. Applied chem. U. S. S. R. v. 10, p. 1696.

Pierson, G. G., 1934, Reducing action of mercurous chloride: Indus. Eng. Chem., Anal. Ed. v. 6, p. 437-439.

Wyrouboff, G., and Verneuil, A., 1898, Sur la separation du thorium et des terres de la cerite: Acad. sci. Paris Comptes rendus v. 126, p. 340. 


\title{
Part 19. THE GEOLOGICAL SURVEY GARBONATE-IODATE- IODINE METHOD FOR THE DETERMINATION OF SMALL AMOUNTS OF THORIUM IN NATURALLY OCCURRING MATERIALS
}

\author{
By J. J. FAHeY and M. D. Foster
}

\section{CONTENTS}

Abstract.
Outline of procedure and discussion
Procedure
Decomposition of sample
Separation of thorium
Determination of thorium
$\quad$ Colorimetric
Gravimetric
1. Analysis of synthetic mixtures
2. Purity of ThO obtained by the procedure
3. Spectral transmittancy and transmittance-concentration curves of
carbon tetrachloride solution of iodine
4. Synthetic color standards for the colorimetric determination of
thorium

Page

154

154

155

157

157

158

158

160

160

161

162

162

162

163

166

\section{ILLUSTRATIONS}

Figure 23. Spectral transmittancy curve of iodine in carbon tetrachloride. 164

24. Transmittance-concentration curve for iodine in carbon tetrachloride

25. Spectral transmittance curves of iodine in carbon tetrachloride, methyl red in acid solution, thymol blue in acid solution.-

\section{TABLES}

TABLE 1. Determination of thorium in synthetic mixtures of known thorium content

2. Spectrographic analyses of thorium oxide from gravimetric determination 


\section{ABSTRACT}

A procedure is presented for the separation and determination of small amounts of thorium in naturally occurring materials. Thorium is separated from the rare earths and titanium by precipitating thorium iodate in the presence of peroxide. It is separated from zirconium by precipitating zirconium phosphate in acid solution. The thorium is finally collected as the iodate and determined either colorimetrically or gravimetrically depending on the amount. In the colorimetric procedure, the thorium iodate is treated with hypophosphorous acid which liberates iodine. The iodine is dissolved in carbon tetrachloride and the density of the solution measured photometrically. In the gravimetric procedure, the thorium iodate is dissolved in hydrochloric acid and ammonium hydroxide added to precipitate thorium hydroxide which is ignited to thorium oxide and weighed.

\section{INTRODUCTION}

During the course of Trace Elements investigations of the U. S. Geological Survey a method was sought for the accurate determination of small amounts of thorium in naturally occurring materials of widely different types. In the development of such a method, adequate provision had to be made for (1) the presence of phosphate, a major constituent of many of the samples; (2) the separation of thorium from interfering elements, such as titanium, zirconium, and the rare earths; and (3) the measurement of quantities of thorium of less than 1 milligram.

The method should be applicable to most types of naturally occurring materials, with a minimum of modifications necessary to handle special types. Many of the methods described in the literature are not applicable in the presence of phosphate, a major constituent of many of the samples, and these methods were therefore eliminated from consideration. Other methods, applicable in the presence of phosphate, were designed for the determination of relatively large amounts of thorium. Tests showed that these methods, under the conditions usually recommended, were not sufficiently sensitive for the determination of thorium in very small amounts.

For example, preliminary tests showed that when the quantity of thorium present is very small, complete recovery of thorium is not obtained in the strong nitric acid solution usually used in the iodate method. ${ }^{1}$ As the iodate precipitation is applicable in the presence of phosphate and affords a separation of thorium from many other elements, experimental work was undertaken to determine whether or not complete precipitation could be obtained under different conditions of acidity. This work showed that complete recovery can be obtained if the nitric acid content is less than 5 percent, but a loss of thorium results if the acidity is as high as 10 percent. In the procedure presented in this report precipitation of thorium as

- Meyer, R. J., 1911, Der Nachweis und die Bestimmung des Thoriums mit Jodsaure: Zeitschr, anorg Ohemio, 7. 71, p. 65. 
iodate in 3 percent nitric acid solution is combined with other wellknown reactions for the separation and determination of thorium. The method is especially designed for the determination of very small quantities of thorium (as low as $0.10 \mathrm{mg}$ ) in rocks and ores of widely different composition, but it can also be used for the determination of larger quantities of thorium.

\section{OUTLINE OF PROCEDURE AND DISCUSSION}

The essential features of the method are:

1. Complete decomposition of the sample.

2. Removal of essentially all iron (and molybdenum) by extraction with ethyl acetate from a $(1+1) \mathrm{HCl}$ solution.

3. Precipitation of thorium with sodium carbonate. Any calcium, magnesium, titanium, zirconium, chromium, manganese, most of the rare earths, and some of the aluminum and phosphate are also precipitated.

4. Solution of the carbonate precipitate in $\mathrm{HNO}_{3}$ and precipitation of thorium, zirconium, and titanium as iodates from 3 percent $\mathrm{HNO}_{3}$ solution in the presence of hydrogen peroxide.

5. Digestion of the iodate precipitate with $\mathrm{HNO}_{3}$ in the presence of excess phosphate, separating zirconium and part of the titanium from thorium.

6. Double precipitation of thorium as iodate in the presence of hydrogen peroxide, separating the rest of the titanium.

7. Determination of thorium spectrophotometrically by measuring the iodine equivalent of thorium iodate, or gravimetrically, as $\mathrm{ThO}_{2}$, after reduction of thorium iodate and precipitation with $\mathrm{NH}_{4} \mathrm{OH}$.

The sample is decomposed by the procedure given in part 2 . Complete decomposition of the sample is essential as it should not be assumed that no thorium is present in undecomposed material. Any hydrolytic precipitates of tantalum, niobium, tin, titanium, zirconium, and tungsten, particularly in the presence of phosphate, may occlude thorium, and should be left in the solution. For samples having high contents of rare earths, it is advisable to add at this point the precipitate obtained in the final sodium hydroxide-peroxide step of the analysis for uranium on the same sample, part 4.

Iron, if present in large amounts, would precipitate with thorium in the iodate precipitation (Procedure, step 4), and remain with thorium in the acid treatment of the phosphates. Iron is therefore removed at the beginning of the analyses by extraction with ethyl acetate. This affords a quick and essentially complete separation and also reduces the bulk of the subsequent carbonate precipitate.

Thorium is precipitated, together with calcium, magnesium, titanium, zirconium, chromium, manganese, most of the rare earths, and some of the aluminum and phosphate, by the sodium carbonate precipitation. Uranium, which is in the filtrate, is separated from thorium, making it possible to determine both elements in a single sample. 
Precipitation as iodate in 3 percent nitric acid solution effects a preliminary separation of thorium, titanium, and zirconium from the other elements coprecipitated or occluded with them in the carbonate precipitation. If quadrivalent cerium is present, this is also precipitated as the iodate. However, part of the cerium and titanium is removed at this stage if the iodate precipitation is made in the presence of hydrogen peroxide. Any phosphate in the sample may be retained combined with titanium and zirconium. Hydrolyzed niobium and tantalum may also be retained.

Boiling and digestion of the precipitated iodates in strong nitric acid solution in the presence of excess phosphate result in a separation of zirconium and part of the titanium from thorium. Thorium phosphate, even in the presence of excess phosphate, is readily soluble in 15 percent nitric acid solution. Zirconium phosphate is very insoluble, even at a much higher acidity. Tests showed that when zirconium phosphate is boiled in $(1+1)$ nitric acid, and in concentrated nitric acid, the amount of zirconium dissolved is insufficient to give a precipitate with potassium iodate in 3 percent nitric acid solution. Titanium phosphate is much less soluble than thorium phosphate but is not as insoluble as zirconium phosphate. Any niobium and tantalum carried along to this point are removed with the insoluble zirconium phosphate. Cerium is soluble and remains in solution with the thorium.

The low acidity ( 3 percent) used in the final iodate precipitations of thorium requires a great reduction in the acidity of the filtrate from the acid treatment of the phosphates. This reduction of acidity is accomplished by precipitating the thorium, and any titanium and cerium present in this filtrate, with sodium hydroxide and dissolving the precipitate in $(1+1)$ nitric acid. The volume of $(1+1)$ nitric acid in which the hydroxide precipitate is dissolved plus the volume of wash solution used is adjusted to provide a final volume of $100 \mathrm{ml}$ containing 3 percent by volume as nitric acid, after addition of hydrogen peroxide and potassium iodate solution in the subsequent iodate precipitation.

Precipitation of thorium as iodate in the presence of excess hydrogen peroxide separates thorium from any titanium and cerium carried through to this point. A second iodate precipitation, again in the presence of excess hydrogen poroxide, is desirablo to removo any remaining traces of titanium and cerium. Additional precipitations with iodate are made if qualitative tests indicate that titanium or cerium is still present. Usually two precipitations are sufficient, but additional precipitations may be necessary for samples, such as monazite, containing much cerium. 
The presence of cerium in the solution is indicated at the time of the iodate precipitation by the development of an orange color accompanied by evolution of oxygen a few minutes after the addition of hydrogen peroxide and potassium iodate. Cerium catalyzes the reduction of iodate by peroxide in acid solution. After about half an hour the color gradually fades and evolution of oxygen ceases. The depth of color developed and the degree of evolution of oxygen is dependent on the amount of cerium present.

In washing the thorium iodate precipitate before the colorimetric determination, use a solution that will completely remove potassium iodate from the filter paper and one in which thorium iodate is insoluble. A number of wash solutions were tested, but none fulfilled the conditions as effectively as 76 percent alcohol. The size of filter paper recommended and the procedure for washing as outlined have been most satisfactory. It is suggested that the procedure be followed carefully.

When thorium iodate is reduced with hypophosphorous acid in the presence of sulfuric acid, iodine is quantitatively liberated. When the reaction takes place in the presence of carbon tetrachloride, the iodine liberated is immediately dissolved, imparting a bluish-red color to the carbon tetrachloride. As the iodine liberated is directly equivalent to the thorium iodate reduced, the intensity of the color of the iodine carbon tetrachloride solution may be used as in indirect measurement of the thorium iodate. Because the measurement is indirect, it is essential that the thorium iodate be free of any other iodate.

In the gravimetric determination, it was shown by repeated determinations on samples of known thorium content that complete solution of the thorium and reduction of the iodate in the thorium iodate precipitate were brought about by treatment with concentrated hydrochloric acid. The thorium hydroxide precipitate must not be washed after filtration, as a small quantity of the thorium hydroxide will be carried through the paper. Weak ammonia and solutions of ammonium nitrate of different strengths tried as wash solutions were ineffective in preventing this. However, the amount of potassium chloride (the only contaminant at this stage) remaining in the welldrained precipitate and paper is of the order of $0.1 \mathrm{mg}$ and most, if not all, of this is volatilized by the blast lamp.

\section{PROCEDURE}

\section{DECOMPOSITION OF SAMPLE}

1. Weigh out $5 \mathrm{~g}$ of the sample, if it has a total radioactivity equivalent to 0.015 percent $U$ or less. Use proportionately smaller weights of samples having higher radioactivities. Prepare a hydro- 
chloric acid solution of the sample as outlined in part 2. Leave any hydrolytic precipitate obtained during the decomposition in the solution.

\section{EXTRACTION OF IRON}

2. After obtaining a $(1+1) \mathrm{HCl}$ solution of the sample, evaporate the volume to about $25 \mathrm{ml}$. Transfer the solution to a $250-\mathrm{ml}$ separatory funnel and shake with $40 \mathrm{ml}$ of ethyl acetate. After the two layers have separated, draw off the acid layer into another separatory funnel of the same size. Add $20 \mathrm{ml}$ of ethyl acetate, shake well, and after the layers have separated, draw off the acid layer into a 400-ml beaker. Combine the ethyl acetate layers and wash once by shaking with $5 \mathrm{ml}$ of $(1+1) \mathrm{HCl}$. Add the washing to the acid layer in the 400 -ml beaker.

\section{SEPARATION OF THORIUM}

3. Dilute the acid solution from the extraction of iron to a volume of 250 to $300 \mathrm{ml}$ and heat to boiling. Remove the beaker from the heat and slowly add 50 percent $\mathrm{NaOH}$ solution until a slight permanent precipitate forms, add dry $\mathrm{Na}_{2} \mathrm{CO}_{3}$ very carefully until effervescence no longer takes place, add 2 to $3 \mathrm{~g}$ of $\mathrm{Na}_{2} \mathrm{CO}_{3}$ in excess and stir until all the $\mathrm{Na}_{2} \mathrm{CO}_{3}$ is dissolved. Place the beaker in a cold water bath for $3 / 4$ to 1 hour before filtering on a no. 40 Whatman 12.5-cm paper. Wash the precipitate five times with a 1 percent $\mathrm{Na}_{2} \mathrm{CO}_{3}$ solution.

If uranium is to be determined in the same sample, transfer the precipitate without washing to the original beaker with a fine stream of distilled water and add $7 \mathrm{ml}$ of $\mathrm{HCl}$. Dilute the solution to 250 or $300 \mathrm{ml}$, heat to boiling and reprecipitate as before with 50 percent $\mathrm{NaOH}$ and dry $\mathrm{Na}_{2} \mathrm{CO}_{3}$. Cool and filter. Scrub out the beaker and wash the precipitate on the paper five times with a 1 percent $\mathrm{Na}_{2} \mathrm{CO}_{3}$ solution. Combine the filtrates from the two carbonate precipitations for the determination of uranium.

4. Transfer the carbonate precipitate to the original beaker with a fine stream of distilled water. Add $\mathrm{HNO}_{3}$ dropwise, with constant stirring, until the mixture is just red to methyl red, taking care to disperse lumps of the precipitate with a stirring rod. Add $5.0 \mathrm{ml}$ of $\mathrm{HNO}_{3}$ in excess and make the volume up to 100 to $125 \mathrm{ml}$ with distilled water. Add $50 \mathrm{ml}$ of a 7 percent water solution of $\mathrm{KIO}_{3}$ and $10 \mathrm{ml} \mathrm{H} \mathrm{H}_{2} \mathrm{O}_{2}$ (27 to 30 percent), stir, and let stand covered overnight. Filter on a no. 42 Whatman 9-cml paper. Do not! wash. Transfer the precipitate from the paper to the original beaker with a fine stream of distilled water. Replace the filter paper in the funnel and pass $30 \mathrm{ml}$ of $(2+1) \mathrm{HNO}_{3}$ through the paper into the beaker. By means of a stirring rod and by tipping, bring the solution into 
contact with any precipitate left on the walls of the beaker. Adjust the volume to about $100 \mathrm{ml}$ with distilled water.

5. Boil the solution plus any undissolved material for about 1 minute, add $0.4 \mathrm{~g}$ of anhydrous disodium acid phosphate $\left(\mathrm{Na}_{2} \mathrm{HPO}_{4}\right)$, stir the solution well and digest (uncovered) on a steam bath until the volume is reduced to about $50 \mathrm{ml}$.

6. Filter on a no. 41 Whatman 9-cm paper, transferring most of the precipitate to the paper. If the filtrate is not clear, refilter on the same paper until a clear filtrate is obtained. Rinse out the beaker and wash the precipitate and paper with $40 \mathrm{ml}$ of $(1+9)$ $\mathrm{HNO}_{3}$ containing 0.4 percent $\mathrm{Na}_{2} \mathrm{HPO}_{4}$ (anhydrous).

7. Neutralize the filtrate to the methyl red end point with 50 percent $\mathrm{NaOH}$ solution and add $10 \mathrm{ml}$ in excess. Digest on the steam bath for about 30 minutes. Filter on a no. 40 Whatman $9-\mathrm{cm}$ paper (or a smaller no. 40 Whatman paper if the bulk of the precipitate permits). If the filtrate comes through turbid, refilter on the same paper until a clear filtrate is obtained. Do not wash the precipitate.

8. Place the filter paper containing the precipitate in the original beaker, add $6 \mathrm{ml}$ of $(1+1) \mathrm{HNO}_{3}$ and macerate the paper with the aid of a stirring rod. Add $25 \mathrm{ml}$ of $\mathrm{H}_{2} \mathrm{O}$ and stir well.

Filter on a no. 40 Whatman 7-cm paper. Wash with $40 \mathrm{ml}$ of distilled water, catching the filtrate and washings in a $150-\mathrm{ml}$ beaker, and allow the paper to drain well.

9. To the combined filtrate and washings, the volume of which is now $70 \mathrm{ml}$, add $10 \mathrm{ml}$ of $\mathrm{H}_{2} \mathrm{O}_{2}(27$ to 30 percent) and $20 \mathrm{ml}$ of a 7 percent water solution of $\mathrm{KIO}_{3}$. Stir and let stand overnight. The next morning add $5 \mathrm{ml}$ of $\mathrm{H}_{2} \mathrm{O}_{2}$ (27 to 30 percent), stir and allow to settle about 1 hour.

Decant the supernatant liquid through a no. 42 Whatman $5.5-\mathrm{cm}$ paper (or a 7-cm paper if the bulk of the precipitate is too large for a $5.5-\mathrm{cm}$ paper). Do not replace the stirring rod in the beaker during the decantation as this tends to stir up the precipitate. When about four-fifths of the supernatant liquid has been passed through the paper, replace the original receiver with a 50-ml beaker. Resume filtration. After most of the precipitate and all the liquid have been transferred to the paper, examine the filtrate in both the original and the second receiver. If it is not crystal clear, refilter on the same paper until a clear filtrate is obtained. Do not wash the precipitate. Test the filtrate for cerium by making ammoniacal in the presence of $\mathrm{H}_{2} \mathrm{O}_{2}$. Place the paper containing the precipitate in the precipitation beaker, add $6 \mathrm{ml}$ of $(1+1) \mathrm{HNO}_{3}$, and macerate the paper with the aid of the stirring rod. After an hour, add $25 \mathrm{ml}$ of distilled water and stir well. 
Filter on a no. 42 Whatman 5.5-cm paper, catching the filtrate in a $150-\mathrm{ml}$ beaker. If the filtrate is not clear refilter on the same paper until a clear filtrate is obtained. Wash the paper with $40 \mathrm{ml}$ of distilled water and drain well.

10. To the filtrate and washings, the volume of which is now $70 \mathrm{ml}$, add $10 \mathrm{ml}$ of $\mathrm{H}_{2} \mathrm{O}_{2}$ (27 to 30 percent) and $20 \mathrm{ml}$ of 7 percent $\mathrm{KIO}_{3}$ solution. Stir. If titanium and cerium are absent, follow step 12 below. If the color of the solution indicates the presence of titanium or cerium, or if the filtrate from the previous iodate precipitate contained cerium (reddish-brown precipitate with ammoniacal $\mathrm{H}_{2} \mathrm{O}_{2}$ ), follow step 11.

11. Let the iodate precipitate stand overnight and follow the procedure of step 9. Repeat until cerium is removed. To the final filtrate and washings, the volume of which is $70 \mathrm{ml}$, add $10 \mathrm{ml}$ of $\mathrm{H}_{2} \mathrm{O}_{2}$ (27 to 30 percent) and $20 \mathrm{ml}$ of 7 percent $\mathrm{KIO}_{3}$ solution. Stir.

12. Prepare a comparison solution containing $0.8 \mathrm{mg}$ of $\mathrm{ThO}_{2}$ in $67 \mathrm{ml}$ of water. Add, in order, $3 \mathrm{ml}$ of $\mathrm{HNO}_{3}, 10 \mathrm{ml}$ of $\mathrm{H}_{2} \mathrm{O}_{2}(27$ to 30 percent), and $20 \mathrm{ml}$ of 7 percent $\mathrm{KIO}_{3}$ solution. Compare the turbidity developed in the sample solution with that developed in the comparison solution. If, from the turbidity, the estimated content of the sample solution is less than $0.8 \mathrm{mg}$ of $\mathrm{ThO}_{2}$, determine thorium colorimetrically (steps 13-15); if the estimated content is more than $0.8 \mathrm{mg}$ of $\mathrm{ThO}_{2}$, determine thorium gravimetrically (step 16).

\section{DETERMINATION OF THORIOM}

\section{COLORIMETRIC}

13. Let the thorium iodate precipitate stand overnight, add $5 \mathrm{ml}$ of $\mathrm{H}_{2} \mathrm{O}_{2}$ (27 to 30 percent), stir and allow to settle. In about an hour, decant the supernatant liquid on a 42 Whatman $4.0-\mathrm{cm}$ paper. Do not replace the stirring rod in the beaker during the filtration, as this tends to stir up the precipitate. When about four-fifths of the supernatant liquid has been passed through the paper, replace the original receiver with a $50-\mathrm{ml}$ beaker. Resume filtration. After most of the precipitate and the last drop of the liquid have been transferred to the paper, examine the filtrate both in the original and second receivers. If it is not crystal clear, refilter on the same paper until a clear filtrate is obtained. Replace the receiver with a $30-\mathrm{ml}$ beaker. Rinse the walls of the precipitation beaker with a fine jet of 76 percent alcohol $(80 \mathrm{ml}$ of 95 percent alcohol diluted with distilled water to $100 \mathrm{ml}$ ). Transfer the rinsings to the filter paper. Scrub the beaker with a policeman, again rinse the beaker with a fine jet of 76 percent alcohol and transfer the rinsings to the paper as before. Make a final rinse of the beaker with the alcohol solution and when this rinsing has drained through the paper, make 3 dis- 
placement washings of the paper with the alcohol solution. When the last of the alcohol solution has drained through the paper shake the liquid from the stem of the funnel. Total alcohol washings of beaker and paper should not exceed $15 \mathrm{ml}$. Wash off the tip of the funnel with the alcohol solution.

14. Replace the receiving beaker with a $100-\mathrm{mm}$ spectrophotometer cell. Treat the iodate precipitate on the paper in the funnel with $1 \mathrm{ml}$ of $(1+1) \mathrm{H}_{2} \mathrm{SO}_{4}$, dropping it around the top, then tilt the funnel to bring the $\mathrm{H}_{2} \mathrm{SO}_{4}$ in contact with any of the precipitate that may have crept above the top of the paper. Let the $\mathrm{H}_{2} \mathrm{SO}_{4}$ remain in contact with the paper for about 5 minutes to permit complete solution of the precipitate. Wash the paper six times by running a fine jet of distilled water around the top of the paper. Total water washings should not exceed $10 \mathrm{ml}$.

15. Add $10 \mathrm{ml}$ of carbon tetrachloride to the solution in the cell and $0.2 \mathrm{ml}$ of hypophosphorous acid, stopper the cell and shake it for 2 minutes. Immediately place the cell in the cell receiver of the spectrophotometer and measure the optical density of the colored solution at 520 millimicrons wavelength. Obtain the milligrams $\mathrm{ThO}_{2}$ equivalent by reference to a standard curve (Experiments, 3). If a spectrophotometer is not available, the $\mathrm{ThO}_{2}$ equivalent of the colored tetrachloride solution may be estimated by comparison with a series of standards prepared by mixing methyl red and thymol blue in acid solution to obtain a proper color tint (Experiments, 4).

\section{GRAVIMETRIC}

16. After letting the thorium iodate precipitate (step 11) stand overnight, add $5 \mathrm{ml}$ of 27 to 30 percent $\mathrm{H}_{2} \mathrm{O}_{2}$, stir and allow to settle for about an hour. Filter on a no. 42 Whatman 5.5 -cm paper (or a larger paper if necessary). If the filtrate is not crystal clear, refilter on the same paper until a clear filtrate is obtained. Make no effort to transfer all the precipitate to the paper. Do not wash. Allow the paper to drain well and place paper and precipitate in the precipitating beaker. Add $5 \mathrm{ml}$ of $\mathrm{HCl}$ and macerate the paper with the aid of the stirring rod. Place the beaker on the steam bath for about 5 minutes, then add $75 \mathrm{ml}$ of distilled water. While stirring, add $\mathrm{NH}_{4} \mathrm{OH}$ to the methyl red end point plus an additional $2 \mathrm{ml}$ excess. Digest on the steam bath for about 15 minutes.

Filter on a no. 42 Whatman $5.5-\mathrm{cm}$ paper, transferring all the precipitate to the paper by rinsing the beaker with a few milliliters of the filtrate. Do not wash. Allow the filter paper to drain well. Dry the precipitate, wrapped in its moist paper, in a weighed platinum crucible, char the paper slowly without allowing it to ignite, and burn the carbon off with a gradually increased flame. Finally heat at the 
full heat of a Meker burner and blast for about 5 minutes. Weigh the residue as $\mathrm{ThO}_{2}$.

\section{EXPERIMENTS}

\section{ANALYSIS OF SYNTHETIC MIXTURES}

The procedure described above was tested by determining thorium in solutions whose thorium content was not known to the analyst. The test solutions were prepared by adding different amounts of a standard thorium nitrate solution $\left.(10 \mathrm{ml}=0.5 \mathrm{mg} \mathrm{ThO})_{2}\right)$ to $50 \mathrm{ml}$ of either of two synthetic mixtures. The standard thorium nitrate solution was made from reagent-grade thorium nitrate that was found spectrographically to contain less than 0.1 percent of any other metal. The solution was standardized by precipitating the thorium as iodate from a $10-\mathrm{ml}$ aliquot, filtering, reducing with concentrated $\mathrm{HCl}$, precipitating with ammonia, and finally weighing as $\mathrm{ThO}_{2}$. As a check on the standardization, the $\mathrm{ThO}_{2}$ in eight samples containing $0.20 \mathrm{ml}$ to $1.60 \mathrm{ml}$ inclusive of the $\mathrm{Th}\left(\mathrm{NO}_{3}\right)_{4}$ solution was precipitated as iodate and the iodine equivalent determined spectrophotometrically. The readings were then compared with a standard curve (Experiments, 3). The two methods of standardization checked very closely.

The synthetic solutions, labeled solution $P$ and solution $S$, contained 10 percent $\mathrm{HCl}$. Their compositions are given in part 18 (p. 145).

In preparing the test samples, $50 \mathrm{ml}$ of solution $S$ or of solution $P$ was used for each test sample. Definite quantities, unknown to the analysts, of standard thorium nitrate solution were added to each test sample, and thorium was separated and determined by the procedure described above. The results obtained are given in table 1.

TABLE 1.-Determination of thorium in synthetic mixtures of known thorium content

\begin{tabular}{|c|c|c|c|c|c|c|c|c|c|}
\hline \multirow[b]{2}{*}{$\begin{array}{c}\text { Samplo } \\
\text { no. }\end{array}$} & \multirow{2}{*}{$\begin{array}{c}\text { Type of } \\
\text { test } \\
\text { samplo }\end{array}$} & \multirow{2}{*}{$\begin{array}{l}\text { Tho, } \\
\text { gdded } \\
\text { (mg) }\end{array}$} & \multicolumn{2}{|c|}{$\mathrm{ThO}_{2}$ found } & \multirow{2}{*}{$\begin{array}{c}\text { Sample } \\
\text { no. }\end{array}$} & \multirow{2}{*}{$\begin{array}{c}\text { Type of } \\
\text { test } \\
\text { sample }\end{array}$} & \multirow{2}{*}{$\begin{array}{c}\mathrm{ThO}_{2} \\
\text { added } \\
\text { (mg) }\end{array}$} & \multicolumn{2}{|c|}{ ThO, found } \\
\hline & & & $\underset{\substack{\text { rically } \\
\text { (mg) }}}{\text { Colorimet- }}$ & $\underset{\substack{\text { ricall } \\
\text { (mg) }}}{\text { Gravimet. }}$ & & & & $\begin{array}{l}\text { Colorimet- } \\
\text { rically } \\
\text { (mg) }\end{array}$ & $\begin{array}{l}\text { Gravimet- } \\
\text { rically } \\
\text { (mg) }\end{array}$ \\
\hline $\begin{array}{l}T_{1} \ldots \ldots \\
T_{1} \ldots \ldots \\
T_{1} \ldots \ldots \\
T_{1} \\
T_{1}\end{array}$ & $\begin{array}{l}\mathbf{S} \\
\mathbf{P} \\
\mathbf{g} \\
\mathbf{P} \\
\mathbf{P} \\
\mathbf{S}\end{array}$ & $\begin{array}{l}0.05 \\
.30 \\
.40 \\
.70 \\
.90 \\
.80\end{array}$ & $\begin{array}{l}0.11 \\
.42 \\
.42 \\
.66 \\
.75 \\
.83\end{array}$ & 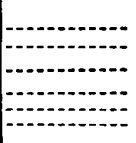 & $\begin{array}{l}Y_{1} \ldots \ldots . . . \\
Y_{1} \\
Y_{1} \ldots \ldots . \\
T_{1} \ldots \ldots . \\
Y_{2}\end{array}$ & $\begin{array}{l}\mathbf{P} \\
\mathbf{S} \\
\mathbf{P} \\
\mathbf{P} \\
\mathbf{P} \\
\mathbf{P}\end{array}$ & $\begin{array}{l}1.2 \\
1.4 \\
1.6 \\
1.85 \\
2.4 \\
4.7\end{array}$ & 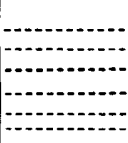 & $\begin{array}{l}1.2 \\
1.3 \\
1.6 \\
1.5 \\
2.2 \\
4.6\end{array}$ \\
\hline
\end{tabular}

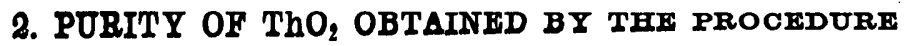

The thorium in four synthetic samples was separated by the procedure described above and determined gravimetrically as $\mathrm{ThO}_{2}$. 
After weighing, the $\mathrm{ThO}_{2}$ precipitates were analyzed spectrographically to determine if they were free from impurities. The results, given in table 2 , show that the impurities in none of the precipitates amounted to more than 0.5 percent of the weight of the precipitate.

TABLE 2.-Spectrographic analyses of $\mathrm{ThO}_{3}$ from gravimetric determinations

\begin{tabular}{|c|c|c|c|c|c|c|c|}
\hline \multirow{2}{*}{ Sample no. } & \multirow{2}{*}{$\underset{\text { (g) }}{\mathrm{ThO}_{2}}$} & \multicolumn{6}{|c|}{ Percent } \\
\hline & & $\mathrm{CeO}_{2}$ & $\mathrm{ZrO}_{2}$ & $\mathrm{SnO}_{2}$ & $\mathrm{TiO}_{2}$ & $\mathrm{Na}_{2} \mathrm{O}$ & $\mathrm{CaO}$ \\
\hline 4 & $\begin{array}{l}0.0016 \\
.0022 \\
.0024 \\
.0024\end{array}$ & $\begin{array}{r}0.1 \\
.3 \\
.4 \\
.2\end{array}$ & $\begin{array}{l}0.003 \\
.01 \\
.01 \\
.01\end{array}$ & $\begin{array}{l}0.01 \\
.003 \\
.02 \\
.01\end{array}$ & $\begin{array}{l}0.003 \\
.007 \\
.006 \\
.006\end{array}$ & $\begin{array}{l}0 \\
0 \\
0 \\
0\end{array}$ & $\begin{array}{l}0 \\
0 \\
0 \\
0\end{array}$ \\
\hline
\end{tabular}

Spectrographic analyses were also made of the $\mathrm{ThO}_{2}$ precipitates obtained from four samples that were so high in cerium that it was necessary to repeat the iodate precipitation six times to obtain a filtrate that gave no test for cerium with ammoniacal $\mathrm{H}_{2} \mathrm{O}_{2}$. The spectrograph showed that none of the samples contained more than 0.3 percent $\mathrm{CeO}_{2}, 0.2$ percent $\mathrm{ZrO}_{2}$, and 0.2 percent $\mathrm{La}_{2} \mathrm{O}_{3}$.

\section{SPECTRAL TRANSMITTANCY AND TRANSMITTANCE-CONCEN- TRATION CURVES OF CARBON TETRACHLORIDE SOLUTION OF IODINE}

The spectral transmittancy curve of a carbon tetrachloride solution of iodine, against carbon tetrachloride as reference, is shown in figure 23. The curve shows a minimum transmittancy at 520 millimicrons. The instrument used was a Coleman Model II, and the cell was 18 $\mathrm{mm}$ in diameter.

The transmittance-concentration curve of carbon tetrachloride solutions equivalent to different amounts of thorium is given in figure 24. To obtain this curve a solution of $\mathrm{KIO}_{3}$ was used of which each milliliter was equivalent to $0.2 \mathrm{mg}$ of $\mathrm{ThO}_{2}$, calculated on the assumption that the formula for thorium iodate is $\mathrm{Th}\left(\mathrm{IO}_{3}\right)_{4}$. Definite amounts of the $\mathrm{KIO}_{3}$ solution were measured into spectrophotometric cells, the volumes made up to $9 \mathrm{ml}$, and $1 \mathrm{ml}$ of $(1+1) \mathrm{H}_{2} \mathrm{SO}_{4}$ and 10 $\mathrm{ml}$ of carbon tetrachloride were added in the order given. The color was developed in one sample at a time by adding $0.2 \mathrm{ml}$ of hypophosphorous acid, stoppering, and shaking the cell for 2 minutes. The reading in the spectrophotometer of the transmittance of the sample was made immediately and before the development of the color in the next sample. 


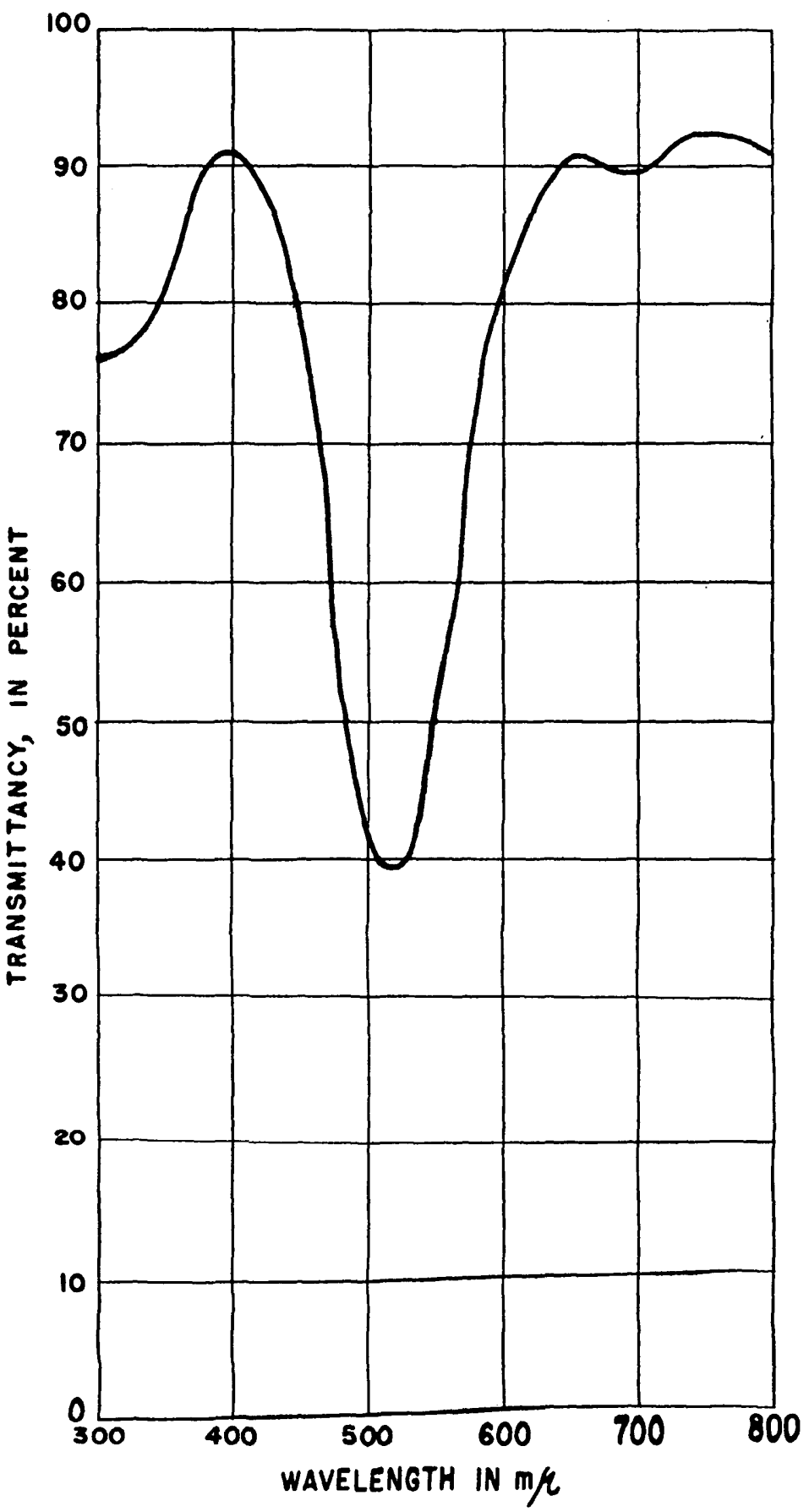

FroURE 23.-Spectral transmittancy curve of lodino in carbon totrocblorido. 


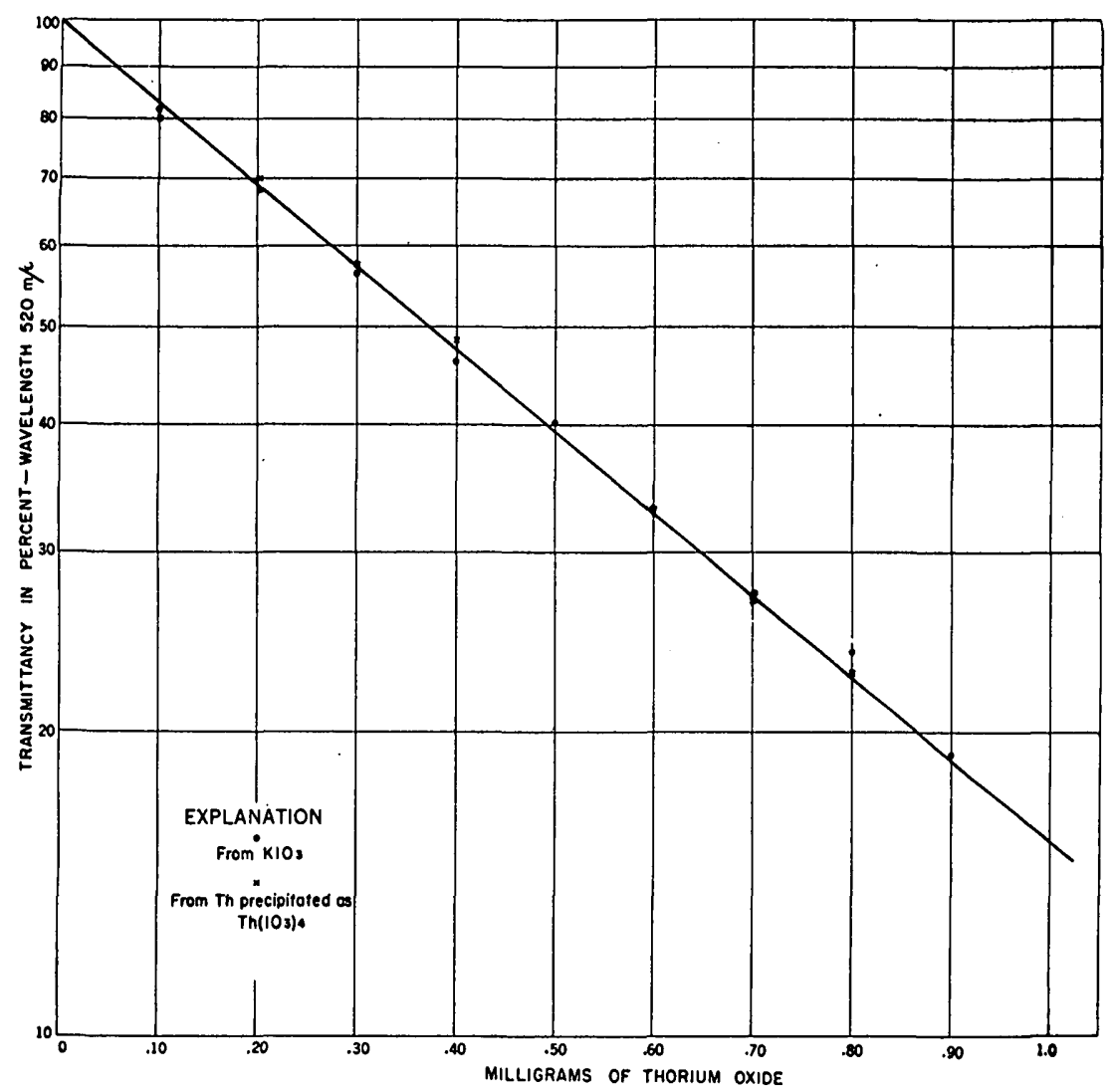

Figure 24.-Transmittance-concentration curve for lodine in carbon tetrachloride.

The completeness of recovery of thorium iodate when precipitated from a 3 percent $\mathrm{HNO}_{3}$ solution with $20 \mathrm{ml}$ of 7 percent $\mathrm{KIO}_{3}$ solution was checked as follows: Definite amounts of the standard thorium nitrate solution were measured out and the thorium precipitated as iodate, filtered after standing overnight, dissolved, and the color developed and read as described in the colorimetric procedure (steps 13-15). The readings plotted on the transmittance-concentration curve obtained with $\mathrm{KIO}_{3}$ solutions (figure 24). indicate that the recovery of thorium as iodate from a 3 percent $\mathrm{HNO}_{3}$ solution is complete within the limits of experimental error. The close agreement between these results and those obtained on a solution of $\mathrm{KIO}_{3}$ indicate that thorium iodate, precipitated under the conditions given in this procedure, has the formula $\mathrm{Th}\left(\mathrm{IO}_{3}\right)_{4}$. 


\section{SYNTHETIC COLOR STANDARDS FOR THE COLORIMETRIC DETERMINATION OF THORIUM}

The spectral transmittance curves of methyl red and thymol blue in acid solution are similar to the spectral transmittance curve of iodine in carbon tetrachloride. They have minimum transmittances at 520 and 540 millimicrons, respectively, compared with 520 millimicrons for iodine in carbon tetrachloride. From the curves (fig. 25), it appears that methyl red in proper concentration should closely match the color of iodine in carbon tetrachloride, but for visual comparison the color is not blue enough and it is necessary to add some thymol blue (in acid solution) to match the color exactly.

The standards may be prepared by visually matching different concentrations of an acid methyl red-thymol blue solution with iodinecarbon tetrachloride solutions prepared from known amounts of a $\mathrm{KIO}_{3}$ standard solution, or, if a spectrophotometer is available, by adjusting such mixtures to give the proper readings on the spectrophotometer for iodine equivalent to definite amounts of thorium. Such synthetic standards have been found stable for about a month. 


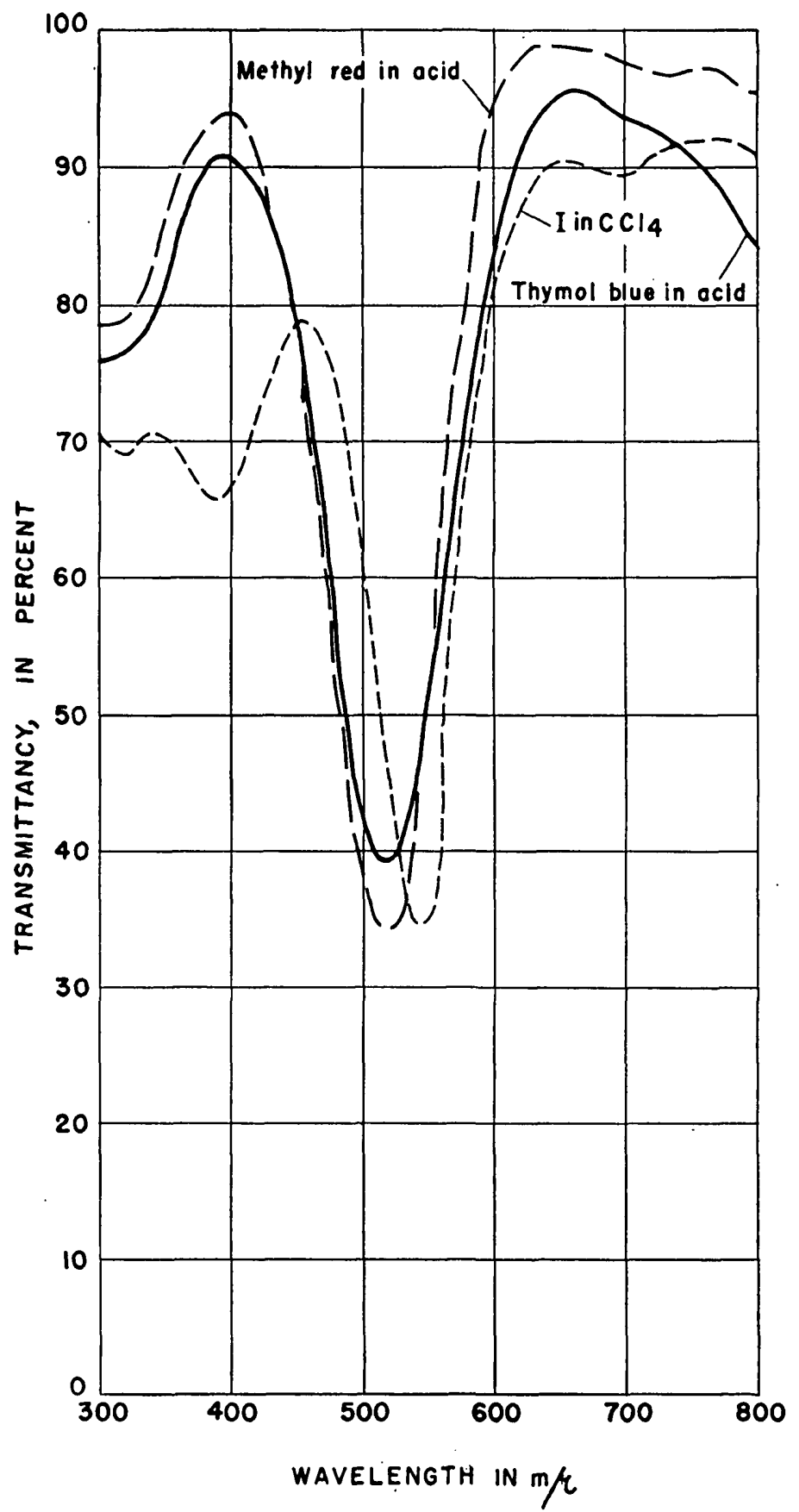

Figure 25.-Spectral transmittancy curves of iodine in carbon tetrachloride, methyl red in acid solution, thymol blue in acid solution. 
, 


\title{
Part 20. THE DETERMINATION OF THORIUM IN HIGH- GRADE AND LOW-GRADE ORES
}

\author{
By F. S. Grimaldi and Charlotte Marsh Warshaw
}

\section{CONTENTS}

Introduction . .

Outline of procedure and discussion................. 170

Solution of the sample.

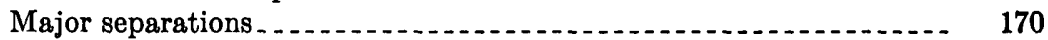

Procedure. .

Experiments

Failure of the peroxynitrate precipitation of thorium in the presence of zirconium . . 175

Separation of thorium from rare earths by the peroxynitrate method _ - 176

\section{TABLES}

TABLE 1. Comparison with results by the phosphate-iodate method.....-

2. Incomplete precipitation of thorium peroxynitrate in presence of zirconium. . 176

3. Separation of thorium from rare earths by peroxynitrate method_ 176

\section{INTRODUCTION}

A procedure is described for the determination of thorium in monazite ores that is applicable to other ores of a wide range of composition. It is successful for both high- and low-grade ores (to as little as 0.04 percent thorium oxide).

Thorium is separated from calcium, magnesium, and from most of the rare earths by double precipitation with ammonia, then from such elements as zirconium; titanium, and niobium by precipitation as fluoride, and separated from the remaining rare earths by peroxynitrate precipitation.

Zirconium and sulfate interfere with the peroxynitrate precipitation. These interferences can be successfully overcome under certain conditions.

This new procedure is designed for ores containing 0.04 percent thorium oxide and more. It is reasonably rapid, enabling a chemist to start a sample one day and obtain the results the next day.

Note.-This report was issued as Trace Elements Inv. Rept. 44 and AECD 2818, 1947. $268681-54-12$ 
We thank C. J. Rodden of the National Bureau of Standards for the use of laboratory space and also for permission to quote Maczkowske's thorium analyses.

\section{OUTLINE OF PROCEDURE AND DISCUSSION}

The essential features of the method are:

1. Decomposition of the sample by fusion with $\mathrm{Na}_{2} \mathrm{O}_{2}$.

2. Solution in $\mathrm{HNO}_{3}$ and precipitation with $\mathrm{NaOH}-\mathrm{H}_{2} \mathrm{O}_{2}$ (separation from most of the phosphorus, aluminum, and silica).

3. Double precipitation with ammonia at the methyl red end point (separation from calcium, magnesium, manganese, and most of the rare earths).

4. Precipitation as fluoride (separation from zirconium, titanium, niobium, and iron).

5. Solution of the fluoride by fusion with $\mathrm{K}_{2} \mathrm{~S}_{2} \mathrm{O}_{7}$ and removal of sulfate by two $\mathrm{NaOH}-\mathrm{H}_{2} \mathrm{O}_{2}$ precipitations.

6. Repetition of steps 3,4 , and 5 .

7. Precipitation as peroxynitrate (separation from the remaining rare earths) and ignition to oxide.

\section{SOLUTION OF THE SAMPLE}

The sample taken for analysis should be $2 \mathrm{~g}$ or less. In general, an $0.5 \mathrm{-g}$ sample suffices. If a $2 \mathrm{-g}$ sample contains less than $0.5 \mathrm{mg}$ $\mathrm{ThO}_{2}$, the trace procedure given in part 18 is more suitable.

The finely powdered sample is decomposed by fusion with sodium peroxide, and the melt leached with water. The hydroxide precipitates that form may go through the filter, if filtered off at this point. Acid is therefore added to dissolve the precipitate, and then a $\mathrm{NaOH}-\mathrm{H}_{2} \mathrm{O}_{2}$ precipitation is made. This precipitation separates thorium from the silica, phosphorus, and aluminum. Magnesium and a large part of the calcium accompany thorium and are separated later.

\section{MAJOR SEPARATIONS}

1. Separation of thorium from rare earths, calcium, magnesium, and manganese, by ammonium hydroxide.

Thorium is separated from calcium, magnesium, manganese, and most of the rare earths by ammonium hydroxide precipitations at controlled acidity.

The precipitation of thorium with ammonia is quantitative at a $p H$ corresponding to the neutral color of methyl red, and at this acidity trivalent cerium and the other rare earths remain largely in solution. Either nitrate or chloride solutions of thorium may be used, but sulfate must be absent. If sulfate is present, considerable losses of thorium result at the methyl red end point, although precipitation of thorium is complete when excess ammonia is used. It is 
absolutely necessary, therefore, to remove sulfate before making ammonia precipitations at the neutral point of methyl red.

2. Separation of thorium from iron, aluminum, zirconium, titanium, and niobium, by hydrofluoric acid.

Thorium is separated from the members of the $\mathrm{R}_{2} \mathrm{O}_{3}$ and acidinsoluble groups with hydrofluoric acid. Hydrofluoric acid is faster and more reliable than oxalic acid for this separation especially when small amounts of thorium are involved. Hydrofluoric acid has the added advantage of dissolving any hydrolytic precipitate of the above elements. As an example, if titanium or niobium were to hydrolyze out of solution, oxalic acid solution would not dissolve the precipitate unless the precipitate were filtered off, fused with pyrosulfate, and the melt leached with oxalic acid. Hydrofluoric acid takes these hydrolytic precipitates directly into solution.

3. Separation of thorium from rare earths by peroxynitrate precipitation.

The small amounts of rare earths left with the thorium after ammonia precipitation are removed by precipitation of thorium peroxynitrate in $0.03 \mathrm{~N}$ nitric acid. Fenner ${ }^{1}$ says,

The precipitation of thorium with hydrogen peroxide is apparently sensitive to changes of conditions, and the method has been thought by some workers to be unreliable. There seems to be some basis for this view, as I have found that unless certain requirements are fulfilled, hydrogen peroxide will fail to precipitate some or even a large part of the thorium ...

We agree with Fenner. The peroxynitrate precipitation is influenced by the acidity of the solution, by the concentration of hydrogen peroxide, by various anions and cations, as well as by the order of addition of reagents. For best separation from the rare earths, the acidity should be as high as possible, because at lower acidities cerium tends to be oxidized by the peroxide and to contaminate strongly the thorium. We believe that the highest acidity at which no thorium is lost is very close to a $p \mathrm{H}$ of 1.5. Precipitation at this acidity is greatly influenced by the presence of zirconium. When zirconium is present, both thorium and zirconium tend to "lose their identity." Certain combinations of zirconium and thorium will actually fail to yield any peroxynitrate precipitate, but generally thorium and zirconium are incompletely precipitated. The losses for thorium are usually less than $1 \mathrm{mg}$ (Experiment 1). The peroxynitrate precipitation, thus, cannot be used unless provision is made first to remove zirconium completely. The procedure given is designed to eliminate this element. The separation obtainable when zirconium is absent is shown under Experiments 2.

\footnotetext{
1 Fenner, C. N., 1928, The analytical determination of uranium, thorium, and lead as a basis for age. calculation: Am. Jour. Scl., 5th ser., v. 16, p. 369-381.
} 
The effect of titanium on the peroxynitrate precipitation of thorium was not studied thoroughly, but it was noted in one experiment (5 mg $\mathrm{ThO}_{2}+10 \mathrm{mg} \mathrm{TiO}{ }_{2}$ ) that this element did not behave like zirconium, as complete precipitation of thorium was obtained.

Sulfate also interferes in the peroxynitrate precipitation of thorium in $0.03 \mathrm{~N}$ nitric acid causing low recoveries. The losses are about 2 $\mathrm{mg}$ or less. Sulfate is eliminated by $\mathrm{NaOH}-\mathrm{H}_{2} \mathrm{O}_{2}$ precipitation of thorium before the peroxynitrate step.

The amount of ammonium nitrate used does not seem to be an important factor in the peroxynitrate precipitation, but some should be present. The amount of hydrogen peroxide should be more than $2 \mathrm{ml}$ of 30 percent $\mathrm{H}_{2} \mathrm{O}_{2}$ per $100 \mathrm{ml}$ of solution, because with higher concentrations of peroxide there are less interferences.

\section{PROCEDURE}

1. Fuse $0.5 \mathrm{~g}$ of finely powdered sample with about $3 \mathrm{~g} \mathrm{Na} \mathrm{Na}_{2}$ in a porcelain crucible.

2. Disintegrate the melt with $180 \mathrm{ml}$ warm water. Neutralize with $\mathrm{HNO}_{3}(1+1)$ and add a few milliliters in excess. Remove and rinse crucible, adding rinses to the solution. Cool the solution to about $50 \mathrm{C}$.

3. Add $1 \mathrm{ml}$ of 30 percent $\mathrm{H}_{2} \mathrm{O}_{2}$ and precipitate with 50 percent $\mathrm{NaOH}$ solution adding $10 \mathrm{ml}$ in excess. Digest on the steam bath a few minutes. Cool. Filter and wash thoroughly with warm 0.1 percent $\mathrm{NaNO}_{3}$.

4. Transfer the precipitate from the filter to the original beaker and dissolve what remains on the filter with $15 \mathrm{ml}$ warm $\mathrm{HNO}_{3}(1+1)$. Wash the paper with water. Reserve the paper. Boil the solution gently for about 5 minutes to destroy most of the peroxide. Dilute to $190 \mathrm{ml}$ with water. Cool. Add $\mathrm{NH}_{4} \mathrm{OH}$ until a precipitate forms that clots, avoiding too great an excess of ammonia (one or two drops excess). Add 3 drops of 0.1 percent methyl red in alcohol and neutralize carefully with $\mathrm{HNO}_{3}(1+50)$ until the methyl red color is just yellow or just under salmon pink. Heat the solution until it starts to boil. Remove the heat, and when the precipitate settles, check the acidity as indicted by methyl red and adjust if necessary. Filter the solution and wash with 0.1 percent $\mathrm{NH}_{4} \mathrm{NO}_{3}$.

5. Dissolve the precipitate off the filter with $15 \mathrm{ml}$ of warm $\mathrm{HNO}_{3}$ $(1+1)$ and wash the filter paper thoroughly with water. Reserve the paper. Repeat the ammonia precipitation as in step 4.

6. Unfold the paper and with a little water transfer the hydroxide precipitate to a platinum dish. Combine the filter paper with those reserved in steps 4 and 5 , ash them, and add the ash to the dish con- 
taining the major precipitate. The volume of the solution at this point should be about $15-25 \mathrm{ml}$.

7. Add $10-15 \mathrm{ml}$ of $\mathrm{HF}$, cover the dish with a platinum cover, and digest the solution on the steam bath for at least 1 hour, stirring occasionally. Allow the sample to stand half an hour at room temperature.

8. Filter on no. 40 Whatman paper through a hard rubber funnel and wash once with dilute HF and twice with water. Transfer the precipitate to a platinum crucible, cover the crucible loosely with a platinum cover to allow access of air, and burn the precipitate carefully at low heat.

9. Add as little $\mathrm{K}_{2} \mathrm{~S}_{2} \mathrm{O}_{7}$ as will dissolve all the precipitate ( $1 \mathrm{~g}$ or less depending on the size of the fluoride precipitate) and fuse carefully until a clear melt is obtained. Care should be taken during the fusion to prevent the loss of thorium by spattering. Cool. Leach the melt with $300 \mathrm{ml}$ of water containing $10 \mathrm{ml} \mathrm{HNO}(1+1)$.

10. Warm the solution to about $50 \mathrm{C}$. Add $0.5 \mathrm{ml} 30$ percent $\mathrm{H}_{2} \mathrm{O}_{2}$ and precipitate with 50 percent $\mathrm{NaOH}$ solution, adding about $4 \mathrm{ml}$ in excess. Digest the sample a few minutes on steam bath. Cool. Filter through a fast paper and wash the precipitate thoroughly with warm 0.1 percent $\mathrm{NaNO}_{3}$. This precipitation as well as the precipitation in step 11 is made to free the sample from sulfate.

11. Dissolve the precipitate off the paper with $10-15 \mathrm{ml}$ of warm $\mathrm{HNO}_{3}(1+1)$ and wash the paper with water. Reserve the filter paper. Reprecipitate with $\mathrm{NaOH}-\mathrm{H}_{2} \mathrm{O}_{2}$ as in step 10 . Filter and wash the precipitate with 0.1 percent $\mathrm{NaNO}_{3}$.

12. Dissolve the precipitate off the paper with $10-15 \mathrm{ml}$ of warm nitric acid $(1+1)$ and wash the paper with water. Reserve the filter paper. Bring the solution to a boil and simmer gently for about 5 minutes to destroy the peroxide. Adjust the volume of solution to about $150 \mathrm{ml}$. Cool. Add $\mathrm{NH}_{4} \mathrm{OH}$ in very slight excess until a precipitate forms that clots. Add a few drops of methyl red and carefully neutralize to just yellow or just under the salmon pink color of methyl red. Heat the solution until it just starts to boil. Remove the heat and allow the precipitate to settle. Check the acidity and adjust if necessary. Filter through a fast paper and wash with 0.1 percent $\mathrm{NH}_{4} \mathrm{NO}_{3}$ solution.

13. Dissolve the precipitate off the filter with $10-15 \mathrm{ml} \mathrm{HNO}_{3}$ $(1+1)$ and wash the paper with water. Reserve the filter paper. Reprecipitate with $\mathrm{NH}_{4} \mathrm{OH}$ in the same manner. Filter and wash with 0.1 percent $\mathrm{NH}_{4} \mathrm{NO}_{3}$. Transfer the paper with precipitate to a platinum crucible and add the filter papers reserved in steps 11, 12, and 13. Ash at a low heat, keeping the crucible loosely covered. 
14. Fill the crucible two-thirds full with $\mathrm{HF}$ (about $10 \mathrm{ml}$ ) cover and digest on the steam bath $1 / 2$ to 1 hour, depending on the size of the precipitate. Transfer to a platinum dish with a stream of water, scrubbing the crucible thoroughly. Adjust the volume of the solution to $25-30 \mathrm{ml}$ with water. Allow to settle a few minutes and filter. Wash with dilute HF and then twice with water. Burn the precipitate carefully in a covered crucible.

15. Dissolve the fluoride precipitate with potassium pyrosulfate as before. Make two $\mathrm{NaOH}-\mathrm{H}_{2} \mathrm{O}_{2}$ precipitations as before.

16. Dissolve the final $\mathrm{NaOH}-\mathrm{H}_{2} \mathrm{O}_{2}$ precipitate with $10 \mathrm{ml}$ of $(1+1) \mathrm{HNO}_{3}$. Boil the solution 5 minutes to destroy most of the peroxide and reduce the cerium. Cool. Add $\mathrm{NH}_{4} \mathrm{OH}$ in very slight excess until a precipitate forms. Add 2 drops of methyl red and neutralize with dilute $\mathrm{HNO}_{3}$ until the color is just red. Add exactly $1 \mathrm{ml}$ of $(1+4) \mathrm{HNO}_{3}$ and $5 \mathrm{ml}$ of 30 percent $\mathrm{H}_{2} \mathrm{O}_{2}$ and stir. Adjust the volume of the solution to $95 \mathrm{ml}$ by adding water and bring the solution to a boil. Digest the precipitate on the steam bath 5 minutes, add filter-paper pulp, filter, and wash thoroughly with $\mathrm{NH}_{4} \mathrm{NO}_{3}$ wash solution. Burn the precipitate carefully in a loosely covered platinum crucible at low heat. Raise the temperature to about $850 \mathrm{C}$ and ignite to constant weight. The peroxynitrate precipitate of thorium tends to spatter and may be lost mechanically if the heating is hurried and the crucible not covered.

Occasionally another peroxynitrate precipitation may be necessary. If the precipitate is off-color instead of white, the peroxynitrate is dissolved in $10 \mathrm{ml}$ of hot $(1+1) \mathrm{HNO}_{3}$, the solution is boiled to remove peroxide and reduce cerium, and the thorium is reprecipitated with $\mathrm{H}_{2} \mathrm{O}_{2}$ before igniting and weighing.

The samples were analyzed by the above procedure and also by the phosphate-iodate procedure described in part 18. Table 1 gives the results obtained on 0.5 -g samples.

TABLE 1.-Comparison with results by the phosphate-iodate method

\begin{tabular}{|c|c|c|c|}
\hline Sample no. & $\begin{array}{l}\mathrm{ThO}_{2} \text { pro- } \\
\text { cedure in } \\
\text { text (per- } \\
\text { oont) }\end{array}$ & $\begin{array}{l}\mathrm{ThO}_{2} \text { phos- } \\
\text { phate-iodate } \\
\text { procedure } \\
\text { (pereont) }\end{array}$ & Remarks \\
\hline NBS 2601.............. & 9.60 & 9.65 & This is a standard monazite sand. The \\
\hline NBS-CP 75-10_.... & 4.16 & 4. 30 & $\begin{array}{l}\text { tories was } 9.65 \text { percent ThO } \\
\text { Maczkowske at National Bureau of Stand- }\end{array}$ \\
\hline $\begin{array}{l}\text { SERX } \\
\text { NBS 2601, diluted... }\end{array}$ & $\begin{array}{l}3.65 \\
1.14\end{array}$ & $\begin{array}{l}\text { 3. } 65 \\
1.13\end{array}$ & $\begin{array}{l}\text { ards reports } 4 \text { sand. } \\
\text { Maczkowske at National Burcal of Stand. }\end{array}$ \\
\hline $\begin{array}{l}\text { Euxenite } \\
\text { NBS-CP } \\
\text { NBS-CP } 75-4 . \\
75-6\end{array}$ & $\begin{array}{r}1.01 \\
.68 \\
.44\end{array}$ & $\begin{array}{r}1.00 \\
.66 \\
.41\end{array}$ & \\
\hline
\end{tabular}




\section{EXPERIMENTS}

\section{FAILURE OF THE PEROXYNITRATE PRECIPITATION OF THORIUM IN THE PRESENCE OF ZIRCONIUM}

In these experiments the combination $5 \mathrm{mg}$ of $\mathrm{ThO}_{2}$ and $10 \mathrm{mg}$ $\mathrm{ZrO}_{2}$ (added as the nitrates) was used. Analyses of solutions containing this combination failed to give quantitative recoveries of thorium no matter what conditions or techniques were used. The losses generally amounted to about $2 \mathrm{mg}$ of $\mathrm{ThO}_{2}$ or less.

The procedure used except for test no. 1 was as follows: The thorium and zirconium nitrates were added to a $150-\mathrm{ml}$ beaker. The solution was diluted to $90 \mathrm{ml}$ with water. A prescribed amount of solid $\mathrm{NH}_{4} \mathrm{NO}_{3}$ was added and dissolved. Dilute $\mathrm{NH}_{4} \mathrm{OH}$ was next added to the yellow color of methyl red. Dilute nitric acid was added until the color turned to just red. The solution was heated just to boiling and the source of heat was removed. A prescribed amount of 30 percent $\mathrm{H}_{2} \mathrm{O}_{2}$ was added, the solution stirred once, and a prescribed amount of nitric acid was added immediately. The volume of the solution was made to $100 \mathrm{ml}$ with water and the sample digested on the steam bath for a prescribed length of time. The precipitate was filtered and washed with ammonium nitrate solution. Quantitative analyses for thorium were made on some of the precipitates; in other tests, the filtrates were tested qualitatively for thorium.

In test no. 1 the solution of zirconium and thorium was made neutral to methyl red and a prescribed excess of dilute $\mathrm{HNO}_{3}$ was added. The peroxide was next added and the solution digested before filtering.

In test no. 20 the precipitation was made in a glass-stoppered Erlenmeyer flask and the solution heated on the steam bath under its own pressure 10 minutes before filtering off the peroxynitrate precipitate.

Table 2 shows that in no case was precipitation of thorium complete. 
TABLE 2.-Incomplete precipitation of thorium peroxynitrate in presence of zirconium

[5 $\mathrm{mg} \mathrm{ThO}+10 \mathrm{mg} \mathrm{ZrO}$ used for each experiment. Total volume $100 \mathrm{ml}]$

\begin{tabular}{|c|c|c|c|c|c|}
\hline Test no. & $\underset{(\mathrm{g})}{\underset{\mathrm{Nmount}}{\text { Amo }}}$ & $\begin{array}{c}\text { Amount } \\
\text { excess } \\
(1+4) \\
\mathrm{HNO}_{3} \\
(\mathrm{ml})\end{array}$ & $\begin{array}{c}\text { Amount } \\
\text { of } 30 \\
\text { percent } \\
\underset{(\mathrm{ml})}{\mathrm{H}_{2} \mathrm{O}_{2}} \\
.\end{array}$ & $\begin{array}{c}\text { Time of } \\
\text { digestion of } \\
\text { peroxymitrate } \\
\text { precipitate } \\
\text { before } \\
\text { flitration } \\
\text { (minutes) }\end{array}$ & $\underset{\substack{\mathrm{ThO}_{3} \\
\text { (mg) }}}{\text { recovered }}$ \\
\hline (12 & $\begin{array}{r}7 \\
2 \\
10 \\
20 \\
7 \\
7 \\
7 \\
7 \\
7 \\
5 \\
20 \\
7 \\
7 \\
7 \\
7 \\
7 \\
20 \\
20 \\
20 \\
7\end{array}$ & $\begin{array}{l}1.00 \\
1.00 \\
1.00 \\
1.00 \\
1.00 \\
1.00 \\
1.00 \\
1.00 \\
1.00 \\
.50 \\
.50 \\
.50 \\
.50 \\
.50 \\
.50 \\
.50 \\
.50 \\
.50 \\
.50 \\
1.00\end{array}$ & $\begin{array}{r}2 \\
2 \\
2 \\
2 \\
5 \\
5 \\
10 \\
20 \\
5 \\
15 \\
2 \\
2 \\
2 \\
5 \\
20 \\
5 \\
5 \\
20 \\
10 \\
10 \\
20 \\
10\end{array}$ & $\begin{array}{r}5 \\
5 \\
5 \\
5 \\
5 \\
5 \\
5 \\
30 \\
60 \\
5 \\
5 \\
5 \\
5 \\
10 \\
60 \\
20 \\
5 \\
20 \\
20 \\
210\end{array}$ & $\begin{array}{cr}\text { None } & \\
& 3.9 \\
& 4.2 \\
& 4.2 \\
& 4.3 \\
& 4.4 \\
& 4.5 \\
(1) & \\
\text { (1) } & \\
\text { (1) } & \\
\text { (1) } & \\
\text { (1) } & \\
& 4.5 \\
& 4.4 \\
\text { (1) } & \\
& 4.6 \\
\text { (1) } & \\
\text { (1) } & \\
\text { (1) } & \\
\text { (1) } & \end{array}$ \\
\hline
\end{tabular}

Incomplete.

2 Under pressure.

\section{SEPARATION OF THORIOM FROM RARE EARTHS BY THE PEROXYNITRATE METHOD}

Table 3 illustrates separations obtainable by peroxynitrate when zirconium is absent.

Cerium was added as cerous ammonium nitrate, thorium as nitrate, and the yttrium group as nitrates.

TABLE 3.-Separation of thorium from rare earths by the peroxynitrate method

\begin{tabular}{|c|c|c|}
\hline Taken & $\begin{array}{l}\text { Number of } \\
\text { peroxynitrate } \\
\text { precipita- } \\
\text { tions made }\end{array}$ & $\begin{array}{c}\mathrm{ThO}_{2} \text { found } \\
(\mathrm{g})\end{array}$ \\
\hline 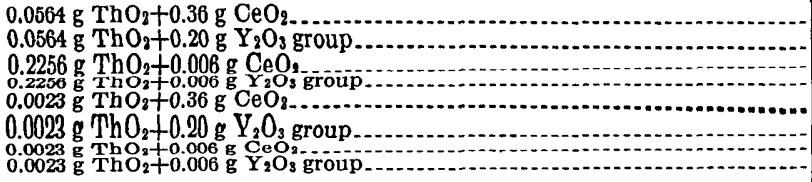 & $\begin{array}{l}2 \\
2 \\
1 \\
1 \\
2 \\
2 \\
1 \\
1 \\
1\end{array}$ & $\begin{array}{l}0.0568 \\
.0567 \\
.2256 \\
.2255 \\
.0023 \\
.0026 \\
.0023 \\
.0023\end{array}$ \\
\hline
\end{tabular}




\title{
Part 21. MESITYL OXIDE EXTRACTION METHOD FOR THORIUM ANALYSIS
}

\author{
By Harry Levine and F. S. Grimaldi
}

\section{CONTENTS}

Introduction . . . . . . . . 177

Extraction of thorium nitrate by some organic solvents............ 178

Extraction of thorium nitrate by mesityl oxide. . . . . . . . . . . . . 179

Metal nitrates extracted by mesityl oxide................ 180

Effect of phosphate, arsenate, sulfate, and borate in the extraction of thorium nitrate by mesityl oxide.

Analysis of thorium ores....

Outline and discussion

Detailed procedure . . .

Results of analyses . .

\section{TABLES}

TABLE 1. Extraction of thorium nitrate by an equal volume of various

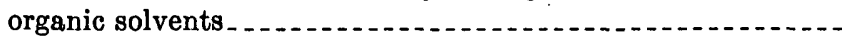

2. Extraction of thorium nitrate by an equal volume mesityl oxide.

3. Extraction of different elements by an equal volume of mesityl oxide.

4. Effect of phosphate in the extraction of thorium by mesityl oxide

5. Analysis of thorium ores

\section{INTRODUCTION}

Thorium nitrate is quantitatively extracted by mesityl oxide from solutions saturated with aluminum nitrate even in the presence of relatively large amounts of phosphate. Uranium is the only other element extracted quantitatively by a single extraction. Zirconium is extracted to a large extent, yttrium and vanadium to a small extent, and cerium in both valence states only to a very slight degree. Ceric cerium is reduced probably by the olefinic bond in the solvent. Mesityl oxide thus is useful not only for the concentration of uranium and thorium but also for the separation of thorium from the rare earths, the separation taking about 10 minutes per sample. 
The mesityl oxide procedure for the determination of thorium has been applied to a wide variety of thorium ores such as monazite, black sand, thorianite, thorite, euxenite, and eschynite.

Solvent extraction methods for the concentration and purification of thorium are important. Extraction from nitric acid solutions is of special interest in that not only thorium but also uranium may be concentrated. It has been known for some time that thorium nitrate is soluble in organic solvents. The earliest papers on this subject were by Misciattelli ${ }^{1}$ and Wells ${ }^{2}$ and gave data on the solubility of thorium nitrate in ether. In a recent paper, Rothschild and others ${ }^{3}$ give data on the distribution of thorium nitrate to various ketones and alcohols.

As far as we know, practically no work has been done on the application of the thorium nitrate extraction process to the chemical analysis of thorium. This paper describes the use of a new solvent, mesityl oxide, together with aluminum nitrate as the salting agent, in the analysis of thorium ores.

\section{EXTRACTION OF THORIUM NITRATE BY SOME ORGANIC BOLVENTS}

Preliminary studies were made on some organic solvents to determine which ones were most efficient in extracting thorium nitrate. These data are included in this report because they may be significant.

In these experiments a standard solution of thorium nitrate $(1 \mathrm{ml}=$ $0.0010 \mathrm{~g} \mathrm{ThO}_{2}$ ) was first made by dissolving the pure salt of known composition in nitric acid $(15+85)$. To $5 \mathrm{ml}$ of this solution $9.5 \mathrm{~g}$ of aluminum nitrate crystals were added and the mixture was warmed to dissolve the aluminum nitrate. The solution was then cooled to room temperature. This amount of aluminum nitrate was found to nearly saturate $5 \mathrm{ml}$ of solution (15 percent by volume in nitric acid) at room temperature. When the aluminum nitrate is dissolved, the volume of the solution increases to about $10 \mathrm{ml}$ or about double the original volume. The solution was then poured into a $60-\mathrm{ml}$ separatory funnel. Ten milliliters of the organic solvent under test was pipetted into the beaker that contained the original solution and the solvent was agitated. The solvent was then poured into the separatory funnel containing the thorium solution to be extracted. The separatory funnel was agitated vigorously for 15 seconds and the liquid layers were allowed to separate. The water layer was drawn

\footnotetext{
'Misciattell, P., 1929, On the separation of thorium from uranium by means of ether: Phil. Mag., v. 7, p. 670 .

Wells, Roger C., 1930, The solubility of some rare-earth nitrates in ether: Washington Acad. Scl. Jour., จ. 20, no. 8 .

Rothschild, B. F., Templeton, C. O., Hall, N. F., 1948, The distribution of thorium nitrate between water and certain alcohols and ketones: Physical and Collold Chemistry Jour., v. 52, no. 6.
} 
off and rejected. The solvent layer was then washed once with 10 $\mathrm{ml}$ of aluminum nitrate wash solution $(2.5 \mathrm{M}$ in aluminum nitrate and $1.2 \mathrm{~N}$ in $\mathrm{HNO}_{3}$ ), the wash solution later being rejected. The washed solvent layer was withdrawn and evaporated to dryness. The residue obtained was gently ignited to remove carbon. The residue was then treated with hydrofluoric acid to remove aluminum and the thorium fluoride was collected, washed, and ignited. This was brought into solution by fusing with potassium pyrosulfate. The melt was cooled, a little dilute nitric acid was added, and the mixture was warmed to dissolve the cake. The thorium was precipitated with an excess of freshly distilled ammonium hydroxide and the thorium hydroxide ignited to thorium oxide and weighed as such.

Table 1 shows the results obtained with the organic solvents tested. This shows that butyl lactate, cyclopropyl methyl ketone, and mesityl oxide gave the best recoveries of thorium. Cyclopropyl methyl ketone is expensive, hard to obtain, and was not considered further. Both butyl lactate and mesityl oxide extracted about the same amount of zirconium. Butyl lactate, however, extracted much more aluminum nitrate than mesityl oxide did and for this reason was not studied further.

\section{EXTRACTION OF THORIUM NITRATE BY MESITYL OXIDE}

In these experiments thorium nitrate representing respectively $0.4 \mathrm{mg}, 1.0 \mathrm{mg}, 5.0 \mathrm{mg}, 15.0 \mathrm{mg}, 50.0 \mathrm{mg}$, and $100.0 \mathrm{mg}$ of thorium oxide were added to $10-\mathrm{ml}$ portions of nitric acid $(15+85)$. Nineteen grams of aluminum nitrate crystals were added and dissolved and the solutions obtained were each extracted once with $20 \mathrm{ml}$ of mesityl oxide by shaking for 15 seconds. The mesityl oxide extract was then analyzed for thorium after eliminating any aluminum with hydrofluoric acid. The results given in table 2 show that quantitative recovery was obtained for all portions.

TABLE 1.-Extraction of thorium nitrate by an equal volume of various organic solvents

[Thorium solution $2.5 \mathrm{M}$ in aluminum nitrate and $1.2 \mathrm{~N}$ in $\mathrm{HNO}_{3}$ ]

\begin{tabular}{|c|c|c|c|}
\hline Solvent & $\begin{array}{l}\text { Thorium } \\
\text { extracted } \\
\text { (percent) }\end{array}$ & Solvent & $\begin{array}{l}\text { Thorium } \\
\text { extracted } \\
\text { (percent) }\end{array}$ \\
\hline $\begin{array}{l}\text { Amyl acetate } \\
\text { Benzyl acetate } \\
n \text {-Butyl } n \text {-butyrate } \\
\text { Isobutyl crotonate } \\
n \text {-Butyl lactate } \\
\text { Isobutyl propionate } \\
\text { Cyclohexyl acetate } \\
\beta \text {-Ethoxy ethyl acetate } \\
\text { Ethyl acetate } \\
\text { Ethyl butyrate } \\
\text { Methyl benzoate }\end{array}$ & \begin{tabular}{r||}
40 \\
30 \\
$<1$ \\
$<1$ \\
$>90.9$ \\
$<1$ \\
32 \\
80 \\
45 \\
35 \\
$<1$
\end{tabular} & $\begin{array}{l}\text { Methyl propionate } \\
\text { Amylene dichloride } \\
\text { Anisole } \\
n \text {-Butyl ether } \\
\text { 2,6 dimethyl furan } \\
\text { Ether } \\
\text { Cyclohexanone } \\
\text { Cyclopropyl methyl ketone } \\
\text { Methyl } n \text {-amyl ketone } \\
\text { Methyl cyclohexanone } \\
\text { Mesityl oxide. }\end{array}$ & $\begin{array}{c}15 \\
<1 \\
<1 \\
35 \\
<1 \\
35 \\
92 \\
>99.8 \\
90 \\
96 \\
>99.8\end{array}$ \\
\hline
\end{tabular}


TABLE 2.-Extraction of thorium nitrate by an equal volume of mesityl oxide [Thorium solutions $2.5 \mathrm{M}$ in aluminum nitrate and $1.2 \mathrm{~N}$ in $\mathrm{HNO}_{3}$ ]

\begin{tabular}{r|r|r|r}
\hline $\begin{array}{c}\mathrm{ThO}_{2} \\
\text { taken } \\
(\mathrm{mg})\end{array}$ & $\begin{array}{c}\mathrm{ThO}_{2} \\
\text { extracted } \\
\text { (mg) }\end{array}$ & $\begin{array}{r}\mathrm{ThO}_{2} \\
\text { taken } \\
\text { (mg) }\end{array}$ & $\begin{array}{r}\text { ThO } \\
\text { extracted } \\
\text { (mg) }\end{array}$ \\
\hline 0.4 & 0.4 & 15.0 & 15.1 \\
1.0 & 1.0 & 50.0 & 50.0 \\
5.0 & 5.0 & 100.0 & 100.1 \\
\hline
\end{tabular}

\section{METAL NITRATES EXTRACTED BY MESITYL OXIDE}

In these experiments a salt (generally the nitrate) of the element under test was dissolved in $10 \mathrm{ml}$ of $\mathrm{HNO}_{3}(15+85)$. Nineteen grams of aluminum nitrate crystals were then added and dissolved. The solution obtained was then extracted once by shaking with a $20-\mathrm{ml}$ portion of mesityl oxide for 15 seconds. The mesityl oxide extract was washed once with $20 \mathrm{ml}$ of aluminum nitrate wash solution and evaporated to dryness on the steam bath after the addition of a slight excess of $\mathrm{NH}_{4} \mathrm{OH}$ (it was necessary to add $\mathrm{NH}_{4} \mathrm{OH}$ to prevent violent bumping during the evaporation of mesityl oxide). The residue was ignited, dissolved, and tested quantitatively for the element under study. The results are shown in table 3.

TABLE 3.-Extraction of different elements by an equal volume of mesityl oxide

[Solution 2.5 $\mathrm{M}$ in $\mathrm{Al}\left(\mathrm{NO}_{3}\right)_{3}$ and $1.2 \mathrm{~N}$ in $\mathrm{HNO}_{3}$ ]

\begin{tabular}{|c|c|c|c|}
\hline Salt & $\begin{array}{l}\text { Weight of } \\
\text { element } \\
\text { taken } \\
\text { (grams) }\end{array}$ & $\begin{array}{c}\text { Amount extracted } \\
\text { (grams) }\end{array}$ & Method of test \\
\hline Calcium nitrate. & & None & Oxalate. \\
\hline Beryllium nitrate. & .1 & $0.00008 \mathrm{BeO}$ & Fluorimetric-quinizarin. \\
\hline Magnesium nitrate.... & .1 & None & NaOH precipitate. \\
\hline Zirconyl nitrate............ & .1 & $0.074 \mathrm{Zr}$ & Evaporation of solvent and ignition of \\
\hline $\begin{array}{l}\text { Aluminum nitrate. } \\
\text { Ncodymium ammonium ni- }\end{array}$ & $\begin{array}{r}1.36 \\
.05\end{array}$ & $\begin{array}{l}\text { o.oos } \mathrm{Al}_{2} \\
\text { None... }\end{array}$ & $\begin{array}{l}\text { Do. } \\
\text { No precipitate with HF. }\end{array}$ \\
\hline $\begin{array}{l}\text { trate. } \\
\text { Cerous ammonium }\end{array}$ & .00 & & $\mathrm{NaOH}-\mathrm{H}_{2} \mathrm{O}_{2}$ \\
\hline $\begin{array}{l}\text { Ceric sulfate } \\
\text { Lanthanum nitrate }\end{array}$ & .05 & $\begin{array}{l}0.0008 \\
\text { None }\end{array}$ & $\begin{array}{l}\mathrm{NaOH}-\mathrm{H}_{2} \mathrm{O}_{2} \\
\text { No precipitate with } \mathrm{HF} \text {. }\end{array}$ \\
\hline Yttrium nitrate...... & .025 & $0.0024 \mathrm{Y}_{2} \mathrm{C}$ & $\mathrm{HF} ; \mathrm{NaOH}-\mathrm{H}_{9} \mathrm{O} \&$ followed by $\mathrm{NH}_{4} \mathrm{OH}$; \\
\hline Titanlum nitra & .08 & 0.000 & 0000.020 \\
\hline Manganous nitrate. & .05 & $0.0002 \mathrm{Mn}$ & $\mathrm{KIO}$. \\
\hline Ammonium metavanadate & .05 & $0.008 \mathrm{~V}_{2} \mathrm{O}_{3}$ & $\mathrm{H}_{2} \mathrm{O}_{3}$ \\
\hline Ferric nitrate. & .05 & $0.002 \mathrm{Fe}$ & KMETS. \\
\hline Uranyl nitrate.. & .0500 & $0.0500 \mathrm{U}$ & Zinc reduction and $\mathrm{KMnO}$, titration. \\
\hline Cupric nitrate. & .05 & $0.0004 \mathrm{C}$ & Ammonia blue color. \\
\hline Zluc uitratc & .05 & $\begin{array}{lll}0.0002 & 7 \\
\text { None }\end{array}$ & Snectrographic. \\
\hline $\begin{array}{l}\text { Nickelous nitrate } \\
\text { Sodium molybdate......... }\end{array}$ & .00 & None.... & $\mathrm{SnCl}_{2}-\mathrm{KCNS}$. \\
\hline $\begin{array}{l}\text { Sttannous chlorido.- } \\
\text { Barium nitrate.... }\end{array}$ & $\begin{array}{l}: 00 \\
: 025 \\
.05\end{array}$ & Noods & $\begin{array}{l}\text { Spectrographic. } \\
\text { No Baso. precipitato. }\end{array}$ \\
\hline Lead nitrate. & .05 & None. & No PDS precipitate. \\
\hline $\begin{array}{l}\text { Indium nitrate } \\
\text { Chloroplatinic acid }\end{array}$ & .05 & $0.002 \mathrm{In}_{\mathrm{Pt}}$ & Spectrographic. \\
\hline & & & \\
\hline
\end{tabular}


EFFECT OF PHOSPHATE, ARSENATE, SULFATE, AND BORATE IN THE EXTRACTION OF THORIUM NITRATE BY MESITYL OXIDE

Combinations of $1 \mathrm{~g} \mathrm{Na}_{2} \mathrm{HAsO}_{4} \cdot 12 \mathrm{H}_{2} \mathrm{O}$ plus $5 \mathrm{mg} \mathrm{ThO}_{2}, 1 \mathrm{~g}$ $\mathrm{Na}_{2} \mathrm{~B}_{4} \mathrm{O}_{7} \cdot 10 \mathrm{H}_{2} \mathrm{O}$ plus $5 \mathrm{mg} \mathrm{ThO}_{2}$, and $1 \mathrm{~g} \mathrm{Na}_{2} \mathrm{SO}_{4}$ plus $5 \mathrm{mg} \mathrm{ThO}_{2}$ were separately extracted. The results obtained showed that mesityl oxide quantitatively extracts thorium from these combinations. The effect of phosphate was studied in more detail. Table 4 shows that quantitative results are obtained in the presence of relatively large amounts of phosphate.

TABLE 4.-Effect of phosphate in the extraction of thorium by mesityl oxide [Thorium solutions $2.5 \mathrm{M}$ in $\mathrm{Al}\left(\mathrm{NO}_{8}\right)_{3}$ and $1.2 \mathrm{~N}$ in $\mathrm{HNO}_{8}$ ]

\begin{tabular}{|c|c|c|c|c|c|c|c|}
\hline $\begin{array}{c}\text { added } \\
\text { (grams) }\end{array}$ & $\begin{array}{c}\mathrm{ThO}_{2} \\
\text { added } \\
\text { (grams) }\end{array}$ & $\begin{array}{c}\mathrm{ThO}_{\mathbf{2}} \\
\text { extracted } \\
\text { (grams) }\end{array}$ & $\begin{array}{c}\mathrm{Mol} \\
\text { ratio } \\
\mathrm{P}_{2} \mathrm{O}_{3} \\
\text { to } \\
\mathrm{ThO}_{2}(1)\end{array}$ & $\begin{array}{c}\left(\mathrm{NH}_{4}\right)_{2} \mathrm{HPO}_{4} \\
\text { (gdded } \\
\text { (grams) }\end{array}$ & $\begin{array}{c}\text { Tho, } \\
\text { added } \\
\text { (grams) }\end{array}$ & $\begin{array}{c}\mathrm{ThO}_{2} \\
\text { extracted } \\
\text { (grams) }\end{array}$ & $\begin{array}{c}\mathrm{Mol} \\
\text { ratio } \\
\mathrm{P}_{2} \mathrm{O}_{5} \\
\text { to } \\
\mathrm{ThO}_{2}(1)\end{array}$ \\
\hline $\begin{array}{r}0.0044 \\
.0088 \\
.0133 \\
.0400\end{array}$ & $\begin{array}{r}0.02000 \\
.0200 \\
.0200 \\
.0200\end{array}$ & $\begin{array}{r}0.0201 \\
.0200 \\
.0200 \\
.0200\end{array}$ & $\begin{array}{l}2: 9 \\
4: 9 \\
2: 3 \\
2: 1\end{array}$ & $\begin{array}{r}0.1200 \\
.2000 \\
.8000\end{array}$ & $\begin{array}{r}0.0200 \\
.0200 \\
.0200\end{array}$ & $\begin{array}{r}0.0199 \\
.0198 \\
.0198\end{array}$ & $\begin{array}{r}6: 1 \\
10: 1 \\
40: 1\end{array}$ \\
\hline
\end{tabular}

1 The most likely mol ratio of $\mathrm{P}_{2} \mathrm{O}_{6}$ to $\mathrm{ThO}_{2}$ for monazite is between 2:1 and 6:1.

The conclusions to be drawn from an analysis of the results in tables 2,3 , and 4 are as follows:

1. The extraction of thorium nitrate by mesityl oxide when aluminum nitrate is used as the salting agent is quantitative in a single extraction. Equilibrium is attained rapidly and the same percentage extraction is obtained for both small and large amounts of thorium.

2. Uranium is also extracted quantitatively. Zirconium extracts about 70 percent and vanadium about 9 percent in the concentrations selected.

3. Yttrium and cerium are incompletely extracted. It is expected that erbium will extract in about the same order of magnitude as yttrium. The other rare earths extract to an even smaller extent.

4. The mesityl oxide extraction process may be used for the separation of thorium from the rare earths. This separation should be especially efficient when thorium is in large excess over the rare earths and/or the amount of rare earths is small.

\section{ANALYSIS OF THORIUM ORES OUTIINE AND DISCUSSION}

1. Decomposition of sample by fusion with a mixture of $\mathrm{NaF}-\mathrm{K}_{2} \mathrm{~S}_{2} \mathrm{O}_{7}$.

2. Precipitation of thorium oxalate (separation from $\mathrm{U}, \mathrm{Nb}$, and $\mathrm{Ti}$ ).

3. Separation of rare earths by mesityl oxide extraction, the rare earths accompanying thorium being removed from the solvent by several washings with aluminum nitrate solution. 
4. Precipitation of thorium oxalate and ignition to $\mathrm{ThO}_{2}$.

An $0.5-\mathrm{g}$ sample is decomposed in a platinum crucible by fusing with $3 \mathrm{~g}$ of flux ( 2 parts by weight $\mathrm{NaF}, 3$ parts by weight $\mathrm{K}_{2} \mathrm{~S}_{2} \mathrm{O}_{7}$ ). This flux is similar to sodium bifluoride and will decompose almost all of the refractory minerals associated with thorium." After the fusion the melt is allowed to cool. Two milliliters of sulfuric acid are added (this amount is a little in excess of that required to convert all the $\mathrm{NaF}$ to $\mathrm{NaHSO}_{4}$ ) and the crucible is gently heated until all the hydrofluoric acid is removed and a clear bisulfate melt is obtained. This process may take as long as 20 minutes. It is most important to remove all the hydrofluoric acid (copious fumes of $\mathrm{SO}_{3}$ are evolved in the last stages of heating), as otherwise some thorium would be lost as thorium fluoride in the later steps of the procedure. The crucible containing the cool melt is immersed in a hot solution of oxalic acid and the thorium oxalate is digested on the steam bath for about 2 hours.

The thorium oxalate is filtered off on sintered glass and dissolved with hot $(1+1)$ nitric acid. The residue left on the filter usually consists of quartz and, surprisingly, hydrolytic precipitates of titanium and zirconium.

It is sometimes difficult for the analyst to be certain of the complete removal of fluorine and the complete conversion of thorium fluoride (formed by the action of the flux) to thorium sulfate. Also, experience with ores high in titanium, niobium, and tantalum has shown that appreciable amounts of these elements precipitate as hydrated oxides rather than dissolve in the oxalic acid. There is a possibility of loss of thorium by the nitric acid failing either to dissolve the thorium fluoride or to leach thorium from the mixture of oxalates and hydrated oxides.

If these difficulties occur, they may be eliminated by certain changes in the initial steps of the analysis. The most important change is the substitution of a hydrofluoric acid precipitation for the first oxalate precipitation. (Details of this separation are given in part 20.) This separation is much cleaner if the sequence of operations before the hydrofluoric acid step consist of decomposition of the sample by fusion with sodium peroxide, solution of the melt in water, filtration of thorium hydroxide, solution of thorium hydroxide and its reprecipitation with excess ammonia. The precipitate is then treated with hydrofluoric acid, the thorium fluoride is filtered and decomposed by a potassium pyrosulfate fusion. Thorium hydroxide is again precipitated with excess ammonia, filtered and dissolved in nitric acid. The mesityl oxide separations then follow with no further changes in the procedure.

\footnotetext{
- Some ores may not decompose completely with the $\mathrm{K}_{2} \mathrm{~S}_{2} \mathrm{O}_{7}-\mathrm{NaF}$ flux. In these instances pure $\mathrm{NaF}$ should be used.
} 
In our experience the residue was always free from thorium. The nitric acid solution of thorium oxalate is evaporated to dryness and the residue treated with a little fuming nitric acid to insure the destruction of the oxalate. Aluminum nitrate is added and thorium nitrate is extracted with two portions of mesityl oxide. The small amounts of rare earths accompanying thorium are separated from the organic solvent by three washings with aluminum nitrate solution. The acid concentration of the solution before extraction is not too critical and may be as high as 25 percent by volume. Low results were obtained when the concentration of nitric acid was as high as 40 percent by volume probably because of oxidation of the solvent. A final thorium oxalate precipitation is made to free thorium from the last traces of impurities and the thorium oxalate is ignited and weighed as thorium oxide.

\section{DETAILED PROCEDURE}

1. Weigh an 0.5 -g sample of finely ground ore sample and transfer it to a platinum crucible.

2. Add $3 \mathrm{~g}$ of flux (2 parts by weight $\mathrm{NaF}$ and 3 parts by weight of $\mathrm{K}_{2} \mathrm{~S}_{2} \mathrm{O}_{7}$ ). Mix and fuse the sample over a burner for about 2 minutes. Cool.

3. Add $2 \mathrm{ml} \mathrm{H}_{2} \mathrm{SO}_{4}$ and heat gently over a burner until all th is removed and a clear bisulfate melt is obtained (in the latte , of the heating copious fumes of $\mathrm{SO}_{3}$ should be evolved). Cool.

4. Immerse the crucible and contents in $80 \mathrm{ml}$ of warm oxali solution (5 g oxalic acid to $100 \mathrm{ml}$ of water). After the mel disintegrated the crucible is removed, rubbed, and rinsed an: washings added to the main solution. Bring the solution to a gentle boil and boil for 1 minute, stirring the solution continuously.

5. Digest the oxalate (beaker covered) on the steam bath for at least 2 hours. There is sometimes a period of induction before the thorium oxalate precipitate appears; if no oxalate precipitate is obtained after 2 hours, the solution should be digested preferably overnight.

6. Filter (suction) the thorium oxalate on a glass-fritted medium filter tube and wash with 2 percent oxalic acid. Reject filtrate.

7. Place a $100-\mathrm{ml}$ beaker under the funnel and dissolve the thorium oxalate with three $10-\mathrm{ml}$ portions of hot $(1+1) \mathrm{HNO}_{3}$, alternating each portion with a limited amount of hot water. Reject residue left on the filter.

8. Evaporate the solution to dryness. Add 3 to $4 \mathrm{ml}$ of fuming $\mathrm{HNO}_{3}$, cover the beaker, and digest the solution for several minutes on the steam bath. Remove the cover and evaporate the solution to dryness. 
9. Take up the residue in $10 \mathrm{ml}$ of $\mathrm{HNO}_{3}(15+85)$ warming the solution to dissolve the residue. Sometimes a cloud remains. This will disappear after the addition of the aluminum nitrate.

10. Add $19 \mathrm{~g} \mathrm{Al}\left(\mathrm{NO}_{3}\right)_{3} \cdot 9 \mathrm{H}_{2} \mathrm{O}$ and warm the mixture to dissolve the crystals. Cool. Pour the solution into a $60-\mathrm{ml}$ separatory funnel.

11. Add $20 \mathrm{ml}$ of mesityl oxide to the beaker containing the original solution. Agitate the solution gently and pour the solvent into the separatory funnel containing the nitric acid solution of the sample.

12. Shake the funnel vigorously for about 20 seconds and allow the layers to separate. Draw off the aqueous layer into a $60-\mathrm{ml}$ separatory funnel. Reserve the organic solvent layer.

13. Repeat the extraction of the aluminum nitrate solution with $10 \mathrm{ml}$ of mesityl oxide and combine the mesityl oxide layers, rejecting the aqueous layer.

14. Strip the rare earths from the organic solvent by shaking for 20 seconds with three separate $20-\mathrm{ml}$ portions of aluminum nitrate wash solution $\left[9.5 \mathrm{~g} \mathrm{Al}\left(\mathrm{NO}_{3}\right)_{3} \cdot 9 \mathrm{H}_{2} \mathrm{O}\right.$ to $5 \mathrm{ml}$ of $(15+85) \mathrm{HNO}_{3}$, rejecting each wash solution.

15. Strip the thorium from the organic solvent with two $20-\mathrm{ml}$ portions of water and transfer the aqueous layers to a $150-\mathrm{ml}$ beaker.

16. Add $1 \mathrm{ml}$ of $\mathrm{H}_{2} \mathrm{SO}_{4}$ and adjust the volume of the solution to about $80 \mathrm{ml}$. Bring the solution to a gentle boil, add $4 \mathrm{~g}$ of oxalic acid, and boil gently for 1 minute, stirring continuously. Digest the thorium oxalate for at least 3 hours, preferably overnight.

17. Filter the thorium oxalate on no. 40 Whatman filter paper and wash with 2 percent oxalic acid solution.

18. Ignite to $\mathrm{ThO}_{2}$ (final temperature about $900 \mathrm{C}$ ) and weigh.

\section{RESULTS OF ANALYSES}

Comparison of the results obtained on eight samples by alternate methods of thorium analysis are given in table 5. Method A represents the method of this report, method $B$ is given in part 20 , and method $\mathrm{C}$ is given in part 18. Considering the complexity of the materiáls analyzed, we believe the agreement is satisfactory.

TABLE 5.-Analysis of thorium ores

\begin{tabular}{|c|c|c|c|c|}
\hline \multirow{2}{*}{ Sample no. } & \multirow{2}{*}{ Description } & \multicolumn{3}{|c|}{ Percent $\mathrm{ThO}_{2} 1$} \\
\hline & & Method A & Method B & Method C \\
\hline $\begin{array}{l}\mathrm{HL} 1 \\
\mathrm{H} L 2 \\
\mathrm{~A}-26 \\
3063 \\
3181 \\
3905 \\
3924 \\
3926\end{array}$ & $\begin{array}{l}\text { Monazite } \\
\text { Thock sand } \\
\text { Thorianite... }\end{array}$ & $\begin{array}{r}4.19 \\
4.22 \\
1.82 \\
1.90,1.80 \\
3.40 \\
2.12 \\
5.01 \\
6.60,6.30\end{array}$ & $\begin{array}{l}4.18 \\
4.21 \\
1.90 \\
1.90 \\
3.26 \\
1.92 \\
5.15 \\
6.55\end{array}$ & \begin{tabular}{r}
4.29 \\
4.26 \\
1.96 \\
\hdashline 1.98 \\
5.18
\end{tabular} \\
\hline
\end{tabular}

1 Method A, mesityl oxide method of this report; method B, method of part 20; method C, method of part 18. 